\title{
The European Parliament as an Accountability Forum
}

Overseeing the Economic and Monetary Union

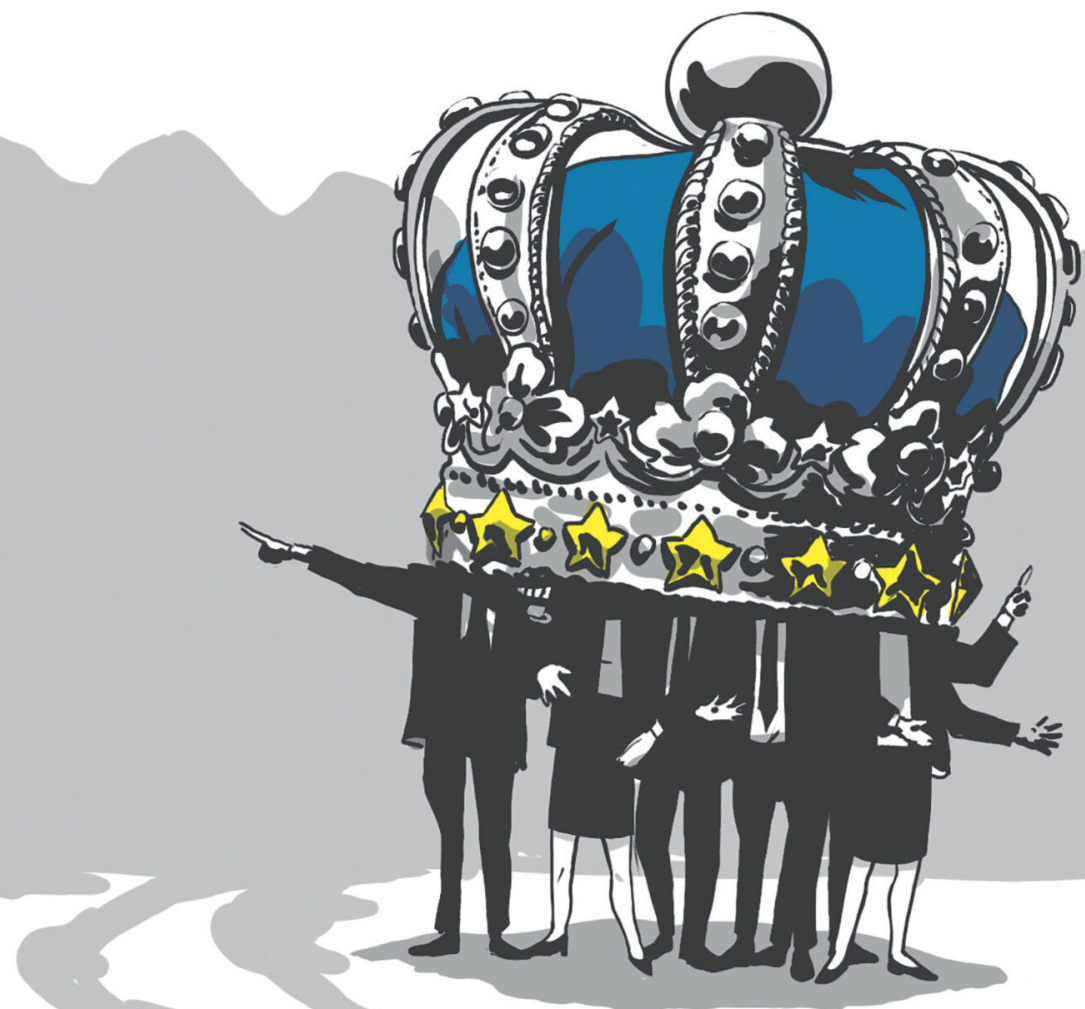




\section{THE EUROPEAN PARLIAMENT AS AN ACCOUNTABILITY FORUM}

This book provides the first in-depth empirical study of the European Parliament's powers of scrutiny of the executive in the European Union (EU), focusing on the politically salient field of the Economic and Monetary Union. The expansion of executive decision-making during the euro crisis was accompanied by an empowerment of the European Parliament through legislative oversight. This book examines how the European Parliament exercises that oversight on a day-today basis and thus contributes to political accountability at the EU level. Building on an innovative analytical framework for the study of parliamentary questions and answers, Adina Akbik sheds light on the European Parliament's possibilities and limitations to hold EU executive bodies accountable more generally. Case studies cover the period 2012-2019 and include the European Central Bank in banking supervision, the European Commission, the Eurogroup, and the Economic and Financial Affairs Council. This book is Open Access.

Adina Akв ik is Assistant Professor of European Politics at Leiden University and Affiliate Research Fellow at the Jacques Delors Centre of the Hertie School in Berlin. She was awarded her PhD summa cum laude at the Central European University and since then has published widely in leading journals. 


\title{
The European Parliament as an Accountability Forum
}

\author{
OVERSEEING THE ECONOMIC AND MONETARY \\ UNION
}

\section{ADINA AKBIK}

Leiden University, Institute of Political Science

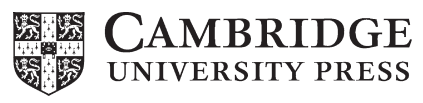




\section{CAMBRIDGE UNIVERSITY PRESS}

University Printing House, Cambridge св2 8вs, United Kingdom

One Liberty Plaza, 2oth Floor, New York, NY 10006, USA

477 Williamstown Road, Port Melbourne, vIC 3207, Australia

314-321, 3rd Floor, Plot 3, Splendor Forum, Jasola District Centre,

New Delhi - 110025, India

103 Penang Road, \#05-06/07, Visioncrest Commercial, Singapore 238467

Cambridge University Press is part of the University of Cambridge.

It furthers the University's mission by disseminating knowledge in the pursuit of education, learning, and research at the highest international levels of excellence.

www.cambridge.org

Information on this title: www.cambridge.org/9781108835756

DOI: $10.1017 / 9781108886611$

(C) Adina Akbik 2022

This work is in copyright. It is subject to statutory exceptions and to the provisions of relevant licensing agreements; with the exception of the Creative Commons version the link for which is provided below, no reproduction of any part of this work may take place without the written permission of Cambridge University Press.

An online version of this work is published at doi.org/10.1017/9781108886611 under a Creative Commons Open Access license CC-BY-NC 4.0 which permits re-use, distribution and reproduction in any medium for non-commercial purposes providing appropriate credit to the original work is given and any changes made are indicated. To view a copy of this license visit https://creativecommons.org/licenses/by-nc/4.o

All versions of this work may contain content reproduced under license from third parties.

Permission to reproduce this third-party content must be obtained from these thirdparties directly.

When citing this work, please include a reference to the DOI 10.1017/9781108886611

First published 2022

A catalogue record for this publication is available from the British Library.

ISB N 978-1-108-83575-6 Hardback

Cambridge University Press has no responsibility for the persistence or accuracy of URLs for external or third-party internet websites referred to in this publication and does not guarantee that any content on such websites is, or will remain, accurate or appropriate. 
To Alex

Because you tell me stories that have their own parliaments and councils 


\section{Contents}

List of Figures

page $\mathrm{x}$

List of Tables

xiv

Acknowledgements $\quad \mathrm{xV}$

List of Abbreviations xvii

1 Introduction 1

1.1 Purpose and Scope

1.2 The European Parliament: A Normalising Abnormal Parliament

1.3 The EP as an Accountability Forum 8

1.4 Analytical Approach and Research Design 11

1.5 Contribution 13

$\begin{array}{lll}1.6 & \text { Outline } & 15\end{array}$

2 The Economic and Monetary Union, the Crisis, and Political Accountability

2.1 The Institutional Development of the EMU

2.1.1 The Euro Crisis and the Reform of the EMU 22

2.1.2 Post-Crisis Institutional Dynamics 24

2.2 The Accountability Framework of the EMU 27

2.2.1 Political Accountability in the EMU 28

2.2.2 Filling the Accountability Void? The Role of the EP after the Crisis

2.3 Summary 
3 Studying Accountability at the European Parliament:

A Legislative Oversight Approach 35

3.1 The Concept of Accountability 36

3.1.1 Measuring the Stages of Accountability 39

3.2 Situating the Accountability Potential of Parliaments 41

3.2.1 Government Accountability and the Role of Parliaments 41

3.2.2 Studying Oversight through Parliamentary Questions 46

3.3 The Analytical Framework: The Q\&A Approach to Legislative Oversight

3.3.1 Six Scenarios of Oversight Interactions

3.3.2 Expectations about the European Parliament in the EMU

3.4 Methodological Considerations

3.4.1 Coding Guide 65

3.5 Outlook

4 Overseeing the European Central Bank in Banking Supervision 70

4.1 Background: The Crisis and the SSM Regulation 72

4.2 Political Accountability in Banking Supervision: Key Issues 75

4.3 Oversight Interactions: Main Findings 79

4.3.1 Profile of Questioners 81

4.3.2 Types of Questions 85

4.3.3 Types of Answers 89

4.4 The Record: Holding the ECB Accountable in Banking Supervision

5 Overseeing the European Commission in the European Semester

5.1 Background: The European Commission in the EMU

5.1.1 The Euro Crisis and the Empowerment of the Commission in the EMU

5.2 The Accountability of the Commission in the European

Semester: Key Issues 104

5.3 Overseeing the Commission in the European Semester 108

5.3.1 Profile of Questioners and Respondents 112

5.3.2 Types of Questions $\quad 116$

5.3.3 Types of Answers 124

5.4 The Record: Holding the Commission Accountable in the European Semester 
6 The Economic Dialogues with the ECOFIN Council and the Eurogroup

6.1 Background: ECOFIN, Eurogroup, and the Political

Accountability of Intergovernmental Actors in the EMU

6.1.1 The Euro Crisis and the Domination of Intergovernmental Bodies

6.2 The Accountability of Intergovernmental Bodies: Key Issues

6.3 The Economic Dialogues with the ECOFIN Council Presidency

6.3.1 Profile of Questioners and Respondents

6.3.2 Types of Questions Asked

6.3.3 Types of Answers Provided

6.3.4 Summary

6.4 The Economic Dialogues with the Eurogroup President 159

6.4.1 Profile of Questioners and Respondents 160

6.4.2 Types of Questions Asked 163

6.4.3 Types of Answers Provided 169

6.4.4 Summary 172

6.5 The Record: Holding Finance Ministers Accountable in the EMU

7 Conclusions: Comparative Evaluation and Necessary Reforms

176

7.1 Case Comparison

7.1.1 The Performance of the EP as an Accountability Forum

7.1.2 The Responsiveness of EMU Executive Actors to EP Oversight

7.1.3 Assessing Oversight Interactions: A Comparison

184

7.2 Looking Forward: Policy Recommendations

190

7.3 The Big Picture: EP Oversight and EU Accountability 


\section{Figures}

3.1 The Q\&A approach to legislative oversight. Own account

3.2 Expectations about oversight interactions between the EP and executive actors in the EMU

4.1 Overview of letters exchanged between the EP and the ECB on banking supervision (October 2013-April 2018). Total letters identified: 283

4.2 Public hearings of the ECB at the EP's ECON Committee in the SSM framework (January 2014-April 2018)

4.3 Nationality of MEPs sending letters with questions to the ECB on banking supervision (October 2013-April 2018).

Total: 220 MEPs identified in 150 letters

4.4 Political affiliation of MEPs sending letters with questions to ECB on banking supervision. Total: 220 MEPs identified in 150 letters

4.5 Nationality of MEPs taking the floor during public hearings of the Chair of the Supervisory Board. Total MEPs identified (counted once per session): 156

4.6 Political affiliation of MEPs taking the floor during public hearings with the Chair of the Supervisory Board. Total MEPs identified (counted once per session): 156

4.7 Types of questions asked by MEPs of the ECB on banking supervision (October 2013-April 2018). Total identified: 706

4.8 List of topics raised in hearings and letters to the ECB on banking supervision (October 2013-April 2018). One question can have one or two codes. Total codes assigned: 1,009 for 706 questions

4.9 Types of answers provided by the ECB on banking supervision to MEPs, in numbers (October 2013-April 2018). Total answers identified: 706 
4.10 Responsiveness of the ECB on banking supervision to MEPs in both letters and hearings (October 2013-April 2018).

Total answers identified: 706

5.1 Economic Dialogues with the European Commission (December 2010-May 2019). Joint Economic Dialogues can be organised with the ECON Committee and the EMPL Committee, or with the ECON Committee and REGI Committee

5.2 Letters with questions and answers exchanged between MEPs and the European Commission on the European Semester (December 2010-May 2019)

5.3 Nationality of MEPs asking oral questions of the Commission in the Economic Dialogues (January 2012-May 2019). One MEP can ask multiple questions in a meeting, but (s)he is only counted once. Total number of MEPs identified: 319

5.4 Political affiliation of MEPs asking oral questions of the Commission in the Economic Dialogues (December 2010-May 2019). One MEP can ask multiple questions in a meeting, but (s)he is only counted once. Total number of MEPs identified: 319

5.5 Nationality of MEPs asking written questions of the Commission on the European Semester (December 2010-May 2019). Some letters can have multiple authors. Total number of MEPs identified: 183

5.6 Political affiliation of MEPs asking written questions of the Commission on the European Semester (December 2010-May 2019). Some letters can have multiple authors. Total number of MEPs identified: 183

5.7 Institutional position of the Commissioners answering questions on the European Semester in Economic Dialogues and letters (December 2010-May 2019)

5.8 Types of questions asked by MEPs of the Commission on the European Semester (December 2010-May 2019). Total identified: 844

5.9 List of topics raised in questions asked by MEPs of the Commission on the European Semester (December 2010-May 2019). One question can have one or two codes. Total codes assigned: 1,423 for 844 questions 
5.10 Types of answers provided by the Commission to MEPs on the European Semester (December 2010-May 2019). Total answers identified: 844

5.11 Responsiveness of the Commission to MEPs on the European Semester (December 2010-May 2019). Total answers identified: 844

6.1 Number of Economic Dialogues with the ECOFIN Council Presidency and number of questions identified during each parliamentary term (2012-2014 and 2014-2019, respectively)

6.2 Nationality of MEPs taking the floor in Economic Dialogues with the ECOFIN Council Presidency (2012-2019). Total MEPs identified: 303

6.3 Political affiliation of MEPs taking the floor in Economic Dialogues with the ECOFIN Council Presidency (2012-2019). Total MEPs identified: 303

6.4 Number of questions addressed to each country holding the six-month ECOFIN Presidency. Total: 613

6.5 Types of questions identified in Economic Dialogues with the ECOFIN Council Presidency (2012-2019). Total questions: 613150

6.6 Range of issues raised by MEPs during Economic Dialogues with the ECOFIN Council Presidency (2012-2019). Most questions are assigned two codes. Total issues: 1,186

6.7 Types of answers received by MEPs in Economic Dialogues with the ECOFIN Council Presidency (2012-2019). Total replies identified: 613

6.8 Degree of responsiveness by ECOFIN ministers holding the Presidency in Economic Dialogues (2012-2019)

6.9 Number of Economic Dialogues and questions addressed to the Eurogroup President during different parliamentary terms (2013-2014 and 2014-2018)

6.10 Nationality of MEPs taking the floor in Economic Dialogues with the Eurogroup President (2013-2018). Total MEPs identified: 224

6.11 Party affiliation of MEPs taking the floor in Economic Dialogues with the Eurogroup President (2013-2018). Total MEPs identified: 224

6.12 Number of questions addressed to different interlocutors during Economic Dialogues with the Eurogroup President (2013-2018) $\quad 162$

6.13 Types of questions identified in Economic Dialogues with the Eurogroup President (2013-2018). Total questions: 474 
6.14 Types of issues raised by MEPs in Economic Dialogues with the Eurogroup President (2013-2018). Most questions have two codes, except those that address ESM programme countries, Greece and Cyprus (which have three codes). Total codes assigned: 1,095 166

6.15 Types of answers provided by the Eurogroup President in Economic Dialogues at the EP (2013-2018). Total answers identified: 474

6.16 Degree of responsiveness by the Eurogroup President in Economic Dialogues (2013-2018)

7.1 Percentage of initial and follow-up questions posed by MEPs to each institution, based on Chapters 4-6

7.2 Types of questions posed by MEPs to each institution, based on Chapters 4-6

7.3 Percentage of explicit, intermediate, and non-replies provided by each institution, based on Chapters 4-6

7.4 Types of answers provided by each institution, based on Chapters 4-6

7.5 Overview of case studies in the book on the continuum from 'high control' to 'no control' by the EP in the EMU 


\section{Tables}

3.1 Six scenarios of legislative oversight

page 55

3.2 Institutional settings of legislative oversight scenarios

3.3 Coding guide: overview of core variables

7.1 Policy recommendations addressed to the EP in order to improve its performance as an accountability forum

7.2 Policy recommendations addressed to EMU executive actors in order to improve their responsiveness to the EP 


\section{Acknowledgements}

In many ways, this book feels like my second $\mathrm{PhD}$ thesis. Similar to my dissertation, I conducted the research and completed the writing within four years in a wonderful academic environment: (this time) the Hertie School of Governance in Berlin. The book is part of the wider research project LEVIATHAN - "Legal and Political Accountability in "Post-Crisis" EU Economic Governance' (2017-2021) - funded by the European Research Council (ERC) in the framework of the Horizon 2020 research and innovation programme (grant agreement 716923 ). I am particularly grateful to Mark Dawson, the principal investigator of the project, who entrusted me to carry out one of the work packages on the subject of political accountability in relation to the European Parliament. Working with Mark in the past years has definitely been the highlight of my time as a postdoc. I learned so much from him in terms of writing and thinking about European Union (EU) governance, pushing the boundaries of my political science training into legal scholarship. Our collaborations have been both intellectually engaging and productive, and I am sure we will continue to co-author papers in the future. I consider Mark and his husband, Pierre, my good friends and we often spend time together outside the university.

More generally, the Hertie School has offered an exciting work environment in terms of both research and teaching. Despite being a small school of governance focused on graduate studies, the Hertie School has a vibrant community of people working on the EU from an academic and think tank perspective. At the Jacques Delors Centre, I appreciated our weekly European Governance Colloquiums, which always brought interesting new research to my attention. I would especially like to thank Markus Jachtenfuchs, the Director of the Centre, who has provided me with a lot of feedback over the years and has often served as a mentor regarding my future career plans. In the postdoc 
community, I am glad to have found Ana Bobić, Marta Migliorati, and Christian Freudlsperger, who are not only my co-authors but also my good friends and support group in case of crises of professional self-confidence which are unavoidable in academia. On the administrative side, I would like to thank Gabi Brühl, the centre manager at the Jacques Delors Centre, who has repeatedly helped me navigate the complex waters of German bureaucracy.

Next to the ERC, which has generously funded the research behind this book, I am grateful to Cambridge University Press and Tom Randall, in particular, for a swift and helpful review process. I would also like to thank the participants of a workshop held on 8 October 2018 at the Hertie School on the subject of accountability of the European Central Bank (ECB). This event has deepened my understanding of the oversight interactions between the European Parliament and the ECB and opened the door towards interacting with practitioners working in or with the two institutions. Special thanks to Marcel Magnus from the European Parliament's Economic Governance Support Unit (EGOV), with whom I talked repeatedly and who has given me feedback on one of the chapters. In composing the data sets and coding the empirical material for the book, I had the help of an excellent group of research associates who contributed to the LEVIATHAN project during 2017-2020 (in chronological order): Evgenija Kroeker, Rebecca Segall, Harry McNeill Adams, Elena Bertolini, and Francesco Lanzone.

On a personal front, I know my work would not be the same without the love and stability provided by my husband, Alex. I feel extremely lucky to have him in my life for many reasons, but when it comes to my career, I am grateful for the constant support and encouragement to persevere. On the same note, I would like to thank my parents and sister in Romania, who have always been in my corner no matter what.

To come back to my opening about $\mathrm{PhD}$ theses, I do have a message for all doctoral students out there struggling to define or complete their dissertations: it gets easier the second time around. 


\section{Abbreviations}

AGS

ALDE

AMR

BEPGs

CJEU

CRD

CRR

CSRs

DBPs

DG

DG ECFIN

DG EMPL

EBA

ECA

ECB

ECOFIN

ECON

ECR

EDIS

EDP

EFC

EFDD

EFSF

EIP

EMPL

EMS

EMU
Annual Growth Survey

Group of the Alliance of Liberals and Democrats for Europe

Alert Mechanism Report

Broad Economic Policy Guidelines

Court of Justice of the European Union

Capital Requirements Directive

Capital Requirements Regulation

Country-Specific Recommendations

Draft Budgetary Plans

Directorate-General

Directorate-General for Economic and Financial Affairs

Directorate-General for Employment, Social Affairs and Inclusion

European Banking Authority

European Court of Auditors

European Central Bank

Economic and Financial Affairs (Council)

Committee on Economic and Monetary Affairs (EP)

European Conservatives and Reformists Group

European Deposit Insurance Scheme

Excessive Deficit Procedure

Economic and Financial Committee

Europe of Freedom and Direct Democracy Group

European Financial Stability Facility

Excessive Imbalances Procedure

Employment and Social Affairs

European Monetary System

Economic and Monetary Union 


$\begin{array}{ll}\text { ENF } & \text { Europe of Nations and Freedom } \\ \text { EP } & \text { European Parliament } \\ \text { EPC } & \text { Economic Policy Committee } \\ \text { EPP } & \text { Group of the European People's Party } \\ \text { ESM } & \text { European Stability Mechanism } \\ \text { EU } & \text { European Union } \\ \text { EWG } & \text { Eurogroup Working Group } \\ \text { FOLTF } & \text { Failing or likely to fail (applicable to banks in banking } \\ & \text { supervision) } \\ \text { Greens/EFA } & \text { The Greens/European Free Alliance } \\ \text { GDP } & \text { gross domestic product } \\ \text { GUE-NGL } & \text { Confederal Group of the European United Left-Nordic } \\ & \text { Green Left } \\ \text { IDR } & \text { in-depth review } \\ \text { IMF } & \text { International Monetary Fund } \\ \text { JSTs } & \text { Joint Supervisory Teams } \\ \text { MEP(s) } & \text { Member(s) of the European Parliament } \\ \text { MIP } & \text { Macroeconomic Imbalances Procedure } \\ \text { NCAs } & \text { National Competent Authorities } \\ \text { NPLs } & \text { non-performing loans } \\ \text { Q\&A } & \text { questions and answers (in legislative oversight) } \\ \text { REGI } & \text { Committee on Regional Development (EP) } \\ \text { RRF } & \text { Recovery and Resilience Facility } \\ \text { S\&D } & \text { Group of the Progressive Alliance of Socialists and } \\ & \text { Democrats in the European Parliament } \\ \text { SGP } & \text { Stability and Growth Pact } \\ \text { SRB } & \text { Single Resolution Board } \\ \text { SRF } & \text { Single Resolution Fund } \\ \text { SRM } & \text { Single Resolution Mechanism } \\ \text { SSM } & \text { Single Supervisory Mechanism } \\ \text { TEU } & \text { Treaty on European Union } \\ \text { TFEU } & \text { Treaty on the Functioning of the European Union } \\ & \end{array}$




\section{Introduction}

My first question relates to the fact that both of you mentioned, rightly, that you were not accountable to this Parliament. So Mr. Regling you are accountable to the Eurogroup and the President of the Eurogroup is accountable to his [national] parliament. So it's strange that in Europe we have such a huge European problem [the third financial assistance programme for Greece] with no accountability to the European Parliament.

\section{Elisa Ferreira, cited in European Parliament 2015b}

On 10 November 2015, Dutch Finance Minister Jeroen Dijsselbloem appeared before the European Parliament (EP) as part of the regular 'Economic Dialogues' established after the euro crisis. Dijsselbloem's participation in an EP committee meeting was related to his position at the time as President of the Eurogroup - the European Union's (EU's) most powerful economic body and key decision-maker on financial assistance programmes (Craig 2017; Puetter 2006). On this occasion, Dijsselbloem was accompanied by Klaus Regling, the Managing Director of the European Stability Mechanism (ESM). Although the ESM was an intergovernmental organisation created outside the EU Treaty framework, the Eurogroup was (and still is) closely involved in its governance structure. In fact, Eurogroup finance ministers act as the ESM's Board of Governors (ESM Treaty, Article 5). During the Economic Dialogue mentioned earlier, the main topic of discussions was the third financial assistance programme for Greece, a package agreed in the summer of 2015 after months of uncertainty and the rejection of similar bailout conditions by Greek citizens in a referendum (Panke 2019).

Against this background, the comment made by Elisa Ferreira illustrates recurrent complaints by Members of the European Parliament (MEPs) regarding the Eurogroup's lack of accountability and its involvement in the 
ESM. In 2014, the EP even adopted a Resolution condemning the absence of EU-level democratic legitimacy and accountability of the Eurogroup when it assumes EU-level executive powers' (European Parliament 2014f). The crisis in Greece and the 2015 referendum served as a reminder that national electorates (and parliaments) could hold their own governments accountable for ESM decisions but not the Eurogroup as a whole (cf. Brandsma et al. 2016: 624-625). Conversely, the EP had no powers in relation to the ESM except for the possibility to ask questions of the Eurogroup President during Economic Dialogues.

As the only directly elected institution in the EU, representing citizens from all Member States, the EP has a legitimate claim to oversee the activities of all EU executive actors - not just the Eurogroup - and ensure that they are held accountable at the appropriate level. There are two concepts crucial to this discussion, namely 'accountability' and 'oversight'. Nowadays, accountability is a ubiquitous term centred on the importance of controls over the exercise of power in a democratic system (Dubnick 2014: 29; Fearon 1999; Strøm 2000). At a basic level, accountability requires public officials - whether elected or not to justify their conduct in front of a higher authority (Bovens et al. 2014; Mulgan 2000a; Philp 2009). In a broader sense, accountability is about making amends for past errors and thus correcting inappropriate conduct or ill-conceived policies (Oliver 1991: 28). The ability to hold public actors accountable is linked to legitimacy considerations, namely the extent to which government decisions are seen as acceptable because they can be justified through rules, evidence, or consent by the population (Beetham 1991: 3). In this respect, the EU is no different than any polity that aspires to be democratic.

Furthermore, accountability is a multi-faceted notion that takes different forms depending on the type of forum demanding an account - which can be political, legal, administrative, professional, and so on (Bovens 2007a: 455457). In the realm of political accountability, legislative oversight allows members of parliaments to check, verify, inspect, criticise, or challenge the activities of the government and public administration (Gregory 1990: 64; see also Aberbach 1990). The objective of oversight is to prevent abuses by executive actors, including but not limited to dishonesty, waste, arbitrariness, unresponsiveness, or deviation from legislative intent (MacMahon 1943: 162-163). Although definitions vary, the common understanding of 'oversight' implies an ex post focus ('review after the fact'), looking at 'policies that are or have been in effect' (Harris 1964: 9). In a democratic system, oversight (alongside elections) is meant to help bridge the gap between those who hold political authority (citizens) and those who exercise it on their behalf (Bovens 2007a: 455; Strøm 2000). 
The question whether the EP can hold EU executive actors accountable on a day-to-day basis - by acting as an effective oversight body - is at the centre of this book. The following pages delineate the purpose and scope of the study and contextualise the topic in relation to the EP. Next, the chapter explains the analytical approach and research design of the book as well as its contribution to the academic literature. The chapter concludes with an overview of the monograph's structure and outline of chapters.

\subsection{PURPOSE AND SCOPE}

This book examines the EP's effectiveness as an accountability forum that oversees EU executive actors on a day-to-day basis. The notion of 'effectiveness' comprises both the performance of the EP as a political oversight body and the extent to which EU executive actors engage with EP oversight. Two aspects are covered here: first, how do MEPs exercise their powers of ex post scrutiny ${ }^{1}$ over EU executive actors? Second, how responsive are EU executive actors to oversight by the EP? To address the two dimensions, the book focuses on parliamentary questions as a key accountability mechanism that allows legislators (1) to interact with executive actors on a regular basis (as opposed to an ad hoc basis) and (2) to scrutinise substantive policy and political decisions made by executive actors (as opposed to checking budgetary abuses or violations of the law). Parliamentary questions probe and challenge executive actors, raising different aspects of accountability such as answerability, responsiveness, transparency, non-arbitrariness, effectiveness, or publicness (Dawson and Maricut-Akbik 2020: 7-8; Dubnick 2014: 33). Moreover, while is it acknowledged that MEPs can ask questions for a variety of reasons (Martin 2011a; Wiberg and Koura 1994), this does not diminish their purpose to ensure effective oversight - and thus hold executive actors accountable.

Empirically, the book investigates the Economic and Monetary Union (EMU), a policy area that provoked fierce controversy across Europe following the 2007-2008 global financial crisis. In EU Member States and especially among countries that adopted the euro (the so-called Eurozone), the global financial crisis turned into a protracted sovereign debt crisis that triggered sweeping reforms of the EMU governance framework (Hodson and Puetter 2016). At the EU level, such reforms led to the empowerment of several executive actors - most prominently the Eurogroup, the European Central Bank (ECB), and the European Commission (henceforth 'the Commission') (Bauer and Becker 2014; Braun and Hübner 2019; Curtin 2017). Moreover, the

1 Throughout the book, the terms oversight and (ex post) scrutiny will be used interchangeably. 
crisis laid bare the consequences of introducing a single currency among diverse economies and thus affecting the lives of millions of citizens across Europe. While some faced unemployment or loss of income as a result of austerity-imposing bailout programmes, others failed to understand why their tax money had to support distant governments in other Member States (Copelovitch et al. 2016; Fabbrini 2013; Schelkle 2017). In the dichotomy between debtor and creditor countries, EMU governance became linked to politically sensitive questions about redistribution and solidarity (Borger 2013; Chalmers 2012). Despite initial attempts at depoliticising the EU response to the crisis, the outcome was an increase in the salience of EMU decisionmaking in public debates at the domestic level (Hobolt and Wratil 2015; Kriesi and Grande 2016; Statham and Trenz 2015).

In this context, the need to improve the accountability of EMU institutions became pressing. Unlike in the field of market integration, EU decisions in the EMU started to have tangible redistributive consequences that affected Member States disproportionately (Genschel and Jachtenfuchs 2018: 181182). Moreover, many citizens became mobilised against the EU response to the crisis - as illustrated by the rise of Eurosceptic parties on both the right and the left of the political spectrum (De Vries 2018; Leruth et al. 2017). Under the circumstances, critics pointed to the expansion of executive power in the EMU since the crisis and the need to create commensurate mechanisms of legal and political accountability (Crum and Curtin 2015; Dawson 2015). In addition to the intensification of crisis management meetings by the European Council and the Eurogroup (Fabbrini 2013; Maricut and Puetter 2018), technocratic institutions such as the ECB and the Commission saw their powers expanded since the crisis (Bauer and Becker 2014; Curtin 2017; Dawson et al. 2019; Savage and Verdun 2016).

In this context, the book focuses on the scrutiny powers gained by the EP in the new governance instruments created in response to the euro crisis. The EP was an obvious choice to address the accountability gap in the EMU because it already possessed scrutiny functions (vis-à-vis the Commission) and could technically act as a political oversight body in a similar way to national parliaments (Crum 2018; Fromage 2018). Since the euro crisis, the EP gained additional powers to scrutinise the activities of several key EMU actors. In banking supervision, the EP has a new accountability framework with the $\mathrm{ECB}$, which is, by all accounts, more comprehensive than corresponding arrangements in monetary policy (Fromage and Ibrido 2018; ter Kuile et al. 2015). In economic governance, the EP now holds regular exchanges of views (the Economic Dialogues) with the Commission, the Council, the Eurogroup, and individual Member States with the purpose 'to ensure greater 
transparency and accountability' (de la Parra 2017: 102). The reforms held great promise for the oversight potential of the EP, signalling that EMU governance decisions are open to scrutiny.

Bearing this in mind, the monograph simultaneously explores parliamentary accountability through the EP and the challenges of EMU governance after the crisis. The EMU is a perfect setting for testing EP oversight of EU executive actors for two reasons. On the one hand, the salience of the field is likely to attract public attention and thus encourage MEPs to take advantage of parliamentary questions in order to exercise their political accountability functions. In the context of the crisis, areas of contention included the appropriateness of austerity policies and structural reforms (Busch et al. 2013; Hermann 2017), the effectiveness of EU instruments such as the European Semester (Efstathiou and Wolff 2018; Maatsch 2017), the legality of market interventions by the ECB (Goldoni 2017; Sauer 2015; Zilioli 2016), or the legitimacy of EU influence in domestic socio-economic affairs more generally (Kriesi and Grande 2016). On the other hand, the new scrutiny instruments introduced during the euro crisis ensure frequent interactions between the EP and different executive actors in the EMU - and hence provide extensive and comparative data for the empirical analysis of parliamentary questions.

In the academic literature, the EP's accountability powers have received little attention - not least because oversight has never been at the top of the political agenda throughout the EP's history. For a long time, the EP has sought to expand its legislative and budgetary functions and has only recently tried to consolidate its control powers over the Commission. The next sections contextualise the EP's capacity for oversight in relation to its institutional development and scrutiny powers.

\subsection{THE EUROPEAN PARLIAMENT: A NORMALISING ABNORMAL} PARLIAMENT

The history of the EP as a transnational legislature is a history of continuous struggle. From humble beginnings as the unelected Common Assembly of the European Coal and Steel Community, in 1979, the EP became the only directly elected institution of the European Community and later of the EU (Jacobs and Corbett 1990). Since then, the EP has constantly expanded its legislative, budgetary, and scrutiny powers (Burns 2019; Hix and Høyland 2013; Judge and Earnshaw 2003; Rittberger 2003). Invoking a direct mandate from EU voters, MEPs have persistently fought to increase the influence of their institution in the EU political system (Corbett et al. 2003: 355-357). In fact, 
every time critics complained about the lack of democratic legitimacy in the European Community or the EU, the answer was typically an empowerment of the EP (Blondel et al. 1998: 4; Føllesdal and Hix 2006: 554-556; Katz and Wessels 1999: 5-6; Rittberger 2005).

Over time, the EP's expansion of powers occurred in all of its areas of activity. In terms of law-making, the EP evolved from a consultative body whose opinions could be ignored by the Council - to a co-decider on equal footing with national governments (Hix et al. 2007: 18). The Lisbon Treaty (2009) renamed co-decision into the ordinary legislative procedure and extended it to many policy areas (Article 289 of the Treaty on the Functioning of the European Union, TFEU). In relation to budgetary control, EP powers also increased over time: nowadays, the EP must give its consent for the EU's multi-annual financial framework (Article 312(2) TFEU) and has the last word on the annual budgetary discharge for the Commission and other EU institutions and agencies (Article 319 TFEU). In terms of scrutiny functions, the Maastricht Treaty empowered the EP in respect of the appointment of the Commission President and the College of Commissioners (Pavy 2020). Since 2014, the Spitzenkandidat process brought additional visibility to EP electoral campaigns, as EU political groups put forth candidates for the position of Commission President (Hobolt 2014, 2019).

In academic studies, the EP's expansion of legislative powers has received the most attention, in parallel to the development of party politics - which is often taken as a sign that the EP has become a 'normal parliament' (Hix et al. 2007: 3). Significantly, scholars attested to the emergence of cohesive political groups and coalitions along the left-right dimension, focused on the representation of distinct socio-economic views rather than territorial units (Hix et al. 2007; Kreppel 2002; Kreppel and Tsebelis 1999). In the past, the main political groups were the centre-right European People's Party (EPP) and the centreleft Progressive Alliance of Socialists and Democrats in the European Parliament (S\&D). For most of the EP's existence, the two pan-European groups benefited from a comfortable majority which allowed them to establish a 'grand coalition' and cooperate on most issues. The dynamic has partially changed in the last two electoral cycles (2014 and 2019), when many voters embraced Eurosceptic parties and the EP became more fragmented (Hobolt 2019; Hobolt and de Vries 2016; Nielsen and Franklin 2017). In itself, however, the fragmentation of political groups does not make the EP less of a 'normal parliament'.

Conversely, authors who challenge the view regarding the normalisation of the EP point to other aspects (Brack and Costa 2018: 3-4; Katz and Wessels 1999: 6). First, unlike national parliaments, the EP lacks the right of legislative 
initiative, which formally belongs to the Commission (Article 17(2) Treaty on European Union, TEU). While MEPs can ask the Commission to submit proposals on any matter, the Commission can refuse by simply providing a justification (Article 225 TFEU). Second, the EP still has limited or no decision-making powers in some policy areas - such as taxation or foreign policy. Even in areas of co-decision, the EP has consistently relied on a grand coalition between centre-right and centre-left groups, creating a highly consensual system that 'dilute[d] ideological differences between left and right' (Brack and Costa 2018: 4). Third, it is unusual for a legislature to have so many members who oppose the existence of the polity which they are supposed to represent - as shown by the increasing number of Eurosceptic parties (Brack 2017).

Undoubtedly, the EP has more legislative powers than ever before. Yet its empowerment did not automatically reduce the EU's infamous 'democratic deficit' (Føllesdal and Hix 2006; Majone 1998; Moravcsik 2002). In fact, EU legislative decision-making continues to be complex, with multiple veto players at different levels of governance. Most significantly, political competition in EP elections does not translate into control over the EU policy agenda: even if citizens were to endorse a particular political programme, their preferences will be lost in negotiations with other institutions and Member States (Hix and Høyland 2011: 131-133). At the same time, EP elections lack the typical 'electoral connection' between members of parliaments and their voters (Hix and Høyland 2013: 184). Technically, EU citizens have the possibility to vote MEPs in and out of office every five years according to their performance; in practice, they tend to vote based on domestic rather than European issues (Hix and Marsh 2011; Mzes 2005; Reif and Schmitt 1980).

In this context, scholars have emphasised the structural deficiencies of political accountability through the EP (Brandsma et al. 2016: 624-625; Gustavsson et al. 2009: 5). Notably, EP elections allow voters to change the composition of the supranational legislature and indirectly of the College of Commissioners, but this does not guarantee control of the EU policy agenda by citizens with knowledge of European issues. By contrast, intergovernmental bodies such as the European Council and the Council are key decisionmakers at the EU level, but they remain accountable to national parliaments and electorates on an individual basis (Article 10(2) TEU). Against this background, it makes sense to shift attention from elections as the main instrument of political accountability to other mechanisms - such as oversight - that allow the EP to hold executive actors accountable, ex post facto, for their decisions at the EU level. The next section outlines the type of oversight instruments available to the EP vis-à-vis EU executive actors. 


\subsection{THE EP AS AN ACCOUNTABILITY FORUM}

In the EU multi-level governance system, the EP is uniquely placed to oversee the actions of executive bodies. Even in the absence of a strong electoral connection to voters, the advantages of a transnational legislature with cohesive political groups are clear for improving the EU's democratic credentials. First and foremost, the EP offers a venue for the representation of a common European interest as opposed to the national interests of each Member State (Crum 2018; Fasone 2014a; Rittberger 2014). Article 10(2) TEU specifies that the EP is to represent citizens directly at the EU level, while empirical research has shown that ideological divides are more important than national lines in driving the behaviour of MEPs (Hix et al. 2007; Scully et al. 2012). This is not to say that MEPs ignore territorial constituencies (Raunio 1996; Scully and Farrell 2003), but they are much more likely than national legislators to invoke a 'common European good' in support of their positions (Lord 2013: 255).

Second, in areas of intergovernmental decision-making, the EP has the potential to compensate for the structural limitations of national parliaments in the EU political system. While each national government in the $\mathrm{EU}$ is accountable to its respective parliament (Article $10 \mathrm{TEU}$ ), intergovernmental decisions are collective - making it difficult to disentangle individual responsibility (Brandsma et al. 2016: 625; Hobolt and Tilley 2014). By overseeing the European Council and the Council, the EP could exercise political accountability for decisions that affect the $\mathrm{EU}$ as a whole. At the same time, by acting as a strong accountability forum, the EP would not diminish the oversight role of national parliaments, which will continue to remain responsible for scrutinising decisions taken at their own level. In other words, the contribution of the EP to oversight is additive and complementary to national parliaments, 'keeping a watchful eye' (Aberbach 1990) over EU executive decisions.

Procedurally speaking, the EP has several mechanisms to oversee the activities of executive actors. The relationship with the Commission is placed front and centre, although EU executive power is fragmented across several other institutions, including the European Council and the Council, the ECB and $\mathrm{EU}$ agencies, as well as committees responsible for implementing decisions (Curtin 2009; Egeberg 2006; Trondal 2010). In relation to the Commission, the concept of 'oversight' excludes the ex ante selection of executive members, for example, the election of the Commission President or the investiture of the College of Commissioners (European Parliament 2019b). Conversely, oversight focuses on ex post scrutiny of Commission activities - where the strongest instrument is indisputably the potential 
dismissal of the College of Commissioners through a motion of censure (Article 234 TFEU). Since the Maastricht Treaty (1993), MEPs have attempted to use the procedure seven times but never succeeded in removing the Commission (Remáč 2019: 26). However, the mere threat of a successful motion of censure can create pressure for the resignation of the Commission as was the case of the Santer Commission in the late 1990s (Ringe 2005: 677).

Another oversight mechanism specific to the Commission refers to delegated acts, a type of non-legislative instrument that allows the supranational institution 'to supplement or amend certain non-essential elements' of EU legislation (Article 290(1) TFEU). The EP (and the Council) can object to a delegated act within a specific time period or revoke it altogether, offering an important avenue of ex post parliamentary control of the executive (Brandsma 2016; Yordanova and Zhelyazkova 2020: 346). In practice, the right to revocation has never been used, while objections by the EP occurred only on eight occasions since 2009 (Remáč 2019: 73). Overall, motions of censure and scrutiny of delegated acts are too infrequent to allow a systematic analysis of the EP's oversight powers of EU executive actors.

Next, there are instruments available to MEPs on an ad hoc basis, such as committees of enquiry. These allow the investigation of 'alleged contraventions or maladministration in the implementation of Union law' (Article 226 TFEU). Enquiry committees are not specific to the Commission - they can be set up against any EU institution, national body, or entity implementing EU law. Over time, the EP has repeatedly complained about the limited powers of enquiry committees and passed two resolutions (in 2014 and 2019) criticising the Commission and the Council for their reluctance to help establish an effective process for EP enquiries (Pavy 2020). The problem is the lack of legal mechanisms to enforce the cooperation of executive actors with EP investigations: unlike enquiry committees at the national level, EP committees cannot summon witnesses or enforce document access (European Parliament 2016g). A similar dynamic can be found in the case of special parliamentary committees, which are also seldom used despite not being limited to enquiries of contravention or maladministration of EU law (Remáč 2019: 45).

Another oversight instrument is the discharge procedure, which is technically part of the EP's budgetary powers (Pavy 2020) but carries elements of ex post scrutiny of the executive. The discharge procedure allows the EP to monitor and vote on the correct implementation of the EU budget by the Commission and other EU bodies (Committee on Budgetary Control 2020). In this respect, the EP works closely with the European Court of Auditors (ECA) and acts as a forum for financial supervision and control (Bovens 2007a: 456). In practice, the EP's refusal to grant discharge to an EU body is a rare 
occurrence: since 2009, it has happened a couple of times in respect of the Council and EU agencies but not vis-à-vis the Commission (Remáč 2019: 60). Overall, the discharge procedure is an important mechanism where auditing and politics meet' in the EU system (Laffan 2003: 773), but which ultimately does not go beyond a form of financial accountability. Nonetheless, the political nature of the EP allows it to move easily from budgetary oversight to ex post scrutiny of substantive policy decisions by EU executive actors.

This is where parliamentary questions come into play - the final and most pervasive mechanism of oversight at the disposal of the EP. MEPs can address questions to different EU institutions: the Commission, the Council, the European Council, the ECB, and so on - in line with the Rules of Procedure for each parliamentary term (European Parliament 2020a). In practice, most questions are directed at the Commission (European Parliament Plenary n.d.). In the repertoire of questions, there are some basic distinctions between interpellations and questions, as well as between oral and

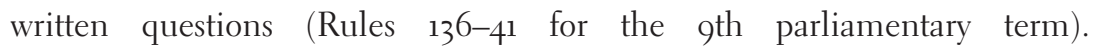
Interpellations are questions of general interest and are limited to thirty per year, distributed fairly between political groups (Rule 139). By contrast, questions are posed on specific topics and are available to all MEPs but include time limitations for oral questions. Oral questions can be addressed within committees, where they are known as 'hearings' or 'exchanges of views', as well as in plenary debates. Written questions are the most common because there are fewer or no restrictions for submitting them; individual MEPs can send them directly to the institution of interest without having to go through the structure of committees or party groups (Proksch and Slapin 2011: 60). The advantage of parliamentary questions is that they can scrutinise any area of $\mathrm{EU}$ policy at any point; as an accountability tool, they can 'request information', 'press for action', 'demand an explanation', 'test' or 'attack' executive actors on controversial policy issues, or simply 'demonstrate [the] fault' of a course of action (Wiberg and Koura 1994: 30-31).

In EP studies, parliamentary questions have attracted considerable attention, albeit from the perspective of the profile of questioners rather than for the value of questions as an oversight mechanism. Previous research found that MEPs from opposition parties at the national level are more likely to ask questions of the Commission and signal violations of EU law in their respective countries (Jensen et al. 2013; Proksch and Slapin 2011). From this perspective, parliamentary questions can function as a 'two-way information channel', allowing MEPs to receive answers about the activity of executive actors and, at the same time, make the Commission aware of specific problems in EU countries (Raunio 1996: 379). Another finding is that there is variation in the 
use of parliamentary questions depending on the type of electoral system in each Member State and the rules regarding access to questions. Based on the premise that parliamentary questions allow MEPs to build a reputation and potentially facilitate their re-election, Sozzi shows that there is a difference between electoral systems that are candidate-centred and those that are partycentred (Sozzi 2016).

While this line of research is useful to reveal political and institutional dynamics behind the use of parliamentary questions, it offers few insights into the role of parliamentary questions for political oversight. To what extent do parliamentary questions allow MEPs to oversee effectively the activity of EU executive actors? This question provides the starting point of the book. Its approach and research design are described in the next section.

\subsection{ANALYTICAL APPROACH AND RESEARCH DESIGN}

To investigate the EP's effectiveness as an accountability forum in the EMU, the book proposes a new analytical framework for evaluating parliamentary questions as an oversight tool. The basic premise is that the study of parliamentary questions $(Q)$ needs to be linked to their respective answers (A) and analysed together at the micro level (Q\&A) in order to assess their effectiveness as an oversight instrument. Drawing on insights from principal-agent theory (Fearon 1999; Strøm 2000), the public administration literature on accountability (Bovens 2007a; Mulgan 2000a), and communication research (Bull and Mayer 1993; Bull and Strawson 2020), the framework offers a step-by-step guide for qualitative content analysis - specifically claims analysis (De Wilde et al. 2014; Koopmans and Statham 1999) - of Q\&A applicable to diverse settings. The key argument is that the effectiveness of parliamentary questions depends on: (1) the strength of questions asked by members of legislatures for the purposes of oversight and ( 2 ) the extent to which executive actors respond to the questions raised. The two dimensions are correspondingly operationalised and developed into six possible scenarios of oversight interactions, ranging from 'High control' to 'No control' over the executive (cf. Maricut-Akbik 2021). The goal of the framework is to provide a theoretically and methodologically consistent toolkit for analysing and evaluating oversight interactions, which can also be applied beyond the EP to other contexts of legislativeexecutive relations at different levels of governance.

In terms of case selection, the institutionalisation of new oversight mechanisms in the EMU offers an ideal venue for analysing the EP's ex post powers of scrutiny through parliamentary questions. The specific bodies under investigation are the EP's Economic and Monetary Affairs Committee (ECON) as 
a political accountability forum and three different executive actors at the heart of EMU: (1) the ECB (in its banking supervision capacity), (2) the Commission - in particular the Directorate-General (DG) for Economic and Financial Affairs (DG ECFIN) and the DG for Employment, Social Affairs and Inclusion (DG EMPL) - and finally, (3) the Council, specifically the Economic and Financial Affairs Council (ECOFIN) and the Eurogroup. The reason why these institutions were selected relates to their centrality and permanent activity as the EU's fragmented executive in the EMU. In terms of technocratic bodies, the ECB and the Commission have a much higher profile in the EMU than single-purpose agencies such as the European Banking Authority (EBA) or the Single Resolution Board (SRB). In terms of intergovernmental bodies, the Eurogroup and the ECOFIN Council are active in economic governance on a permanent basis - unlike the European Council, which only intervenes in times of crisis or reform when its leadership is needed (Puetter 2013, 2014). At the same time, MEPs do not have proper mechanisms to ask questions of the European Council: although the European Council President appears before the EP after each meeting of heads of state and government, the format of plenary debates is geared towards information-sharing and political declarations rather than oversight (European Parliament 2010a; see Chapter 2.2.2).

Furthermore, given the influence and scale of governance measures introduced during the euro crisis, the book examines the functioning of the Single Supervisory Mechanism (SSM) and the European Semester as two of the most far-reaching institutionalised instruments of EMU reform. The SSM (created in 2013) empowered an already powerful monetary policy institution, the $\mathrm{ECB}$, in the field of banking supervision (Alexander 2015; Braun 2017; Fromage and Ibrido 2018). The launch of the European Semester (2010) provided an extensive toolkit for macroeconomic and budgetary coordination in the $\mathrm{EU}$, with significant consequences on the socio-economic policies of the Member States (Copeland and Daly 2018; Verdun and Zeitlin 2018). Taking this into consideration, the case studies of the monograph will investigate the EP's (1) relationship with the ECB in banking supervision, (2) Economic Dialogues with the European Commission in relation to the European Semester, and (3) Economic Dialogues with the Eurogroup and the ECOFIN Council in the framework of the European Semester. While all case studies cover the period 2010-2019 (the first decade after the euro crisis), the time frames of individual chapters differ in order to take into account when the EP introduced new mechanisms of accountability vis-à-vis each institution (see Section 1.6). To sum up, the cases of the book were selected based on logic that if the EP can demonstrably show that it is able to hold EMU executive 
actors accountable, these are the relevant institutions and policy instruments to consider.

\subsection{CONTRIBUTION}

The book contributes in at least three ways to the academic literature on democratic accountability in the $\mathrm{EU}$ and parliamentary oversight more broadly. First, in respect of EU institutional issues, the book expands the scope of research on the EP by examining its powers to scrutinise the executive on a day-to-day basis. Previous studies on the EP have focused on legislative and budgetary competences, especially in terms of analysing the dynamics of party politics in coalition formation (Hix et al. 2007; Hix and Høyland 2011; Kreppel 2002; Tsebelis 1994) or its evolution over time (Corbett 1998; Katz and Wessels 1999; Rittberger 2005). But if the empowerment of the EP as a legislative body has been thoroughly covered in the academic literature (for a general review, see Hix and Høyland 2013), its performance as an accountability forum is yet to be explored. In relation to parliamentary control of the executive, the EP attracted attention in the late 1990s for its role in the resignation of the Santer Commission (Judge and Earnshaw 2002; Magnette 2001) as well as in the 2014 appointment of the Juncker Commission (Christiansen 2016; Hobolt 2014). However, there is a significant difference between 'grand' events such as the appointment or dismissal of the College of Commissioners and regular accountability interactions designed to oversee routine executive decisions. The only relevant literature here concerns the effectiveness of the Monetary Dialogue with the ECB, a field of research that remains disjointed - as reflected by the few academic articles on the topic (e.g. Amtenbrink and van Duin 2009; Collignon and Diessner 2016; Eijffinger and Mujagic 2004). The novelty of the monograph lies in its comprehensive, methodical overview of the EP's performance as an accountability forum in relation to different executive actors across EMU policy subfields.

Second, in respect of EMU in particular, the book offers the first systematic qualitative study of the functioning of political structures of accountability created at the EU level in response to the euro crisis. The emphasis on the implementation of political accountability goes beyond existing analyses of legal provisions (Cygan 2017; Estella 2018; Fromage and Ibrido 2018; Jančić 2016; Markakis 2020; ter Kuile et al. 2015; Tuori and Tuori 2014) or general studies criticising the post-crisis accountability deficit in EU economic governance (Barrett 2018; Crum and Merlo 2020; Dawson 2015; Naert 2016). Furthermore, the bulk of the literature on democratic accountability in the euro area focuses on the reduced role of 
national parliaments in scrutinising budgetary and fiscal decisions of their respective Member State (Auel and Höing 2015; Hallerberg et al. 2018; Hefftler and Wessels 2013; Kreilinger 2018b; Maatsch 2017; Rasmussen 2018). However, most studies are limited to examining the frequency of parliamentary activities - such as the number of debates, resolutions, opinions, and votes in the plenary on EU-related decisions - rather than analysing the content and effect of specific interactions between parliaments and executive actors.

To address this gap, the monograph places oversight interactions at the centre of empirical research, based on the assumption that what matters for political accountability is not how often issues are discussed, but how members of parliaments oversee executive decisions (through parliamentary questions) and with what result. Moreover, considering the EP's empowerment in the EMU after the crisis, it makes sense to shift the focus from the national to the EU level. Unlike national parliaments - which have a long-standing tradition as 'government watchdogs' - the EP is currently building its profile as an accountability forum. Under the circumstances, the subject has so far received little attention from scholars (Crum 2018; de la Parra 2017; Fasone 2014a; Fromage 2018; Kluger Dionigi 2020; Markakis 2020). For this reason, the monograph is set to make a timely and necessary contribution to the literature on political accountability in post-crisis EMU.

Third, the book moves beyond EU studies by making a distinct theoretical and methodological contribution to the general literature on the effectiveness of parliamentary oversight. Theoretically, the book offers an original framework for analysing parliamentary questions that combines insights from principal-agent theory, the public administration literature on accountability, and communication research. While the framework has been developed in relation to the EP, there is nothing specific about its elements that prevents it from being applied to other parliaments at different levels of governance. The categories of Q\&A envisaged in the analytical framework are not unique to the EMU; conversely, they can occur in any oversight interaction between legislators and executive actors. From a methodological perspective, the case studies reveal the systematicity and broad applicability of the framework. Chapter 3.4.1 summarises the coding guide that allows other researchers to replicate the method proposed in the book. Finally, from a practical standpoint, the case studies illustrate the problem-solving value of the analytical framework, facilitating the identification of concrete shortcomings in the oversight relationship under focus. In the case of the EP in the EMU, future reforms should simultaneously take into account problems of weak oversight questions and the limited responsiveness of (some) executive actors. For 
scholars and practitioners interested in fixing accountability deficits, such insights can easily generate concrete policy recommendations.

\subsection{OUTLINE}

The remainder of the book is organised as follows. Chapter 2 provides an overview of EMU as the testing ground for the effectiveness of the EP as an accountability forum. The idea is that any discussion about EP oversight in the field needs to be positioned in the EMU institutional and substantive policy context. Accordingly, the first part of the chapter describes the historical development of EMU as well as the institutional and policy reforms introduced as a result of the euro crisis. The second part problematises the political accountability framework of EMU before and after the crisis, focusing on national parliaments and the EP in particular. Taking into account the EP's new scrutiny powers acquired during the crisis, the chapter sets the scene for the subsequent case studies.

Chapter 3 describes the theoretical and methodological approach of the study. The starting points are definitions of accountability from the public administration literature, which connect oversight to the broader point of checks and balances in a democratic system. While oversight has been extensively theorised in political science through the lens of principal-agent theory, there are few systematic applications examining its effectiveness in practice. Narrowing down on parliamentary questions as an essential tool of legislative oversight, the chapter introduces a comprehensive analytical framework for the analysis of Q\&A in parliamentary oversight. The framework includes clear criteria for establishing the effectiveness of oversight in practice, based on the strength of the questions asked and the responsiveness of answers provided. The criteria are then combined to develop six possible scenarios of oversight interactions, ranging from 'High control' to 'No control' over the executive. The chapter concludes with methodological considerations of the framework and the coding guide used for the empirical analysis.

Chapters 4-6 constitute the empirical section of the book. They follow a common structure, as the presentation of oversight interactions between the $\mathrm{EP}$ and various executive actors in the EMU requires similar elements: first, a background on the policy and institutional characteristics of the subfield; second, an overview of the issues likely to arise in the exercise of political accountability; third, a summary of the results of the empirical analysis (which includes the profiles of MEPs who ask questions, types of questions, and types of answers); fourth, an evaluation of the EP's capacity to hold each actor accountable in that particular field, in line with scenarios of 
legislative oversight delineated in the analytical framework. The comparability of chapters is facilitated by the use of identical methodology, namely the claims analysis of letters exchanged between institutions and/or transcripts of public hearings or exchanges of views held at the ECON Committee.

Accordingly, Chapter 4 presents the first case study on EP oversight of the ECB in banking supervision. The analysis shows the establishment and functioning of a frequently used infrastructure of political accountability that is, however, limited in ensuring effective oversight by the EP. The findings reveal important shortcomings in the performance of MEPs, who often ask questions that are outside the ECB's competence in banking supervision or that simply do not challenge anything about the ECB's decisions in the SSM. However, the results are treated with caution: there are structural flaws in the SSM legal framework that allow the ECB to evade questions on many politically salient issues by invoking confidentiality requirements. Moreover, when MEPs receive an unsatisfactory answer, there is little they can do to pursue the matter further. The time frame covered is from October 2013 - when the SSM Regulation was adopted - until April 2018.

Chapter 5 sets forth the second case study on EP oversight of the Commission in the framework of the European Semester. The analysis illustrates a close accountability relationship embedded in the EP's treaty competence to exercise political control over the Commission. On multiple occasions, MEPs in the ECON Committee clearly rejected the Commission's justification for failing to take further action against some Member States on matters related to excessive deficits and macroeconomic imbalances. Yet the Commission did not change its decision as a result of the EP's accusations of preferential treatment. Overall, despite steady progress in the institutionalisation of the Economic Dialogues, EP oversight of the Commission remains limited. The findings are based on transcripts of Economic Dialogues with the relevant Commissioners and letters exchanged between the two institutions from 2010 (since the launch of the European Semester) until the EP elections of May 2019.

Chapter 6 presents the third case study on the Economic Dialogues between the EP and the ECOFIN Council and the Eurogroup. The two executive bodies are discussed together owing to their overlapping composition - bringing together finance ministers of all Member States and Eurozone countries, respectively. However, the Economic Dialogues with the two institutions vary considerably: while interactions with ECOFIN often focus on the legislative priorities of the Council Presidency, the interactions with the Eurogroup President revolve around financial assistance programmes and multi-lateral surveillance of public finances in Eurozone countries. 
Economic Dialogues with the Eurogroup are thus much more confrontational than Dialogues with ECOFIN. Given the different topics of discussion, the responsiveness of the two institutions is surprising. In fact, despite recurrent criticism for its informality and secrecy of proceedings (Braun and Hübner 2019; Craig 2017), the Eurogroup is the institution that is most answerable to the EP, meaning it is willing to justify and defend its decisions before MEPs in the ECON Committee. However, as in the case of the Commission, the Eurogroup does not change its conduct if the EP rejects the validity of its justifications. Taking into account the entry into force of the Six-Pack (2011) and the Two-Pack (2013), the analysis is based on transcripts of Economic Dialogues since they were first established - in 2012 (for ECOFIN) and in 2013 (for the Eurogroup) - until the EP elections of May 2019.

Chapter 7 concludes with a comparison of the interactions between the EP and the different executive bodies under analysis. Taking into account the expectations of the analytical framework, the first section shows that the EP has the strongest accountability record when it comes to overseeing the Eurogroup, followed by the Commission, the ECB in banking supervision, and finally the ECOFIN Council. But there are important limitations even in the case of the Eurogroup, which means that the setting where the EP acts the strongest as an accountability forum is far from being strong enough: more specifically, the Eurogroup is answerable to the EP, but MEPs have no control over Eurogroup decisions. The second section is forward-looking and examines the general outlook of the EP in overseeing EMU for the foreseeable future. Focusing on policy recommendations, the conclusion outlines concrete ways to improve the performance of the EP as an accountability forum and increase the responsiveness of executive actors. The final section provides insights into the broader implications of the monograph for the study of accountability in the EU's multi-level system. 


\section{The Economic and Monetary Union, the Crisis, and Political Accountability}

The EMU is one of the central policy fields of the European Union. Established in 1993 by the Maastricht Treaty, the EMU comprises a tangible symbol of European integration - the euro - present in the lives of millions of citizens across Europe. For countries that adopted the euro and formed the Eurozone, the economic, fiscal, and social impact of EMU policies is profound. Non-Eurozone economies are also affected by EMU decisions, albeit to a more limited extent. Yet despite the significant shift in decision-making powers from the national to the EU level entailed in the EMU, its architects did not establish corresponding mechanisms to hold relevant actors accountable for policy decisions in the field. The global economic and financial crisis of 2007-2008 triggered a prolonged sovereign debt crisis in the Eurozone (henceforth the 'euro crisis') that forced a reckoning of the original EMU architecture. Since then, the institutional design and policy scope of EMU have expanded, while the accountability framework has been strengthened especially when it comes to the role of the EP in scrutinising the decisions of different executive actors.

To introduce the policy specifics of the book, this chapter provides an overview of the EMU and its political accountability structure. The starting point is the historical development of the EMU at the EU level, emphasising the institutional asymmetry between its economic and monetary policy arms. The reforms triggered by the euro crisis (roughly 2009-2014) are hence contextualised against the background of the systemic deficiencies of EMU design. Next, the chapter moves to discussing the accountability framework of EMU and, in particular, the characteristics of its political accountability mechanisms. Focusing on national parliaments and the EP, the chapter underlines the difficulties of holding executive actors accountable for EMU decisions. Since the euro crisis, the EP gained new scrutiny powers over both intergovernmental and supranational institutions in the EMU. The question 
remains to what extent the EP uses these new powers in practice and is able to act as an effective accountability forum in the EMU - an issue that will be discussed in the remainder of the book.

\subsection{THE INSTITUTIONAL DEVELOPMENT OF THE EMU}

The idea to construct the EMU can be traced back to the late 196os and the recommendations of a working group chaired by Luxembourg's Prime Minister and Finance Minister Pierre Werner (Werner Report 1970). The Werner Plan envisaged the establishment of the European Community institutions for economic decision-making as well as the creation of an integrated system of national central banks - which proved unfeasible at the time, given domestic and international ${ }^{2}$ circumstances (Maes 2004: 28). Two initiatives from the period are notable: (1) the so-called snake in the tunnel (operational in the early 1970s) and (2) the European Monetary System (EMS) launched in 1979. The 'snake' was an arrangement to peg Member States' currencies to each other in the hope of reducing the fluctuation of exchange rates inside the European Community; later, the EMS attempted to take this idea further by creating a 'zone of monetary stability in Europe' (Dyson and Featherstone 1999: 2). While the 'snake' failed almost immediately, the EMS held together for more than a decade - thus being considered 'a relative success ... in the history of attempts to move towards EMU' (Bache et al. 2015: 135). Very importantly, both schemes allowed economic and monetary elites in Western Europe to interact with each other and build a consensus on the need for a common approach to the EMU. Heavily influenced by the success of the Deutsche Mark, this consensus revolved around ordoliberal economic ideas - favouring monetary policy stability, budgetary discipline, and market credibility (Dyson et al. 1995; McNamara 1999; Verdun 1999).

As a result, in the late 1980s, the EMU returned to the top of the political agenda in the European Community. In the context of reforms triggered by the Single European Act (1986) and the completion of the single market, the European Council entrusted a committee chaired by Commission President Jacques Delors 'the task of studying and proposing concrete stages towards this Union' (European Council 1988). The Delors Committee proposed a step-by-step approach that included increased cooperation between national central banks, the gradual

2 Internationally, the period was marked by the collapse of the Bretton Woods system (1971), the first oil crisis (1973), and the second oil crisis (1979) - all leading to a concurrence of high oil prices, low growth, high unemployment, and high inflation (stagflation). As Member States focused on 'weathering the storm', further integration plans stalled in the 1970s (Gilbert 2011: 89-9o). 
convergence of national economic and fiscal policies, and crucially, the introduction of a common currency among participating Member States (Committee for the Study of Economic and Monetary Union 1989). The European Council followed the recommendations of the Delors Committee, and the EMU was formally incorporated into the Maastricht Treaty (1993). As other areas of EU policy activity, the EMU was designed as a composite field encompassing economic, fiscal, monetary, and financial supervision issues.

From the beginning, EMU was characterised by an institutional asymmetry between its economic and monetary components. On the monetary side, Member States agreed to establish an independent supranational central bank (the ECB), which became operational on 1 June 1998 and oversaw the introduction of the euro between 1999 and 2002 (European Central Bank zozob). From eleven initially participating countries, the Eurozone expanded

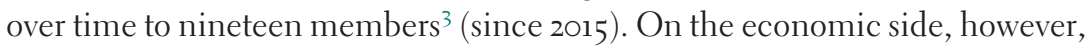
there was no political will to transfer decision-making powers away from national governments (Jones et al. 2016: 1017-1018). Instead, Member States opted for the regulation of economic and fiscal policies, hoping that this would be enough to counter spillover effects from unstainable practices such as national deficits and debt levels (Genschel and Jachtenfuchs 2016: 45). Compliance with EU regulations was to be ensured through a system of intergovernmental policy coordination - at the heart of which were finance ministers in the ECOFIN Council and the informal Eurogroup (Puetter 2006, 2014).

Many economists were critical of the EMU architecture, noting that the Eurozone was not an 'optimal currency area' (Mundell 1961) and that it required institutional substitutes to increase its resilience - such as a banking union, a fiscal union, or a broader mandate for the ECB (Lane 2012; Pisani-Ferry 2012). The point was that in order to reap the benefits of the common currency, EMU would have needed a corresponding political commitment to risk-sharing, that is, a type of monetary solidarity (Schelkle 2017). Yet this was not reflected in the evolution of economic and fiscal policies throughout the 1990s and the early zooos. The key instrument in the field was the Stability and Growth Pact (SGP), adopted in 1997. The SGP was an agreement between Member States to pursue 'sound public finances' by coordinating their economic and fiscal policies in order to enforce limits set

3 The following Member States are part of the Eurozone, in alphabetical order: Austria, Belgium, Cyprus, Estonia, Finland, France, Germany, Greece, Ireland, Italy, Latvia, Lithuania, Luxembourg, Malta, the Netherlands, Portugal, Slovakia, Slovenia, and Spain (European Union 2018). 
by the Maastricht Treaty on government deficits (maximum 3 per cent of gross domestic product (GDP)) and public debt (maximum 6o per cent of the GDP). ${ }^{4}$ Every year, Member States submitted stability programmes (Eurozone countries) and convergence programmes (non-Eurozone countries) that outlined their plans to meet Maastricht Treaty targets over the medium term; subsequently, these were monitored by the Council through multi-lateral surveillance in what became known as the SGP's 'preventive arm' (Council Regulation 1466/97). If a government breached the deficit and/ or debt limits set by the Maastricht Treaty, the Council could initiate the Excessive Deficit Procedure (EDP) in the so-called corrective arm of the SGP, which included the possibility for economic sanctions if Member States failed to reduce their deficits after multiple warnings (Council Regulation 1467/97). Up to the euro crisis, the implementation of the SGP was characterised by 'discretion, leniency, and political control': large Member States like France and Germany could avoid sanctions due to their voting rights in the Council, while the Commission could not check the reliability of national data (e.g. for Greece) or put pressure on governments to honour their policy commitments (Schuknecht et al. 2011: 10).

In hindsight, creating a common currency among a group of heterogeneous nation states was bound to cause systemic problems (Copelovitch et al. 2016: 818-823). First, there were macroeconomic divergences, that is, differences between the stagnating economies of Northern Member States (Germany, the Netherlands, and France) and the booming economies of peripheral Member States (Italy, Spain, Greece, Ireland, and later the Central and Eastern European countries). As the ECB pursued a single monetary policy for the Eurozone, it provided different economies with opposite incentives: either to lend (in the North/central Europe) or to borrow (in the periphery). This led to increased capital flows - especially from North to South - that further deepened the economic divergences between Eurozone members (Baldwin et al. 2015). One way to minimise the impact of these divergences would have been to ensure effective policy coordination between Member States with the goal to restrain demand (in booming economies) or stimulate it (in stagnating economies). At the same time, complementary measures in labour market or pension reforms would have helped close the gap between deficit and surplus countries. In the 1990s, national governments attempted to achieve this through the SGP and the so-called Broad Economic Policy Guidelines (BEPGs) - a process of 'soft coordination' of both economic and social policies (Hodson and Maher 2001). The BEPGs were adopted by the ECOFIN

4 Deficits and debt levels are currently found in Protocol 12 TEU. 
Council and monitored by the Commission and the Council in a system of multi-lateral surveillance (also known as peer review), where the Council could issue non-binding recommendations for corrective action (Deroose et al. 2008). In practice, the faulty enforcement of the SGP and the poor implementation of the BEPGs did nothing to reduce macroeconomic divergences between Member States, planting the seeds of a core-periphery conflict in the Eurozone (Laffan 2016).

Another problem of EMU design was the weak and fragmented nature of financial regulation, which remained in the hands of national central banks and specialised agencies (Jones et al. 2016: 1019). As financial institutions expanded across borders, it was impossible to exercise effective regulatory supervision from one Member State to another because national competent authorities (NCAs) had difficulties observing the operations of banks in other jurisdictions. At the same time, an interconnected banking system implied increased vulnerability, as losses in one country were certain to affect depositors in another country. Moreover, in the event of a crisis, financial markets expected Member States to help each other out and protect the stability of the system as a whole - despite the infamous 'no bailout clause' of the Maastricht Treaty. In theory, EMU Treaty provisions prohibited the monetary financing of budgetary deficits by the ECB (Article 123 TFEU) and explicitly rejected the notion that the EU could be liable for debt incurred by national or local actors (Article 125 TFEU). Yet borrowing conditions on international financial markets before the euro crisis revealed that market participants did not take the 'no bailout clause' seriously, that is, international financial markets offered almost the same conditions to borrowers from Spain or Germany (Copelovitch et al. 2016: 821-822).

The consequences of the EMU institutional asymmetry became painfully obvious during the euro crisis and required sweeping reforms, as discussed in the following pages.

\subsubsection{The Euro Crisis and the Reform of the EMU}

The global economic and financial crisis of 2007-2008 found the EMU totally unprepared to deal with the consequences of an interconnected yet uncoordinated banking system. Eurozone banks were badly exposed to the subprime mortgage crisis in the United States, but the EU lacked both the capacity and the instruments to provide a centralised response to the rapidly evolving crisis. Initially, each Member State had to react on its own, in line with national budgetary resources and the legal framework on banking resolution - which underlined the necessity for a banking union in the Eurozone (Hodson and Puetter 2016: 367). In the Eurozone periphery, the banking crisis soon developed 
into a sovereign debt crisis, as domestic banks and sovereign debt became caught in a destabilising loop. As described by Howard and Quaglia, 'at-risk domestic banks came to hold growing amounts of downgrading sovereign debt, while the ability of sovereigns to bail out or wind down domestic banks in an orderly manner ... diminished as public debt loads rose' (2013: 106). To deal with the crisis, the EU governance architecture would have required both a lender of last resort (e.g. a central bank) allowed to buy government bonds of distressed Member States and a common fiscal backstop, that is, a budgetary instrument that would ensure automatic transfers to regions negatively affected by the economic shock (de Grauwe 2011: 11).

By contrast, the EU response to the financial crisis was uneven and piecemeal. Overall, there were three main areas of reform. First, there was immediate pressure to offer financial assistance to the countries most affected by the crisis (Greece, Ireland, and Portugal). The model for financial assistance was effectively borrowed from the International Monetary Fund (IMF), that is, loans in exchange for structural reforms or, in EU jargon, 'macroeconomic adjustment programmes' accompanied by conditionality and the monitoring of reforms (European Stability Mechanism 2020b). In May 2010, Member States agreed on an emergency rescue package for Greece as well as the establishment of the European Financial Stability Facility (EFSF), a temporary fund designed to help any Eurozone Member State that had difficulties borrowing on international financial markets (European Stability Mechanism 2019: 4). A year later, the EFSF would be rolled into a permanent international financial institution, the ESM. Operational since 2013, the ESM was established outside the EU legal framework through an intergovernmental agreement - with the Eurogroup finance ministers acting as the key decisionmaking body (ESM Treaty, Article 5). Since then, several countries have accessed ESM loans: Greece, Ireland, Portugal, Cyprus, and Spain.

The second major area of EMU reform triggered by the euro crisis concerned the governance framework for economic and fiscal policy coordination. In order to avoid the mistakes of the past, it was considered necessary to 'reinforce the SGP, broaden economic surveillance, [and ensure] stronger coordination of national fiscal frameworks' (European Council 2010: 11). To this end, in 2010, the EU introduced the 'European Semester', an umbrella term for a myriad of rules and measures designed to avert excessive debt, prevent extreme macroeconomic imbalances, support structural reforms, and boost investment (European Commission 202ob). Two legislative packages form the legal basis of the Semester - the Six-Pack (2011) and the Two-Pack (2013) - together with the 2012 Treaty on Stability, Coordination and Governance in the Economic and Monetary Union (known as the "Fiscal 
Compact'). The Six-Pack extended the SGP framework with a Macroeconomic Imbalance Procedure (MIP) meant to detect, prevent, and correct (potentially severe) macroeconomic developments (EU Regulation 1176/2011, Article 2[1]). The Two-Pack introduced a stricter timeline for the budgetary cycle, requiring Eurozone Member States to submit their yearly budgetary plans earlier in order to allow EU policy recommendations to be 'appropriately integrated in the national budgetary preparations' (EU Regulation 473/2013, Article 1[1c]). By signing the Fiscal Compact, twenty-two Member States (the Eurozone countries plus Denmark, Bulgaria, and Romania) became formally bound to the 'balanced budget' rule, which had to be enshrined into national law (Fiscal Compact, Article 3). Over time, the Semester became a complex machinery of policy coordination and the main tool of the EU's economic governance architecture.

Last but not least, the third area of EMU reform triggered by the crisis concerned the creation of a banking union with three pillars (European Commission 2015a; Véron 2015). The first pillar was meant to address the leniency in banking supervision during the pre-crisis period by establishing a uniform system of banking supervision - the Single Supervisory Mechanism (SSM) - coordinated and enforced by the ECB (Council Regulation 1024/ 2013). The second pillar aimed to introduce a common EU approach for dealing with failing banks in an orderly fashion 'with minimal costs for taxpayers and to the real economy' (Single Resolution Board 2017). This was partially achieved through the Single Resolution Mechanism (SRM), which set up a central authority for winding up banks (the Single Resolution Board (SRB)) but with a transitional and intergovermentally managed Resolution Fund (EU Regulation 8o6/2014). The final pillar was supposed to provide a unique scheme to guarantee bank deposits across the Eurozone through a European Deposit Insurance Scheme (EDIS) - but this is yet to be adopted (Council of the European Union 2020c). EDIS remains controversial owing to its strong redistributive implications, causing concern about moral hazard in countries with weak banking systems (Howarth and Quaglia 2018; Schoenmaker 2018).

Overall, the new reforms altered not only the scope of EMU at the EU level but also the institutional dynamics in the field - as shown in the following pages.

\subsubsection{Post-Crisis Institutional Dynamics}

The euro crisis brought the EU's highest political body - the European Council - to the forefront of EMU decision-making. Since 2008, the 
European Council started to meet more frequently to discuss economic developments. For example, in 2011 alone, there were eleven meetings sometimes in a restricted Eurozone format known as 'Euro Summits' (Puetter 2014: 91-97). The European Council thus became the EU's de facto 'crisis manager' (Van Kemseke 2014), a role which coincided with its formal institutionalisation in the Lisbon Treaty (2009) and the appointment of its first permanent President, Herman Van Rompuy. The objective to 'strengthen economic governance' was a top priority for Van Rompuy, who headed the Task Force that laid out the vision for the necessary EMU reforms (European Council 2010). However, while the European Council was instrumental in setting the political agenda during the crisis, day-to-day decisionmaking on economic and fiscal affairs remained the responsibility of finance ministers in the Council. For instance, during 2010-2015 - roughly the duration of the EU's sovereign debt crisis - finance ministers met eightynine times in the Eurogroup format and eighty-one times in the ECOFIN format $^{5}$ (Maricut and Puetter 2018: 201). The frequency of meetings illustrates the urgency of matters as well as the need for constant executive action which the EMU lacked before the crisis.

For its part, the European Commission saw its competences in economic governance expanded after the crisis. The European Semester in particular increased the Commission's powers to monitor compliance with economic and fiscal rules - a different role from its traditional position as agenda-setter in legislative decision-making (Bauer and Becker 2014). Moreover, within the Commission, significant human and financial resources were put into the European Semester (Savage and Verdun 2016), which required the close coordination of the Secretariat General, DG ECFIN, and DG EMPL (Maricut and Puetter 2018: 206). In respect of the interpretation and application of rules, the Commission gained wide discretion to decide what counted as a 'structural' deficit or when countries made progress towards their 'medium-term budgetary objectives' (Dawson 2019: 66). At the same time, the Commission's autonomy in the field was consolidated by the introduction of 'reverse qualified majority voting' in the Council in the case of sanctions for breaking excessive deficit rules (Seikel 2016). Contrary to expectations that the Commission will ensure a stricter implementation of fiscal discipline than the Council, the patchy implementation of sanctions in the EDP demonstrates the Commission's leeway in the field (Dehousse 2016: 621). Overall, the crisis not only empowered the Commission in economic governance but also made

5 By comparison, the reunion of ministers of labor and social affairs - the EPSCO Council - met thirty-eight times during 2010-2015 (Maricut and Puetter 2018: 201). 
it politically more conscious of specific dynamics within Member States (van der Veer and Haverland 2018).

The other supranational institution empowered by the euro crisis was undoubtedly the ECB (Curtin 2017; Dawson et al. 2019). Through 'quantitative easing' (i.e. the purchase of government bonds on secondary markets), the ECB became the Eurozone's 'only credible sovereign lender of last resort' (Buiter and Rahbari 2012). After declaring that it will do 'whatever it takes to save the euro' (Wishart 2012), the ECB announced the Outright Monetary Transactions programme in 2012 and launched an expanded Asset Purchase Programme in 2014-2015. The use of unconventional balance sheet instruments to increase the money supply followed similar measures by other central banks in the world (Jančić 2017: 147-148). However, the ECB did not have the same room for manoeuvre as other central banks; given the Treaty's explicit 'no bailout clause' (Article 123 TFEU), the ECB was soon faced with legal challenges to unconventional monetary policies (cf. Adamski 2015; Dawson and Bobić 2019; Goldoni 2017; Zilioli 2016).

Next, the ECB participated in negotiations over financial assistance programmes as part of the so-called Troika - later the 'Quadriga'. Next to the ECB, the Troika included the Commission, the IMF, and later the ESM, all considered 'expert' institutions tasked to assess the amount of funds and conditionality offered to a country in crisis (Henning 2017: 8). The participation of the ECB was problematic due to its simultaneous responsibility for monetary policy and emergency liquidity for the Eurozone member demanding financial assistance (Braun 2017: 6). Last but not least, the ECB undertook new tasks for banking supervision in the SSM, which required an intrainstitutional separation between its monetary and supervisory activities (Alexander 2015: 165). In fact, the SSM Regulation assigned exclusive supervisory competences to the ECB, while NCAs remained responsible for assisting the ECB in carrying them out (Karagianni and Scholten 2018).

In respect of decision-making, the EP also gained powers in the EMU during the crisis. In fact, the EP was involved in all major legislative reforms adopted since the crisis: the Six-Pack (2011), the Two-Pack (2013), the SSM (2013), and the SRM (2014). Its role, however, varied across legislative dossiers. In economic governance, the EP's contribution was diminished by 'the shadow of the European Council', which actively lobbied for a specific outcome - namely fiscal discipline - and used its authority to build coalitions across EP political groups (Bressanelli and Chelotti 2016; Warren 2018). By contrast, the EP took advantage of the Council's need for swiftness in adopting the SSM Regulation and pushed for a stronger scrutiny role for itself in banking supervision (Rittberger 2014: 1180; Schoeller and Héritier 2019: 281). 
Finally, in negotiations on the SRM Regulation, there was little the EP could do to convince the Council to minimise the transitional period for the Single Resolution Fund or increase the Commission's role in the process (Howarth and Quaglia 2014: 137). Overall, the EP gained a say in decision-making over EMU reforms, but its influence remained limited.

Nevertheless, the policy and institutional reforms of the crisis had important implications for the EMU accountability framework, as discussed in the following pages.

\subsection{THE ACCOUNTABILITY FRAMEWORK OF THE EMU}

At first sight, the EMU accountability framework resembles that of any policy area in a democratic setting. Both in theory and practice, there are political, legal, and administrative mechanisms to hold EMU executive actors accountable. Traditionally, political accountability includes elections and parliamentary scrutiny of the executive; legal accountability refers to judicial review of government acts, while administrative accountability entails investigations by ombudsmen, auditing, and anti-fraud bodies (Bovens 2007a: 455-456). All these require corresponding accountability forums, which can actually be found in the EMU through (1) national parliaments and the EP (together with their respective voters), (2) national courts and the Court of Justice of the European Union (CJEU), and (3) the European Ombudsman, the ECA, and the European Anti-Fraud Office. In addition to such external sources of democratic control, there are accountability mechanisms internal to public organisations, for example, hierarchy within bureaucracies or professional peer review (Romzek and Dubnick 1998: 9). In the EMU, the Commission fulfils the criteria of a hierarchical bureaucracy with a clear managerial and financial accountability infrastructure (Wille 2010: 1108). At the same time, the Eurogroup and the ECOFIN Council routinely use professional peer review as a form of 'dynamic accountability' focused on mutual learning (Sabel and Zeitlin 2008: 303-304). For example, the application of SGP rules before the crisis was monitored in the ECOFIN Council through a process of multilateral surveillance that additionally included monitoring compliance with the BEPGs (Hodson and Maher 2001).

While each mechanism is important in its own right, political accountability overlaps most closely to the democratic delegation chain and the connection between those who hold political authority in a governance system (i.e. voters) and those who exercise it on their behalf (Fearon 1999; Strøm 2000) in this case EU institutions. Moreover, the EMU's political accountability is relevant because of the nature of the policy field itself. Unlike market 
regulation - the classic domain of EU policy activity - the EMU affects constitutive functions of states such as the ability to tax and spend (through fiscal policy) and the use of a unique currency (through monetary policy) (Genschel and Jachtenfuchs 2014: 9). As a result, the types of accountability standards applied to market regulation, for example, clarity, legality, openness, and justifiability of decision-making processes (Majone 1998, 1999), are insufficient in fields of 'core state powers' such as the EMU (Genschel and Jachtenfuchs 2014, 2016).

In fact, there are several reasons why the EMU is substantively different from market regulation (Genschel and Jachtenfuchs 2018: 181-182). First, EMU policies have clear (re-)distributive implications: most decisions imply that some Member States gain (euros), while others incur losses. ${ }^{6}$ By contrast, market regulation allows - at least on paper - the correction of market failures without making anyone worse off, following a Pareto-improving logic (Majone 1994: 81). Second, the costs for regulatory compliance in areas of core state powers are borne by Member States instead of market participants - which means the EU has gone beyond a mere 'regulatory state' (Majone 1999). In the EMU, governments have to be both willing and able to invest national fiscal capacities into complying with EU regulations such as the SGP or the European Semester. Third, and crucial for accountability, the material and ideational costs for integrating core state powers attract the attention of mass publics (Hooghe and Marks 2009), who are likely to reject re-distributive measures across Member States - as seen during the euro crisis in Northwestern European countries (Hutter and Kriesi 2019). Conversely, market regulation is rarely controversial enough to attract public attention and mobilise voters to the polls to oppose EU policies (Genschel and Jachtenfuchs 2016: 53 ).

Under the circumstances, the role of political accountability in the EMU is essential because it creates mechanisms to contest policy decisions in a redistributive, politicised field that impacts national fiscal capacities and economic performance. The main challenges and institutional constellations of political accountability in the EMU are discussed below.

\subsubsection{Political Accountability in the EMU}

In the EMU, the possibility for political accountability has been disputed from the beginning (Elgie 2002; Jabko 2003; Jones 2002; Verdun 1998). Due to its

6 For example, even before the euro crisis, the EMU triggered redistributive effects owing to the 'one-size-fits-all' approach of ECB monetary policy (Enderlein and Verdun 2009: 494). 
institutional design and the uniqueness of the EU political system, EMU actors could not establish the type of electoral connection usually found at the national level. As EU decision-making involved many actors negotiating at different levels of governance, there could be no direct link between electoral preferences and EU policy outputs (Hix and Høyland 2011: 131-133). Moreover, as in other fields of EU policy activity, executive power in the EMU was fragmented, with several institutions responsible for taking nonlegislative decisions with direct implementing or operational effect (Curtin 2009). Accordingly, the main decision-making bodies were either intergovernmental institutions (the European Council, the Eurogroup, and the ECOFIN Council) or supranational technocratic bodies (the ECB or the Commission). Both categories of institutions raised political accountability challenges: on the one hand, the collective decisions of intergovernmental institutions were decoupled from national elections; on the other hand, supranational technocratic institutions were delegated specific tasks that political actors had neither the expertise nor the appropriate mechanisms to oversee.

More generally, the accountability of intergovernmental bodies in EU decision-making has been a matter of controversy in academic debates. Some scholars consider that the European Council and the Council have no legitimacy problems because their members are accountable to their respective national parliaments and electorates (Moravcsik 2002). As described in Article 10 TEU:

1. The functioning of the Union shall be founded on representative democracy.

2. Citizens are directly represented at Union level in the European Parliament. Member States are represented in the European Council by their Heads of State or Government and in the Council by their governments, themselves democratically accountable either to their national Parliaments, or to their citizens.

In EMU decision-making, the emphasis falls on the European Council and the Council because the EP has a minor role in the adoption of policies. Nevertheless, the problem with intergovernmental institutions is that they take decisions collectively - often behind closed doors (Curtin 2014; Hillebrandt and Novak 2016) - which means it is impossible to disentangle individual responsibility (Brandsma 2013: 50-51). Moreover, negotiations are based on compromises, so national governments can rarely achieve domestic preferences as indicated by their electorates. This makes it difficult for voters to assign blame via the ballot box and thus hold EU actors accountable for poor (economic) performance (Hobolt und Tilley 2014). While national 
governments can be replaced, there is little voters or national parliaments can do to change their Member State's bargaining power in intergovernmental negotiations.

In response, defenders of intergovernmental decision-making point to national parliaments as the appropriate political accountability forum in the EMU. There is, however, significant variation among national parliaments regarding their involvement in EU decision-making and oversight, depending on their respective constitutional powers and relative 'strength' vis-à-vis their governments (Auel 2007; Bergman 1997; Raunio 2005). Since the euro crisis, the inequality between national parliaments has deepened in the context of bailout negotiations and fiscal reforms that transferred new powers to the $\mathrm{EU}$ level (Auel and Höing 2014; Crum 2018; Maatsch 2017; Moschella 2017). In fact, most authors agree that the role of national parliaments in scrutinising budgetary and fiscal decisions of their respective Member State has been reduced since the crisis (Auel and Höing 2015; Fasone 2014b; Jancic 2017; Rasmussen 2018; Rittberger 2014). From a structural perspective, the problem remains the distinction between individual decisions of national governments and collective decisions of intergovernmental bodies. National parliaments can only hold their respective government accountable but not the Council (or the European Council) as a whole.

Against this background, several reforms were introduced in recent years to strengthen the role of national parliaments in the EMU. First, national parliaments increased their scrutiny of European Council decision-making by organising more hearings either to discuss, ex ante, the mandate of their governments for such summits or to scrutinise, ex post, their outcomes and conclusions (Fromage 2017: 174). As mentioned above, the effectiveness of the effort depended on pre-existing oversight capacities at the plenary or the committee level, which again meant that some parliaments were more influential than others (Wessels et al. 2013: 37). Second, some national parliaments became involved in the European Semester, requesting to be informed of their governments' Stability or Convergence Programmes and National Reform Programmes, or alternatively, discussing the CountrySpecific Recommendations (CSRs) (Rozenberg 2017: 44-45). Interestingly enough, existing studies found a higher interest in the European Semester from non-Eurozone rather than Eurozone parliaments (Hallerberg et al. 2018; Kreilinger 2016; Maatsch 2017; Rasmussen 2018). In fact, while the involvement of many parliaments in the European Semester has increased over time this has not been the case in the countries most affected by the crisis, for example, Cyprus, Greece, Ireland, Italy, Spain, or Portugal. 
Third, it was hoped that combining the resources of national parliaments and the EP would compensate for their respective asymmetries in the EU system and ensure a mechanism for joint scrutiny of EMU (Kreilinger 2018a). To achieve this goal, Article 13 of the Fiscal Compact introduced the prospect of an interparliamentary conference that would bring together relevant committees of the $\mathrm{EP}$ and national parliaments in order to discuss the EU's new economic regime. The first meetings were marked by conflict between MEPs and members of national parliaments, who could not agree on the scope and composition of the new conference (Cooper 2016). The conflict hindered the institutionalisation of an effective network for inter-parliamentary cooperation: when the Rules of Procedure were finally agreed in 2015, they specified the frequency of meetings (twice per year) but left open the issue of size and composition of national delegations (Rozenberg 2017: 46-47). Since 2012, the EP and Council Presidencies have co-organised an annual 'European Parliamentary Week', which coupled the Article 13 conference with a European Semester conference on exchanging best practices of parliamentary scrutiny in the Member States (European Parliament 2020b). This has led to the marginalisation of the Article 13 Conference and generated discontinuity between different events - whose focus was always determined by the country holding the Presidency (Lupo and Griglio 2018: 365). For all these reasons, the contribution of national parliaments to holding EMU actors accountable remains modest.

Moving to the EP, its most significant contribution to political accountability in the EMU concerned for the longest time the relationship with the ECB in monetary policy. In the late 1990s, the two institutions established a 'Monetary Dialogue' through which the ECB President would appear four times a year before the ECON Committee, a possibility now envisaged in Article 284(3) TFEU and regulated in the EP's Rules of Procedure. The practice of Monetary Dialogues has been researched extensively in the academic literature, with mixed results. On the one hand, the Monetary Dialogue was criticised for operating at a high level of generality, focused on debating economic and monetary policy issues rather than assessing the performance of the ECB in fulfilling its mandate (Amtenbrink and van Duin 2009; Braun 2017; Claeys et al. 2014; Gros 2004). On the other hand, scholars found that the Monetary Dialogue has improved over the years in terms of the relevance of topics discussed and the extent to which the ECB engages with questions from MEPs (Collignon and Diessner 2016; Eijffinger and Mujagic 2004; Fraccaroli et al. 2018). However, there is no shortage of suggestions of how the Monetary Dialogue could be improved in order to increase the political accountability of the ECB (Claeys and Domínguez-Jiménez 2020; Lastra 2020; Whelan 2020). 
Overall, the EMU is a field of executive decision-making par excellence, which raises serious concerns regarding its political accountability record. Moreover, the rapid expansion of executive power during the euro crisis has not been matched by a corresponding establishment of accountability mechanisms at the national or the EU level (Crum 2018; Dawson 2015; Rittberger 2014). Nonetheless, there were some reforms that empowered the EP in the EMU - as illustrated in the next section.

\subsubsection{Filling the Accountability Void? The Role of the EP after the Crisis}

The EP is a relative newcomer in the EMU: excluding the regular Monetary Dialogue with the ECB since 1999, the EP's activity in the field has been limited to participation in the few legislative dossiers adopted - and even there its influence was limited (Bressanelli and Chelotti 2018). It was in the context of the euro crisis that the EP's powers of scrutiny expanded. The logic was straightforward: 'any conferral of [new] powers to the Union level should be balanced by appropriate accountability requirements' (Interinstitutional Agreement 2013/694/EU between the EP and the ECB, Recital 4). In fact, the EP gained competences to scrutinise all new instruments except the ESM, which had been created outside the EU Treaties framework. In the SSM, the EP established multiple public reporting obligations for the ECB, considered by scholars as a possible model for the Monetary Dialogue (Fromage and Ibrido 2018: 306). Since 2014, the EP has held regular public accountability hearings with the chairpersons of both the SSM and the SRB. In addition, in the framework of the European Semester, the EP institutionalised 'Economic Dialogues' with the Commission, the Eurogroup, the ECOFIN Council, and individual Member States. The hearings or dialogues always take place in the ECON Committee, but all MEPs can send each institution written questions that have to be answered formally and in a timely manner. ${ }^{7}$

From a legal perspective, the consequences of the new scrutiny mechanisms are vague. While the secondary legislation establishing the new instruments namely the SSM, the SRM, the Two-Pack, and the Six-Pack - clearly mentions accountability obligations and the role of the EP thereof, there are no provisions

7 The possibility to address written questions to the ECB on banking supervision and the SRB on banking resolution is stipulated in the SSM Regulation (Article 20[6]) and the SRM Regulation (Article 45[6]), respectively. By contrast, MEPs send written questions to the Commission and the Council in line with Rule 138 of the EP's Rules of Procedure (European Parliament 2020a). As the Commission received thousands of written questions from the EP in the past, there is now a limit of five questions per month (European Parliament 2014e). 
on what happens when the ECB or the SRB avoids to answer questions or when an Economic Dialogue fails (Fasone 2014a: 175). The EP cannot sanction or correct the performance of executive actors in the EMU, even if MEPs had clear benchmarks to assess their performance - which they lack (Amtenbrink and Markakis 2019: 22-23). In respect of the Economic Dialogues, preliminary studies dispute the impact of such meetings on the institutions and Member States involved (de la Parra 2017: 117; Kluger Dionigi 2020). In this context, Fromage argued that the EP still needs to exploit the full potential of the new accountability instruments in the EMU; otherwise, it will remain an institution empowered 'on paper only' (Fromage 2018).

One of the relationships that stayed stable throughout the euro crisis is that between the EP and the European Council. Since the Maastricht Treaty, the European Council has been required 'to submit to the EP a report after each of its meetings and a yearly written report on the progress achieved by the Union' (Article 4 TEU). Before the Lisbon Treaty and the creation of a permanent President of the European Council, the task typically fell to the rotating Presidency of the Council, which attended EP plenary sessions after each European Council meeting in order to inform MEPs of summit conclusions. The right to be 'informed' placed the EP in a weak accountability position from the beginning: MEPs heard the decisions of the European Council but could do nothing about them (van de Steeg 2009).

After the Lisbon Treaty, the European Council President became responsible for informing the EP of the outcomes of European Council meetings (Article 15[6] TFEU). Unfortunately, the format of plenary sessions did not change during the mandates of Herman Van Rompuy (2009-2014) and Donald Tusk (2014-2019). In each session, the European Council President gives a long opening statement about the discussions and conclusions of the summit, followed by similarly long remarks by the Commission President. In advance of the plenary, the EP President decides if MEPs will take the floor for a full 'debate' or a 30-minute session of 'brief and concise questions' (European Parliament 2010b).

In practice, the 'debate' was the usual format for plenary sessions on the conclusions of European Council meetings. ${ }^{8}$ In line with the EP's Rules of Procedure, speaking time was first allocated equally among political groups and later in proportion to the total number of their members (Rule 149[4] of the $7^{\text {th }}$ parliamentary term). In the first round, MEPs would appoint a speaker

8 The author searched the EP website for plenary sessions with the European Council President during 2010-2015. All sessions followed the 'debate' format of EP plenaries. The transcripts of these debates are available in their original language. 
on behalf of their group and take the floor in the order of the relative size of the groups in the EP. Sometimes, the European Council President would speak after the first round and answer some of the questions raised (European Parliament 2010a); other times, he would just take the floor at the end for a closing statement (e.g. European Parliament 2014a). In any case, MEPs would not be allowed to speak twice in order to request a specific reply for a question that was evaded (van de Steeg 2009: 5).

Overall, this type of plenary debate cannot be considered a platform for political accountability because the format does not allow MEPs to ask questions systematically and receive answers from the European Council. If anything, plenary debates offer the space for MEPs to give speeches outlining the vision of their political groups on the issues discussed by the European Council. By contrast, committee meetings offer a more suitable format for executive scrutiny, allowing MEPs to question EU executive actors in a restricted format. For this reason, the oversight powers gained by the EP in the aftermath of the euro crisis - focused on parliamentary questions and committee meetings - constitute a more promising avenue for achieving political accountability in the EMU. Their actual effectiveness remains to be established.

\subsection{SUMMARY}

Given its far-reaching impact on Member States' economies, the EMU has always been central to the EU political agenda. The euro crisis exposed the flawed institutional architecture of the field and accentuated cleavages between Northern and Southern European economies. As the crisis deepened, the redistributive implications of the EMU became clear, and EU measures started to be increasingly contested by national publics. From a governance perspective, critics questioned the dominance of intergovernmental bodies in decision-making and the empowerment of supranational institutions in policy implementation. Against this background, the discussion about political accountability intensified - especially in respect of the role of national parliaments and the EP. Taking into account the structural limitations of national parliaments in the EU - which can hold their own governments accountable but not EU institutions as a whole - attention turned towards the EP and its newly acquired scrutiny powers. To what extent could the EP act as an effective accountability forum in the EMU? The next chapter puts forth the analytical toolkit to answer the question. 


\title{
Studying Accountability at the European Parliament
}

\author{
A Legislative Oversight Approach
}

This chapter sets forth the theoretical and methodological approach of the book. The underlying assumption is that the study of the EP as an accountability forum needs to be situated in the specialised literature in public administration (on accountability) and political science (on legislative oversight). After all, the EP is a legislative body with powers of scrutiny over EU executive actors in the EMU. Throughout the chapter, the terms 'legislative oversight' and 'parliamentary scrutiny' are used interchangeably to denote a political accountability relationship between legislatures and executive actors with an ex post focus on past government activities. By contrast, 'public accountability' is a broader term that includes all mechanisms - electoral, legal, and administrative - through which public sector actors are required to justify their conduct in front of a higher authority and potentially face sanctions (Mulgan 2000a: 555).

Accordingly, the chapter starts with the introduction of the concept of accountability, which became popular in political discourse and public administration starting the 1970s (Dubnick 2014: 28). Next, the chapter narrows down on accountability as the relationship between an account-giver (an 'actor') and an account-holder (a 'forum'), where the latter has the right to ask questions and receive answers regarding the activity of the former (cf. Bovens 2007). This narrow focus on discursive interactions is explained by the types of accountability relationships existing between the EP and executive actors in the EMU - for instance, the Monetary Dialogue, the hearings on banking supervision, or the Economic Dialogues (see Chapter 2.2.2). Since the EP lacks clear sanctioning mechanisms vis-à-vis executive actors in the EMU, it makes little sense to consider accountability as punishment (for a discussion of the topic, see Mansbridge 2014). Conversely, the interest here is in accountability exchanges between legislative and executive actors, which require a theoretical anchor in legislative oversight studies in political science. 
While oversight has been extensively theorised through the lens of principalagent theory, the assessment of its effectiveness in practice is more complicated - especially when it comes to the analysis of discursive interactions between parliaments and executive actors.

Against this background, the chapter emphasises the importance of parliamentary questions in legislative oversight and the need for a systematic framework to examine their effectiveness. The idea is that the study of parliamentary questions $(\mathrm{Q})$ needs to be connected to their respective answers (A) and examined together (Q\&A) at the micro level as an exchange of claims between legislative and executive actors. Drawing on principal-agent theory, the public administration literature on accountability, and communication research, the chapter offers a step-by-step guide for qualitative content analysis of Q\&A that can be applied to different legislative oversight contexts at different levels of governance - not just to the EP. It is argued that the effectiveness of Q\&A depends on the strength of the questions asked and the responsiveness of answers provided, which are correspondingly operationalised. The two dimensions are then developed into six possible scenarios of oversight interactions, ranging from 'High control' over the executive (or 'responsiveness' to the accountability forum) to 'No control'. Coming back to the EMU, the chapter formulates theoretically-informed expectations about the potential accountability interactions between the EP and the four EMU executive actors selected for empirical investigation: the $\mathrm{ECB}$, the Commission, the ECOFIN Council, and the Eurogroup (see Chapter 1.4). The final section puts forth the methodological considerations of the study, including the coding guide used for the empirical analysis.

\subsection{THE CONCEPT OF ACCOUNTABILITY}

How do we know if an actor is being held accountable in a given context? Where do we draw the line between degrees of accountability in specific cases? In accountability studies, questions of operationalisation and measurement remain a minefield owing to the concept's vast semantic field - including words such as 'responsibility', 'answerability', 'control', 'responsiveness', 'liability', 'transparency', 'public ethics', and so forth (Dubnick 2002, 2014; Koppell 2005; Mulgan 2000a). Indeed, the public administration literature abounds in studies that seek to conceptualise accountability (Behn 2001; Bovens 2010; Bovens et al. 2014; Brandsma and Schillemans 2013; Day and Klein 1987; Dubnick 2011; Dubnick and Frederickson 2011; Mulgan 2000; Romzek and Dubnick 1987; Schillemans and Busuioc 2015). Despite variation in terminology, there is in fact a minimal consensus on some core features of 
the term. Accountability is generally understood as the relationship between an account-giver and an account-taker, in which the former has to answer to the latter by providing information and justification of conduct (Bovens 2007: 450; Lindberg 2013: 209; Philp 2009; Romzek and Dubnick 1998; Schillemans 2013 Scott 2000). The two parties of the relationship can have different names: actors and forums (Bovens 2007a), accountability holdees and holders (Behn 2001), and accountors and accountees (Pollitt 2003). While such relationships exist in both the public and the private sectors, the concept gained wide currency in the democratic lexicon in relation to the importance of imposing controls on the exercise of power by public officials (Flinders 2011; Mulgan 2003; Schedler 1999; Schmitter 2004). At the same time, accountability relationships involve both individuals and organisations: for example, civil servants accountable to their superiors, public agencies accountable to parliaments, experts accountable to professional bodies, governments accountable to administrative and constitutional courts, and so on (Romzek and Dubnick 1987: 228-229).

A common position in the public administration literature is that accountability is an obligation that can be either mandatory, required by law, or voluntary, a deliberate choice of the account-giver to provide information and justify conduct, usually in order to improve legitimacy (Bovens et al. 2014: 12; Busuioc and Lodge 2016: 253-255; Koenig-Archibugi 2004: 245-246; Koop 2014). Research on the adequacy of mandatory accountability is far more prevalent in the specialised literature, taking into consideration the connection with democracy and its inherent requirement for public officials whether elected or not - to be accountable to a higher authority (Dowdle 2006; Mulgan 2003; Przeworski et al. 1999; Schmitter and Karl 1991: 76). In contrast, voluntary accountability is not legally binding and varies considerably depending on the practices of public organisations (Koop 2014: 569; see also Moore 2014). Mandatory accountability is associated with institutional mechanisms stipulated by law, which are in principle easier to identify and evaluate.

The work of Mark Bovens systematised the study of mandatory accountability by offering a parsimonious definition that could be applied to different contexts and levels of governance (Bovens 2007a, 2010; Bovens et al. 2014). He popularised a mechanistic approach to the term, focusing on the institutional arrangements of accountability and their impact on the behaviour of actors in other words, accountability as the independent variable (Bovens 2010: 957). In his view, accountability referred to a series of institutionalised mechanisms through which actors could be held accountable, ex post facto, by a forum (Bovens 2010: 948). The goal of the conceptualisation was primarily 
descriptive, namely to map institutional arrangements of accountability and identify their (potential) shortcomings (Schillemans and Bovens 2011). In practice, the analytical focus on mechanisms is never purely descriptive because an independent variable does not make sense in isolation: there is always a dependent variable - in this case the behaviour of actors - that is considered by association. But the emphasis on institutional arrangements narrowed down the scope of accountability research significantly.

Furthermore, Bovens put forth a sequential understanding of accountability relationships in which he distinguished between three stages. First, the actor must be under a formal or informal obligation to render account translated into the regular disclosure of information about its activities (the 'information stage'). Second, the forum must have the capacity to ask questions regarding the conduct of the actor, demanding further information and/ or justification for certain decisions (the 'debate' or 'discussion stage'). Third, the forum must be able to pass judgement on the behaviour of the actor, using sanctions when considered appropriate (the 'consequences stage') (Bovens 2007a: 451-452; Schillemans and Bovens 2011: 5). Elsewhere, the stages are described as 'analytically distinct phases' (Schillemans 2013: 13) or as 'a heuristic device' that helps organise research on accountability by pointing out deficiencies in one of the stages (Brandsma and Schillemans 2013: 956).

As any heuristic, the idea of stages impacts the operationalisation of accountability. If the term is defined as a sequence of institutionalised mechanisms, then the evaluation of accountability will start by examining the presence or absence of those stages (Brandsma and Schillemans 2013). Next, the assessment will zoom in on individual stages with the goal to identify institutional inadequacies: there can be either too many or too few accountability mechanisms in a given setting (Bovens 2007a: 462). Empirically, this analytical focus assumes an investigation of accountability procedures and their functioning, which can be more quantitative or qualitative depending on the methodological orientations of the researcher. But regardless of methods, the lack of accountability is similarly explained in terms of institutional overloads or deficits that can only be fixed if the right balance of mechanisms is found for every context (Bovens and Schillemans 2014: 677-679). The key question is whether there are appropriate measures to ensure accountability at every stage.

In Bovens's writing, the question whether actors 'behaved in an accountable way' (Bovens et al. 2014: 8) is actually secondary. He argues that depending on the effects of different mechanisms, accountability can be evaluated from a democratic, constitutional, or learning perspective. First, democratic accountability is assessed in principal-agent terms, asking to what extent 
principals can exercise control over agents in the institutionalised chain of delegation from voters to elected representative to executives to bureaucracies. Second, constitutional accountability is analysed from a legal and administrative viewpoint, looking at courts and chambers of auditors in order to examine whether an actor has abused its power or mismanaged funds in any way. Third, the learning perspective of accountability focuses on public performance reviews centred on stakeholder and public account-giving, weighing the appropriateness of the incentive structure, which allows actors to learn from and correct past mistakes in order to provide greater societal outcomes (Bovens 2007a: 463-466). There are implicit normative assumptions behind each perspective, as accountability is expected to enhance the legitimacy of an actor via 'democratic control', by 'preventing the development of dangerous concentrations of executive power', or by 'making governments deliver better public value' (Bovens et al. 2010a: 50). The three perspectives can not only complement but also contradict one another: for example, democratic control through electoral politics is at odds with constitutional accountability through judicial processes (Bovens 2007a: 466). In the end, Bovens deliberately leaves the evaluation of accountability open-ended: it is up to the researcher to choose his/her most preferred theoretical apparatus and understand the tradeoffs involved in that choice.

Over time, this approach to accountability became widely employed in empirical research, especially in EU studies (e.g. Bovens et al. 2010b; Busuioc 2013; Curtin and Egeberg 2008; Harlow and Rawlings 2007; Markakis 2020; Papadopoulos 2007; Schillemans 2008). The generality of the stages made the approach particularly applicable to the EU's multi-level system. Indeed, indicators of the 'information', 'discussion', and 'consequences' stage could be identified to a greater or lesser extent within all accountability relationships. What is trickier is to assess individual indicators and take stock of the extent of accountability in a given context. The challenges of that process are discussed in the following pages.

\subsubsection{Measuring the Stages of Accountability}

When it comes to measuring Bovens's approach to accountability, indicators for the 'information stage' and 'the consequences stage' are straightforward. Usually, these are provided in the legal framework of the actor under investigation. In terms of information, indicators refer to periodic self-evaluation reports and testimonies about the performance, results, or processes of the actor (Bovens 2007a: 451). Sanctions are expected to offer the possibility for redress, providing 'safeguards against bad government' (Oliver 1991: 23); for 
instance, the forum could quash or amend the actor's decisions or take disciplinary measures through rewards, bonuses, termination, or changes of contract (Behn 2001). In addition to indicators measuring legal provisions which can be limiting because they only assess de jure accountability - there are also ways to capture practices or de facto accountability (Busuioc 2009). Such practices include the amount and type of information released by an actor on a regular basis or the informal consequences a forum can impose through public criticism and rebukes (Brandsma and Schillemans 2013: 955958). From a methodological perspective, surveys and interviews are useful here. On the one hand, surveys can ask actors detailed questions about the type of information they share and inquire whether forums find this information sufficient (Brandsma 2014: 148). On the other hand, interviews can add precious details regarding the type of accountability relationship at play and the reasons behind the imposition of sanctions or their lack thereof (Busuioc 2013; Yang 2014).

By contrast, the discussion stage is much more challenging to capture from an empirical perspective. The reason is related to the nature of the stage: accountability debates are not always public, and even when they are, discursive interactions are naturally open to qualitative interpretation. One pertinent attempt to investigate the 'discussion stage' has been made by Brandsma (2013, 2014) and Brandsma and Schillemans (2013), who proposed to examine the 'intensity' of discussions. Intensity refers to 'the extent to which an actor's behaviour is discussed with her afterwards' (Brandsma 2014: 150) and whether 'a message [is getting] across through an exchange of views' (Brandsma and Schillemans 2013: 965). Based on survey material and interviews with participants in accountability arrangements, the authors categorised discussions as being about principles or visions, that is, points of views of either actors or forums (Brandsma 2013: 133). Elsewhere, Carman (2009) evaluated the interactions between funders and non-profit organisations in the United States and created scales to operationalise various dimensions of those exchanges, for example, external monitoring, descriptive reporting, and evaluation and performance measurement. While both approaches yield valuable results, they are based on participants' own understanding and post hoc rationalisation of the accountability interaction rather than on the interaction per se.

Examining the actual discussion of the 'discussion stage' is difficult because of access to data. Indeed, numerous accountability interactions are never recorded in writing or in a video/audio form. Parliamentary debates offer a rare glimpse into the 'discussion stage' by allowing the researcher to explore the dialogue of accountability interactions (Amtenbrink and van Duin 2009; Auel 2007; Eijffinger and Mujagic 2004). In respect of the EP, one of the most 
comprehensive analyses of the discussion stage is provided by van de Steeg (2009), who devised a checklist regarding the efficient use of 'question time' by MEPs, the clarity of their questions, and the extent to which the actors answered the 'core' of the questions posed. Such an approach is essential because it demonstrates how accountability is enacted, that is the ways in which accountability forums use the means at their disposal to hold actors to account and, in turn, how actors respond to this challenge. The point is to go beyond checking whether a 'discussion stage' exists on paper and looking into the practice of that accountability relationship by examining the extent to which relevant questions are asked and appropriate answers are provided or investigating differences in interactions over time. Indeed, researchers need a better understanding of the 'discussion stage' because it provides a unique angle into the day-to-day implementation of accountability.

When it comes to political accountability, the 'discussion stage' overlaps with legislative oversight of executive actors, as shown in the next section.

\subsection{SITUATING THE ACCOUNTABILITY POTENTIAL OF PARLIAMENTS}

In the political science literature on democratic accountability, parliaments occupy a central role for at least two reasons: (1) members of parliaments are accountable to their voters through elections and (2) they are responsible for holding the governments to account through different means (Strøm 2000: 267). This book is concerned with the second dimension, namely the relationship between parliaments (classically seen as legislative bodies) and governing actors (collectively known as the executive). The discussion here covers mainstream political science studies on legislative oversight and principalagent relations.

\subsubsection{Government Accountability and the Role of Parliaments}

In the institutional logic of parliaments, the relationship with the executive covers both their elective and controlling functions (von Beyme 2000: 72). The elective function refers to a parliament's power to appoint the executive (Bagehot 1873: 119), which differs depending on the system of government in place. In parliamentary democracies, governments can be voted in and out of office by parliamentary majorities, so they are dependent on the legislature's support (Müller et al. 2006: 12-13). Conversely, in presidential systems, the head of state is directly elected by citizens for a fixed term; s/he selects members of the cabinet and administration; and together, they operate independently from 
parliamentary votes of no confidence (Linz 1990: 52). Semi-presidential or mixed systems lie somewhere in-between, but recent research shows that there is actually significant heterogeneity in all three regime types (Cheibub et al. 2014: 528). For accountability purposes, the elective function of parliaments is thus more relevant in some contexts than others.

In contrast, the controlling function - the notion of parliamentary control over the executive - is at the heart of democratic accountability regardless of whether the system of government is parliamentary, presidential, or mixed. The importance of the idea was first articulated by John Stuart Mill in the nineteenth century:

Instead of the function of governing, for which it is radically unfit, the proper office of a representative assembly is to watch and control the government: to throw the light of publicity on its acts; to compel a full exposition and justification of all of them which any one considers questionable; to censure them if found condemnable, and, if the men who compose the government abuse their trust, or fulfil it in a manner which conflicts with the deliberate sense of the nation, to expel them from office, and either expressly or virtually appoint their successors. (Mill 1861)

Nowadays, parliaments are commonly referred to as government 'watchdogs' (Frears 1990), playing a key role in legislative oversight (McCubbins and Schwartz 1984; Ogul and Rockman 1990) or the scrutiny of the executive (House of Lords 2011). The terms are often used interchangeably and accepted as part of the established vocabulary of political accountability surrounding executive-legislative relations. In the academic literature, the notion of 'oversight' gained traction in the 1970s, in parallel to developments in the US Congress regarding the need to 'keep a watchful eye' over the administration after the Watergate scandal (Aberbach 1990).

In legislative studies, 'oversight' is conceptualised in an inclusive or restrictive way depending on the number and type of instruments entailed in the process, as well as on the form of control they place over the executive (Rockman 1984: 416-417). A broad definition is provided by Ogul, who describes oversight as 'behaviour by legislators and their staffs, individually or collectively, which results in an impact, intended or not, on bureaucratic behaviour' (Ogul 1976: 11). His focus is not on the government per se but on the entire administrative apparatus of the state, including civil servants. Harris proposes a narrower understanding: 'oversight, strictly speaking, refers to review after the fact. It includes inquiries about policies that are or have been in effect, investigations of past administrative actions, and the calling of executive officers to account for their financial transactions' (Harris 1964: 9). 
In relation to legislation in particular, the National Democratic Institute (NDI) portrays oversight as 'the obvious follow-on activity linked to lawmaking. After participating in lawmaking, the legislature's main role is to see whether laws are being effectively implemented and whether, in fact, they address and correct problems as intended by their drafters' (National Democratic Institute 2000: 24). Oversight has thus an important ex post dimension in government action, focusing on the executive's past conduct in terms of implementing legislation and adopting specific measures.

From a theoretical perspective, the study of legislative oversight became intertwined with principal-agent applications to delegation in representative democracies (Kiewiet and McCubbins 1991; Lupia and McCubbins 1994; Strøm 2000). In fact, this is how definitions of oversight came to be equated with a parliament's (mechanisms of) control over the government and the bureaucracy. The principal-agent model is not a theory as much as an approach to delegation dominant in economics, political science, sociology, and policy studies (Braun and Guston 2003). The bedrock of the approach is the idea that in a representative democracy, 'those authorised to make political decisions [i.e. citizens] conditionally designate others [i.e. elected politicians, technocrats etc.] to make such decisions in their name and place' (Müller et al. 2006: 19). The person or group/institution doing the designation is the principal, whereas the person or group/institution acting on the principal's behalf is called the agent (Lupia 2006: 33). Delegation is typically perceived in the form of a chain, with direct links from voters to members of parliament, from members of parliament to governments, from governments to individual ministries and regulatory/implementing agencies, and finally from ministers and agency heads to civil servants (Busuioc 2013; Müller 2000; Niskanen 1973; Strøm 2000). This single-chain type of delegation is common in parliamentary democracies, whereas presidential systems have a different model, resembling a grid - with multiple principals (voters in different constituencies) electing multiple agents for the office of the president and parliament, respectively (Strøm 2006: 65).

Against this background, the principal-agent framework introduced accountability as the counterpart of delegation in democratic systems. In fact, when describing electoral accountability, Fearon presents delegation as the necessary condition for accountability, based on the understanding that 'A is obliged to act in some way on behalf of B' and, in turn, that ' $\mathrm{B}$ is empowered by some formal institutional or perhaps informal rules to sanction or reward A for her activities or performance in this capacity' (1999). To put it differently, if delegation is the process through which principals entrust agents with 
specific tasks, accountability is meant to ensure that the same principals maintain control over their agents. As explained by Lupia:

An agent is accountable to a principal if the principal can exercise control over the agent and delegation is not accountable if the principal is unable to exercise control. If a principal in situation A exerts more control than a principal in situation $B$, then accountability is greater in situation $\mathrm{A}$ than it is in situation B. (Lupia 2006: 35)

Based on this premise, the principal-agent model is concerned with the formal incentive structure through which principals can influence the behaviour of agents and make them act accountably (Gailmard 2014: 91). The model is based on rationalist assumptions of fixed preferences and self-interested behaviour, operating in an environment of scarce information and a hierarchy of principals over agents (Strøm 2006: 59). These assumptions create automatic problems for accountability because the preferences of principals and agents are bound to diverge over time. Agents are therefore expected to 'shirk' their obligations before principals either by hiding information before they are appointed (adverse selection) or by hiding their behaviour while on the job (moral hazard) (Moe 1984: 754-755). In the attempt to control their agents, principals are faced with a decision between the benefits of realising their own preferences and the costs of making the agent act in their most preferred way (Gailmard 2014: 92). Although there are several variations of principal-agent frameworks applied to accountability, they all share a focus on sanctions and the role of punishment in holding actors accountable (Mansbridge 2014: 55-56). The logic is straightforward: sanctions reinstate the principal's control over an agent and prevent future agency drift.

In respect of accountability, the principal-agent literature describes four different ways to address agency problems. These are: (1) contract design, (2) screening and selection mechanisms, (3) monitoring and reporting requirements, and (4) institutional checks (Kiewiet and McCubbins 1991: 27). The first two operate ex ante (framing the principal-agent relationship), while the other two function ex post, ensuring ongoing oversight of the agent. Kaare Strøm elaborated on the four measures in the context of executive-legislative relations. In his view, contract design refers to 'the set of terms on which the cabinet is allowed to take office' (1995: 73). Contract terms are to specify not only the shared interests between principals and agents ('incentive compatibility') but also the rules by which the agent is to take office ('investiture rules') (Strøm 1995: 74-75). Screening and selection mechanisms aim to solve the problem of adverse selection by eliminating 'potentially troublesome' agents 
'before they ever get into office' (Strøm 1995: 75). Political parties in parliament play a major role in the process of screening, voting, or appointing cabinet members and agency heads (Saalfeld 2000: 356).

Monitoring and reporting requirements overlap most clearly with the legislative oversight instruments mentioned above. Such requirements include committee hearings, questions, audits, special commissioners ('ombudsmen'), plenary debates, plus the 'ultimate sanction of the no confidence vote' in parliamentary regimes (Strøm 1995: 75). Elsewhere in the literature, monitoring mechanisms are categorised as (1) proactive and centralised ('police patrols') or (2) reactive and decentralised, meaning instruments available at the disposal of those affected in case of necessity ('fire alarms') (McCubbins and Schwartz 1984). The centralised aspect of 'police patrols' is contested, taking into account that there is no parliamentary-wide, systematic review of government measures; instead, police patrols are decentralised in committees and can often act in response to a scandal inside the executive (Ogul and Rockman 1990: 13). Fire-alarm oversight refers to the totality of procedures through which interested third parties (citizens, civil society organisations, and interest groups) can complain directly to the parliament about past or prospective executive measures (Saalfeld 2000: 363).

Finally, institutional checks are safety mechanisms designed to ensure that the decisions of agents are subject to 'the veto power or other checks exercised by other political agencies' (Strøm 1995: 76). For example, institutional checks and balances encompass judicial review by courts, the division of competences within federal systems, or internal procedures within executives and parliaments. It is important to mention that the range of mechanisms available in principal-agent models cannot eliminate agency loss completely. In fact, it is expected that the very act of delegation presupposes a loss of agency by the principal (Lupia 2006: 35). After all, the reason why the principal agreed to delegate specific functions to an agent is because it lacked the necessary information and resources to perform the task by itself. Under the circumstances, the role of accountability is to reduce agency loss, meaning that the conduct of the agent does not drift significantly from the principal's ideal preferences (Strøm 2000: 275). The interest of principal-agent studies is then to outline game-theoretical models mapping the different choices of principals and agents or, alternatively, to check whether the elements of the model are empirically present (Gailmard 2014).

Having outlined the theoretical roots of democratic accountability through parliaments, the next question is how principal-agent relations work in practice and how best to investigate them empirically. 


\subsubsection{Studying Oversight through Parliamentary Questions}

Whilst legislative oversight studies might have originated in the American context, the concept can be identified all over the world, with some variation between parliamentary and presidential regimes (Strøm 2000). Typically, the framework for legislative-executive relations is described in constitutions (or equivalent) in relation to the separation of powers, while the details of legislative oversight are stipulated in legislation and/or parliamentary rules of procedures (Yamamoto 2007). From an organisational perspective, legislative oversight is visible in (1) committee hearings, (2) plenary hearings on specific topics, (3) the creation and functioning of commissions of inquiry, (4) the submission of written questions, as well as the use of in-chamber, (5) 'question time', and (5) interpellations (Pelizzo and Stapenhurst 2012: 32-36). The availability and use of different tools depend on the jurisdiction; important factors include the legal framework of executive-legislative relations, the adequacy of parliamentary staff and research capacity, the influence of political parties, and the activity of individual legislators (Ogul 1976; Pelizzo and Stapenhurst 2012).

On the whole, oversight tools allow a parliament to make demands of the executive and react to specific policies in writing or orally through reports, speeches, and statements and in direct engagement with the government or civil servants - by asking questions. In fact, the study of parliamentary questions constitutes a field of its own with different areas of focus. In the UK House of Commons, the use of 'Question Time' has attracted a lot of attention as a historical development (Chester and Bowring 1962), in terms of why members of parliament ask questions and how (Franklin and Norton 1993), and in relation to what type of control over the government can be exercised through questions (Cole 1999; Gregory 1990). There is also extensive research on the practices of parliamentary questions in European legislatures with an emphasis on the political behaviour of members who address questions (Martin 2011a; Russo and Wiberg 2010; Wiberg and Koura 1994).

Although questions are almost always linked to oversight, they carry additional connotations for members of parliament such as self-promotion, acting on behalf of one's constituency (Martin 2011b), gaining strategic advantages within one's party, or competing over issues with others (Proksch and Slapin 2011; Vliegenthart et al. 2013). In fact, it is widely recognised that members of parliament ask questions for a plurality of reasons (Wiberg and Koura 1994: 30-31). Furthermore, examining the behaviour of members of parliament driving parliamentary questions contributes to the study of electoral links, government-opposition relations, and 
intra-party dynamics in legislatures. But although these subjects are fascinating in themselves, they move away from the legislative oversight goal of limiting agency loss through monitoring and reporting requirements (Kiewiet and McCubbins 1991). To put it simply, even if members of parliament ask questions for electoral or career gains, this does not diminish their original 'oversight purpose' to control the executive. After all, different motivations can be served through the same question.

From a research perspective, the challenge is to establish when a parliamentary question is effective in achieving the effect of control. So far, this methodological conundrum has been addressed by scholars in two ways. One avenue was to ask members of parliament, through surveys and interviews, whether the use of parliamentary questions has fulfilled their expectations of holding ministers accountable (Franklin and Norton 1993). Surveys are helpful in conveying the perceptions of a sample of members of parliament regarding the usefulness of parliamentary questions; however, they risk being under-representative owing to low participation rates (Bailer 2014: 186). Interviews suffer from the same problem to a higher extent, namely the inability to capture whole-of-parliament views about the effectiveness of oversight activities. At the same time, surveys and interviews take a snapshot of participants' views at a certain moment in time, meaning that findings cannot cover longer legislative periods.

Another popular approach is to conduct content analyses of parliamentary questions, which aim 'to extract meaningful content from an entire corpus of text in a systematic way' (Slapin and Proksch 2014: 128). Typical investigations include analyses of the frequency of questions on different indicators, such as government department/agency and subject matter (Cole 1999) or type of procedure and political affiliation of members of parliament posing questions (Proksch and Slapin 2011; Wiberg and Koura 1994). Quantitative content analysis of oral and written questions overcomes the representativeness problem of surveys and interviews; nevertheless, the method cannot capture qualitative aspects about the content of the question in terms of their suitability for oversight.

To sum up, the literature on legislative oversight is rich but simultaneously disjointed. As with many other academic subfields, scholars have been interested throughout time in different aspects of oversight, some theoretical and others empirically driven. When it comes to the study of parliamentary questions in particular, what is currently missing from the literature is a systematic analytical approach for evaluating their effectiveness in achieving control of the executive. The next section introduces such a framework. 


\subsection{THE ANALYTICAL FRAMEWORK: THE Q\&A APPROACH TO \\ LEGISLATIVE OVERSIGHT}

So far, the chapter has established the scarcity of research on the 'discussion stage' of public accountability relationships and the problem of measuring the extent to which actors can be held accountable through this stage alone. In respect of political accountability and the relationship between parliaments and executive actors in particular, the 'discussion stage' is captured in legislative oversight and the pervasive use of parliamentary questions. From a theoretical perspective, oversight is widely conceptualised in principalagent terms, but the literature lacks a comprehensive framework for assessing whether parliamentary questions can control the executive and actually hold governmental actors accountable in practice.

To establish the effectiveness of parliamentary questions in the 'discussion stage' of political accountability, the approach presented here ${ }^{9}$ builds on two underlying assumptions. The first is that the study of parliamentary questions cannot be separated from the study of executive answers, keeping in mind that legislative oversight presupposes a discursive exchange between two actors: the legislative and the executive. Following the convention in the literature, the 'executive' can refer to cabinet members (including prime ministers/presidents), politically appointed government officials in ministries or agencies, or civil servants in public administration. The legislative can include members of parliament (individually or in groups), a parliamentary committee, or the parliament as a whole. The second assumption is that evaluating the effectiveness of parliamentary questions must be limited in scope; otherwise, researchers risk getting lost in assessing the broader impact of legislative oversight on the political system (Rockman 1984: 430). Indeed, 'impact' can mean different things to different people, including but not limited to changes in policy decisions, changes in the attitudes of the executive towards the legislative (e.g. more transparency), or changes in legislative oversight practices (e.g. more hearings). The problem is that such (longer-term) effects can be caused by multiple factors that are not related to parliamentary questions. To avoid the confusion, it is proposed to limit the evaluation of parliamentary questions to their content on the one hand and their corresponding answers on the other hand, that is, the exchange of claims between legislative and executive actors.

Taking into account the emphasis on questions and answers as a discursive exchange, the analytical framework is labelled the 'Q\&A approach to

9 Parts of this chapter were previously published in the European Journal of Political Research (Maricut-Akbik 2021). 
legislative oversight'. Two implications come with the label: (1) that the content of Q\&A in oversight interactions is essential and should be analysed in itself and (2) that the exchange of claims between legislative and executive actors is the result of 'the actual, strategic actions of the claims makers' (Koopmans and Statham 1999: 216). Indeed, legislative oversight interactions have a certain dynamic dictated by the nature of their relationship, bearing in mind that the legislative has the authority to judge the appropriateness of executive actions, while the executive has to answer to the legislative for its performance (Aberbach 1990; Kiewiet and McCubbins 1991; Ogul 1976). Q\&A will thus correspondingly reflect the strategic positions of actors towards these goals. Moreover, since legislative oversight is an institutionalised process, Q\&A can be found in organised hearings, meetings, and more frequently, the exchange of documents between the two parties. Accordingly, Q\&A takes the form of both verbal and written communication.

Furthermore, the Q\&A approach to legislative oversight puts forth an analytical model entailing (a minimum of) three steps: (1) the legislative asks a question of the executive, (2) the executive provides an answer, and (3) the legislative reacts to that response. If the legislative continues one line of questioning, there is a feedback loop back to the executive's replies. Portraying Q\&A as a three-step process is not random. In a legislative oversight interaction, not only does the legislative ask a question and the executive reply but also there is a back-and-forth that reveals essential information about the dynamics of oversight in a particular setting. Follow-up questions suggest dissatisfaction with the executive's response, which is why they have to be considered separately from questions asked only once (Sánchez de Dios and Wiberg 2011: 356). Figure 3.1 offers an overview of the framework, which is explained below.

Column I lists the types of questions a member of parliament can ask the executive. Borrowing from the public administration literature, the Q\&A approach to legislative oversight connects parliamentary questions to the stages of public accountability - information, discussion, and consequences envisaged by Mark Bovens (2007; see Section 3.1). The idea is that (1) the actor is obliged to disclose information about its activities on a regular basis, (2) the forum can interrogate the actor about the adequacy of its conduct, and (3) the forum can pass positive or negative judgements on the behaviour of the actor, including through the imposition of sanctions (Bovens 2007a: 450-451). Technically speaking, parliamentary questions are part of Bovens's second stage because they constitute only one element of holding actors accountable. However, for the purposes of analysing parliamentary questions, the stages are 


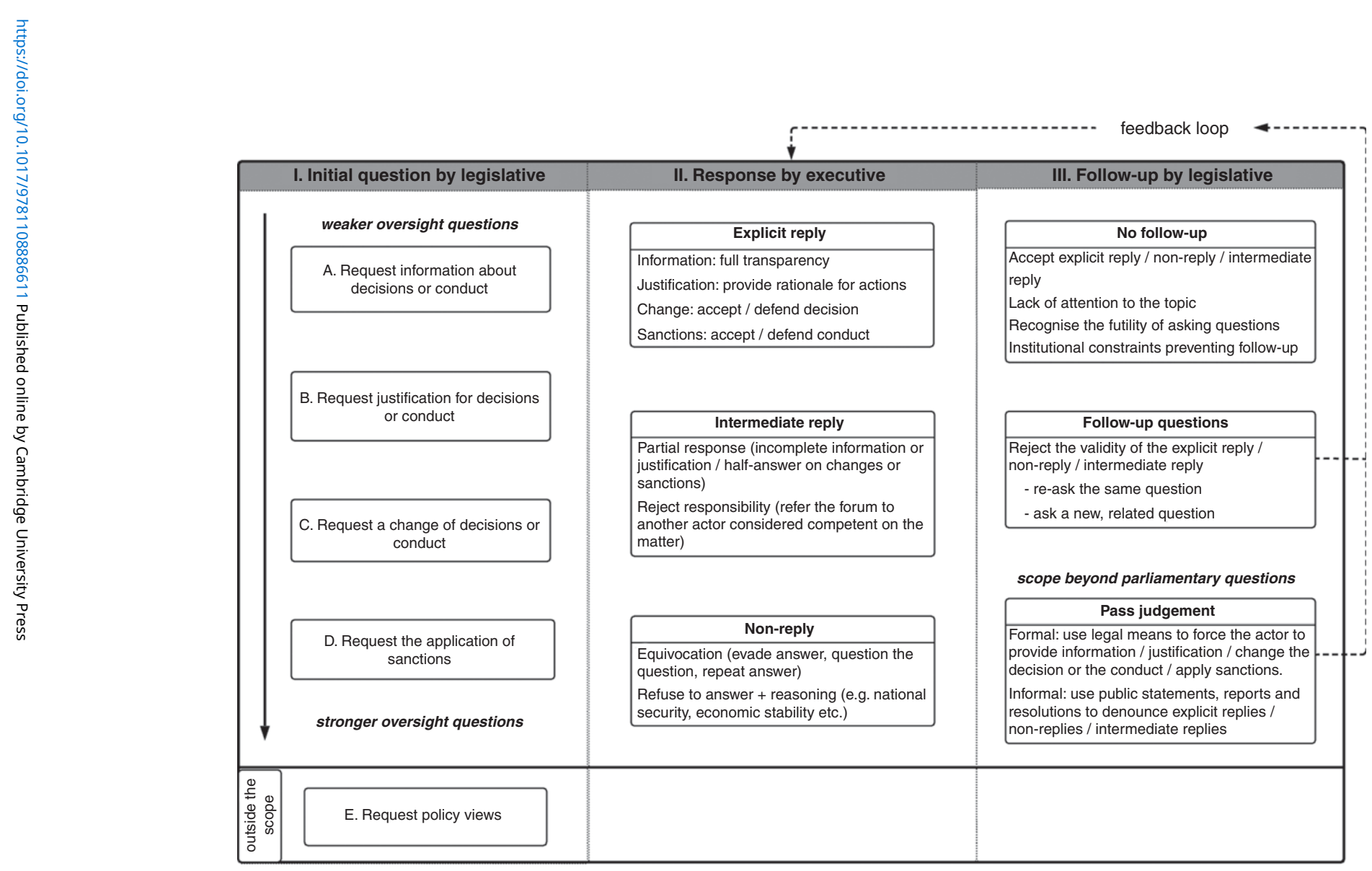

FIGURE 3.1 The Q\&A approach to legislative oversight. Own account 
extremely useful for identifying both the objectives of questions and the degree to which they challenge executive action.

Accordingly, it is posited that the legislative can make four types of requests from the executive: (type A) to provide information about (the context of) a decision; (type B) to justify a decision taken or explain conduct in a given situation; (type C) to amend a decision or change a conduct in a specific or general way; and (type D) to sanction individuals who are considered to be at fault for the negative effects of a decision or conduct. The Q\&A approach to legislative oversight distinguishes demands to change decisions from requests for sanctions, keeping in mind that in principal-agent models, sanctions are the ultimate weapon of the principal (Fearon 1999). Amendments of decisions can occur without necessarily sanctioning responsible parties for past errors. Overall, applying Bovens's logic allows the researcher to distinguish 'weaker' oversight questions requesting information and justification of conduct from 'stronger' oversight questions demanding changes of decisions and the imposition of sanctions. In addition, there is the possibility that the legislative asks a question that is outside the scope of oversight (Figure 3.1, requests of type E). Examples include questions for policy views that do not challenge the executive's past decisions or conduct in any way. Indeed, not all questions are relevant for legislative oversight purposes.

Next, column II illustrates the categories of answers provided by the executive in response to parliamentary questions. The point here is to establish the extent to which executive actors actually respond to questions, or alternatively, if they 'evade questions and/or give insufficient responses' (National Democratic Institute 2000: 38). The classification of answers is borrowed from communication research, specifically the strand dealing with equivocation in political interviews, that is, the ways in which politicians fail to reply to questions and how (Bull 1994; Bull and Mayer 1993). Peter Bull recently refined his 'response typology' for the purposes of analysing 'Question Time' with the prime minister in the House of Commons, demonstrating the applicability of his categories for judging executive answers in legislative oversight (Bull and Strawson 2020). Following his typology, column II shows that in response to parliamentary questions, the executive can provide (1) an explicit reply, (2) a non-reply, or (3) an intermediate reply.

Explicit replies show full engagement with the substance of questions. For requests for information and justification, this means offering full transparency or providing a comprehensive explanation of the rationale behind a certain decision. Likewise, when responding to requests for changes of conduct or for sanctions, executive actors can accept the request or defend the conduct in question. Explicit replies do not necessarily promise to redress 
a situation contested by the legislative; it may simply be that the government stands by the contested decision. For example, in the aftermath of the financial crisis, the Treasury Committee in the House of Commons held a series of hearings with the leadership of the Bank of England to discuss past errors and future reforms (2010-2012). One area of contention concerned the functions of the Court of Directors of the Bank of England, responsible for resource organisation (budget and appointments). In an oral testimony on 28 June 2011, the Governor of the Bank of England, Sir Mervyn King, rejected a suggestion by a member of parliament, Mark Garnier, that the role of the Court of Directors will be to 'run the Bank of England'; instead, he argued that the Court will 'not be responsible and should not be responsible for policy' because the Bank should be fully independent from political interference (House of Commons Treasury Committee 2011: 126). The point of explicit replies is that they address the question head-on, without attempts at subterfuge or by invoking reasons why parliamentary requests cannot be met.

Second, if the executive provides a non-reply, it can do so in two ways. One is equivocation, which can mean evading an answer, questioning the question, or repeating a previous response (Bull and Strawson 2020: 10-11). In the same hearing from June 2011, the Governor of the Bank of England evaded a question from a member of parliament, Andrea Leadsom, who contested the extent to which the Court of Directors reviewed the Bank's handling of the financial crisis. Instead of answering the question, Sir Mervin King claimed that the Treasury Committee actually fulfilled that function by conducting a permanent standing public inquiry into the financial crisis' (House of Commons Treasury Committee 2011: 129). Attention was thus deflected from what the Court should have done to the direct flattery of the Treasury Committee. The other category of non-replies concerns a clear refusal to reply accompanied by a rationale, which in legislative oversight could refer to national security, economic stability, or executive actions that require secrecy. In the same hearing with the Governor of the Bank of England, a member of parliament, George Mudie, asked for 'one time, one action' when the Bank changed its conduct because the 'Committee came across strongly on a given issue'. Sir Mervyn King answered, 'I sincerely hope that there was no action that we took that was as a direct result of what you have said because that would be to compromise [our] independence' (House of Commons Treasury Committee 2011: 131). In this context, we see that central bank independence is considered a sufficient rationale for not complying with requests for change of conduct in legislative oversight.

Finally, intermediate replies lie in-between explicit and non-replies. Some intermediate replies are just partial responses, providing incomplete 
information and justification or only half-answering requests for changes and sanctions (Bull and Mayer 1993: 660). In the above-cited hearing, an intermediate reply is provided by the Governor of the Bank of England when he acknowledges that it is essential to delineate clearly the role of the Court of Directors, but that this should be done by the legislators (House of Commons Treasury Committee 2011: 125-126). A second type of intermediate reply concerns instances of rejecting responsibility for the matter because it is not within the competence of the executive actor questioned. In the example above, Sir Mervin King replies to questions regarding mistakes done prior to the financial crisis in banking supervision by referring to the Financial Services Authority, which was responsible for prudential supervision and financial (mis-)conduct during the crisis. These situations should be investigated further because they can include cases of blame-shifting or avoidance of oversight (Hood 2010). If the question was indeed asked of the incorrect addressee, the reply is still considered 'intermediate' because the legislative does not receive a full response; however, the situation is not the fault of the executive actor under consideration.

In a third step (column III), the legislative reacts to the response of the actor by (1) providing no follow-up, (2) asking follow-up questions, or (3) passing judgement on the actions of the executive. The reaction of the forum as 'no follow-up', 'follow-up', and 'passing judgement' can occur regardless of whether the request was for information, justification of conduct, changes of policy, or the application of sanctions. The lack of follow-up can have different reasons, which are often hidden to the observer because they concern the personal motivations of legislative actors. Accordingly, a lack of follow-up can mean that the legislative is satisfied with the answer of the executive, that public attention has moved away from the topic, or simply that the legislative is aware that a complete answer will never be provided - in the case of nonreplies and intermediate replies. Moreover, not all parliamentary systems allow members to ask follow-up questions orally; this depends on each assembly's rules of procedure, which can create institutional constraints that prevent follow-up altogether. Follow-up questions occur for all categories of responses: explicit replies (when the legislative seeks additional information about the issue), non-replies (when the legislative rejects the lack of answer and restates the question), and intermediate replies (when the legislative seeks a full answer either by re-asking the same question or demanding additional information).

The final category of follow-up reactions, namely the 'passing of judgement' (cf. Bovens 2007a), goes beyond the scope of Q\&A in legislative oversight. In fact, members of parliament use other parliamentary tools - not questions - to express positive or negative assessments of the executive's conduct. Such tools 
can be formal, for example, legislative acts that force the executive's hand in some respect, and also informal, when legislatures criticise or approve the executive's response in public statements, reports, and resolutions (Bovens 2007a: 452). The challenge is to establish the extent to which these other forms of follow-up are linked to specific parliamentary questions. In the end, the decision to include the 'passing of judgement' in an analysis of Q\&A is an empirical question to be settled by researchers on a case-by-case basis.

\subsubsection{Six Scenarios of Oversight Interactions}

Having established the main categories of Q\&A, the next step is to evaluate their effectiveness. Following principal-agent insights, the purpose of oversight is to ensure legislative control of the executive (Fearon 1999; Lupia and McCubbins 1994; Strøm 2000; see Section 3.2.1). This book puts forth six scenarios capturing different dynamics of principal-agent control - or its lack thereof. Two criteria are considered: one concerns the type of questions asked by the legislature, and the other refers to the responsiveness of the executive actor providing the answer. In line with the Q\&A approach to legislative oversight, requests of type A (for information) and type B (for justification of conduct) are considered 'weaker' oversight questions, whereas requests of type $\mathrm{C}$ (for change of conduct) and type $\mathrm{D}$ (for sanctions) are seen as 'stronger' oversight questions. In respect of the responsiveness of the executive, three patterns are possible: the actor accepts the legislative's requests for change of conduct or sanctions and promises to do better in the future (rectification); the actor explains or defends its decisions without promising any changes (justification); or the actor evades answering altogether, dodging the question from the legislative (equivocation).

Accordingly, the effectiveness of parliamentary questions is operationalised in terms of (1) the strength of questions raised for the purposes of oversight and (2) the extent to which the executive is ready to justify and, if needed, rectify its behaviour in front of members of parliament. Justification and rectification are intrinsic in many definitions of public accountability (Mulgan 200ob), taking into account the expectation that the actor will explain and, if necessary, make amends for past errors of judgement (Oliver 1991: 28). In the Q\&A approach to legislative oversight, justification and rectification correspond to "explicit replies' and are categorised depending on the emphasis of the answer - either to explain/defend behaviour or promise to correct ill-conceived decisions. Conversely, equivocation is borrowed from communication research (Bull and Mayer 1993) and can be identified under 'non-replies' in Figure 3.1. Table 3.1 provides a summary of the interactions between the two dimensions, creating six scenarios of legislative oversight. 
TABLE 3.1 Six scenarios of legislative oversight

\begin{tabular}{lcccc}
\hline \hline & \multicolumn{3}{c}{ How does the actor respond to the question? } \\
& $\begin{array}{l}\text { Through } \\
\text { rectification }\end{array}$ & $\begin{array}{l}\text { Through } \\
\text { justification }\end{array}$ & $\begin{array}{l}\text { Through } \\
\text { equivocation }\end{array}$ \\
\hline $\begin{array}{c}\text { Types of } \\
\text { questions } \\
\text { asked as } \\
\text { part of } \\
\text { oversight }\end{array}$ & $\begin{array}{c}\text { Stronger } \\
\text { (types }\end{array}$ & $\begin{array}{c}\text { (1) High control/ } \\
\text { Cesponsiveness }\end{array}$ & (2) Answerability & (5) Drift \\
& Weaker & (3) Voluntary & (4) Transparency & (6) No \\
accountability & & control \\
& A and B) & & & \\
\hline \hline
\end{tabular}

The numbering of the scenarios illustrates their placement on a continuum from '(1) High control/responsiveness' to '(6) No control'. The order of the inbetween scenarios is complicated by the strength of parliamentary questions. Specifically, scenario '(2) Answerability' indicates a higher degree of legislative control over the executive than '(3) Voluntary accountability' because rectification in the absence of strong requests for changes of conduct/sanctions is entirely dependent on the benevolence of the executive. Conversely, scenario '4) Transparency' denotes a higher degree of legislative control over the executive than '(5) Drift' because a transparent executive that addresses requests for information/justification illustrates a higher degree of legislative control than an executive that evades strong parliamentary questions altogether.

Under what conditions is each scenario more likely? The legislative oversight literature offers no encompassing explanation of the reasons behind crossnational and cross-temporal variation in the strength of parliamentary questions (Rozenberg and Martin 2011: 402-403). Based on empirical studies, we have, however, some indication of the institutional settings and legislative-executive constellations that increase the likelihood of stronger questions (types C and D). First, public pressure on an issue is essential for legislative oversight, regardless of whether it is triggered by 'fire alarms' (McCubbins and Schwartz 1984), constituency demands (Martin 2011b), or general media scrutiny that allows members of parliament to build a reputation (Wiberg and Koura 1994). Second, there are structural opportunities such as the oversight mandate of the legislative, the institutional procedures available to ask questions in committee or plenary meetings, and adequate staff resources supporting members of parliament in asking strong questions (Ogul 1976; Rockman 1984). In this respect, parliamentary systems have on average a greater capacity for oversight than semi-presidential and presidential systems (Pelizzo and Stapenhurst 2012: 52). 
Third, there is the relative strength of various functions played by parliaments, namely 'law-making', the 'ex ante [s]election of officeholders', and 'the ex post control of the cabinet' (Sieberer 2011: 731; for a general index of parliamentary powers, see Fish and Kroenig 2009). It can thus be expected that legislatures with strong law-making powers are less likely to prioritise parliamentary questions than legislatures with strong elective and control powers (Sieberer 2011). Fourth, single-party cabinets tend to face more effective questioning procedures than coalition governments because the latter have a lower potential for confrontation (Russo and Wiberg 2010). In summary, we can expect stronger oversight questions under the following conditions:

(1) High public pressure on an issue

(2) Multiple structural opportunities for legislative oversight in settings where...

(3) Parliaments have stronger elective and control functions rather than lawmaking powers, while

(4) Cabinets are led by single parties rather than coalitions

At the same time, the incidence of follow-up questions has an additive effect as suggested in Section 3.3-meaning that more follow-up questions are also an indicator of strong oversight by a parliamentary forum.

Furthermore, the oversight literature offers some clues regarding the likelihood for rectification, justification, or equivocation in response to questions. Rectification as '(1) High control/responsiveness' can be anticipated in parliamentary systems where there is a direct chain of delegation between parliaments and cabinet members (Strøm 2000). In contrast, rectification as '(3) Voluntary accountability' can be expected from independent agencies that seek self-legitimation in different systems, especially when dealing with politically salient issues (Koop 2014; Schillemans and Busuioc 2015). Next, justification as '(2) Answerability' or '(4) Transparency' is applicable to a wide range of legislative-executive interactions regardless of the system of government; nevertheless, the two scenarios are more likely when parliaments and governments are in an indirect principal-agent relationship in which the focus is on account-giving rather than control (Bovens 2007a). Examples include legislatures and independent agencies in parliamentary systems (Thatcher 2005) or legislatures and cabinets in presidential systems (Aberbach 1990; Strøm 2000).

Finally, equivocation in the form of '(5) Drift' or '(6) No control' can be predicted in two contexts. First, under conditions of asymmetric information between legislatures and bureaucracies/expert agencies, there is a higher chance that executive actors will 'explain away' the questions raised 
in any system of government (Lupia and McCubbins 1994; Moe 1984). Second, when collective decisions by multiple actors cannot be disentangled, the potential for blame-shifting increases exponentially (Hobolt and Tilley 2014; Hood 2010). Table 3.2 provides an overview of these expectations in connection to the conditions for stronger oversight questions outlined above.

The following pages describe the six scenarios in brief. The first scenario 'High control/responsiveness' occurs when parliaments ask stronger questions as part of legislative oversight, requesting the executive to change its decisions or apply sanctions, while the executive answers through rectification, acknowledging that something needs to be changed or sanctions should be applied to the responsible parties. The likelihood for the first scenario to occur increases under conditions of (1) high public pressure on an issue, (2) multiple structural opportunities for legislative oversight (e.g. organisation of 'Question Time' sessions, regular or inquiry committee hearings), (3) strong parliamentary powers focused on control of the executive (e.g. Danish, Austrian, or Spanish parliaments), and (4) the presence of single-party cabinets as in the United Kingdom.

The second scenario 'Answerability' also occurs when parliaments ask stronger oversight questions, requesting executive actors to change their decisions or impose sanctions, but executive actors answer through justification rather than rectification, that is they focus on explaining their decisions or defending the conduct under scrutiny. 'Answerability' is also consistent with a high number of follow-up questions, even if they are requests for information or justification of conduct. In terms of likelihood of occurrence, 'Answerability' is expected when (1) public pressure on the executive actor is high, (2) there are multiple structural opportunities facilitating legislative oversight, (3) parliaments have strong powers to control the executive (as opposed to or in addition to law-marking powers), and (4) the party system is conducive to single-party governments that are strongly connected to parliamentary majorities.

The third scenario 'Voluntary accountability' occurs when parliaments ask weaker questions as part of legislative oversight, mostly requesting information and justification of conduct from bureaucracies and independent agencies. These executive actors acknowledge on their own the need for rectification and promise to change problematic decisions or sanction individuals found responsible for past errors. The assumption is that bureaucracies and independent agencies suffer from a lack of 'input legitimacy' because they are not directly elected, that is, they are non-majoritarian institutions (Thatcher and Sweet 2002). Consequently, they can be expected to seek self-legitimation 
TABLE 3.2 Institutional settings of legislative oversight scenarios

\begin{tabular}{|c|c|c|c|c|}
\hline $\begin{array}{l}\text { Institutional settings (constellation of legislative- } \\
\text { executive relationships) }\end{array}$ & Public pressure & $\begin{array}{l}\text { Structural } \\
\text { opportunities } \\
\text { for oversight }\end{array}$ & $\begin{array}{l}\text { Focus of } \\
\text { parliamentary } \\
\text { powers }\end{array}$ & $\begin{array}{l}\text { Single-party vs coalition } \\
\text { government }\end{array}$ \\
\hline $\begin{array}{l}\text { (1) High control/responsiveness } \\
\text { - L-C relationships in parliamentary systems }\end{array}$ & High & Many & $\begin{array}{l}\text { Select and control } \\
\text { the executive }\end{array}$ & Single-party government \\
\hline $\begin{array}{l}\text { (2) Answerability } \\
\text { - L-B/A relationships in parliamentary } \\
\text { systems/L-C relationships in presidential } \\
\text { systems } \\
\text { - Multi-level settings (e.g. EU) }\end{array}$ & High & Many & $\begin{array}{l}\text { Select and control } \\
\text { the executive }\end{array}$ & Single-party government \\
\hline $\begin{array}{l}\text { (3) Voluntary accountability } \\
\text { - L-B/A relationships in salient fields, regardless } \\
\text { of the system }\end{array}$ & High & Fewer & Law-making & Coalition government \\
\hline $\begin{array}{l}\text { (4) Transparency } \\
\text { - L-B/A relationships in parliamentary } \\
\text { systems/L-C relationships in presidential } \\
\text { systems }\end{array}$ & Medium & Fewer & Law-making & Coalition government \\
\hline $\begin{array}{l}\text { (5) Drift } \\
\text { - L-B/A relationships in parliamentary and } \\
\text { presidential systems } \\
\text { - Collective decision-making } \\
\text { (6) No control }\end{array}$ & Medium & Many & $\begin{array}{l}\text { Select and control } \\
\text { the executive }\end{array}$ & Single-party government \\
\hline $\begin{array}{l}\text { - L-B/A relationships in parliamentary and } \\
\text { presidential systems } \\
\text { - Collective decision-making }\end{array}$ & Low & Fewer & Law-making & Coalition government \\
\hline
\end{tabular}

Legend: $\mathrm{L}=$ legislative, $\mathrm{C}=$ cabinet, and $\mathrm{B} / \mathrm{A}=$ bureaucracy/agencies. Own account based on the literature. ${ }^{10}$

10 Table 3.2 is based on studies concerning public pressure in legislative oversight (Martin 2011b; McCubbins and Schwartz 1984; Wiberg and Koura 1994), structural opportunities for oversight (Ogul 1976; Rockman 1984), types of parliamentary powers (Fish and Kroenig 2009; Sieberer 2011), single-party cabinets as opposed to 'coalition governments' (Russo and Wiberg 2010), L-C relationships in parliamentary systems (Strøm 2000), L-B/A relationships in politically salient fields (Koop 2014; Schillemans and Busuioc 2015), L-B/A relationships in parliamentary systems (Bovens 2007), L-C relationships in presidential systems (Aberbach 1990; Weingast 1984), and L-B/A relationships in presidential systems (Lupia and McCubbins 1994; Moe 1984). 
through voluntary means in any system of government but especially when dealing with politically salient issues (Koop 2014; Schillemans and Busuioc 2015). The third scenario is thus expected when (1) public pressure on an issue is high, but otherwise, there are (2) fewer structural opportunities for legislative oversight, (3) the parliament has strong law-making powers in a given institutional context (as opposed to strong elective and control powers over the executive), whereas (4) the party system is conducive to coalition governments.

The fourth scenario 'Transparency' occurs when parliaments ask weaker questions as part of legislative oversight, focusing on requests for information and justification of conduct from executive actors. For their part, executive actors acknowledge the substance of questions and answer by justifying their decisions or defending the conduct under scrutiny. Similar to 'Answerability', this scenario is expected when legislatures and executive actors are not in a direct principal-agent relationship (Bovens 2007a: 451). Since parliaments cannot control governments by changing their composition (especially in the case of cabinets) or the legal framework in which they act (especially in the case of agencies or bureaucracies), the legislative-executive relationship focuses on transparency, that is, the exchange of information between the two parties. The scenario is more likely to be encountered when (1) there is moderate public attention given to the issue or the executive actor under scrutiny, (2) there are fewer structural opportunities for legislative oversight, while the institutional context is characterised by (3) parliaments with strong law-making powers, and (4) a multi-party system conducive to coalition governments.

The fifth scenario 'Drift' occurs when parliaments ask stronger oversight questions focused on changing decisions and imposing sanctions, to which executive actors respond through equivocation, evading, or failing to address the substance of questions. This scenario follows classic principal-agent expectations regarding legislative oversight, based on assumptions of asymmetric information between parliaments and government agencies with specialised knowledge, which can explain any question away regardless of the system of government (Lupia and McCubbins 1994; Moe 1984). Moreover, 'Drift' is likely to occur in institutional contexts where executive decisions are taken collectively across different agencies or levels of government, thus opening the space for blame-shifting from one actor to another (Hobolt and Tilley 2014; Hood 2010). Legislative relationships with bureaucracies and specialised agencies are predicted to fulfil the criteria, as well as multi-level settings that mix decision-making competences, for example, the EU. Moreover, the scenario is expected under the following conditions: (1) 
a moderate level of public pressure on the executive actor or the issue at stake, (2) multiple structural opportunities for legislative oversight, (3) strong parliamentary powers in respect of controlling the executive, and (4) a party system conducive to single-party governments. The point here is that the legislature has both the means (structural opportunities, direct connections to the government) and the willingness to control the executive, but the latter fails to engage with oversight appropriately.

The sixth scenario 'No control' occurs when parliaments ask weaker oversight questions centred on access to information and justification of governing decisions. Yet executive actors equivocate even these questions, avoiding answering or failing to engage substantively with the legislature. Similar to 'Drift', this scenario is expected under conditions of asymmetric information and collective decision-making in various institutional settings (Hobolt and Tilley 2014; Hood 2010; Lupia and McCubbins 1994; Moe 1984). Relationships between parliaments and bureaucracies or specialised agencies fall in this category because the latter can exploit the legislature's knowledge gaps and lack of time/attention to understand complex policy issues (Majone 1999: 34). Moreover, 'No control' is facilitated by (1) low levels of public pressure on the executive actor and the policy issues under its jurisdiction, (2) fewer structural opportunities for legislative oversight, (3) a parliamentary tradition focused on law-making rather than selection and control of the executive, and (4) a multi-party system conducive to coalition governments. The point is that parliaments lack both the means and willingness to ask strong oversight questions, whereas executives seek to obscure their conduct or shift responsibility to other actors.

From a normative perspective, the order of the scenarios is consistent with principal-agent expectations regarding the purpose of legislative oversight and accountability more generally, namely to ensure that agents are responsive to the principals that elected/appointed them (Przeworski et al. 1999). However, in some instances, 'Answerability' can be as important as 'High control/ responsiveness' depending on the specificities of the political and organisational setting under consideration (Dubnick 2014: 33). For example, if governments are seen 'to do a good job', then the need for rectification will automatically be weaker than in contexts where executives deviate from legislative intent and hence have to be regularly 'controlled'. Moreover, there is also the question of whether rectification or executive responsiveness to legislatures is always desirable: for example, independent (regulatory) agencies were delegated to fulfil specific tasks not least in order to be insulated from political changes over time (Majone 1999: 13-14); in these cases, the justification of executive decisions might be more valuable than their 
rectification or appearing responsive to parliamentary pressure. The point is that researchers must decide on a case-by-case basis whether 'High control/ responsiveness' or 'Answerability' is the best-case scenario in a given oversight context.

\subsubsection{Expectations about the European Parliament in the EMU}

Taking into account the literature above, we can formulate several expectations about the accountability relationship between the EP and various executive actors in the EMU. The only caveat is that the vast majority of studies on legislative oversight are based on national parliaments, so it is necessary to make adjustments to the variables identified in order to fit the characteristics of the EP in EU multi-level governance and the EMU specifically.

First, given the structure of the EU political system, the interactions between the EP and the Commission come closest to the relationship between a legislative and a cabinet in parliamentary systems. According to Articles 14(1) and $17(7)$ TEU, the EP elects the Commission President and votes on the College of Commissioners as a whole; in addition, MEPs can initiate a motion of censure and dismiss the current Commission, in line with Article 17(8) TEU and Article 234 TFEU. While there are caveats to the chain of delegation in place - for example, the European Council appoints a candidate for Commission President (not the EP) - we can still expect the highest level of political accountability from the College of Commissioners who earn their jobs (and can subsequently lose them) as a result of a plenary vote in the EP. Based on this logic, the best outcome for the oversight relationship between the EP and the Commission is 'High control/responsiveness' (scenario 1).

Conversely, the interactions with intergovernmental bodies (the ECOFIN Council and the Eurogroup) are different because Member States' governments are formally accountable to their respective national parliaments and citizens, not to the EP (Article $10 \mathrm{TEU}$ ). For this reason, the oversight dynamic between the EP and the Council comes closest to the relationship between a legislature and a cabinet in a presidential system, where the executive is directly accountable to citizens. Under the circumstances, such relationships are unlikely to be characterised by 'High control/responsiveness' (scenario 1). Consequently, the best outcome for the oversight relationship between the EP and the ECOFIN Council/the Eurogroup is 'Answerability' (scenario 2).

The same expectation can be formed regarding the interactions between the EP and the ECB (the other main executive actor in the EMU) but for different reasons. Given the political independence of the ECB - stipulated in the Treaties (Article $130 \mathrm{TEU}$ ) - we can envisage a dynamic similar to the one 
found between legislatures and bureaucracies/agencies at the national level. The more independent the executive agency, the more unfeasible the possibility for political control or 'responsiveness' to an accountability forum. By contrast, the emphasis of such a relationship would be on account-giving, meaning that the best outcome for the oversight relationship between the EP and the ECB is also 'Answerability' (scenario 2).

Starting from these preliminary expectations, the other variables mentioned in Table 3.2 can shift accountability interactions closer or farther from the best-case scenario. First, high political pressure on an issue (such as financial assistance programmes or the health of banks in the Eurozone) is likely to increase the strength of parliamentary questions and the responsiveness of executive actors. In a similar vein, the ability to ask written questions or the format of committee meetings (e.g. the number of speakers permitted per session) will allow MEPs to ask stronger oversight questions and expand the time in which executive actors must respond. The structural opportunities for oversight might also limit the possibility to ask follow-up questions, which would normally indicate a strong performance by the accountability forum.

Conversely, the remaining variables in Table 3.2 are not favourable to facilitating oversight and hence move accountability interactions closer to the best-case scenario. On the one hand, the profile of the EP is not geared towards scrutiny of the executive and government-opposition dynamics. As described in Chapter 1.2, the EP is a parliament focused on law-making as opposed to control of the executive; in addition, political polarisation is diffused among 7-8 political groups per parliamentary term. Although a 'governing coalition' exists in support of the Commission and is typically composed of 2-3 political groups, the competition between groups is less clear. Moreover, in the relationship with the ECB and the Council, the absence of a 'governing coalition' is more pronounced because - unlike the Commission - these bodies are not in a principal-agent relationship with the EP (for a detailed discussion, see Chapters 4.2 and 6.2, respectively).

On the other hand, there are the variables related to asymmetric information and collective decision-making, which have a similarly negative effect on the accountability relationship between the EP and EU executive actors. In the EMU, the secrecy regime of the ECB and the Council (Curtin 2014, 2017; Hillebrandt and Novak 2016) is particularly detrimental for political accountability, as MEPs do not have access to the decision-making process within these institutions. The situation is also applicable to the ECOFIN Council and to a lesser extent to the Commission. Furthermore, collective decision-making is a common feature in the EMU, particularly in respect of the Eurogroup and the ECOFIN Council or the implementation of the European Semester. This 

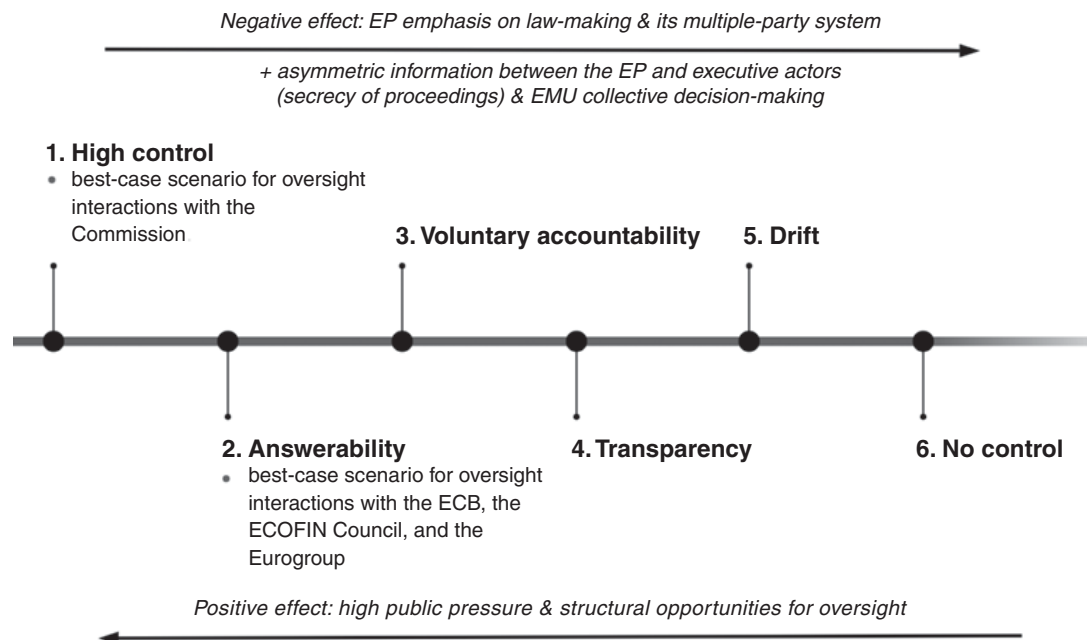

FIGURE 3.2 Expectations about oversight interactions between the EP and executive actors in the EMU

means that the actor appearing before the EP may not necessarily be the one responsible for the decision taken, for example, the Presidency of the Council in respect of decisions of ECOFIN as a whole or the European Commission with regard to the domestic effectiveness of the European Semester.

Bearing all this in mind, Figure 3.2 provides a summary of the book's theoretical expectations regarding the capacity of the EP to hold executive actors accountable in the EMU. Building on the continuum from 'High control/responsiveness' to 'No control' in legislative oversight, the purpose is to illustrate the best-case scenarios for each institution and capture the positive or negative effects of the variable identified.

Based on these criteria, the empirical analysis will establish the extent to which the EP can hold the ECB, the Commission, the ECOFIN Council, and the Eurogroup accountable in the EMU. The purpose is to place each oversight interaction on the continuum from 'High control/responsiveness' to 'No control' and discuss the impact of the different variables considered (see Chapter 7.1). Before moving to the empirical analysis of oversight interactions, the chapter outlines the methodological tenets of the study.

\section{$3 \cdot 4$ METHODOLOGICAL CONSIDERATIONS}

To assess the effectiveness of Q\&A in legislative oversight, the book employs an adaptation of the method of political claims analysis developed in the social 
movement literature and later applied to politicisation research (De Wilde et al. 2014; Koopmans and Statham 1999). Claims analysis is a form of qualitative content analysis that combines actor- and discourse-centred approaches: in a legislative oversight context, it allows the researcher to link legislative and executive actors with the content of their interactions, including their respective positions and frames of justification used to support them. The unit of analysis is the claim, which is a sentence or a set of sentences on a particular topic. Leifeld and Haunss explain the process: 'each time an actor makes a claim, this action or statement is manually coded along with various other variables containing information about the actor, the context, addressees, opponents, aims, and frames, among others' (2010:6).

In a legislative oversight context, there is always a 'claimant' and an 'addressee' depending on the direction of communication: either the legislative asks questions of the executive, or the executive replies to the legislative. Accordingly, questions-as-claims include interrogative sentences and are often preceded by a short paragraph introducing the topic. Answers-as-claims typically include more sentences and can go on for paragraphs, elaborating on the topic. In line with Figure 3.1, the goal is to identify initial questions, replies, and follow-ups in order to assign manually corresponding codes to claims made by legislative and executive actors.

For the purposes of evaluating oversight interactions, the results of the coding are aggregated by counting the number of occurrences in each category. There are several goals to the exercise. First, one can establish the frequency of questions along different categories, capturing the inclinations of legislatures to ask 'stronger' or 'weaker' oversight questions. Second, one can identify problems in the practices of parliamentary questions, for example, asking questions outside the scope of legislative oversight or failing to follow up on non-replies/intermediate replies. Third, one can detect trends in answers provided by the executive, such as tendencies to avoid substantive replies (equivocation) or shift responsibility for the question to other actors. The idea is to trace empirically the underlying dynamics of oversight relationships and identify trends over time and across issues.

At the same time, the description of Q\&A is accompanied by a discussion of the institutional and policy context in which oversight interactions occurred. This facilitates a broader analysis of the variables that have positive or negative effects on the accountability relationship at play, such as high public pressure on an issue or the extent of asymmetric information between MEPs and executive actors. Each empirical chapter will conclude with a theoretical reflection of the oversight scenario fitting the evidence collected, whereas Chapter 7.1 will provide a comparison between the four cases under 
investigation - covering the EP's accountability relationships with the ECB, the Commission, the ECOFIN Council, and the Eurogroup after the euro crisis.

To structure the data set of $Q \& A$ available, the analysis follows a systematic coding guide, which is outlined below.

\subsubsection{Coding Guide ${ }^{11}$}

The coding loosely follows the template provided by de Wilde and colleagues in their application of representative claim analysis in the research project 'The Political Sociology of Cosmopolitanism and Communitarianism' (2014). Accordingly, the claim analysis approach to legislative oversight directs attention to variables related to context, claimants, addressees, issues, and positions identified for (1) initial questions, (2) replies, and (3) follow-ups, as envisaged in Figure 3.1. The classification is done manually by human coders and is thus both time- and labour-intensive (Slapin and Proksch 2014: 128). To facilitate the process, claims are coded using a software for qualitative data analysis (ATLAS.ti), which allows the researcher to manage large segments of text (De Wilde et al. 2014: 56). At the same time, this ensures the easy retrieval of research output in terms of coding schemes, claims per code, and list of cooccurring codes (Woods et al. 2016: 610). The idea is to trace empirically the underlying dynamics of legislative oversight and identify trends over time and across issues.

Table 3.3 provides a general overview of the core variables employed, which are detailed in the following pages.

Each variable has a specific range of meanings expected. First, the variable 'Year' is applied to individual documents where Q\&A were found, not to the number of questions or answers per document. This allows the researcher to identify the frequency of the legislative oversight medium used (written letters and hearings) in addition to the number of questions addressed per year, which can be computed from each document (applicable to Chapters 4 and 5).

Second, the variable 'Claimant' applies to both legislative actors (in the case of questions) and executive actors (in the case of answers). The key subcode here is 'claimant function', indicating the official title of the person/institutional body making the claim. When it comes to questions, claimants include individual MEPs, committee chairs, the committee as a whole, or - on rare

${ }^{11}$ For a full overview of the codebook, please see the Online Appendix of the article ' $Q \& A$ in legislative oversight' (Maricut-Akbik 2021). 
TABLE 3.3 Coding guide: overview of core variables

\begin{tabular}{|c|c|}
\hline Claim aspect & Core variables \\
\hline When & Year \\
\hline \multirow[t]{3}{*}{ Who is making the claim? } & Claimant function \\
\hline & Claimant nationality \\
\hline & Claimant party \\
\hline \multirow{2}{*}{$\begin{array}{l}\text { To whom is the claim } \\
\text { addressed? }\end{array}$} & Addressee function \\
\hline & Addressee nationality \\
\hline & Issue type (dependent on policy area) \\
\hline claim refer? & 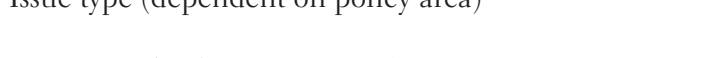 \\
\hline \multirow{5}{*}{$\begin{array}{l}\text { What is the claimant } \\
\text { demanding? (initial } \\
\text { question by legislative } \\
\text { actor) }\end{array}$} & A. Demand information (weaker question) \\
\hline & B. Demand justification of conduct (weaker question) \\
\hline & C. Demand change of conduct (stronger question) \\
\hline & D. Demand sanctions for actors (stronger question). \\
\hline & $\begin{array}{l}\text { E. Demand policy views (additional category, outside } \\
\text { the scope of oversight) }\end{array}$ \\
\hline \multirow{11}{*}{$\begin{array}{l}\text { How is the addressee } \\
\text { responding? (response } \\
\text { from executive actor) }\end{array}$} & Explicit reply_Full answer_A.B.C.D.E. \\
\hline & - Provide information/justification of conduct \\
\hline & (answer subtype: justification) \\
\hline & $\begin{array}{l}\text { - Defend decision/conduct (justification) } \\
\text { - Accept need for change/sanctions (rectification) }\end{array}$ \\
\hline & Non-reply_Evasion_A.B.C.D.E (equivocation) \\
\hline & $\begin{array}{l}\text { Non-reply_Refuse to answer + reasoning_A.B.C.D.E } \\
\text { (equivocation) }\end{array}$ \\
\hline & Intermediate reply_Partial answer_A.B.C.D.E \\
\hline & - Provide information/justification of conduct \\
\hline & (answer subtype: justification) \\
\hline & $\begin{array}{l}\text { - Defend decision/conduct (justification) } \\
\text { - Accept need for change/sanctions (rectification) }\end{array}$ \\
\hline & $\begin{array}{l}\text { Intermediate reply_Refer to another actor deemed } \\
\text { responsible_A.B.C.D.E (equivocation/need for } \\
\text { qualitative assessment) }\end{array}$ \\
\hline \multirow{9}{*}{$\begin{array}{l}\text { Is there a follow-up? (by the } \\
\text { legislative actor) }\end{array}$} & The absence of follow-up questions is a negative, \\
\hline & so it cannot be demonstrated via the presence of \\
\hline & claims. It thus makes more sense to count the \\
\hline & overall instances of 'observable' follow-ups rather \\
\hline & $\begin{array}{l}\text { than try to trace the unobservable lack of follow-up. } \\
\text { Follow-up_Continue_A. Demands for information } \\
\text { (weaker question) }\end{array}$ \\
\hline & $\begin{array}{l}\text { Follow-up_Continue_B. Demands for justification } \\
\text { (weaker question) }\end{array}$ \\
\hline & $\begin{array}{l}\text { Follow-up_Continue_C. Demands for change } \\
\text { (stronger question) }\end{array}$ \\
\hline & Follow-up_Continue_D. Demands for sanctions \\
\hline & $\begin{array}{l}\text { Follow-up_Continue_E. Demands for policy views } \\
\text { (outside the scope) }\end{array}$ \\
\hline
\end{tabular}


occasions - the EP President. To capture political and national dynamics in the EP, the coding additionally includes information about the nationality of MEPs as well as their political affiliation. When it comes to answers, claimants consist of the Chair of the Supervisory Board of the ECB (Chapter 4), members of the College of Commissioners in charge of economic and social affairs (Chapter 5), or the finance ministers holding the Council Presidency and the Eurogroup President (Chapter 6).

Third, the variable 'Addressee' corresponds to the 'Claimant', following an inverse logic: addressees of questions are the same executive actors coded as 'claimants' in the case of answers, while addressees of answers are the same parliamentary officials coded as 'claimants' in the case of questions.

Fourth, the variable 'Issue' refers to specific policy areas in which legislative oversight can be exercised. The list of issues varies in line with the institution under investigation; accordingly, the focus can be banking supervision (Chapter 4 on the ECB), European Semester instruments (Chapter 5 on the Commission), legislative dossiers currently under negotiations between the Council and the EP (Chapter 6 on ECOFIN), or financial assistance programmes managed through the ESM (Chapter 6 on the Eurogroup).

Fifth, the code 'initial question' applies to questions asked for the first time by MEPs of executive actors. In line with Figure 3.1, questions can be used to demand information, justification of decisions or conduct, change of decisions, and the application of sanctions. The first two are considered weaker oversight questions, whereas the latter two are stronger oversight questions. There is an additional category, labelled 'demand policy views', which is considered outside the scope of legislative oversight because such questions do not contest anything about the decisions or conduct of executive actors. In Chapter 5, a supplementary category titled 'Irrelevant issues' (type F) was inductively added in order to distinguish questions that do not demand policy views (type E) but are still outside the scope of oversight as defined in the analytical framework.

Sixth, the category of codes referring to 'replies' is applied to all answers provided by executive actors in response to both initial and follow-up questions. The variation in the format for answers is much higher than in the case of questions. Answers can be short (a few sentences to one paragraph), medium (a few paragraphs), or long (a few pages of text, including graphs). As indicated in Figure 3.1, answers can be categorised as follows: (1) explicit replies, (2) non-replies, or (3) intermediate replies. Explicit replies presuppose full engagement with the substance of the question. Non-replies signify evasion or a downright refusal to answer the question. Intermediate replies offer a partial response to the question or deny responsibility for the topic while at the same time explaining which other actor is the appropriate addressee for 
the question. Each of these categories corresponds to the four types of questions identified, creating further subcodes.

Moreover, the subcodes under 'replies' provide additional categories regarding the direction of answers, namely whether they provide 'rectification', 'justification', or 'equivocation' in response to parliamentary questions. 'Rectification' is only applicable to demands for policy change and sanctions when executive actors agree that a change is necessary or when they promise to make changes as suggested by MEPs in their questions. 'Equivocation' occurs when executive actors clearly evade questions, invoke secrecy requirements as grounds for not answering questions, or claim that they are not responsible for the issue under discussion. The last category needs to be assessed qualitatively on a case-by-case basis because it might be that the 'lack of competence' is real or an instance of shifting the blame to another institution (Hood 2010).

Finally, the code 'follow-up' applies to all questions whose exact topic has already been encountered in the coding. For this reason, coding has to be done chronologically, switching between written questions and hearings (where applicable, in Chapters 4 and 5). At the same time, coding on a case study is done in monthly batches, without long breaks in-between, so that the topics covered are fresh in the mind of the coders. ${ }^{12}$ Moreover, when a followup question is identified in a different document, the coders used the "comments' section of the software in order to reference the document with the initial question. This way, follow-up questions can be cross-checked at a later point in time. The most obvious follow-up questions occur during hearings and committee meetings when MEPs ask multiple questions on the same topic, seeking to push executive actors to provide full replies.

Overall, the Q\&A approach to legislative oversight provides a theoretically and methodologically consistent toolkit for analysing accountability interactions between legislative forums and executive actors. Moreover, the approach allows the researcher to evaluate the extent of parliamentary control of the executive in a given situation, as reflected in practices of Q\&A.

\section{$3 \cdot 5$ OUTLOOK}

Parliaments are crucial political accountability bodies in any democratic system. Yet studying their effectiveness in legislative oversight is not an easy task. In

12 In composing the data sets and coding, I am grateful to a wonderful group of research associates who worked on the LEVIATHAN project at the Hertie School during 2017-2020 (in chronological order): Evgenija Kroeker, Rebecca Segall, Harry McNeill Adams, Elena Bertolini, and Francesco Lanzone. 
the absence of clear rules that allow parliaments to impose consequences on governmental actors for their performance, legislatures often rely on the 'discussion stage' of their political accountability relationship with executives. In legislative oversight, the 'discussion stage' is manifested through Q\&A exchanged between members of parliaments and government officials. The connection between parliamentary questions and the ability of legislatures to control executives has always been implicit, following the logic that questions allow parliaments to 'call to account' the government and the administration (Gregory 1990:). However, when it came to analysing the effectiveness of parliamentary questions in controlling the executive, the academic literature offered little guidance. The present chapter addressed this gap by proposing an original and systematic framework for evaluating the extent to which parliamentary questions can be effective in ensuring the responsiveness of executive actors to their political accountability forums.

The framework is particularly suited for studying the accountability record of the EP in the EMU. Given the institutional architecture of EMU and the EU political system in general, the EP's competences for legislative oversight are limited. Even after the euro crisis, the main mechanisms at the EP level are committee hearings or meetings with various executive actors (the ECB, the Commission, the Council, or the Eurogroup). Within these hearings, MEPs can ask oversight questions and hope to receive full answers from the different officials present. The Q\&A approach to legislative oversight is perfect for studying these accountability interactions in order to determine the strength of parliamentary questions on the one hand and the responsiveness of executive actors on the other. The next chapters illustrate the dynamics between the EP and various executive actors in the EMU (for case selection, see Chapter 1.4). 


\section{4}

\section{Overseeing the European Central Bank in Banking Supervision}

In 2014, Danièle Nouy - the first Chair of the Supervisory Board of the ECB praised the 'robust accountability' framework of the newly established SSM. In her introductory remarks at an EP committee hearing, Nouy argued that 'this framework is perhaps one of the most far-reaching that is in place for an independent central bank that is responsible for supervision. I believe we have already lived up to the word and spirit of this framework' (Nouy 2014). The Chair of the Supervisory Board is not alone in emphasising the strength of the accountability obligations set in place by the SSM Regulation (Council Regulation 1024/2013). Ter Kuile and colleagues claim that the SSM has successfully established a form of "tailor-made accountability which keeps power in check while respecting the independence of the banking supervisors' (2015: 155). In terms of political accountability, the SSM created multiple reporting requirements for the ECB - regulated for the first time through an Interinstitutional Agreement with the EP and a Memorandum of Understanding with the Council (European Central Bank 2021a). In this context, Fromage and Ibrido argue that the accountability framework of the SSM 'could open new avenues in the ECB's ... quest for reinforced democratic accountability' that could be extended to the relationship with the EPG on monetary policy (2018: 306). Overall, the mechanisms to hold the ECB accountable in banking supervision are generally seen as a marked improvement over similar arrangements in monetary policy (Braun 2017: 47).

The reason why ECB accountability was contentious in the first place concerns its status as a non-majoritarian, technocratic organisation and at the same time one of the most independent central banks in the world (Curtin 2017; Elgie 2002; Naurin 2009). Generally speaking, independent

Parts of this chapter were previously published in the Journal of Common Market Studies (Maricut-Akbik 2020). 
central banks with unequivocal mandates to maintain price stability are not exceptional institutions: in fact, they have been part of the monetary policy orthodoxy in advanced economies since the late 1980s (Alesina and Summers 1993; Cukierman et al. 1992). Furthermore, it is not uncommon for central banks to take over responsibilities for banking supervision, albeit the latter is more controversial due to potential situations when monetary and supervisory tasks can come into conflict (Buiter 2014: 270). From the perspective of democratic accountability, the political independence of central banks was always bound to be problematic (Elgie 1998; Levy 1995). When central banks take decisions independently from democratic elections, there is no political debate about the trade-offs involved in monetary policy or financial supervision. Instead, such decisions become cloaked in the technical language of expertise (Stiglitz 1998: 216-217). To address the shortcoming, the legal framework of central banks typically includes political accountability mechanisms most often in the form of parliamentary oversight or an institutionalised dialogue with governments (De Haan et al. 1999: 178-179). The scope and functioning of these mechanisms differ, however, from setting to setting.

This chapter investigates how the EP exercises oversight of the ECB in the field of banking supervision. The goal is to evaluate the extent to which the ECB is being held accountable by its main political interlocutor in the SSM framework - the EP's ECON Committee. Following the theoretical approach outlined in Chapter 3.3, the focus is on parliamentary Q\&A exchanged between the two institutions both orally and in writing. The analysis below is based on 283 letters with questions and 13 public hearings that took place at the ECON Committee between October 2013 (since the adoption of the SSM Regulation) and April 2018. The findings reveal that MEPs ask many questions of the ECB on banking supervision, but oversight remains 'weak' - focused on requests for information and justification of conduct. The emphasis on weaker oversight questions stems from the ECB legal framework, which imposes strict confidentiality requirements regarding decisions about supervised banks, as well as from the strong independence of the ECB in the EU political system. For its part, the ECB is open to justifying its conduct and explaining its decisions to MEPs, but it rarely agrees to policy changes in response to EP oversight. In line with the expectations set out in Chapter 3.3.1, the preponderance of weak oversight questions and explicit, justificatory replies places this oversight relationship in scenario 4 - 'Transparency'.

The chapter is structured as follows. The first part introduces the background of the SSM and its main institutional features. The second part explains the key issues in the accountability relationship between the EP and the ECB in banking supervision, drawing on principal-agent insights. 
The third part provides the empirical analysis of oversight interactions, focusing on three aspects: (1) the profile of MEPs asking questions of the ECB on banking supervision, (2) the types of questions asked and substantive policy issues raised, and (3) the responsiveness of the ECB as reflected in answers to parliamentary questions. The conclusion problematises the accountability shortfalls of the SSM in relation to the six scenarios of oversight outlined in the theoretical framework (Chapter 3.3.1).

\subsection{BACKGROUND: THE CRISIS AND THE SSM REGULATION}

Before the creation of the SSM, the subject of ECB accountability revolved around its monetary policy functions as the central bank of the Eurozone. From the very beginning, the academic debate on the topic was dominated by the tension between the ECB's high degree of independence and the scope for holding it accountable for its decisions (Curtin 2017; Dawson et al. 2019; Magnette 2000). The political independence of the ECB is constitutionally enshrined in the Treaties and has been consistently implemented since the establishment of the Bank in 1998 (Scheller 2004: 121). Specifically, Article 130 TFEU prohibits the ECB from seeking or taking instructions from Union institutions, bodies, offices or agencies, from any government of a Member State or from any other body'. Moreover, Article 282(3) TFEU specifies that the ECB 'shall be independent in the exercise of its powers and in the management of its finances' and that 'Union institutions, bodies, offices and agencies and the governments of the Member States shall respect that independence'. In contrast to national central banks, whose mandate can be changed through parliamentary majorities, the ECB legal framework can only be altered through Treaty changes and hence the unanimous vote of all EU Member States (De Haan 1997: 413-414). In the official institutional discourse, the ECB does not see its independence as a hindrance to democratic accountability; conversely, the two are often presented as 'two sides of the same coin' - equally necessary to ensure the bank's legitimacy (Cœuré 2017; European Central Bank 2002: 46).

Under the circumstances, the Monetary Dialogue with the EP became the main instrument of political accountability of the ECB. The Monetary Dialogue has three dimensions: (1) the presentation of an annual report of activity before the EP, which triggers a parliamentary resolution in response; (2) the participation of the ECB President in quarterly hearings of the ECON Committee; and (3) the submission of written questions to the ECB by individual MEPs (Fromage and Ibrido 2018: 299-300). Unsurprisingly, public hearings with the ECB President received the most attention. Previous studies 
criticised the generic and sometimes superficial scope of the Monetary Dialogue with the EP, which was focused - especially in the early years - on debating economic and financial policies rather than contesting the performance of the ECB (Amtenbrink and van Duin 2009; Braun 2017: 42; Gros 2004). Moreover, empirical research found that the ECB President often repeats to MEPs the information conveyed in his regular press conferences, which receive more media attention than the Monetary Dialogue (Belke 2017; Claeys et al. 2014). Nonetheless, it is widely recognised that the Monetary Dialogue has improved over the years: MEPs ask questions that are both more frequent and more relevant, while the ECB is generally responsive to their requests (Collignon and Diessner 2016; Eijffinger and Mujagic 2004; Fraccaroli et al. 2018). Overall, the pre-SSM record of the EP as an accountability forum of the ECB is mixed; as the name suggests, the Monetary Dialogue was more a 'dialogue' than an intense 'holding to account' relationship.

It was against this background that the $\mathrm{ECB}$ received additional powers to supervise the banking system in the Eurozone. In fact, the SSM was one of the key institutional reforms adopted at the $\mathrm{EU}$ level in response to the euro crisis (see Chapter 2.1.2). Its rationale was rooted in the way in which the 2008-2009 global financial crisis unfolded in Europe as a sovereign debt crisis: failing banks were 'rescued' by governments using public funds, and then some states were 'rescued' using an EU scheme, thus creating a vicious circle between banks and sovereigns (Schoenmaker and Véron 2016: 6). At the same time, a European system of banking supervision was portrayed as the necessary counterpart to the potential direct recapitalisation of banks through the ESM (Eurozone Summit 2012), although the latter never materialised. Proposed in 2012 by European Council President Herman Van Rompuy, the SSM aimed to integrate supervisory tasks at the EU level in order to 'ensure that the supervision of banks in all EU Member States is equally effective in reducing the probability of bank failure and preventing the need for intervention by joint deposit guarantees or resolution funds' (Van Rompuy 2012: 4).

After the political goal was set, it was quickly decided that the ECB should take over the new task, since the possibility was already foreseen in Article ${ }_{127}(6)$ TFEU. However, there were some concerns over the distributive implications of supervisory decisions and the difficulties of separating a central bank's monetary and supervisory functions (Buiter 2014). Moreover, supervisory decisions could have conflicting objectives in themselves, such as 'financial stability, investor and depositor protection, consumer protection and financial crime' (Alexander 2016: 486). The SSM Regulation clearly prioritised one of these objectives, namely 'the safety and soundness of credit 
institutions and the stability of the financial system within the Union and each Member State' (SSM Regulation, Article 1). Consistent supervision and financial integration are also cited among the main goals of the SSM (European Central Bank 2019). So far, the ECB has not issued a quantifiable operationalisation of these objectives, although several official documents emphasise the need to act as a 'tough and fair' bank supervisor (Nouy 2015).

Once established, the SSM became a complex institutional system involving the ECB and national supervisors of Eurozone Member States - renamed as NCAs. As of December 2020, the ECB is responsible for the direct supervision of 115 so-called significant banks, which together hold almost 82 per cent of the banking assets in the Eurozone (European Central Bank 2020a). Daily supervision is organised into Joint Supervisory Teams (JSTs), led by the ECB and comprising members of NCAs. The tasks of the ECB in the context are clearly delineated: conducting supervisory reviews, on-site inspections, and investigations; granting and withdrawing banking licences; assessing banks' acquisition and disposal of qualifying holdings; ensuring compliance with $\mathrm{EU}$ prudential rules; and setting higher capital requirements ('buffers') in order to counter financial risks (European Central Bank 2019). The remaining banks are known as 'less significant' and continue to be supervised by NCAs, with the ECB taking a back seat. The main decision-making body is the Supervisory Board, composed of six ECB representatives (including the chair and the vicechair) and one representative from the NCA of each participating Member State (SSM Regulation, Article 26).

To balance the expansion of ECB powers in banking supervision, separate accountability obligations were put in place at the political, legal, and administrative levels, hence adding to the already existing accountability toolbox on the monetary policy side of the ECB. In terms of political accountability, the relationship with the EP became central - in a similar way to the already established Monetary Dialogue. Unlike in monetary policy, the ECB was given additional political accountability obligations in banking supervision towards the Eurogroup and national parliaments (SSM Regulation, Articles 20-21). However, interactions with the Eurogroup remain confidential, while visits to national parliaments take place on an ad hoc basis, so it is very difficult to assess their functioning in a systematic manner. By contrast, EP hearings with the Chair of the Supervisory Board and the exchange of documents between the two institutions are public and occur regularly.

The accountability obligations of the ECB towards the EP in banking supervision are detailed in a first-time Interinstitutional Agreement signed between the two institutions (European Central Bank 2013). In line with the SSM Regulation, the obligations entail (1) the publication of an annual report 
on the execution of tasks conferred by the SSM Regulation; (2) participation of the Chair of the Supervisory Board in ordinary and ad hoc public hearings at the ECON Committee and, upon request, in confidential meetings with members of the Committee; (3) the provision of written response within five weeks to written questions sent by MEPs; and (4) the transmission of confidential, annotated records of the Proceedings of the Supervisory Board that allow ECON Members to understand the substance of discussions and decisions taken (Articles 1-4).

The implementation of these obligations needs to be understood in the broader context of parliamentary oversight of executive decisions. To contextualise the case, the next section links parliamentary oversight of ECB supervisory decisions with the principal-agent model. In addition, there is a discussion of the key issues in banking supervision relevant for the EPECB accountability relationship.

\subsection{POLITICAL ACCOUNTABILITY IN BANKING SUPERVISION:}

KEY ISSUES

The relationship between the ECB and the EP in banking supervision is an example of central bank accountability and, more generally, of legislative oversight of an executive agency delegated to fulfil specific functions. In some sense, this is a classic principal-agent relationship in which an authorised principal delegated powers to an agent with the expertise and policy credibility to carry out specific tasks (Majone 1999: 3-4; Strøm 2000). Indeed, the EP contributed to the legal framework that gave the ECB an explicit mandate for banking supervision in the Eurozone. However, the SSM was created by a Council Regulation adopted through a special legislative procedure in which the EP was only consulted - and was thus on the same level as the ECB itself (Amtenbrink and Markakis 2019). While the ECON Committee was closely involved in the legislative process and even gained additional accountability powers in the SSM - as demonstrated by the Interinstitutional Agreement - it cannot accurately be considered the "principal' of the ECB in the field. If anything, the Member States of the Eurozone, acting through the Council, are the main 'principal' of the ECB in banking supervision.

As a result, there are formal limitations to the EP's powers to hold the ECB accountable for its supervisory decisions. If the EP depends on the Council for revising the ECB's mandate in the SSM, then its ability to influence the incentive structure in which the agent operates (through 'contracting') is automatically curtailed. In addition, the SSM Regulation (Article 19) prohibits 
the ECB from taking instructions from other Union institutions. The SSM Regulation specifies that the ECB should exercise the supervisory tasks conferred on it in full independence, in particular free from undue political influence' (Recital 75; see also Article 19). This means that any recommendations made by the EP in its 'Resolutions on the Banking Union-Annual Reports' might have an informal impact on supervisory conduct but do not constitute formal mechanisms to sanction the ECB because parliamentary resolutions are never legally binding. On the plus side, the EP can veto the appointment of the Chair and Vice-Chair of the Supervisory Board and approve the dismissal of the former in case of poor performance or serious misconduct (SSM Regulation, Article 26). In addition, the ECB has the obligation to "cooperate sincerely with any investigations by the European Parliament, subject to the TFEU' (SSM Regulation, Article 2O(9)). Otherwise, there is a clear focus on accountability though monitoring and justification: the ECB has regular reporting obligations towards the EP, while MEPs can ask questions and pass (non-binding) judgement in their reports and resolutions (Interinstitutional Agreement, Article 1-4).

Furthermore, the accountability challenges faced by the EP and the ECB in banking supervision reflect basic principal-agent expectations. Most significantly, there are problems of ( 1 ) asymmetric information, as the ECB is an expert body possessing much more knowledge than the EP in the field of banking supervision, and (2) hidden action, given that ECB supervisory decisions remain unseen by MEPs (Strøm 2000: 270). Banking supervision is a highly technical area that requires financial, legal, and accounting expertise; moreover, there are strict confidentiality requirements that prevent the disclosure of sensitive supervisory data and decisions (Angeloni 2015). However, the risk of 'agency drift' - the ECB diverging from its mandate - is not the same as in monetary policy. The first difference lies in the selection procedure, as the EP can veto the appointment of the Chair of the Supervisory Board, but the same cannot be done for Members of the ECB Executive Board (Fromage and Ibrido 2018: 296). The second difference concerns the nature of the mandate in banking supervision, where the ECB has to apply secondary law (ter Kuile et al. 2015: 167-168). By contrast, in monetary policy, the ECB is free to decide and implement its preferred policy instruments within the confines of the Treaty (especially Articles 119 and 123 TFEU). This means that banking supervision leaves limited room for discretion in comparison to monetary policy. The SSM legal framework is elaborate, based on international regulatory standards (Basel III), which were translated into EU legislation through the Capital Requirements Directive IV (CRD IV) and the Capital Requirements Regulation (CRR). The ECB is responsible for enforcing 
these rules, which again are subject to change by the co-legislators, that is, the EP and the Council. The dynamic allows the EP to act as a classic oversight body, checking whether ECB actions deviate from legislative intent.

In terms of substance, the most contentious accountability issue in banking supervision refers to the transparency of supervisory decisions and bank-level information. Here, there is a huge gap between American and European practices regarding the disclosure of financial supervisory data, as the latter is traditionally more inclined towards confidentiality (Gandrud and Hallerberg 2018: 1029). The reasons for secrecy concern legality, trust between the supervisor and the supervisee, and financial stability at large. Legally, EU bank supervisors are not allowed to disclose information that would endanger the competitive position of a credit institution on the market (Directive 2003/ 6/EC on insider dealing and market manipulation). In relation to trust, banks are more likely to share sensitive information with the supervisor if they are confident that this will be treated confidentially. From the perspective of financial stability, liquidity problems at a bank can trigger bank runs and panic in the population (Angeloni 2015). Conversely, the arguments for transparency are more general: transparency is a pre-condition for accountability that increases the legitimacy of the supervisors by allowing accountability forums to judge whether the supervisor is acting in the public interest. Moreover, transparency reduces the scope for arbitrary decisions and creates stable expectations that incentivise banks to adhere to regulations (Liedorp et al. 2013: 311).

In the Interinstitutional Agreement with the ECB, the EP consented to balance accountability obligations with secrecy requirements (Article 5). Accordingly, MEPs can read a non-confidential version of Records of the Proceedings of the Supervisory Board, which are summaries of discussions after each meeting. In addition, there are confidential 'in camera meetings' that take place before hearings of the Chair of the Supervisory Board at the ECON Committee. These are meetings between the coordinators of all political groups, the ECON Chair and Vice-Chairs, and the Chair of the Supervisory Board, who work on organising the agenda of public hearings. ${ }^{13}$ These encounters are reported to be much more confrontational than public hearings, with 'tough' language that is often absent in public interactions between the two institutions. ${ }^{14}$ But the downside of confidential accountability

13 ECON Committee Chair Roberto Gualtieri sometimes refers to 'meetings at the coordinators' level' in his announcements at the beginning of public hearings.

14 Information about ECON in-camera meetings was shared during the closed workshop "Contesting the Incontestable: The "Post-Crisis" Accountability of the European Central Bank' held on 8 October 2018 at the Hertie School of Governance in Berlin, Germany. 
is the suspicion that there is something to hide; after all, how can the public be sure that the ECB is being held accountable behind closed doors? The same problem is found in the accountability interactions between the ECB and the Council in banking supervision: formally, the provisions of the Interinstitutional Agreement are mirrored in a Memorandum of Understanding signed in 2013 between the ECB and the Council, more specifically the Eurogroup. However, exchanges of views and questions from national finance ministers remain confidential, in line with Eurogroup practices (Puetter 2006). It is thus impossible to evaluate their accountability relationship other than to say that the Chair of the Supervisory Board participates in Eurogroup meetings at least twice per year, when they appear to discuss the same topics as in hearings at the ECON Committee (Council of the European Union n.d.).

Two final issues further complicate the scope for political accountability of the ECB in banking supervision. On the one hand, the SSM is part of a banking union that is still work-in-progress. Several legislative dossiers amending or seeking to complete the banking union are currently under review, which means that the framework of rules in which the ECB operates remains in flux (Council of the European Union 2018a). On the other hand, the banking union is a complex arrangement spread over several institutions: the EBA (in charge of banking regulation), the ECB (responsible for banking supervision), and the $\mathrm{SRB} /$ the Commission (in charge of banking resolution) (Council of the European Union 2018b). In addition, the ECB is part of a layered supervisory system in which it acts in coordination with domestic supervisors, the NCAs. This means that the ECB functions in a changing environment where the division of competences is difficult to disentangle. Holding the ECB accountable as a bank supervisor is bound to be complicated from the outset.

Having established the main parameters of political accountability in the SSM, the next section turns towards the analysis of oversight interactions between the EP and the ECB in banking supervision in the early years since the establishment of the SSM. Considering the accessibility of documents, the analysis is based on transcripts of public hearings and letters exchanged between the two institutions in the framework of their accountability relationship. The analysis follows the Q\&A approach to legislative oversight (outlined in Chapter 3.3) and is divided into three parts, covering (1) the frequency of interactions and profile of questioners, (2) types of questions addressed by MEPs, and (3) types of answers provided by the ECB on banking supervision.

According to Chatham House Rules, the identity or affiliation of the speakers cannot be revealed, unless the participants explicitly consented to be cited anonymously. 


\subsection{OVERSIGHT INTERACTIONS: MAIN FINDINGS}

The SSM Regulation was adopted in October 2013, giving the ECB one year to prepare for taking over banking supervision in the Eurozone. The dialogue with the ECON Committee started right away, while the first Chair of the Supervisory Board, Danièle Nouy, took office in January 2014. The analysis below covers the period from October 2013 to April 2018 and includes 283 written letters exchanged between the two institutions and 13 public hearings of the Chair of the Supervisory Board at the ECON Committee. ${ }^{15}$

Figure 4.1 offers an overview of the letters identified in the period under focus. Overall, the ECB used 123 documents to answer 150 letters sent by MEPs in the SSM framework. There are two reasons why the number of letters with questions does not correspond to the number of letters with answers published by the ECB. First, letters sent at the end of the calendar year are answered early in the new year, so there is never an equivalence between the numbers of documents exchanged per year. Second, the ECB has the practice of using one document to answer multiple letters sent by the same $\operatorname{MEP}(\mathrm{s})$. This is not to say that individual questions go unanswered, but that one

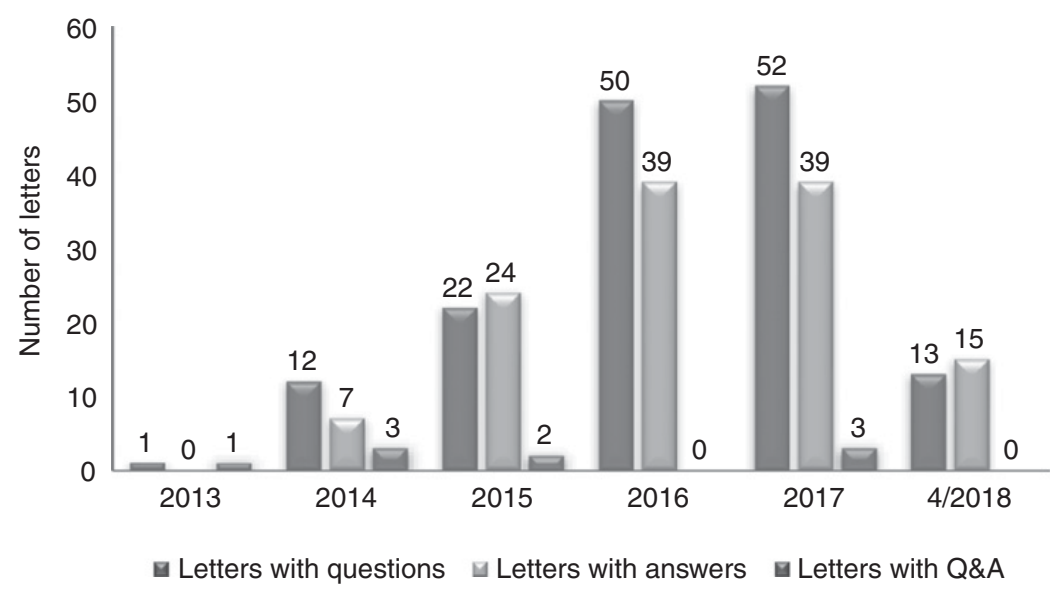

FIGURE 4.1 Overview of letters exchanged between the EP and the ECB on banking supervision (October 2013-April 2018). Total letters identified: 283

15 All documents and videos were retrieved from the official websites of the EP and the ECB, respectively. Videos of public hearings were transcribed manually with helpful research assistance from Evgenija Kröker. 
document can contain multiple answers. At the same time, seven ECB letters simply followed up on questions raised during hearings at the ECON Committee. In addition, three documents included both questions and answers addressed by Members of the ECON Committee to ECB President Mario Draghi before the appointment of the first Chair of the Supervisory Board.

Furthermore, there have been 13 public hearings of the ECB at the ECON Committee during the period January 2014-April 2018, after the first Chair of the Supervisory Board was appointed. Figure 4.2 provides an overview of the type of hearings taking place in the period under focus. Ordinary hearings as well as hearings on the SSM annual report make the bulk of the data. In terms of format, hearings usually last between 90 and 120 minutes and follow a specific structure, starting with (1) welcome announcements by the ECON Chair, followed by (2) an introductory statement by the Chair of the Supervisory Board, and then moving to (3) questions and answers (Q\&A) from MEPs. In line with the EP's Internal Rules of Procedure (European Parliament 2017e), speaking time is allocated in order of the size of political groups and in proportion to their total number of members (Rule 162 for the 8th parliamentary term).

Using the qualitative data analysis software ATLAS.ti, each single topic question and corresponding answer have been manually coded in line with

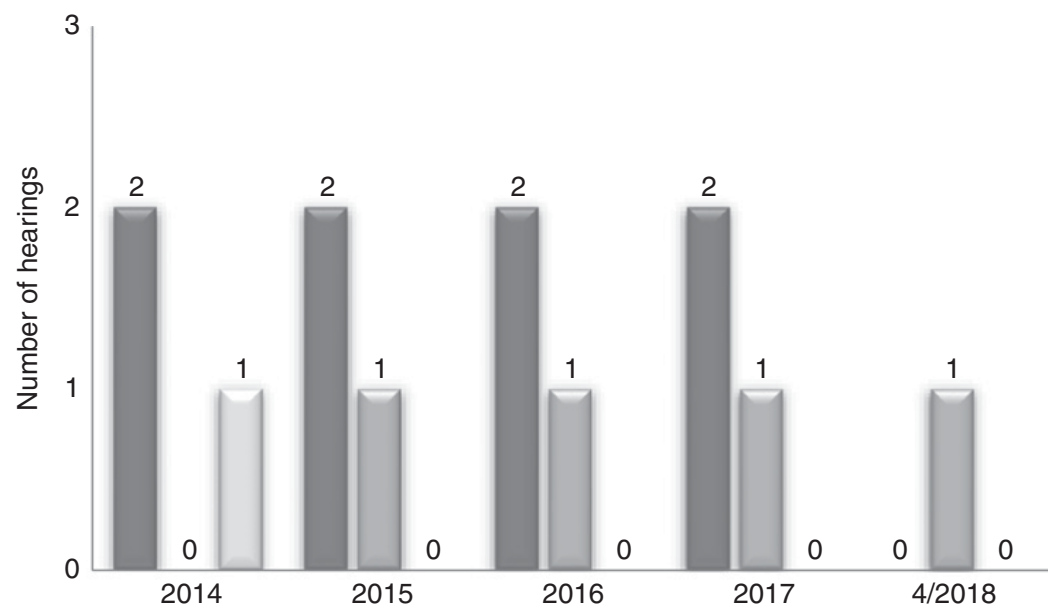

$\square$ Ordinary hearings $\square$ Hearings on the annual report $\square$ Exchanges of views

FIGURE 4.2 Public hearings of the ECB at the EP's ECON Committee in the SSM framework (January 2014-April 2018) 
the analytical approach outlined in Chapter 3.3. Overall, MEPs asked 337 single-topic questions in writing - posing on average 2 questions per letter. In parallel, during hearings, MEPs asked on average 28 questions per session, bringing the total to 369 questions in the period under consideration.

Having established the number of questions raised by the EP to the ECB on banking supervision, the next relevant aspect concerns the profile of MEPs who ask questions.

\subsubsection{Profile of Questioners}

Who are the MEPs who ask questions of the ECB on banking supervision? In respect of letters, the majority are sent by individual or groups of MEPs from the ECON Committee, although there were four questionnaires sent by the ECON Chair on behalf of the entire committee and one letter sent by the EP President. All political groups sent letters to the ECB on banking supervision, regardless of their size in the EP. As the period under focus overlaps with the 8th parliamentary term (2014-2019), the following political groups were identified (in order of size): the EPP, the S\&D, the European Conservatives and Reformists Group (ECR), the Group of the Alliance of Liberals and Democrats for Europe (ALDE), the Greens/European Free Alliance (Greens/EFA); the Confederal Group of the European United Left-Nordic Green Left (GUE-NGL); Europe of Freedom and Direct Democracy Group (EFDD); and Europe of Nations and Freedom (ENF).

Figure 4.3 captures the nationalities of MEPs asking questions of the ECB on banking supervision in the period under focus. Each MEP is only counted once, regardless of how many questions are posed in a letter. Out of the total 150 letters, 24 letters have multiple authors among MEPs of different nationalities. Overall, most letters are sent by MEPs from Portugal (23\%), Germany $(21 \%)$, Italy (18\%), and Spain (16\%). When it comes to the content of questions, the national affiliation of MEPs matters more for some members than others: for instance, MEPs from Portugal, Spain, Ireland, and Greece tend to ask questions regarding their own Member States. The others ask more general questions that go beyond their national context, although they also inquire about specific situations in their national or regional constituencies.

In terms of political affiliation (Figure 4.4), the most active groups were GUE-NGL (24\%), the Greens/EFA (17\%), the EPP (16\%), and the S\&D $(14 \%)$. When letters have multiple authors, they are grouped together by political group. It is important to mention that MEPs from S\&D and ALDE tend to send letters in large groups: for example, 30 MEPs from S\&D sent 10 letters, while 20 MEPs from the ALDE sent 5 letters. This means that the 


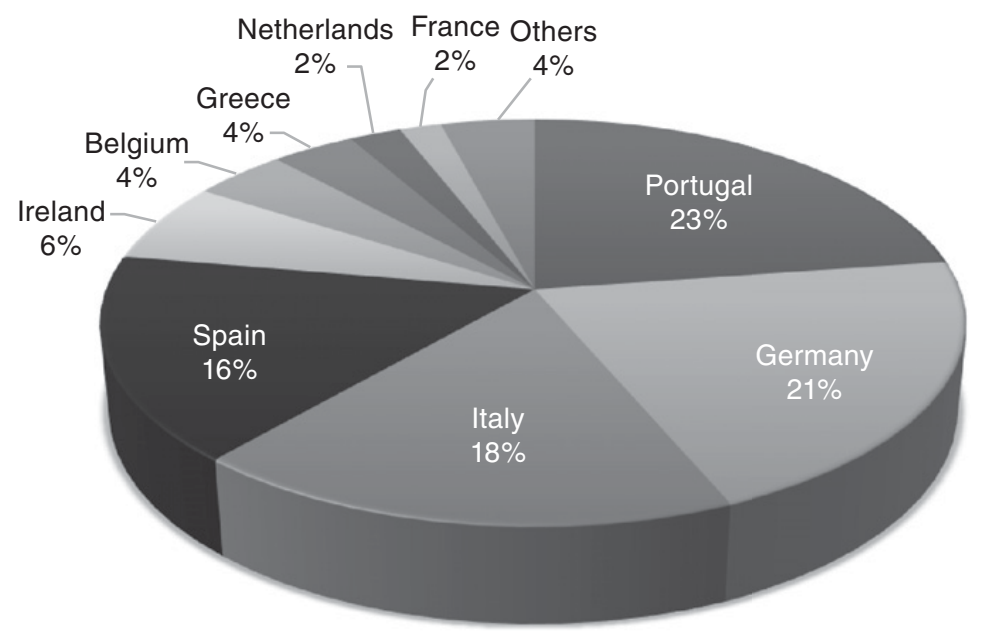

FIGURE 4.3 Nationality of MEPs sending letters with questions to the ECB on banking supervision (October 2013-April 2018). Total: 220 MEPs identified in 150 letters

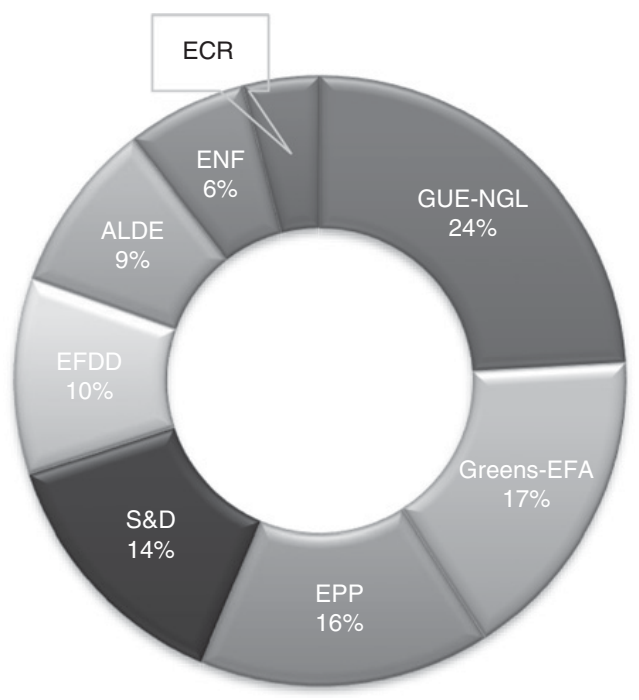

FIGURE 4.4 Political affiliation of MEPs sending letters with questions to ECB on banking supervision. Total: 220 MEPs identified in 150 letters 
contribution of smaller groups such as GUE-NGL and the Greens/EFA is underestimated: they send more individual questions to the ECB than larger political groups. A similar dynamic has been found in relation to written questions addressed by MEPs to the ECB in monetary policy (Fraccaroli et al. 2018: 60). Since smaller political groups get less time for questions during committee meetings, letters are a way to compensate for the deficiency, allowing smaller groups to be equally active in oversight. However, the ideological position of MEPs also plays a role, as the two most active political groups in written letters - GUE-NGL and the Greens/EFA - are on the left of the political spectrum.

Moving to public hearings, the breakdown of MEPs asking questions by political group and nationality looks different. In respect of nationality (Figure 4.5), German MEPs are leading in public hearings (speaking 23 per cent of the time), followed by MEPs from France (13 per cent), and Italy and Spain (12 per cent each). Keeping in mind that the MEPs who take the floor in public hearings are often the coordinators of political groups in the committees, the statistic is a reflection of the nationality of several ECON Committee coordinators in the 8th parliamentary term for the largest groups, for example, Burkhard Balz (Germany, EPP), Pervenche Berès (France, S\&D), Sylvie Goulard (France, ALDE), and Sven Giegold (Germany, the Greens/EFA). Italian MEPs were also consistently active, especially through the contributions of Marco Zanni (EFDD/ENF) and Marco Valli (EFDD).

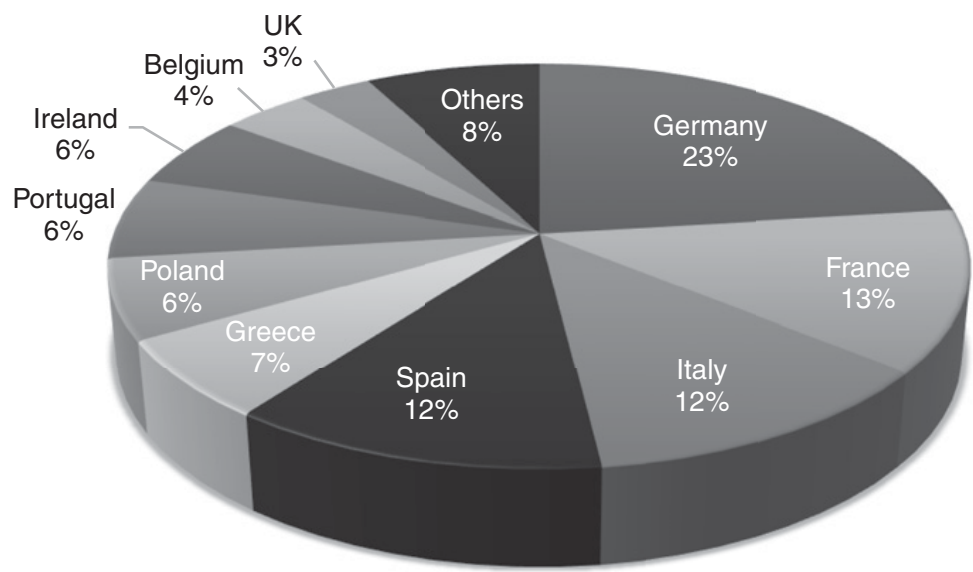

FIGURE 4.5 Nationality of MEPs taking the floor during public hearings of the

Chair of the Supervisory Board. Total MEPs identified (counted once per session): 156 


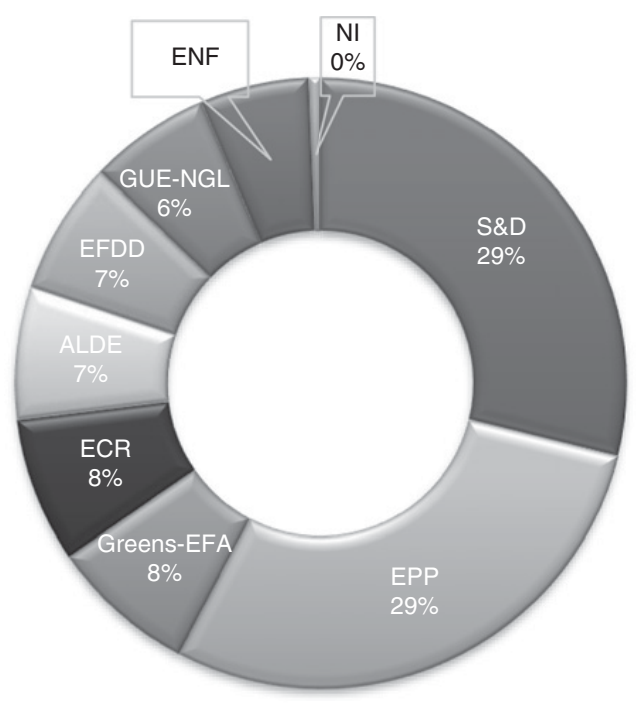

FIGURE 4.6 Political affiliation of MEPs taking the floor during public hearings with the Chair of the Supervisory Board. Total MEPs identified (counted once per session): 156

In respect of political affiliation, the EP's Rules of Procedure automatically incline the balance towards larger groups (see Figure 4.6). Accordingly, MEPs from the two largest political groups in the 8th parliamentary term - the EPP and the S\&D - took the floor most often (each 29 per cent of the time). They were followed by MEPs from the ECR and the Greens/EFA (each 8 per cent of the time). By comparison, smaller political groups get limited speaking time during public hearings, in line with the proportion of their seats in each parliamentary term.

Overall, we can observe that MEPs interact frequently with the ECB in the framework of the SSM, both in writing and in person through hearings. Members from smaller political groups on the left (GUE-NGL and the Greens/EFA) tend to send more written questions, while the largest groups (EPP and S\&D) dominate the public hearings. In terms of nationality, there is a correlation between the size of a Member State and the number of questions sent by their MEPs, although there are exceptions, for example, Portugal. This is directly related to the problems experienced by Portuguese banks in the period under focus, although by the same logic, we would have expected more questions from Greece - which has the same number of MEPs. The data does not clarify why MEPs from certain Member States tend to be more active; 
ultimately, this is an empirical question related to the parliamentary tradition of each country and the personal record of MEPs during their term.

In terms of the theoretical expectations outlined in Chapter 3.3.2, the high number of political groups allowed to ask questions and the absence of a government-opposition dynamic vis-à-vis the ECB is bound to limit the strength of parliamentary questions. As MEPs represent a variety of political and national interests, it is by default more difficult to coordinate legislative oversight and ask pointed questions of executive actors. The problem is illustrated in the next section.

\subsubsection{Types of Questions}

Moving to the subject of oversight, the analysis identified a total of 706 singletopic questions and a corresponding number of answers in both letters and hearings. Following the analytical framework outlined in Chapter 3.3, parliamentary questions were categorised along four types of requests - for information, justification, change of decisions/conduct, and sanctions. Simultaneously, it was possible to distinguish between questions asked for the first time (initial questions) and questions on which MEPs followed up because they were dissatisfied with the original answer (follow-up questions). Given the procedural limitations to asking follow-up questions in EP committees, the analysis grouped together questions on the same issues - even if they were asked by different MEPs. Despite this extension, the number of follow-up questions remains lower, suggesting that MEPs have diverse interests and do not systematically coordinate their oversight of the ECB in banking supervision. Figure 4.7 offers an overview of the types of questions identified in the period under focus.

There are several observations coming out of the figure. First, there is a fifth category of questions that falls outside the scope of oversight interactions. This refers to 'requests for policy views' - present in 111 out of the 706 total questions. Such requests typically include demands for the ECB's expert opinion on ongoing legislative files or issues relevant to Member States domestically. While it makes sense for MEPs to consult the ECB on their legislative activity, this can be done separately and not filed under accountability. In fact, the ECB is formally consulted on proposed EMU legislation more generally (European Central Bank 2021b). Requests for policy views cannot be considered a form of oversight because they do not concern the past activity of the ECB in terms of decisions or conduct. Conversely, they typically refer to the future legal framework of the banking union. Requests for policy views are more common during hearings ( 22 per cent of all questions asked) 


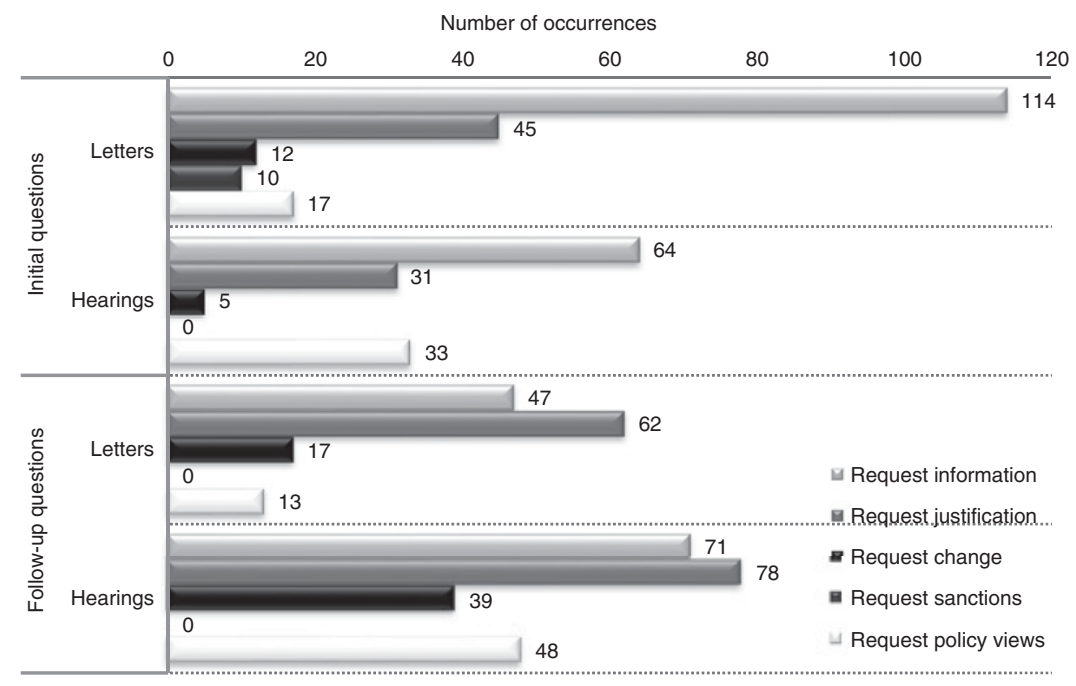

FIGURE 4.7 Types of questions asked by MEPs of the ECB on banking supervision (October 2013-April 2018). Total identified: 706

than in letters (8.9 per cent of all questions sent), with the additional observation that rapporteurs on legislative proposals are most likely to use hearings with the Chair of the Supervisory Board to ask for input on files within their purview. From this perspective, it appears that a fifth of all questions in hearings are wasted on issues that have nothing to do with accountability. ${ }^{16}$

Furthermore, the most prevalent types of questions in both letters and hearings are requests for information (49.7 per cent overall) and justification of conduct (36.3 per cent overall). This is not surprising, considering the institutional independence of the ECB and the lack of political mechanisms to demand changes of decisions or impose sanctions (see Section 4.2). Moreover, since the SSM was only established in 2013-2014, many questions addressed the internal organisation of the ECB in banking supervision and the 2014 comprehensive assessment. However, the most popular subject of questions by far refers to the situation at specific banks under the direct or indirect supervision of the ECB (Figure 4.8).

16 According to the ECB, these questions are not in fact wasted because the ECB can 'provide important advice on financial legislation and it is in the interest of both EP and the ECB to exchange frequently also on such policy issues, even if this is not strictly speaking a discharge of accountability'. These comments were made by an ECB official at a closed workshop on ECB accountability held on 8 October 2018 at the Hertie School in Berlin (Chatham House rules). 


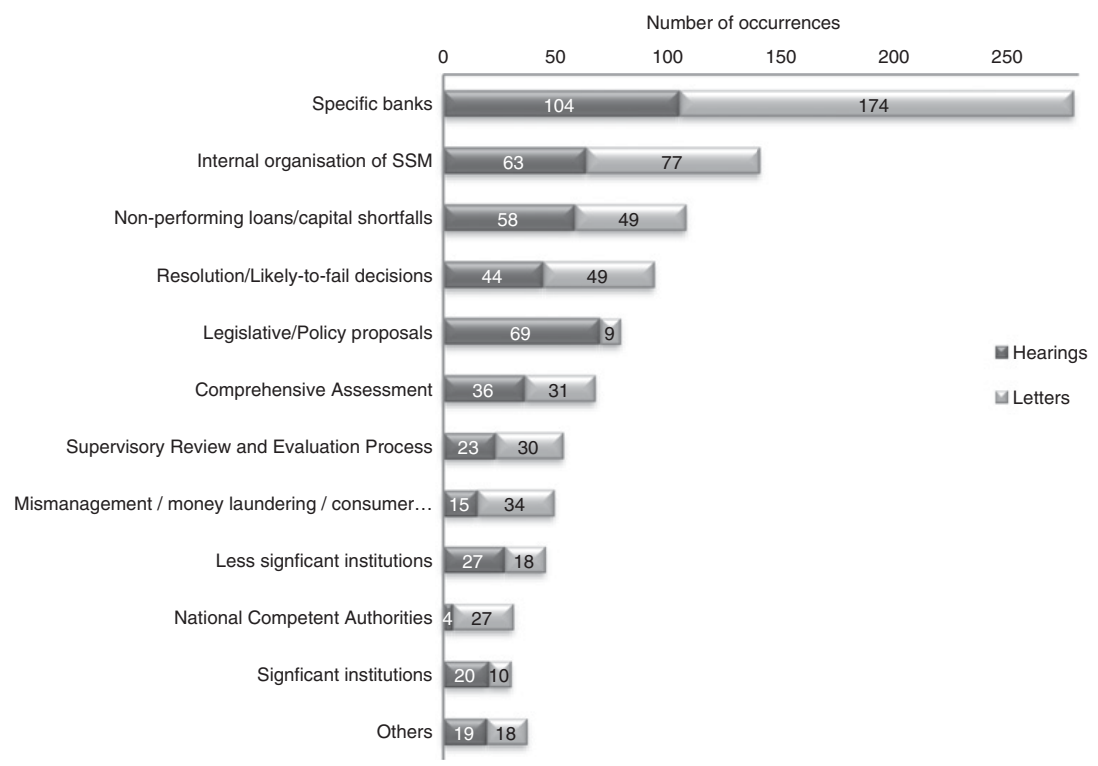

FIGURE 4. 8 List of topics raised in hearings and letters to the ECB on banking supervision (October 2013-April 2018). One question can have one or two codes. Total codes assigned: 1,009 for 706 questions

Banks that attract the most attention are usually those that performed poorly in stress tests and had a high level of non-performing loans (NPLs), such as the Italian banks Monte dei Paschi di Siena, Banco Populare de Vicenza, and Veneto Banca. Other examples include banks that were formally declared failing or likely to fail (FOLTF) (e.g. the Spanish Banco Popular) or alternatively were considered to receive preferential treatment in stress tests (e.g. the German Deutsche Bank). MEPs also ask many questions about the resolution of less significant institutions (e.g. the Portuguese bank Banif) or the recapitalisation of state-owned significant banks with the approval of the Commission (e.g. the Portuguese bank Caixa Geral de Depósitos). Unsurprisingly, these are also the banks that are most often mentioned in press reports regarding the performance of the SSM. However, given the professional secrecy requirements laid down in the Interinstitutional Agreement between the EP and the ECB and in the CRD IV, the ECB 'cannot comment on the interactions with individual supervised institutions or on the supervisory measures taken with regard to them' (Nouy 2016a). There is thus a tension between the issue that MEPs care most about - the next one is 'SSM internal organisation' (see Figure 4.8) - and the likelihood that they will 
receive the information they publicly seek. Holding the ECB accountable in banking supervision is bound to be limited from the outset.

Moreover, follow-up questions are more likely to occur in hearings (65.3 per cent of all questions) than in letters (41 per cent of all questions raised). This happens because some hearings have a central topic that dominates the Q\&A session. In the period under focus, there were three instances of hearings with 'heated' debates: (1) in November 2016, in relation to the methodology of stress tests and the alleged preferential treatment of Deutsche Bank thereof; (2) in June 2017, on the recent decision to declare Banco Popular FOLTF; and (3) in November 2017, when MEPs contested the draft Addendum to the ECB Guidance on NPLs (the Addendum) as overstepping the institution's mandate (see below).

The Deutsche Bank case received a lot of attention in both oral and written questions. In short, the problem was that in the 2016 stress test, the ECB accepted in the assessment of Deutsche Bank the sale of its stake in the Chinese bank Hua Xia, even though the transaction was going to be completed at the end of the year and the stress test took place in the summer. There were nine letters asking the ECB for the reasoning behind its agreement to 'bend the rules' for Deutsche Bank. The questions share common ground, as MEPs referenced or copied text directly from a Financial Times article reporting the ECB's preferential treatment in this case (Noonan et al. 2016). The Chair of the Supervisory Board defended the decision, explaining that the conclusion of the transaction was regarded as a mere formality (it was concluded by the end of the year). In addition, Deutsche Bank formally requested the exception; by comparison, other banks claiming to be in a similar position did not request such an exception. In response to the nine letters, the ECB provided an almost identical text, with large portions of the reply copy-pasted from the first answer offered. Judging from the follow-up questions in the November 2016 hearing, many MEPs did not accept the ECB's answers as valid. The point here is that MEPs are eager to challenge ECB supervisory decisions, but there are only a few cases in which they have the background information and knowledge to do so.

The case of the Addendum also deserves further attention - not least because it was the subject of a letter sent by the EP President to the ECB. This is also the main clear-cut example of MEPs demanding concrete changes to the ECB's conduct. The Addendum aimed to address one of the most persistent and controversial problems in banking supervision, namely how banks should deal with high levels of NPLs on their balance sheets. The document was designed to supplement the earlier ECB Guidance on the matter by specifying minimum levels of prudential provisions for new NPLs 
starting 1 January 2018 (European Central Bank 2017). Several Members of the ECON Committee, after asking the opinion of the EP's Legal Service, challenged elements of these supervisory expectations as ultra vires because they effectively introduced additional obligations for banks beyond the current regulatory framework. At the same time, MEPs considered that the ECB did not give legislators and the public sufficient time to provide feedback on the Addendum, as its date of entry into force was less than three months from the publication of the draft version. Nouy acknowledged during the hearing that the phrasing of several provisions could be improved, as the meaning seems to have been misunderstood from what the ECB had intended. One example is the so-called comply or explain mechanism, criticised for inverting the burden of proof from the supervisor to the supervised bank, with the implication that banks would become responsible for showing that their provisioning level was adequate instead of the supervisor demonstrating that it was inadequate. This was changed in the revised version of the Addendum, whose date of entry into force was also postponed to 1 April 2018 (European Central Bank 2018: 7). The case is an example of the effective performance of the EP as an accountability forum when there is a clear, coordinated agenda about what to ask from the $\mathrm{ECB}$ on banking supervision. The pressure put by MEPs asking questions on the same issue, even if sometimes they were repeated, is something to bear in mind for improving future hearings of the ECON Committee.

Overall, the questions asked by MEPs to the ECB on banking supervision paint a layered picture of the EP's performance as an accountability forum. At the outer layer, the track record of MEPs in holding the ECB accountable is underwhelming: too often their questions demand policy views or contest issues that the ECB cannot fully address due to the legal framework to which the EP contributed. But the inner layer brings nuance to the picture: there are structural problems - especially confidentiality requirements - that make it difficult for MEPs to receive answers to the questions they find important. The next section shifts the attention from the accountability forum to the actor, examining the ranges of answers provided by the ECB on banking supervision.

\subsubsection{Types of Answers}

The ECB is legally required to reply to written and oral questions from MEPs in the framework of their accountability relationship in the SSM. However, there is a difference between answering questions as a procedural requirement and engaging with the substance of the issue raised. Requests for policy views are almost always answered fully: as a specialised public body, the ECB is happy to share its expertise on different matters of banking supervision. 
However, for the purposes of legislative oversight, what matters are answers to requests $\mathrm{A}-\mathrm{D}$, which are discussed in the next pages.

Figure 4.9 lists the number of answers identified as explicit replies, intermediate replies, and non-replies in the period under investigation. At first sight, the overview of answers shows the high responsiveness of the ECB to EP oversight. On the whole, the ECB provides explicit replies in response to almost two thirds of all questions received in the SSM framework (429 out of 706 answers), showing the willingness of the institution to engage with the questions raised by MEPs. However, when calculated as a percentage of all questions (excluding the irrelevant requests for policy views), answers that count as explicit replies only make up 47.45 per cent of the total. Figure 4.9 shows the breakdown of ECB answers in both letters and public hearings.

When it comes to explicit replies (identified 429 times), most answers provide information (33.1 per cent) or justification of conduct (35.4 per cent). In relation to questions of type A, explicit replies (142 overall) can offer full information about decisions (policy transparency) or decisionmaking processes (procedural transparency). In response to questions of type $\mathrm{B}$, there is a clear tendency for the ECB to justify its conduct or explain the rationale behind decisions (on 152 occasions). Although there are fewer explicit replies given in response to type-C questions (8.6 per cent), the number is consistent with the total amount of requests for change (10.3 per cent of all

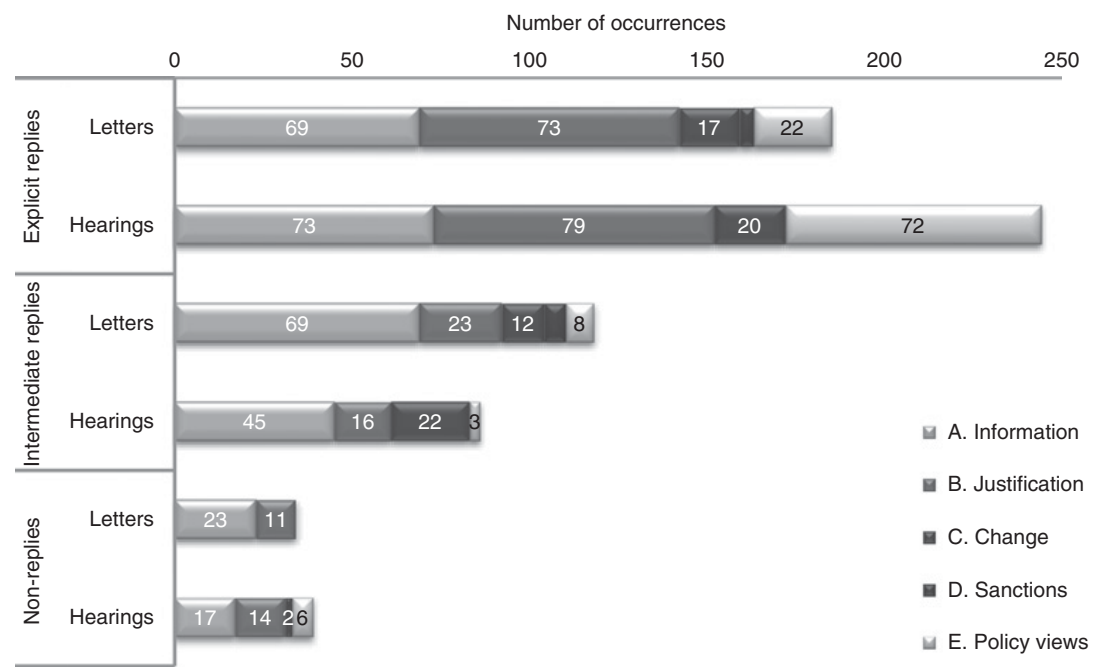

FIgURE 4.9 Types of answers provided by the ECB on banking supervision to MEPs, in numbers (October 2013-April 2018). Total answers identified: 706 
questions). In respect of sanctions, these were no longer necessary in three instances (because the responsible parties had already resigned), while on one occasion, the ECB rejected the need for sanctions.

The next category includes intermediate replies (identified in 204 instances), where the majority of answers (55.9 per cent) addressed requests for information. One example is partial or incomplete answers which engage with some elements of the question raised or talk about the topic in general terms, without going into specifics. Other types of intermediate replies promise to provide information or justification of conduct at some point in the future, based on ongoing developments. The answer is legitimate but dependent on follow-up questions that may or may not be raised by MEPs. Finally, intermediate replies can acknowledge the topic of a question but claim the ECB's lack of competence on the matter and refer the EP towards another actor deemed responsible (see discussion on equivocation below).

The final category of answers is made of non-replies and was identified on 73 occasions. Non-replies are answers in which the ECB avoids or openly refuses to respond to issues raised by MEPs. Here, there is a difference between written and oral questions, as the lack of answers in letters is supported by confidentiality requirements of the SSM legal framework, while non-replies in hearings are an example of evasion - that is, not addressing the substantive point of a question. In the case of the latter, it is difficult to identify ill-intent: most often, the Chair of the Supervisory Board simply spends more time covering one question and does not have time for the others.

Having established the main types of replies provided by the ECB on banking supervision, the next step is to examine how they engage with parliamentary questions from MEPs. Figure 4.10 illustrates the categories of answers given through 'rectification', 'justification', and 'equivocation' in the period under focus. The first observation coming out of the table is that the ECB rarely changes its conduct in response to demands from MEPs; in fact, the only instance when the Chair of the Supervisory Board engaged with requests for policy change coming from MEPs concerned the Addendum (see Section 4.3.2). During hearings at the ECON Committee, the Chair of the Supervisory Board acknowledged the lack of clarity regarding the Addendum's 'comply-or-explain' mechanism and considered the possibility of postponing the document's entry into force. This was, however, an isolated case (present in 24 partial answers). Conversely, the majority of questions addressed to the ECB on banking supervision are answered through justification, providing full or partial information about a particular issue, explaining the rationale of decisions, or defending the appropriateness of a measure. The proportion of 


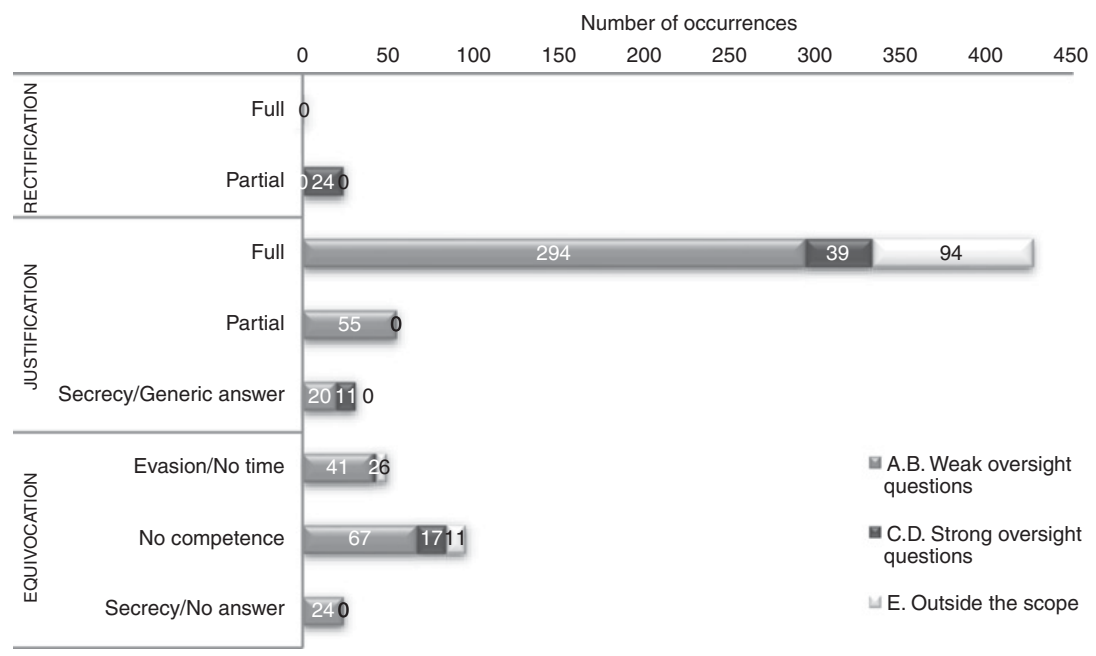

FIGURE 4.10 Responsiveness of the ECB on banking supervision to MEPs in both letters and hearings (October 2013-April 2018). Total answers identified: 706

answers marked as 'full' as opposed to 'partial' justification (427 vs 55) speaks to the engagement of the ECB with parliamentary questions.

What are the questions that go unanswered? Equivocated replies are answers that do not offer MEPs substantive responses to the questions they raised. There are three categories of replies identified here. First, there are generic answers that come across as evasion or questions not answered due to time considerations, which were identified on 49 occasions. These correspond to non-replies in Figure 4.9 and have been discussed above. Second, intermediate replies that claim 'lack of competence' are usually seen as problematic in accountability studies because they suggest the passing of responsibility from one executive actor to another (Hood 2010). On banking supervision, such answers occur when the ECB claims that certain issues are within the purview of NCAs or lie outside its mandate in banking supervision (95 in total). These answers are given in response to questions on (1) the methodology of stress tests, especially the choice of adverse scenarios, for which the EBA and the European Systemic Risk Board are responsible; (2) the resolution process of specific banks, where the SRB and/or the European Commission have competence; (3) issues of consumer protection - especially concerning unfair practices of banks - where national bodies have jurisdiction; and (4) cases of financial misconduct and money laundering in different member states, where national authorities are also the competent institutions. 
The high frequency of such questions is the result of the intricate multilevel framework of the banking union, where the division of tasks is spread across many institutions at different levels of governance. Separating bank regulation (EBA) from bank supervision (ECB) and bank resolution (the SRB and the Commission) created overlapping areas of activity that remain difficult to disentangle from an accountability perspective. At the same time, the fact that the SSM mandate is limited to prudential supervision and hence does not include matters such as consumer protection or money laundering additionally complicated matters because it restricts the range of issues for which the ECB can be held accountable. It is difficult to establish whether MEPs ask questions outside the ECB's supervisory competence unknowingly or on purpose - because they are important to their constituencies. As a general pattern, it seems that many MEPs base their questions on current financial news in the national or international media, which suggests an interest in politically salient issues that is disconnected from considerations of the relevant competent authority.

Nonetheless, not all cases are straightforward when it comes to the ECB's lack of competence. For instance, in the first report on the functioning of the SSM, the Commission discretely criticised the ECB for pointing the finger at the EBA regarding the flaws of stress tests methodologies, keeping in mind its own responsibility for the quality of the process (European Commission 2017). Another relevant example concerns the Portuguese bank Banif, a less significant institution under the supervision of Banco de Portugal, which was put into resolution in December 2015. The controversy concerned the ECB's approval to limit Banif's access to Eurosystem liquidity prior to the announced decision that the bank was FOLTF, as well as the involvement therein of ECB Vice-President Vítor Constâncio, who was the former Governor of Banco de Portugal. In the following year, Portuguese MEP Nuno Melo (EPP) sent 12 letters to the ECB demanding information and justification of conduct about the ECB's role prior to and during the FOLTF decision-making process (European Parliament 2016f). On the supervisory part, the SSM Chair repeatedly invoked lack of competence and directed the MEP towards Banco de Portugal as the 'right addressee' for the questions (Nouy 2016b). The point here is that the banking union established a convoluted system: it is not always clear who bears responsibility for specific actions or how to differentiate 'real' lack of competence from passing the buck from one institution to another.

The other type of equivocated answer that deserves close attention refers to non-replies given on confidentiality grounds, present on 24 occasions. Such answers concern questions that require information or justification of decisions regarding a specific supervised bank. In the early years, the ECB would 
address such requests by invoking its confidentiality regime and offering no answer whatsoever. Over time, the SSM Chair started to provide general considerations about the bank in question and what the ECB did under similar circumstances for any supervised bank. This allowed an answer to be provided without revealing what is considered sensitive supervisory information on specific banks. Such instances are marked in Figure 4.10 as 'justification' - invoke 'secrecy generic answer' in order to distinguish them from replies where no answer was given at all (illustrated under 'equivocation invoke secrecy'). When confronted with questions about the legitimacy of the ECB secrecy regime, the Chair of the Supervisory Board answered as follows:

These [confidentiality] requirements, as adopted by the European EP and/or the Council of the European Union, form the cornerstone of the legal supervisory framework under which European banking supervision operates. They are aimed at instilling confidence in credit institutions that the banking supervisor will treat their sensitive information appropriately. This is essential for an open supervisory dialogue and thus an important basis for effective banking supervision. (Nouy 2017)

Invoking confidentiality requirements means that parliamentary questions are dealt with expediently and unsatisfactorily from the perspective of an accountability forum. While some MEPs ask multiple rounds of questions about the same bank, they give up at some point and move on to different issues - aware that there is nothing they can legally do to force the ECB to provide public information or justification.

The importance of the secrecy regime is interpreted differently by the ECB. According to one official, "what is observable by the public is the nonconfidential part. But there are several possibilities to exchange [information] on a confidential basis', such as the routine in-camera meetings before hearings of the Chair of the Supervisory Board or the (as-yet-unused) formal confidential oral discussions and inquiry committees. Moreover, from the perspective of the ECB, such questions remain important even if they cannot reply with bank-specific information: 'On the one hand, it helps us understand the thinking of MEPs and on the other hand it may allow us to clarify our general policies which are of relevance to the specific case. ${ }^{17}$

Ultimately, the problem of the ECB's confidentiality requirements can be solved in two ways: either the two institutions agree on a change in the legal framework that would allow the EP to receive answers to politically salient

17 Comments by an ECB official on a presentation of an earlier draft of this chapter at a closed workshop on 8 October 2018 at the Hertie School in Berlin (Chatham House rules). 
questions, or MEPs must alter the type of questions they send to the ECB on banking supervision. Information about specific banks is at the heart of banking supervision because it concerns the way in which SSM rules are enforced; for this reason, it can be expected that the EP will continue to ask such questions in the future even if they will rarely receive full answers in response.

\subsection{THE RECORD: HOLDING THE ECB ACCOUNTABLE IN BANKING SUPERVISION}

The early years of the functioning of the SSM institutionalised the accountability relationship between the EP and the ECB in banking supervision. As noted by the ECB Annual Reports on the SSM, the two institutions interact on a regular basis through hearings and letters. MEPs ask the Supervisory Board numerous oral and written questions, to which the ECB replies in a timely manner. Going back to the variables expected to have a positive effect on parliamentary questions (Chapter 3.3.1), this means that the EP has multiple structural opportunities for oversight in banking supervision. More specifically, MEPs can interact directly with the Chair of the Supervisory Board in a single committee (ECON) every couple of months and can ask written questions of the ECB at any time. Moreover, the aspect of high public pressure mentioned in the analytical framework is present in banking supervision in respect of the results of stress tests or if a bank is declared FOLTF. Whenever such events are covered by the media, the number of follow-up questions to the ECB increases in a corresponding manner. By contrast, the institutional characteristics of the EP - the emphasis on law-making and the high number of political groups - have a negative effect on the strength of parliamentary questions. This is visible in the significant number of requests for policy views on legislative dossiers as well as in the diversity of questions addressed by MEPs across political groups. Overall, MEPs from Portugal, Germany, Italy, Spain, and France ask the bulk of questions, while smaller political groups on the left tend to be more active.

In terms of the substance of questions, the analysis identified multiple examples outside the scope of oversight or related to issues that went beyond the ECB's competence in banking supervision. In line with the analytical framework of Chapter 3.3, the majority of questions were 'weak', focused on demands for information and justification of conduct. The problem, however, turned out to be systemic - rooted in the strict confidentiality regime that protects supervised banks and ensures that the ECB does not disclose sensitive information about supervisory decisions. This is in line with the expectation regarding the level of asymmetric information in principal-agent relations 
(Chapter 3.3.2): in this case, the underlying accountability deficit is the inability to assess the performance of the ECB in banking supervision in the absence of information about the specific decisions taken. Other authors have already noted the lack of a clear yardstick to measure whether the ECB is achieving its mandate in the SSM (Amtenbrink and Markakis 2019; Braun 2017: 7). To put it differently, if the ECB is doing a good job in banking supervision, how would MEPs - and the public at large - know it?

For its part, the ECB engaged openly with parliamentary questions, as most answers identified were explicit or partial/intermediate replies. The more important finding is the focus on justification rather than rectification, which suggests that the ECB is willing to explain and defend the rationale of its decisions on banking supervision, but it would rarely accept policy changes in response to EP oversight. In relation to the scenarios for legislative oversight outlined in the analytical framework, the dynamic puts the relationship between the EP and the ECB in banking supervision in 'Transparency' (scenario 4) - reflecting a higher proportion of 'weak' oversight questions and an emphasis on answers through justification (see Chapter 3.3.1). Nevertheless, the caveat remains the secrecy regime outlined above. The only time the ECB changed its decisions as a result of EP oversight occurred when MEPs across political groups acted together and on the basis of advice from the EP Legal Service, which provided evidence that specific ECB measures went beyond the tasks delegated to the institution in banking supervision. As in other cases of political oversight of bureaucratic actors or independent agencies, there is a clear imbalance between the expertise of the EP and that of the institution they are supposed to hold accountable. The EP's Economic Governance Support Unit (EGOV) has partially helped in this respect by preparing background notes before every public hearing of the Chair of the Supervisory Board. But the problem of asymmetric information will continue to characterise oversight interactions between the ECB and the EP.

In the future, the ECB will be considered accountable to the EP in banking supervision depending on the way in which the next Chairs of the Supervisory Board will substantively answer questions from MEPs. While the ECB is not expected to comply indiscriminately with requests from the EP and thus be 'responsive' to a political forum, it should stand ready to explain and defend its conduct in the SSM - and thus come closer to scenario 2 of legislative oversight interactions, namely 'Answerability' (see Chapter 3.3.1). The book's analytical framework had higher expectations for the EP's accountability relationship with the European Commission, which were similarly unfulfilled - as shown in the next chapter. 


\section{Overseeing the European Commission in the European Semester}

The European Commission is often described as the EU's central executive authority - reminiscent of national executives (Egeberg 2009; Wille 2013). Like regular governments, the Commission has a political and an administrative arm: on the one hand, the Commission's leadership is ensured by a politically appointed/elected President working in a team of twenty-seven Commissioners (one from each Member State); on the other hand, the Commission's administrative apparatus is composed of policy-area-specific departments with permanent staff named DGs (European Union 2016). But while the Commission may be the central actor in the EU's 'accumulated executive order' (Curtin and Egeberg 2008), it is by far not the only one. Other actors with executive functions include the Council (in non-legislative policy areas), the committee infrastructure (known as 'comitology' in relation to implementing acts), or EU agencies (Curtin 2009; Egeberg 2006; Trondal 2010). Among these actors, the Commission is a classic supranational institution that conducts independent policy activities within the limits of the mandate delegated by Member States (Majone 2001; Pollack 1997).

In the EMU, the Commission's executive powers increased considerably over time. In the initial intergovernmental framework of the Maastricht Treaty, the Commission played a support role to finance ministers in the Eurogroup and the ECOFIN Council - the main actors responsible for agenda-setting and decision-making in the field (Puetter 2012, 2014). The centrality of intergovernmentalism in the EMU was consolidated at the start of the euro crisis when heads of state and government in the European Council took the lead in setting the reform agenda (Fabbrini 2013). Yet one of the outcomes was the empowerment of the Commission. In the new governance framework for economic and fiscal policy coordination - known as the European Semester - the Commission acquired a strong implementing role (Dehousse 2016). Since 2010, the Commission has allocated significant 
resources to monitoring and enforcing the myriad of Semester rules on excessive deficits, macroeconomic imbalances, or structural reforms (Bauer and Becker 2014; Savage and Verdun 2016). In addition, the Commission became involved in the implementation of financial assistance programmes as part of the Troika (later 'Quadriga') - an informal partnership with the ECB, the IMF, and later the ESM (European Stability Mechanism 2019: 77). Nowadays, the Commission is an influential actor in the EMU, performing key executive functions in the day-to-day management of EU economic governance and financial assistance (where applicable).

To counter the Commission's expansion of executive powers from a democratic perspective, a new transparency and accountability mechanism was institutionalised in the aftermath of the crisis. This referred to the Economic Dialogues held regularly in the EP's relevant committees. Established by the Six-Pack (2011) and Two-Pack (2013) regulations, the Economic Dialogues allowed MEPs to ask the Commission questions about the European Semester and its various instruments. In addition to the Commission, the EP organises Economic Dialogues with the ECOFIN Council and the Eurogroup (see Chapter 6), as well as with invited national governments (European Parliament 2019a). The present chapter examines the content of Economic Dialogues with the Commission alongside the use of written questions related to the European Semester. On the one hand, the analysis is based on transcripts of Economic Dialogues with relevant Commissioners held at the ECON Committee or jointly with the Employment and Social Affairs (EMPL) Committee. On the other hand, the study includes Semester-related letters sent by MEPs from 2010 (since the launch of the European Semester) until the 2019 EP elections.

The findings reveal a keen interest from MEPs in the activities of the Commission in the European Semester and the problems thereof. In contrast to oversight interactions with the ECB on banking supervision (covered in Chapter 4.3), parliamentary questions to the Commission focus on requests for justification of conduct and concrete changes to policy priorities or decisions. One problem, however, is the low number of follow-up questions, demonstrating the diversity of political and national interests of MEPs regarding the activity of the Commission in economic governance. For its part, the Commission engages with most questions openly, albeit there is a clear tendency to defend conduct and maintain previous courses of action - regardless of what the EP says. Although the Commission does not have the ECB's independence nor its strict secrecy regime, there is little evidence of Commissioners' willingness to rectify their conduct in response to requests from MEPs. Against the expectations set out in Chapter 3.3.2, the EP does not 
exercise 'High control' of the Commission in the European Semester; in fact, their oversight relationship is a mixture of 'Answerability' and 'Transparency' depending on the strength of questions asked by MEPs on different issues.

The chapter is divided as follows. The first part reviews the Commission's role in the EMU before and after the euro crisis. Against this background, the second part maps out the possible issues that could arise in the EP oversight of the Commission on the European Semester. Next, the chapter moves to the empirical analysis of Economic Dialogues and connected parliamentary letters to the Commission. In line with Chapter 4 , the analysis includes an overview of the profile of questioners and respondents, the types of questions asked, and the categories of answers provided. The conclusion problematises the findings in light of the six scenarios of legislation oversight identified in Chapter 3.3.

\subsection{BACKGROUND: THE EUROPEAN COMMISSION IN THE EMU}

The European Commission was involved in the creation of the EMU but became a minor player in the ensuing institutional framework of the Maastricht Treaty. Former Commission President Jacques Delors chaired the 'Delors Committee' (1988-1989), a group of like-minded central bank governors and economic policy experts who produced the blueprint for the EMU (Verdun 1999). But while Member States agreed to establish gradually the EMU at Maastricht, they made a deliberate decision to empower in the field intergovernmental bodies at the expense of the Commission (Bickerton et al. 2015). From a delegation perspective, it would have been easier to have a supranational actor with extensive competences in economic governance in order to reduce decision-making costs and provide the stability of a permanent bureaucracy (Majone 2001: 103). In fact, it is both more complex and more expensive to organise intergovernmental meetings intermittently instead of relying on the resources of a long-term supranational administration. Yet Member States were not inclined to delegate such competences to the Commission. As macroeconomic and fiscal policy coordination were "core state powers' - central to national sovereignty and the understanding of statehood in modern politics - Member States opted for a particular governance arrangement that ensured that the EU would not turn into a federation (Genschel and Jachtenfuchs 2016). Careful of the Commission's standing as the main EU supranational institution and a proactive 'engine of integration' in the past (Pollack 1998; Sweet and Sandholtz 1997), governments sought to curtail its competences in the EMU from the onset. The following pages describe the ensuing institutional arrangements in detail. 
First, unlike in other policy fields, the Commission lacked its traditional right of initiative in the EMU, which meant it had less power to shape policy negotiations between national governments (Dyson 2000: 69). The key instrument adopted in the field (the SGP) came at the initiative of German Finance Minister Theo Waigel and was then taken over and adjusted by the Commission (Costello 2001: 106-107). This is not to say that the Commission had no influence whatsoever in setting the economic governance agenda, but its role was diminished - shared with Council senior expert committees (Puetter 2014: 193). In this respect, the most important bodies were the Economic and Financial Committee (EFC) and its Eurozone configuration, the Eurogroup Working Group (EWG). In an unconventional move, the EFC secretariat was located inside the Commission rather than the Council Secretariat, which allowed the institution to provide expertise to committee meetings and test policy proposals before they reached the agendas of the ECOFIN Council and the Eurogroup (Heipertz and Verdun 2010: 68).

Second, the implementation of the SGP did not change the intergovernmental dynamic established at Maastricht. Hellen Wallace described the arrangement as 'intensive transgovernmentalism' - an EU decision-making mode in areas at the heart of national sovereignty in which the European Council set the overall direction of the policy, the Council consolidated cooperation by bringing together national policy-makers into dense networks, the Commission played a marginal role, while the EP and the CJEU had no involvement whatsoever (Wallace 2005: 87). Alternatively, Bickerton and colleagues proposed the term 'new intergovernmentalism' to capture the phenomenon, focusing on the deliberative and consensus-seeking nature of decision-making in the European Council and the Council, in parallel to the Commission's open support of intergovernmental decision-making in sensitive policy areas (Bickerton et al. 2015: 711-712). In both accounts, the reduced role of the Commission is clear.

In fact, in the first decade of EMU, the Commission served as a small administration helping with the implementation of the SGP and economic policy coordination. The main focus was compliance with budgetary rules, namely the 3 per cent deficit-to-GDP threshold and the 60 per cent debt-toGDP ratio (Protocol 12 TEU). In this context, the Commission's powers were limited to monitoring national economic and budgetary policies and 'sounding the alarm' if a government broke deficit rules (Hodson 2011: 4). Within the Commission, the key departments involved were DG ECFIN and Eurostat, the statistical office in charge of gathering economic and social data (Dyson 2000: 69-70). The problem, however, was that Commission forecasts were dependent on data provided by national authorities, which could easily use 
'creative accounting' to update their budgetary reporting whenever they were close to breaking deficit rules (Buti et al. 2003: 5). Moreover, before initiating any recommendation against a country, the Commission required the political endorsement of the College of Commissioners, which could refuse to support the imposition of sanctions on their own Member State (Schuknecht et al. 2011: 9).

The difficulties in implementing the SGP came to the fore in the early 200os. In the context of declining economic circumstances, several Eurozone countries ran excessive deficits: Portugal (in 2001 and 2005), France and Germany (2002), Greece and the Netherlands (2003), as well as Italy (2004) (Morris et al. 2006: 16). The Commission made multiple recommendations to the Council to give countries early earnings (Germany and Portugal in 2002) or notices that sanctions are forthcoming (France and Germany in 2003), but the Council did not adopt them (Morris et al. 2006: 17). Faced with strong opposition from the same governments ignoring deficit rules, the Commission had to be ready to engage in a 'losing battle' or retreat before proposing unfeasible recommendations (Heipertz and Verdun 2010: 126-127). In the cases of France and Germany in 2003, the Council decided to hold the EDP 'in abeyance for the time being' (Council of the European Union 2003), meaning that the rules were simply suspended by virtue of Council conclusions. The Commission challenged the outcome before the CJEU, which acknowledged the misuse of Council conclusions in the case but accepted that the Council could de facto hold the EDP in abeyance when there was no qualified majority to adopt a formal decision. ${ }^{18}$ However, the willingness of the Commission to start litigation on the matter showed that it took its role as 'guardian of the Pact' seriously and sought to strengthen legal obligations in the EDP (Hodson and Maher 2004: 801).

A similar dynamic can be found in respect of the lack of sanctioning mechanisms in the implementation of the BEPGs. Originally adopted in 1993, the BEPGs expanded in scope over the years and came to include a variety of issues such as structural reforms in labour and capital markets, redirecting expenditure towards economic growth, or pension reform (Deroose et al. 2008: 828). Moreover, the BEPGs had a stronger legal basis than the Open Method of Coordination (today Article 121(4) TFEU), which technically should have increased the Commission's influence in providing country-specific guidelines. However, the first case selected for a warning under Article 121(4) - namely Ireland in 2001 - raised suspicions about the Commission's impartiality in reprimanding small as opposed to large Member

18

Case C-27/04, Commission v. Council, ECLI:EU:C:2004:436. 
States (Heipertz and Verdun 2010: 118). Politically, it was tactless to chastise a government with a strong growth record and a budget surplus at a time when other countries had clear deficits problems (Hodson 2011: 81). Although the reasons for warning Ireland revolved around tax cuts in deviation from earlier BEPGs, the case set a precedent for domestic political backlash against Commission recommendations in economic governance.

Based on these experiences, the Commission sought to reform the SGP in 2004. Its key proposals included (1) paying more attention to country-specific conditions when assessing deficits and surpluses, (2) considering debt sustainability (in addition to deficits) in the medium and long term, (3) dealing with 'inadequate budgetary developments' earlier in the process of economic policy coordination, and (4) taking into account economic circumstances in the implementation of the EDP (European Commission 2004). The final text adopted by the Council is considered a watered-down version of the original SGP rules and could not solve the problem of weak enforcement (Morris et al. 2006: 22). In fact, all the difficulties of the post-Maastricht period - the patchy implementation of rules, the broad Council discretion in decision-making, and political control by large Member States - were bound to diminish the Commission's influence in the field.

The reforms of the euro crisis have strengthened the Commission's position in the EMU, as discussed in the following pages.

\subsubsection{The Euro Crisis and the Empowerment of the Commission in the EMU}

The euro crisis brought significant reforms to the EU economic governance architecture (Chapter 2.1.1). For the Commission, the most significant development was undoubtedly the introduction of the European Semester - an umbrella framework for the coordination of Member States' economic, budgetary, and social policies. The name 'Semester' is actually a misnomer because the process is an annual one. For the Commission, there are three 'peak' moments during the year. Every November, the Commission publishes its 'Autumn Forecast', including an Annual Growth Survey (AGS), an Alert Mechanism Report (AMR) for macroeconomic imbalances, a Joint Employment Report, general recommendations for the Eurozone, as well as individual opinions on each government's Draft Budgetary Plans (DBPs). February is the month of Country Reports, when the Commission assesses Member States' progress towards implementing their respective reform agendas and provides In-Depth Reviews (IDR) for countries with macroeconomic imbalances highlighted in the AMR. After receiving Member States' national reform programmes (on economic issues) and stability and 
convergence programmes (on budgetary issues), the Commission starts preparing CSRs - which are officially proposed in May and adopted by the Council in June (European Commission 2020b). In 2015, the Juncker Commission adjusted the process by reducing the number and scope of CSRs for each Member State in order to focus "on "key priority issues of macro-economic and social relevance" identified as actionable and monitorable within a twelve-eighteen month timescale' (Zeitlin and Vanhercke 2018: 163).

Furthermore, the Semester strengthened the Commission's role in the EDP and created a new instrument - the MIP - designed to monitor and assess macroeconomic imbalances in the Member States. In the EDP, the Commission benefited from a stricter timeline for scrutinising DBPs, which allowed its policy recommendations to be included in countries' final budget proposals (EU Regulation 473/2013, Article 1[1c]). In addition, the Commission's autonomy in the field was consolidated through the introduction of 'reverse qualified majority' in the Council when voting on sanctions for breaking excessive deficit rules (Dehousse 2016: 620). This ensured that Commission recommendations would be automatically adopted unless there was a qualified majority of Member States voting to overturn the recommendation. In the MIP, the Commission evaluated whether countries suffered from simple 'imbalances' or imbalances that were 'excessive' and required 'corrective action' (Regulation (EU) No. 1176/2011). Similar to the EDP, if a government failed to correct excessive imbalances, it could receive a fine following a recommendation from the Commission (Regulation (EU) No. 1174/2011).

From an organisational perspective, the distribution of staff within Commission DGs mirrored the institution's expansion of powers. In the early years of the crisis, both DG ECFIN and the Eurostat team in charge of macroeconomic and fiscal surveillance saw an inflow of new personnel (Savage and Verdun 2016: 107-111). More generally, the Commission allocated significant human and financial resources to producing Country Reports and the CSR process, which required the close coordination of the SecretariatGeneral, DG ECFIN, and DG EMPL (Maricut and Puetter 2018: 206). Overall, the Semester implied a steady increase in the Commission's monitoring and enforcement capacities in economic governance - stronger than before the euro crisis and different from its traditional role in agenda-setting (Bauer and Becker 2014).

To counter this expansion of powers, the legislation establishing the European Semester included provisions regarding the accountability of the 
Commission to the EP in the field. To this end, five regulations of the Six-Pack and the two regulations of the Two-Pack specified that:

In order to enhance the dialogue between the institutions of the Union, in particular the European Parliament, the Council and the Commission, and to ensure greater transparency and accountability, the competent committee of the European Parliament may invite the President of the Council, the Commission and, where appropriate, the President of the European Council or the President of the Eurogroup to appear before the committee to discuss: [list of specific instruments]. ${ }^{19}$

The list of instruments captures different elements of the new EU economic and fiscal governance framework: from the BEPGs to the AGS, the MIP, the EDP, Commission opinions on DBPs, the application of the SGP and general results of multi-lateral surveillance, including enhanced surveillance in the Eurozone and macroeconomic adjustment programmes (de la Parra 2017: 107). The language of the regulations is open-ended, referring to a 'dialogue' where the Commission is invited to 'discuss' its activities in the field and 'inform' the EP of the application of the regulations (see, in particular, Article 18 of Regulation (EU) No. 472/2013). This is different from a classic oversight 'hearing' where the purpose is to allow members of parliament to interrogate executive actors and ask them to justify and defend their conduct. Nevertheless, the Economic Dialogues open the possibility for accountability interactions and allow MEPs to question EU Commissioners on economic and fiscal governance issues. The evaluation of the Commission's activities in the field is not conflict-free - as discussed in the next section.

\subsection{THE ACCOUNTABILITY OF THE COMMISSION IN THE EUROPEAN} SEMESTER: KEY ISSUES

From a political accountability perspective, the relationship between the EP and the Commission is the closest the $\mathrm{EU}$ comes to the principal-agent model in parliamentary democracies (Fearon 1999; Strøm 2000). In line with the Treaties, the EP has institutionalised procedures for the investiture and removal of the College of Commissioners (through motions of censure),

19 In the Six-Pack, the text is listed in Article za-b of Regulation (EC) No. 1466/97 as amended by Regulation (EU) No. 1175/2011; Article 2a of Regulation (EC) No. 1467/97 as amended by Regulation (EU) No. 1177/2011; Article 3 of Regulation (EU) No. 1173/2011; Article 14(1) of Regulation (EU) No. 1176/2011; and Article 6 of Regulation (EU) No. 1174/2011. In the TwoPack, the text is listed in Article $7(1)$ and Article 15(1) and (3) of Regulation (EU) No. 473/2013 as well as in Article 3(9), Article 7(1), (4) and (10), and Article 18 of Regulation (EU) No. 472/ 2013 . 
parliamentary questions, committees of inquiry, and budgetary control (European Parliament 2019b; Remáč 2019). On paper, the EP has all the regular scrutiny instruments necessary to oversee the activity of the College of Commissioners as a political body with executive powers. There are, however, structural limitations to the process. Most significantly, EP political groups fail to function as 'transmission belts' between citizen preferences and policy outputs in the same way as parties in national settings (Lindberg et al. 2008; Mühlböck 2012). Even if citizens were to endorse a particular political programme in EP elections, their preferences will not be translated into the Commission's policy agenda because of the numerous veto points in the EU decision-making process (Hix and Høyland 2011: 131-133). That means that political accountability lines are short-circuited, especially when it comes to the responsiveness of the Commission to the EP (after investiture) or the extent to which the EP can use sanctions against the College. The most notable instance of EP oversight of the Commission - namely the threat of a motion of censure that led to the resignation of the Santer Commission in the late 1990s - concerned corruption allegations (Topan 2002), not substantive policy issues. Holding the Commission accountable politically is difficult because it requires parliamentary majorities in a multi-party, multi-national system with ever more fragmented interests (Hix and Høyland 2013; Hobolt 2019). Indeed, the government-opposition dynamic is not straightforward in EP oversight of the Commission: if anything, what seems to play a role is whether MEPs are members of opposition parties at the national level (Jensen et al. 2013; Proksch and Slapin 2011).

Despite these limitations, the EP's accountability relationship with the Commission remains the most developed among EU executive actors, which is why it is reasonable to expect a higher level of EP control of the Commission in the EMU. In the post-crisis period, there were at least three specific concerns regarding the performance of the Commission in the economic governance framework of the European Semester. The list below has been compiled from existing literature and is not exhaustive, meaning that these are not the only problematic issues in the conduct of the Commission likely to be challenged by the EP or other accountability forums. However, for the purposes of the analysis below, the three elements are sufficient to frame parliamentary questions in the Economic Dialogues.

First, there is the Commission's supposed neutrality in assessing various tools of the European Semester. In theory, the process of defining budgetary deficits, macroeconomic imbalances, or progress towards structural reforms is apolitical, based on the Commission's technocratic expertise (Radaelli 1999). Indeed, the staff of Commission services - such as DG ECFIN and Eurostat - comprise 
specialists with in-depth economic and statistical knowledge as well as familiarity with the EU economic governance architecture. The official institutional discourse is that the European Semester is a 'rule-based' coordination and surveillance framework (Angerer et al. 2019: 17) in which the Commission is responsible to check whether national governments have complied with the rules and their own commitments in the process of economic and budgetary coordination. In practice, however, technocratic decisions are more political than they appear (cf. Boswell 2008). For example, the Commission has significant discretion to decide what constitutes a 'structural deficit' and whether countries are making progress towards achieving their respective objectives (Dawson 2016: 66). The same applies to the MIP, where the Commission can draw the line between a simple imbalance and one that is harmful enough to require corrective action (Dehousse 2016: 620).

The leeway of the Commission in taking executive decisions in the European Semester has been on display on multiple occasions since the crisis. In 2015, the Commission gave France a two-year extension to correct its excessive deficit despite the fact that EDP rules would have suggested the application of sanctions as the next 'rule-based' step (European Commission 2015b). A year later, when asked on French television why the Commission did not pursue sanctions against France, President Jean-Claude Juncker candidly replied 'because it is France' (Guarascio 2016). The answer sparked controversy across Europe, attracting criticism from Eurogroup President Jeroen Dijsselbloem, who accused Juncker of damaging the credibility of the Commission as guardian of the [stability] pact' (EurActiv 2016). In 2016, the Commission also decided against imposing fines on Spain and Portugal for failing to correct their budgetary deficits, taking into account their 'challenging economic environment, [their] reform efforts, and their commitments to comply with the rules of the SGP' (Smith-Meyer 2016). The only instance when the Commission sanctioned a Member State in the EDP - namely Spain in 2015 - was not for breaking deficit rules but for manipulating statistical data on budgetary and debt levels (Savage and Howarth 2018: 213).

In addition, the Commission's discretion in the interpretation of rules is present in other areas of the Semester. In the early years of the MIP, the number of countries subject to an IDR or flagged for having imbalances and excessive imbalances increased steadily, making authors question the utility of an instrument that includes so many diverse issues (e.g. Bokhorst 2019: 296). A report from the ECA condemned the Commission's practice of connecting multiple CSRs to the MIP although they were only 'remotely linked to macroeconomic imbalances' (European Court of Auditors 2018: 7). Yet despite the wide use of the MIP, the Commission has never opened the Excessive 
Imbalances Procedure (EIP) for any Member State, not even for governments failing to correct imbalances in consecutive years (Zoppè 2020: 11). One of the long-standing disputes of the MIP concerns Germany's account surplus, seen by Southern Eurozone governments as a way of exploiting 'demand in neighbouring countries that have trade and current account deficits, [instead of] stimulating greater domestic demand in Germany, increasing investment, and importing more' (Gnath et al. 2018: 5). Economists recognise the problem that definitions of thresholds for account surpluses are ultimately arbitrary (Gros and Busse 2013), so the Commission has leeway to decide when an imbalance exists and if it is excessive. Overall, these examples show that the Commission's technical decisions are much more political than it appears on the surface (see also van der Veer and Haverland 2018). From an accountability perspective, the issue is whether the Commission treats Member States equally or alternatively, if it shows bias against some countries while 'turning a blind eye' to deviations by others.

The second major concern regarding the Commission's conduct in the European Semester refers to the effectiveness of its instruments. Given that the Commission has invested considerable resources into economic and social policy coordination since the crisis (Savage and Verdun 2016), it is legitimate to ask whether the Semester is taken seriously at the domestic level and if it produces concrete results. In this context, the notion of 'results' refers to both the transposition of CSRs into national priorities and the actual effects of the Semester on the economy (in terms of unemployment, growth, labour market flexibility, etc.). The poor transposition record of CSRs into national priorities is well known in the specialised literature and has only worsened over time (Alcidi and Gros 2017; Darvas and Leandro 2015; Efstathiou and Wolff 2018; Maatsch 2017). As to the effects of the Semester on various economic indicators, there have been several lines of criticism throughout the years. In respect of the first CSRs, the Commission was accused of adopting a 'one-size-fits-all' approach towards Member States, without taking into account the specificities of their political economies (D'Erman et al. 2019; Regan 2017). At the same time, critics observed the asymmetry between economic and social issues among Commission recommendations, as social concerns were subordinated to fiscal discipline and structural reforms (Costamagna 2013; Hermann 2017; Parker and Pye 2018). While the Commission sought to expand its social priorities since the crisis - especially during Juncker's mandate (European Commission 2019: 2) - many voices remain sceptical whether the Commission's core 'neoliberal' views to the Semester have genuinely changed (Copeland and Daly 2018; Dawson 2018). 
Last but not least, the third major concern regarding the Commission's accountability in the post-crisis context refers to its activities in the Troika (later the 'Quadriga'). While financial assistance is not formally part of the Semester (or the EU legal framework for that matter), the Commission is responsible for implementing loan programmes in a 'tangled governance' arrangement that additionally involves the ECB, the IMF, and since 2015 the ESM (Henning 2017). More specifically, the Commission's role in bailout negotiations raises questions about its handling of 'programme countries' as well as the policy reforms required from indebted governments. In terms of process, the Commission has tasks in (1) the initial evaluation of a country's application for financial assistance, (2) the ensuing negotiations with the applicant state on the conditions attached to each loan, and (3) the monitoring of compliance with agreed conditions (Bauer and Becker 2014: 218). The new tasks put the Commission in an 'uncomfortable dual role' where it was forced to act as a 'punitive surveying institution' in conflict with governments of programme countries while at the same time keeping all its other competences - including guardian of the Treaties (European Stability Mechanism 2019: 81-82). In terms of policy substance, the Commission remained a staunch supporter of austerity measures throughout the crisis, demanding that indebted governments enforce fiscal discipline and structural reforms in exchange for financial assistance (Schmidt 2020: 186). As growth remained low and unemployment skyrocketed in programme countries, accountability forums came to contest both the effectiveness of austerity measures and the lack of democratic oversight of the Troika more generally (European Parliament 2014f).

Overall, the increase of Commission powers in the EMU not only strengthened the supranational institution but also opened it to criticism on different grounds. From the perspective of democratic accountability, it is essential to understand whether the Commission's empowerment in the field was accompanied by appropriate oversight mechanisms. Focusing on the EP, the remainder of the chapter presents the practice of parliamentary questions on the Commission's activities in economic and fiscal policy coordination - as envisaged by the Six-Pack and the Two-Pack regulations.

\subsection{OVERSEEING THE COMMISSION IN THE EUROPEAN SEMESTER}

The analysis below includes a list of all the Economic Dialogues, which occurred between January 2012 and May 2019, covering the $7^{\text {th }}$ and 8th parliamentary terms. In addition to committee meetings, the data includes letters with questions on the Semester sent to the Commission by individual or 
groups of MEPs in the period under focus. Written questions are not specific to economic governance; instead, they are part of regular oversight instruments of the EP vis-à-vis the Commission, according to Rule 138 of the current Rules of Procedure (European Parliament 2020a). The goal is to see whether there is any variation between oral and written questions on the European Semester.

Keeping in mind that the Six-Pack entered into force in December 2011, the first Economic Dialogue with the Commission took place at the ECON Committee in June 2012. Since then, there were typically two or three Economic Dialogues per year: one held at the ECON Committee and the other(s) jointly with the EMPL Committee. The joint meetings were attended by both Commissioners for ECOFIN (Olli Rehn during 2010-2014 and Pierre Moscovici during 2014-2019) and EMPL (László Andor during 2010-2014 and Marianne Thyssen during 2014-2019). Since December 2014, all meetings were also attended by the Vice-President for the Euro and Social Dialogue, Valdis Dombrovskis. One exception was 2016 when there was an additional 'structured dialogue' held jointly between the ECON Committee and the Committee on Regional Development (REGI). The subject of this meeting was the possible suspension of structural funds to Spain and Portugal as a sanction for failing to reduce their budgetary deficits as part of the EDP (Regulation 1303/2013, Article 23[15]). The structured dialogue was attended by the Vice-President for Jobs, Growth, Investment and Competitiveness, Jyrki Katainen, and the Commissioner for Regional Policy, Corina Crețu. During the years when only two Economic Dialogues took place, they were usually organised in November/December to discuss the Commission's 'Autumn Forecast' and in June to debate the CSRs. In 2013, 2015, and 2016, an additional joint Economic Dialogue was held in April to cover Country Reports and the results of the MIP. In 2014, 2016, and 2017, there was a supplementary Economic Dialogue at the ECON Committee on the DBPs of Eurozone countries. Figure 5.1 offers an overview of the twenty Economic Dialogues identified in the period under investigation.

In terms of the format of Economic Dialogues, meetings held solely at the ECON Committee are better organised and easier to follow than joint meetings. This is related to the number of speakers allowed per session: in the ECON Committee, Commissioners respond to one MEP at a time, which makes it easier to establish if questions have been answered or not. After the EP elections of May 2014, once there were two Commissioners present in each meeting, Dombrovskis and Moscovici started to take turns answering questions in order to avoid the duplication of replies. By contrast, joint ECON/EMPL meetings have the practice of grouping three-four MEPs together, who jointly ask around ten 


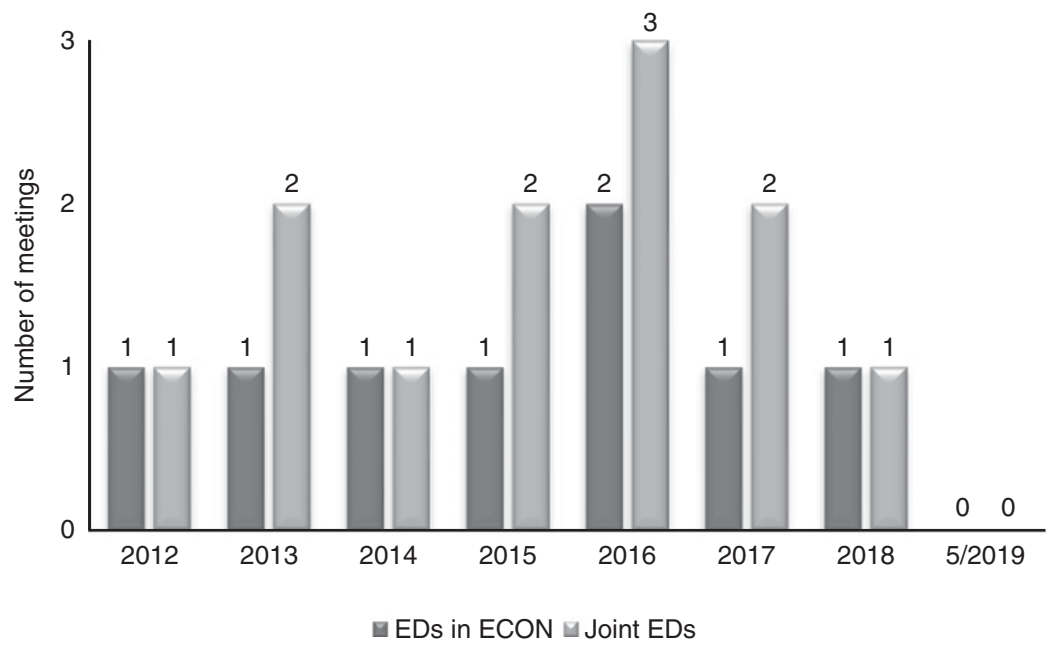

FIGURE 5.1 Economic Dialogues with the European Commission (December 2010-May 2019). Joint Economic Dialogues can be organised with the ECON Committee and the EMPL Committee or with the ECON Committee and REGI Committee

questions, which are then answered by three Commissioners. The second format facilitates evasion, as Commissioners can focus their answers on a couple of questions and leave the rest unanswered due to the lack of time. Since an Economic Dialogue typically lasts 1.5 hours, it is challenging for committee chairs to make MEPs keep to the time allocated, especially since many of them start their questions with a short political declaration on the issues at hand.

Moving to written questions sent by MEPs to the Commission, these were identified on the EP website using a keyword search for the main Semester instruments. ${ }^{20}$ Taking into consideration that written questions were not dependent on the adoption of the Six-Pack, the data set includes letters exchanged between December 2010 (the official launch of the European Semester) and May 2019. A total of 255 documents were retrieved from the EP website, including 141 letters with questions and 114 letters with answers from the Commission. Typically, the Commission has an interval of six weeks to reply to written questions, meaning that letters sent at the end of year will be answered the following year. Moreover, the Commission can use one response to answer several letters

20 The search retrieved letters including the keywords 'European Semester', 'CSRs', 'MIP', 'EDP', 'AMR', 'AGS', 'SGP', 'Six-Pack', and 'Two-Pack'. 
from MEPs, so the number of letters with questions and letters with answers need not be equal. There is one instance when an MEP clearly abused the possibility to ask questions: on 21 June 2012, Portuguese MEP Diogo Feio (EPP) sent 27 letters to the Commission asking for the CSRs for each Member State - including the Commission's specific findings, challenges faced by national governments, and recommendations to improve them. However, since the Commission had already published (and publicised) the CSRs that year, the questions cannot be considered a form of oversight but rather an attempt by the MEP to boost his record of parliamentary activity. ${ }^{21}$ In this respect, Diogo Feio was an outlier; other MEPs used the instrument of written questions more purposefully. Figure 5.2 shows the yearly division of letters identified, with 2012 an exception as explained above.

In respect of structural opportunities for oversight (Chapter 3.3), the availability of oral and written questions suggests that MEPs have many chances to exercise oversight of the Commission with regard to the European Semester. The following pages describe the findings of the analysis in detail, starting with the profile of questioners and respondents.

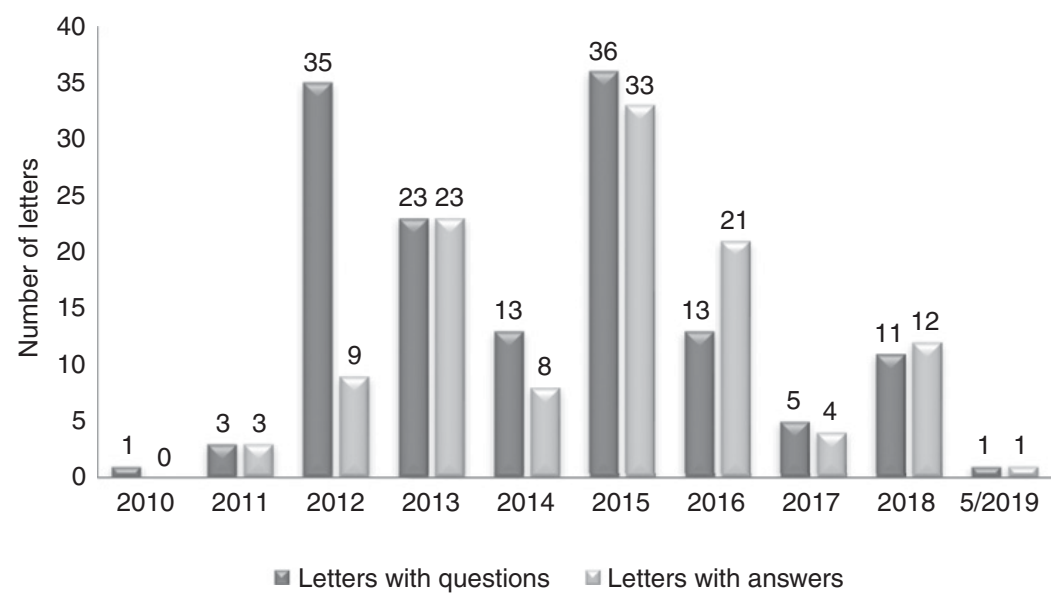

FIGURE 5.2 Letters with questions and answers exchanged between MEPs and the European Commission on the European Semester (December 2010-May 2019)

${ }^{21}$ Judging by the sheer number of parliamentary questions, Diogo Feio was one of the most active MEPs of his term, having sent over 1,400 questions during 2009-2014 (VoteWatch Europe 2014: 6). However, if most of his questions were as the ones identified here, his high parliamentary activity is an obvious example of quantity over quality. 


\subsubsection{Profile of Questioners and Respondents}

Who are the MEPs who ask questions of the Commission on the European Semester? Figures 5.3 and 5.4 illustrate the nationality of the 319 MEPs identified as asking oral questions during the Economic Dialogues with the Commission in the period under focus. Each MEP is only counted once despite asking multiple questions when taking the floor in a committee meeting. Accordingly, MEPs from Germany (14\%), Spain (13\%), Portugal (13\%), and France (12\%) asked the most oral questions of the Commission on the Semester.

In respect of party affiliation, the distribution among political groups reflects the number of seats they hold during a parliamentary term, in line with the EP's Rules of Procedure (Rule 171; European Parliament 2020a). Consequently, the most active political groups were the EPP $(29 \%)$, the S\&D (24\%), ALDE (10\%), the Greens/EFA (10\%), and GUENGL $(9 \%)$.

For written questions, the breakdown of nationality and political affiliation does not look very different. A total of 183 MEPs sent 141 letters to the Commission on Semester topics, with the general tendency that most letters are single-authored. As illustrated in Figures 5.5 and 5.6, most letters were sent

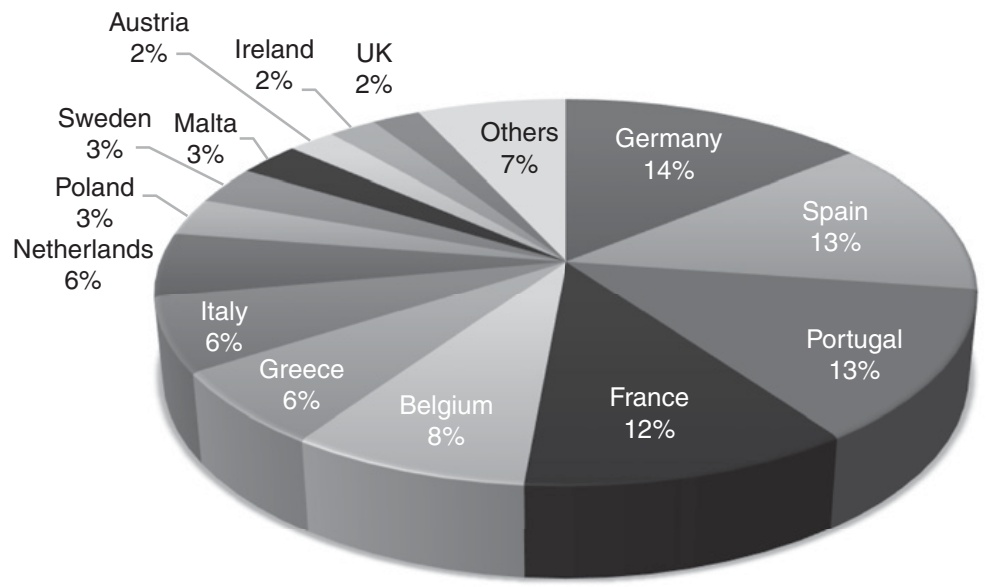

FIGURE 5.3 Nationality of MEPs asking oral questions of the Commission in the

Economic Dialogues (January 2012-May 2019). One MEP can ask multiple questions in a meeting, but (s)he is only counted once. Total number of MEPs identified: 319 


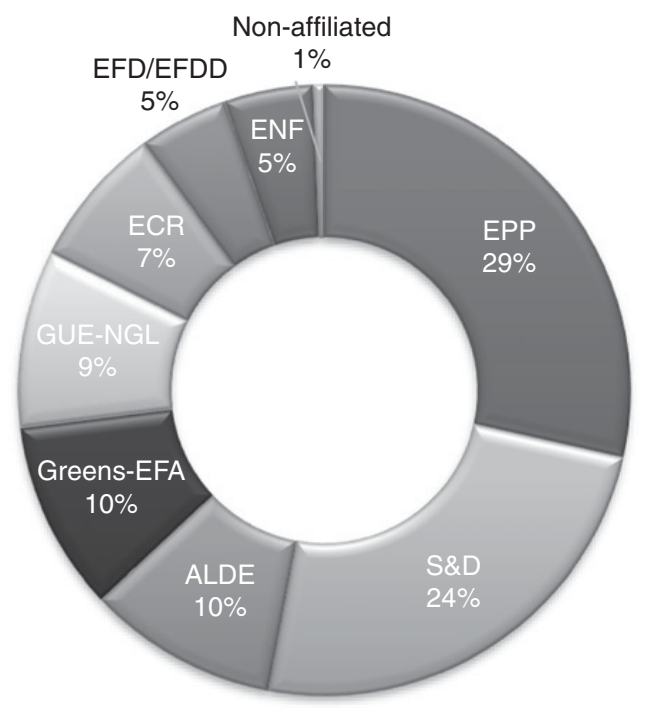

FIGURE 5.4 Political affiliation of MEPs asking oral questions of the Commission in the Economic Dialogues (December 2010-May 2019). One MEP can ask multiple questions in a meeting, but (s)he is only counted once. Total number of MEPs identified: 319

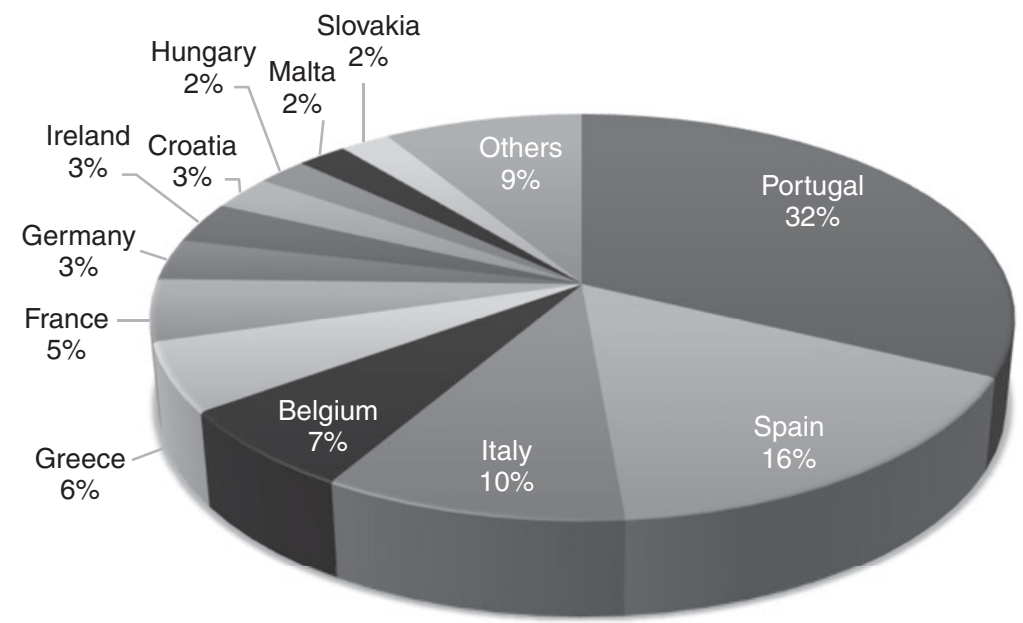

FIGURE 5.5 Nationality of MEPs asking written questions of the Commission on the European Semester (December 2010-May 2019). Some letters can have multiple authors. Total number of MEPs identified: 183 


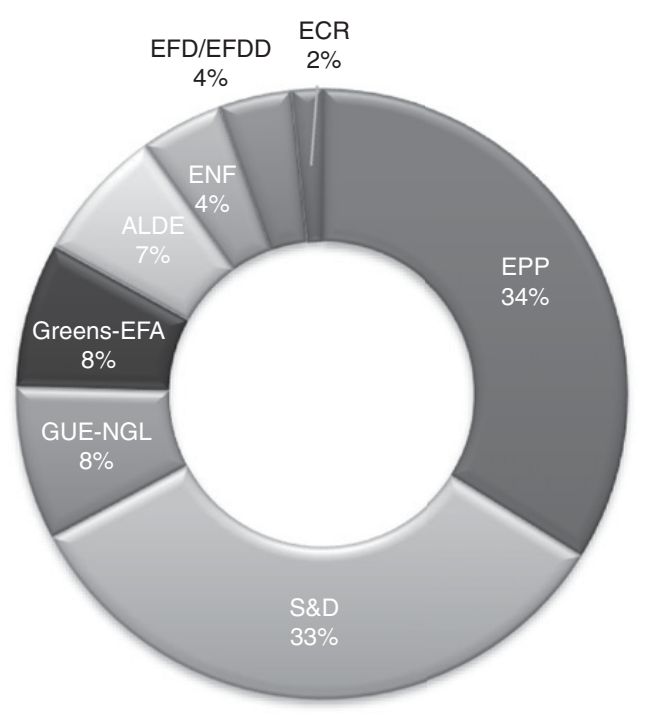

FIGURE 5.6 Political affiliation of MEPs asking written questions of the Commission on the European Semester (December 2010-May 2019). Some letters can have multiple authors. Total number of MEPs identified: 183

by MEPs from Portugal (32\%, including Diogo Feio), Spain (16\%), Italy (10\%), Belgium (7\%), and Greece $(6 \%)$.

In terms of political groups, the most active MEPs came from the EPP (34\%, including Diogo Feio), the S\&D (33\%), GUE-NGL (8\%), the Greens/ EFA $(8 \%)$, and ALDE ( $7 \%)$. Since written questions are not limited according to the size of political groups during a parliamentary term (as oral questions are), it was expected that smaller groups would compensate by sending more letters to the Commission - as they do, for instance, with the ECB as a complement to the Monetary Dialogue (Fraccaroli et al. 2018: 60). However, this did not happen in respect of letters on the European Semester sent to the Commission.

On the whole, the national and political affiliations of MEPs who ask questions of the Commission clearly illustrate the diversity of interests represented in the EP. In line with the analytical framework of the book (Chapter 3.3.2), this is expected to have a negative effect on oversight because parliamentary questioning becomes more diffuse - and consequently less targeted than in a two-party or two-and-a-half-party system. As shown in the next section, the low number of follow-up questions is an indicator of this diffusion of interests. Nevertheless, in contrast to the ECB in banking 
supervision (Chapter 4), the relationship of the EP with the Commission does illustrate a certain government-opposition dynamic. Indeed, political groups that did not support the current College of Commissioners (especially the Greens/EFA, GUE-NGL, and the Eurosceptic EFDD and ENF) were more likely to ask stronger oversight questions than groups that voted for the Commission (particularly the EPP and the S\&D). However, if an MEP came from a country heavily affected by the euro crisis - such as Greece or Portugal - they would ask stronger oversight questions regardless of their political affiliation to one of the largest political groups in the EP.

Furthermore, when it comes to replies by the Commission, most questions are answered by the ECOFIN Commissioner, followed by the Vice-President for the Euro and the EMPL Commissioner (Figure 5.7). This statistic applies to both oral and written questions, which is interesting because it shows that the European Semester is generally perceived by MEPs as the competence of DG ECFIN. This has not changed over time, even though DG EMPL became more involved in decision-making on the social side of the Semester (Zeitlin and Vanhercke 2018). As to the Vice-President for the Euro, the position did not exist before 2014 - the system was introduced by the Juncker Commission in order to streamline the leadership of the Commission and coordinate the portfolios of Commissioners in charge of connected fields (King 2014). It is not clear, however, whether the 2014 reform

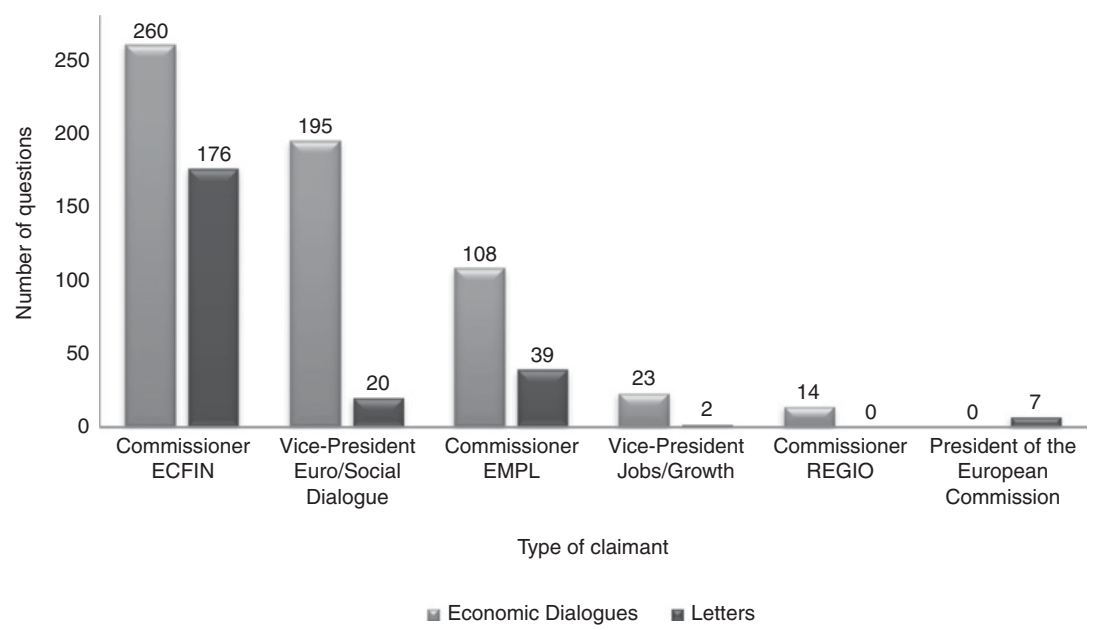

FIGURE 5.7 Institutional position of the Commissioners answering questions on the European Semester in Economic Dialogues and letters (December 2010-

May 2019) 
of the College created a hierarchy between Commissioners - as some authors suggest (Nugent and Rhinard 2015: 98). Between 2014 and 2019, the Commission Vice-Presidents did not have a DG assigned to them, meaning they had to rely on their small cabinets, the secretariat-general, and personal networks for administrative support and policy expertise (Russack 2017: 5). In the EMU, the authority of Vice-President Valdis Dombrovskis vis-à-vis Commissioner Pierre Moscovici is doubtful: in 2015, when France was in the EDP for breaking deficit rules, Juncker reportedly sided with Moscovici against Dombrovskis regarding the imposition of sanctions (Bürgin 2018: 845). In the Economic Dialogues, the substance of discussions does not indicate that Dombrovskis is the superior of Moscovici, albeit in terms of protocol he gets the floor first for opening remarks. In terms of the format of meetings, the multiplicity of speakers does not make oversight easier: on the contrary, the structural opportunities for oversight decrease (Chapter 3.3.2) because MEPs have fewer chances to ask follow-up questions of the same speaker.

On average, the ECOFIN Commissioner and the Vice-President for the Euro attend Economic Dialogues more often than the EMPL Commissioner - because they are present in regular ECON Committee meeting as well as in joint hearings with other committees (EMPL or REGI). Consequently, it is not surprising that there is a focus on issues under the jurisdiction of Commissioners in charge of economic affairs - as DG ECFIN remains the 'pre-eminent DG' responsible for the Semester, despite the increasing involvement of other DGs in the process (Savage and Verdun 2016: 110). But while the Semester started as a framework for the coordination of economic and fiscal issues, the social dimension became increasingly important over time - both in terms of policy orientations and the active participation in decision-making of DG EMPL and of Council formations in charge of employment and social affairs (Zeitlin and Vanhercke 2018: 161-163). As we will see later in the analysis, social issues are central in the questions MEPs pose to the Commission. The following pages describe the typology of questions in depth.

\subsubsection{Types of Questions}

What kind of questions do MEPs ask the Commission on the European Semester? During the period under focus, a total of 844 questions were identified in both Economic Dialogues and letters. 600 questions were asked orally during 20 committee meetings, while 244 questions were asked in writing using 141 letters. On average, MEPs asked around 30 questions in one Economic Dialogue and included 1-3 questions in a letter. In line with 
the Q\&A approach to legislative oversight (Figure 3.1), questions were classified as initial or follow-up questions which requested: (type A) information, (type B) justification of decisions or conduct, (type C) change of decisions or conduct, (type D) sanctions on responsible actors, and (type E) policy views. In this chapter, there is a sixth category - titled irrelevant questions (type F). Unlike requests for policy views, irrelevant questions either touch on topics that have nothing to do with the Semester (e.g. they are about justice and home affairs) or appear to be within the scope of oversight, but their subject blatantly shows MEPs' lack of knowledge about the functioning of the European Semester. In the period under investigation, most irrelevant questions (27) came from letters sent by Diogo Feio on the content of 2012 CSRs which technically would qualify as requests for information if the Commission had not already made the information available as one of the main points of the Semester. To distinguish these questions from legitimate requests for information, they have been classified as 'irrelevant'. The other 8 irrelevant questions concern topics that clearly go beyond the Semester - such as trade policy, immigration, or defence.

From the outset, Figure 5.8 shows that MEPs ask far fewer follow-up questions than initial questions. In Economic Dialogues, there were a total of 483 initial questions and 117 follow-up questions, which suggests that MEPs rarely press the Commission to answer a specific question. Taking into account that an MEP who is not a rapporteur has 1.5 minutes to ask a question, it was to be expected that the number of follow-up questions would be lower. For this reason, the classification considered all questions in one meeting pressing for the same issue as follow-up questions, even if another MEP asked the question. For example, in the 2016 dialogue with Jyrki Katainen and Corina Crețu, almost all MEPs from the REGI Committee and many from the ECON Committee spoke vehemently against the suspension of structural funds for Spain and Portugal, referencing the social difficulties experienced by the two countries during the crisis (European Parliament 2016e). These were clear requests for change in the Commission's (and the Council's) decisions on the matter, as many MEPs followed up on the questions of previous speakers.

In general, the low number of follow-up questions suggests the diversity of interests in the EP, as MEPs tend to ask questions relevant for their constituency or for their committee mandate (ECON/EMPL/REGI). The situation does not differ in letters, where MEPs asked 227 initial questions and only 17 follow-up questions. Seldom does an MEP express dissatisfaction with an answer received from the Commission or with an unfulfilled commitment of the supranational institution. For instance, on 22 January 2012, Dutch MEP 
Marije Cornelissen from the Greens sent a letter referencing a 2011 EP resolution that called on the Commission to involve civil society and social partners in the Semester through the production of annual shadow reports on each Member State (Cornelissen 2012). There are also a few instances when a question asked in writing is being reposed to the Commission during an Economic Dialogue, for example, when Dutch MEP Cora van Nieuwenhuizen (ALDE) asked for 'clarification on the precise methodology and analysis that is being used to determine whether a member states is compliant with the conditionality attached to financial assistance' because the answer provided was 'rather vague and lacked substance' (European Parliament 2016b).

Figure 5.8 shows that the majority of questions are requests for information, justification of conduct, and policy change - asked to similar extents. In fact, if we look at the total number of questions across Economic Dialogues and letters, we find 288 requests for policy change, 246 requests for justification of conduct, and 230 requests for information. This suggests that there is no clear trend towards one type of question; if we are to compare the result with questions asked of the ECB on banking supervision (Chapter 4), we can see

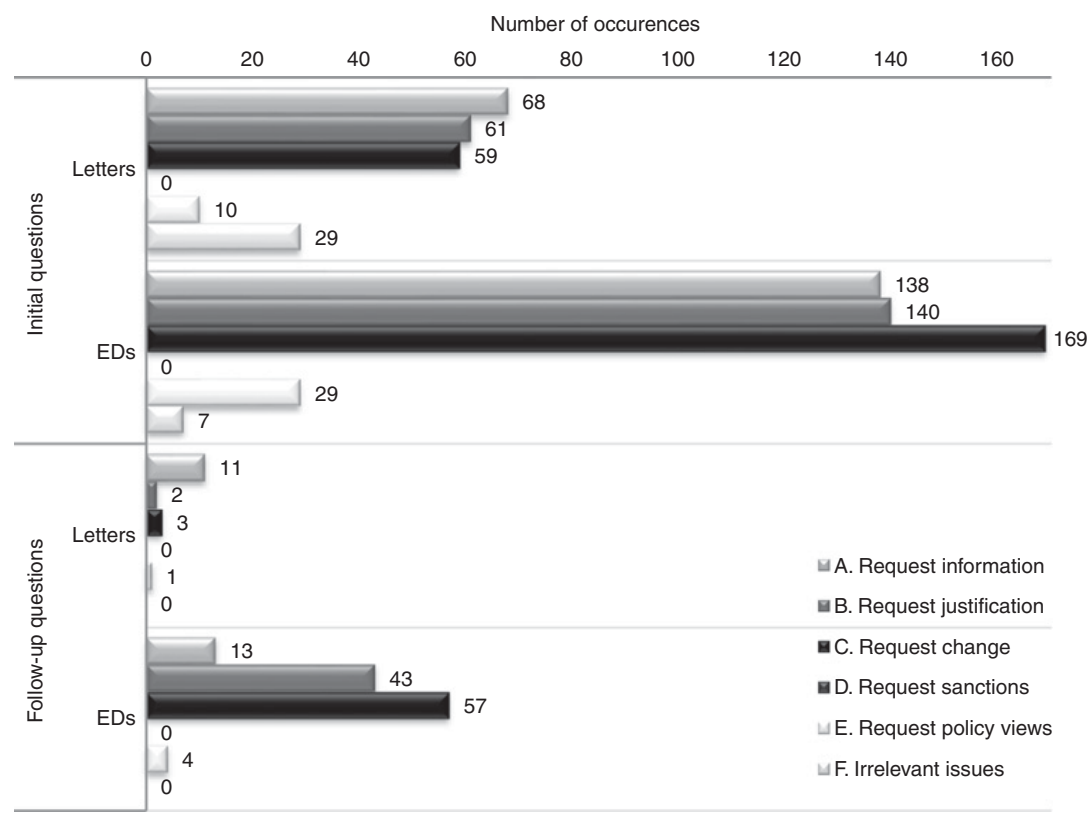

FIGURE 5.8 Types of questions asked by MEPs of the Commission on the European Semester (December 2010-May 2019). Total identified: 844 
that most of the requests there are for transparency of decisions (MaricutAkbik 2020: 1207). By contrast, the Commission does not have the ECB's independence nor its strict secrecy regime - which would anyhow not be justified in macroeconomic and fiscal policy. However, if we follow the six scenarios of oversight interactions outlined in Table 3.1, we can see that weaker oversight questions (types A and B) have almost double the frequency of stronger oversight questions (types $\mathrm{C}$ and $\mathrm{D}$ ). In fact, no single request for sanctions could be identified in the data set, which could suggest that the Commission performed well during the period, that the EP was lax in exercising its responsibility as an oversight body, or that MEPs simply lacked the mechanisms to demands sanctions. In the institutional dynamic between the Commission and the EP, demands for sanctions are rare, albeit possible - for example, in the late 1990s against Edith Cresson, leading to the resignation of the Santer Commission (Topan 2002).

Requests for information can address a variety of issues. For instance, MEPs can inquire about the Commission's current efforts to tackle unemployment or stimulate growth or pose more specific questions about ongoing reforms and negotiations with the Council. Take for instance the question asked by Greek MEP Rodi Kratsa-Tsagaropoulou (EPP) in the joint Economic Dialogue on 28 November 2012:

Commissioners, first of all I would like to refer to the issue of unemployment. It's needless to stress how this is a serious issue for our European perspectives and also the survival of our political effort, political effort for Europe. The action groups that have been created in the countries that have big problems and could develop the various programmes from the 82 million have not been absorbed including [in] Greece. How does this effort progress? Do you have any results? Do we have an implementation of programme? (European Parliament 2012c)

By contrast, requests for justification often assume a disagreement with the Commission's approach on a given topic. One prominent example concerns the methodology behind the EDP and the MIP, namely how the Commission calculates compliance with structural deficit rules or whether a country is experiencing macroeconomic imbalances. For instance, Portuguese MEP Miguel Viegas (GUE/NGL) is very critical of the Commission's assessment of his country's DBP:

When you're calculating the potential output of the economy, which of course affects the structural balance and primary expenditure, then I mean the targets are very close and there's variability as well. These are very volatile measures. So why do you consider Portugal to be at risk of non-compliance? 
For Portugal's population, I think it's difficult for them to understand why a country that has a nominal deficit of 1.4 is labelled as being at risk of noncompliance. (European Parliament 2017a)

On the MIP, Marco Valli (EFDD, Italy) has consistently questioned the Commission's preferential treatment of Germany, whose persistent trade surplus caused macroeconomic imbalances in the euro area (European Parliament 2016b). In general, depending on their nationality and political affiliation, MEPs either considered the Commission's approach too harsh or, alternatively, too lax in running the MIP. For instance, in 2013, German MEP Sven Giegold (Greens/EFA) asked why the Commission did not move to the next step of the MIP in relation to Spain's and Slovenia's excessive imbalances (Giegold 2013). The importance of equal treatment is a recurrent topic in parliamentary questions to the Commission, featuring sixty-eight times in the data set under investigation.

Furthermore, there are questions that are openly critical of the Commission or dispute the general purpose of the Semester. One example of a clear demand for change can be found in a letter sent by two French MEPs from the Front National (ENF group) in 2015:

Within the framework of economic governance, every six months the European Union sets out recommendations to the Member States as part of the European Semester, which aims to provide each Member State with its own set of country persists in presenting more and more recommendations.

1. Is the Commission aware of the fact that the European Semester is pointless?

2. Does the Commission have any plans to purely and simply abolish it? (Martin and Mélin 2015)

From an ideological perspective, MEPs from the ENF group are never expected to say anything positive about the Commission (or the EU for that matter), and in this case, they are incorrect that recommendations are issued every six months (that happens once a year). However, their position is not unique in questioning the effectiveness of the Semester. In fact, multiple academic and think tank studies have noted the poor implementation record of CSRs, which has only worsened over time (Darvas and Leandro 2015; Efstathiou and Wolff 2018; Gros and Alcidi 2015; Maatsch 2017). The failure of Member States to implement CSRs is a recurrent topic in the Economic Dialogues, as described by Slovenian MEP Romana Tomc (EPP):

In my country Slovenia, the reforms which Slovenia had to implement urgently in the health care system, in the pension system and in the labour market ... these reforms exist only on paper. So my question is: if we want 
to ensure that the Member States really take this seriously and this applies not just to Slovenia but to other Member States as well, if we want them to act in a more responsible way, we're going to have to come up with some kind of recipe for what will happen if the Member States do not act. Some sort of response to that. So I'd like to ask both of you: is there anything that we can do to ensure that Member States implement reforms more seriously? (European Parliament 2016a)

The demand to change the Semester by improving the implementation of CSRs is common; other MEPs do not ask for sanctions but for ways to enhance national ownership over CSRs in order to make Member States internally motivated to implement recommendations. Other topics in reference to which MEPs request changes concern the democratic accountability of the Semester. Such a question was posed, for example, in 2013 by two MEPs from the S\&D - Marc Tarabella (Belgium) and Jean Louis Cottigny (France) - in relation to the role of parliaments in the Semester:

The European Semester must in no way jeopardise the prerogatives of the European Parliament or the national parliaments. Can the Commission ensure the proper formal involvement of Parliament in all the steps of the European Semester process in order to increase the legitimacy of decisions which affect all citizens? (Tarabella and Cottigny 2013)

Later, after the so-called 'streamlining of the Semester' during Juncker's presidency, MEPs praised the Commission for publishing Country Reports three months in advance, thus providing the EP sufficient time to discuss them before the publication of CSRs in May. At the same time, the ECON Committee - through the voice of its Chair Roberto Gualtieri (S\&D, Italy) - occasionally reminded the Commission to be more responsive to national parliaments (European Parliament 2015a).

The last type of questions to be discussed are those marked 'outside the scope' of legislative oversight in Figure 3.1 (types E and F). In both Economic Dialogues and letters, there are a total of forty-four requests for policy views asking the Commission's opinion on proposed reforms to the Semester - for example, 'What is the Commission's view on the revision of the Six-Pack?' (Urtasun 2015) - or inquiring about the Commission's stance on actions of other institutions (such as the ECB) which might have consequences for the Semester. Such questions are thematically relevant but fall outside the scope of oversight because they are not an attempt to hold the Commission accountable. According to the analytical framework presented in Chapter 3.3, the exchange of policy views is a form of interinstitutional dialogue, but it cannot be subsumed under accountability. As mentioned earlier, this category is 
different from 'irrelevant questions' (type F), which refer to topics disconnected from the Semester or linked to documents already made public by the Commission.

Moving to the subject matter of questions, Figure 5.9 provides an overview of the issues encountered most frequently in the data set. Initially, questions were coded according to instruments of the Semester (AGS/AMR, CSRs, MIP, EDP, etc.). However, it soon became clear that these are insufficient to capture the thematic complexity of the topics covered. Consequently, most questions received two codes - one denoting an instrument and the other a substantive concern of the question, for example, the social dimension of CSRs, their monitoring by the Commission, or the success of their implementation in the Member States. In respect of the MIP, the SGP, or the EDP, the EP often questioned the Commission's interpretation of rules - especially

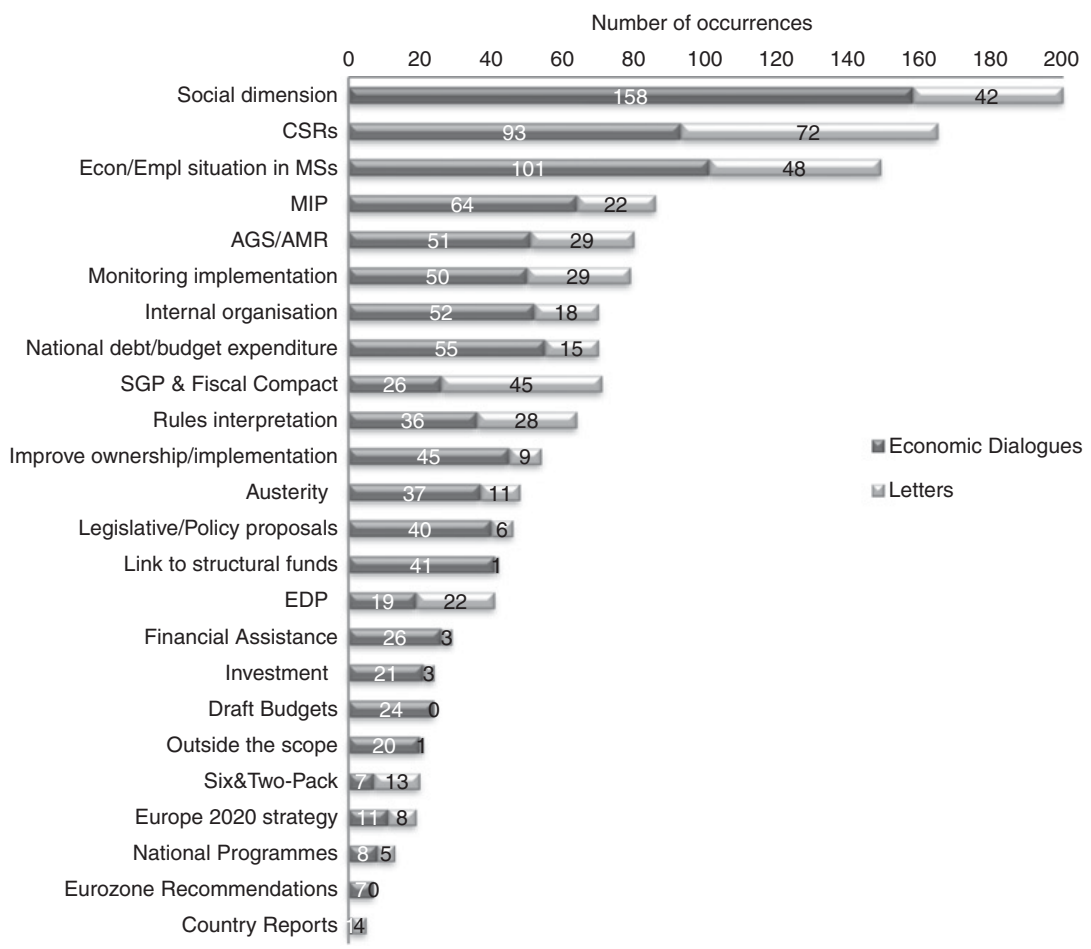

FIGURE 5.9 List of topics raised in questions asked by MEPs of the Commission on the European Semester (December 2010-May 2019). One question can have one or two codes. Total codes assigned: 1,423 for 844 questions 
when it came to proposals for sanctions. In the end, any two codes could be combined, depending on the interests of MEPs.

Figure 5.9 illustrates a clear domination of social aspects - such as unemployment, pension reform, labour market policies, and so on - although this is primarily seen in oral rather than written questions. ${ }^{22}$ CSRs are the second big topic, especially in relation to their monitoring by the Commission and ownership/implementation in Member States. Next, there are questions anchored in the economic or employment situation of one country - typically linked to the AGS, the AMR, DBPs, or Country Reports. On substantive issues, internal organisation' referred to the Commission's handling of different Semester processes, including the inclusion of social partners and increased accountability to the EP. 'National debt/budget expenditure' refers to questions about the application of the SGP or the EDP in relation to the policies pursued by specific governments. Elsewhere, some questions concerned ongoing legislative dossiers, policy proposals, and envisaged reforms to the SGP, the Six-Pack, and the Two-Pack. However, against the theoretical expectation regarding the profile of the EP as a lawmaking parliament, MEPs ask fewer questions about legislative dossiers than those addressed to the ECB on banking supervision (Chapter 4.3.2) or to the ECOFIN Council (Chapter 6.3.2). In addition, there are also fewer questions on 'austerity' and 'financial assistance' than expected - which were instead addressed in the Economic Dialogues with the Eurogroup (see Chapter 6.4).

However, the Commission's participation in the Troika does come up occasionally in meetings with the EP. For instance, in 2013, Greek MEP Anni Podimata (S\&D) criticised the Commission's position vis-à-vis reforms required in Greece as part of programme conditionality:

... you said that you support reform efforts in Greece. Since this allows for very many interpretations, let me ask you: can the European Commission support decisions that violate basic rules of democratic operation? For the sake of implementing the goals of the programme, do you think that this increases the effectiveness of these programmes? Does it strengthen reform efforts or does it act against them, undercut them? (European Parliament 2013b)

The question here is a demand for justification referring to the discontinuation of the national state-owned radio and television broadcaster ERT (the Hellenic Broadcasting Corporation). This was ordered by the Greek

22 This difference could be a consequence of data selection: since letters were identified according to their mentioning of specific Semester instruments, the data set excludes written questions asking about unemployment and other social aspects without specifying keywords of the Semester. 
government as part of the Second Economic Adjustment Programme for the country. In this example, the MEP asked the Commission to justify its position in the episode, which the Commission failed to provide (see next section).

In general, the operations of the Troika (later the 'Quadriga') were of significant concern for MEPs throughout the euro crisis, but their criticism was articulated in venues other than the Economic Dialogues with the Commission. For instance, in May 2013, the ECON Committee organised a separate meeting with Members of the Troika on the Adjustment Programme for Cyprus (European Parliament 2013a). In addition, in 2013/ 2014, the EP launched an own-initiative report on the role and operations of the Troika, which resulted in a Resolution criticising the Commission's 'dual role' in the Troika 'as both an agent of Member States and an EU institution' (European Parliament 2014f). Paragraph 53 of the Resolution described a potential conflict of interest between the Commission's responsibilities as 'guardian of the Treaties' in areas of exclusive of EU competence (such as competition, state aid, and cohesion policy) and its tasks in the Troika affecting policy areas where the EU has no competence (such as wage policy). Commissioners Olli Rehn and László Andor were present in the plenary debate of the report for a resolution (European Parliament 2014b), showing the overlap between interlocutors of Economic Dialogues and those of other scrutiny instruments managed by the EP. To put it differently, the low number of questions on financial assistance included here does not mean that MEPs were not interested in the topic.

The next section shifts the focus to the Commission and its answers to parliamentary questions on the European Semester.

\section{$5 \cdot 3 \cdot 3$ Types of Answers}

How does the Commission reply to questions raised by MEPs on the European Semester? Figure 5.10 shows that the majority of answers are explicit replies provided in both Economic Dialogues and letters. Indeed, 434 out of 844 total answers are explicit replies - although 56 are given in response to questions outside the scope of oversight on the Semester (types E and F). In the case of explicit replies during Economic Dialogues, numbers are similar in response to questions for information (85), justification of conduct (92), and policy change (98). For letters, there are more explicit replies providing information (47) and justification of conduct (33) than those addressing requests for policy change (23). Intermediate replies come second, with 312 occurrences in total - out of which 19 concern questions outside the scope of oversight (types $\mathrm{E}$ and $\mathrm{F}$ ). In absolute numbers, there are more intermediate 


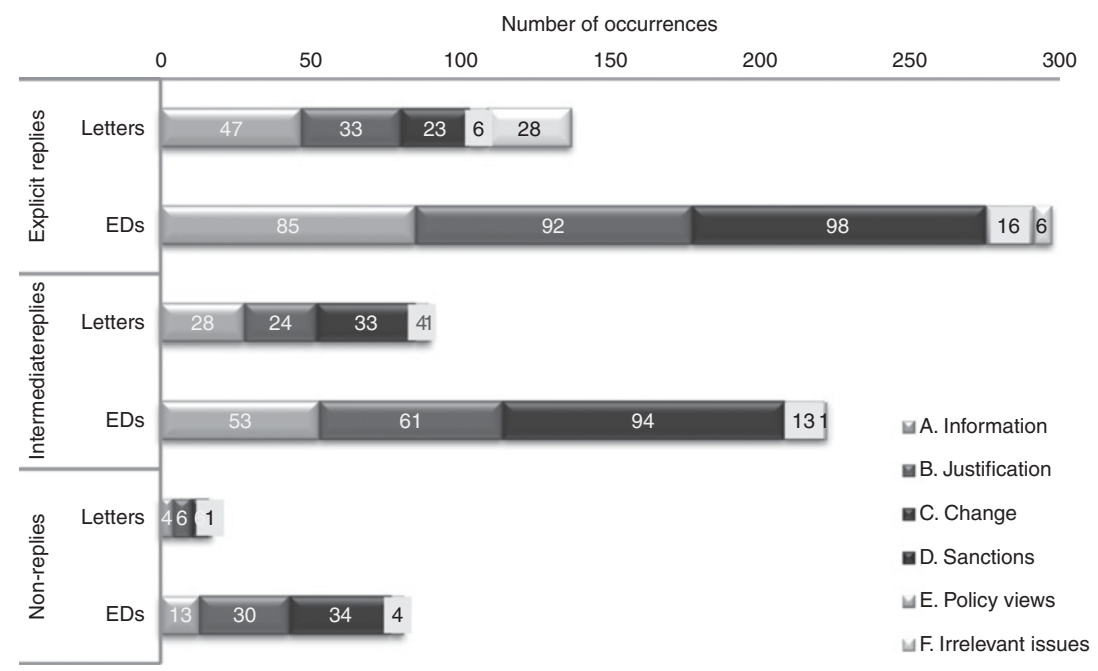

FIgURE 5.10 Types of answers provided by the Commission to MEPs on the European Semester (December 2010-May 2019). Total answers identified: 844

answers in response to demands for policy change in both Economic Dialogues and letters. Finally, non-replies make up the last category, with 98 total occurrences and 5 answers to questions outside the scope of oversight on the Semester. These answers concern questions which the Commission failed to acknowledge altogether, which are much more likely to occur in Economic Dialogues than in letters. However, there are exceptions: in response to the letter cited above by Dutch MEP Marije Cornelissen (Greens/EFA), the Commission gave a generic reply about its commitment to involving civil society and social partners in the Semester - but mentioned nothing about shadow reports as required in the question (Rehn 2012). On the whole, this statistic demonstrates that the Commission is open to engage with questions raised by MEPs on the European Semester, at least partially if not fully.

Beyond the threefold categorisation into explicit, intermediate, and nonreplies, it is necessary to look more closely at the types of answers provided by the Commission. Following the typology in Table 3.1, Figure 5.11 further specifies the direction of the answers, grouping replies depending on whether the Commission responded through rectification (by accepting policy change fully or partially), justification (by defending its decisions or conduct fully or partially), or equivocation (by evading questions or by invoking lack of competence for the issue under discussion and referring MEPs to a different actor deemed responsible). While the Commission provided on average many 
explicit replies, answers tended to fall in to the second category - defending the institution's policies and conduct. For example, in response to the questions cited above from ENF members Dominique Martin and Joëlle Mélin (on whether the European Semester is pointless), the Commission gave a longer defensive answer:

Since its creation, the European Semester has become one of the pillars of the EU's economic governance framework. In particular, it has proved its efficiency in identifying key challenges in Member States, formulating relevant policy advice and fostering the reform process in Member States. All Member States have made some progress in addressing the issues identified in the CSRs for 2014-2015.

Moreover, in the recent years, the European Semester has undergone a number of changes to further improve its efficiency, translating into CSRs, focused on a selected number of issues of macroeconomic and social relevance, and more time for exchange at all levels. (Dombrovskis 2015)

Furthermore, in relation to the accusations brought by Portuguese MEP Miguel Viegas regarding the Commission's discretion in the interpretation of rules on nominal deficits (see previous section), Commissioner Moscovici again defended the approach of his institution:

Let me remind you of what our rules are because of course, the Commission takes a position on the basis of the rules. We don't come up with the rules, we apply them. We've got the structural deficit. And if there's a problem there, there could be significant deviation with the efforts required. We should be 0.6 percent in 2017 and 2018. I just said to Mr. Pereira a few minutes ago that that didn't mean that, uh you haven't made considerable effort and that the gaps and deviations often go reduced as the year goes along. And so there is confidence in the Portuguese economy. ... So please don't charge it with so much emotion because these words aren't as charged as you think they are. They will allow us to move forward together. (European Parliament 2017a)

In a similar vein, in response to the question of Slovenian MEP Romana Tomc (EPP) on the implementation of CSRs, Vice-President Valdis Dombrovskis explained that sanctions are counter-productive because national reforms have to be supported by domestic actors; otherwise, they will not work:

Then on the questions on CSRs' implementation. Indeed, this is [a] concern also of the Commission that we see between limited and some progress in [the] implementation of CSRs and that we need to engage stronger with Member State to improve this implementation. But once again to reiterate, 
there are no specific enforcement mechanisms linked to the CSRs. Well, there are some links for example as regards macroeconomic conditionality in case of EU structural and investment plans which can be put to also, put to use to effectively implement CSRs. But well the Commission's intention is not to come, so to say, with some kind of sanctions mechanisms associated with CSRs. We believe that those are reforms and recommendations which are in the interest of Member State. (European Parliament 2016a)

Despite agreeing about the poor record on the implementation of CSRs, the Commission defends its approach to benchmarking and not forcing Member States into reforms that lack national ownership. On the other hand, equivocated answers occur when the Commission provides generic responses that address the broad topic of a question but not the specific issue raised by an MEP. Take the answer of Commissioner Olli Rehn given to Anni Podimata (S\&D) on the contribution of the Troika to the closure of the national broadcaster ERT and the inclusion of programme countries in the Semester process:

Madam Podimata referred to whether [...] programme countries should be part of the overall process of the European Semester and its economic policy coordination. I think that's something that we have to discuss and we can discuss this. On the other hand, I would not say that we do not have a quite strong accountability as regards these countries because we have discussed this continuously also in this committee and I have responded to your questions over the years very frequently and regularly on the economic policies and programme of the economic adjustment of the programme countries. (European Parliament 2013b)

In this example, the Commissioner acknowledges the question on the European Semester but says nothing about the abolishment of the ERT. The question is thus equivocated. On a different note, the Commission does not answer many questions through rectification. One important example refers to the involvement of national parliaments in the Semester, raised by MEPs on multiple occasions. In 2018, Vice-President Dombrovskis acknowledged that the Semester's inclusiveness of national parliaments could be improved:

The Commission has repeatedly stressed that, in spite of positive developments, there is room for a better involvement of national Parliaments in the European Semester, and made proposals on how to further increase democratic legitimacy of economic governance, most recently in its Communication on further steps towards completing Europe's Economic and Monetary Union. (Dombrovskis 2018) 
Overall, the responsiveness of the Commission in the European Semester is clearly focused on justifying its decisions and conduct to MEPs. Figure 5.11 provides a snapshot of the main findings.

Figure 5.11 shows that in 646 of the total 844 answers, the Commission defended its conduct fully or partially. In respect of the former, the Commission provided 244 replies providing full information and justification of conduct (answers A and B in response to weaker oversight questions), and 94 replies defended a decision or conduct (answers $\mathrm{C}$ and $\mathrm{D}$ in response to stronger oversight questions). Two well-known examples include the decisions of the Commission not to propose sanctions against France's excessive deficit and Germany's macroeconomic imbalances in 2014-2015 - which were widely criticised by the EP (de la Parra 2017: 114). In these cases, MEPs questioned the Commission's discretion in the interpretation of Semester rules and contested whether Member States are being treated equally. Such decisions dominated several Economic Dialogues in 2014-2015 and re-emerged in the years afterwards - especially in terms of sanctioning Germany for its excessive account surplus that could have been, in the view of some MEPs, used for domestic investment (meeting on 14 April 2015, European Parliament 2015). In response,

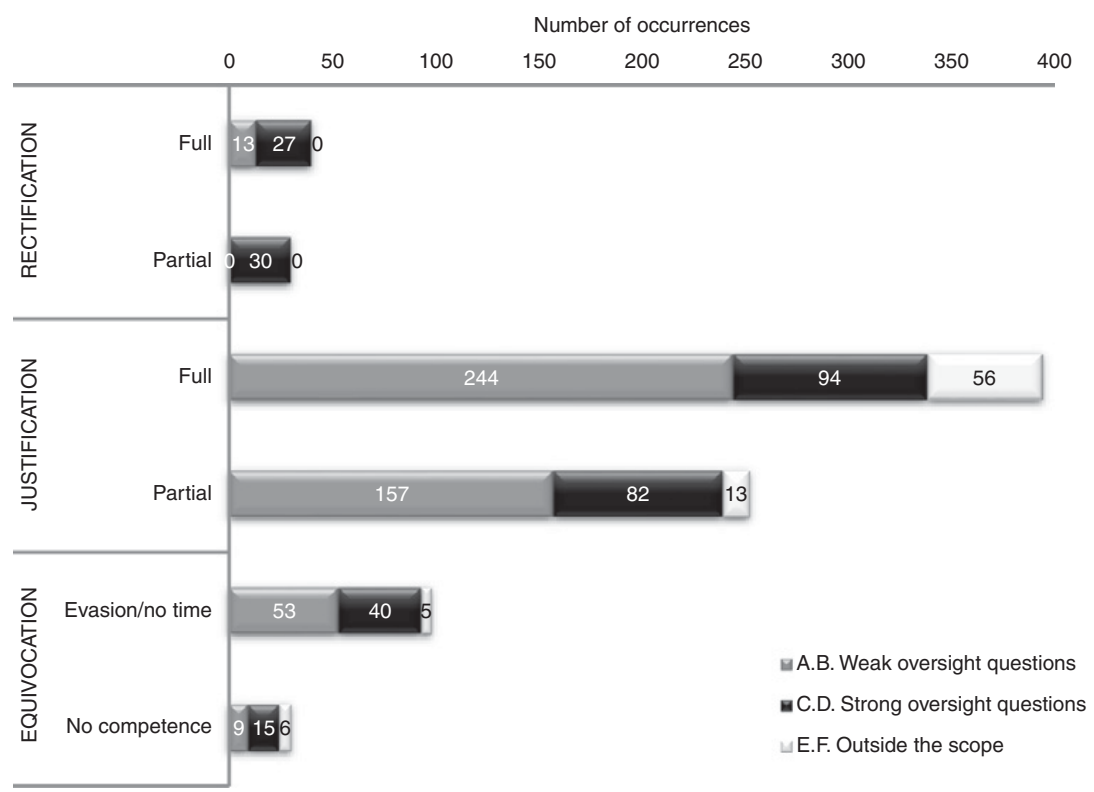

FIGURE 5.11 Responsiveness of the Commission to MEPs on the European Semester (December 2010-May 2019). Total answers identified: 844 
the Commission defended its position, arguing that Germany was already in the MIP - albeit not for excessive imbalances - and that the CSRs for the country consistently emphasised the need to increase domestic investment. In this respect, the Commission justified or defended its conduct without actually changing any decisions on the matter.

On the other hand, equivocated questions are wilfully ignored by the Commission or simply not answered due to the lack of time - which in practice is difficult to differentiate. Due to the high number of speakers in joint meetings, it is sometimes impossible for Commissioners to address all questions even if they wish to, as committee chairs push for short answers due to time constraints. However, in respect of answers equivocated without time pressure, László Andor has the worst record among the Commissioners in the data set, as he repeatedly used his time during Economic Dialogues to make general policy statements and discuss issues that were not clearly raised in any questions. In joint meetings, Dombrovskis has a tendency to answer many questions, leaving only a handful for the ECOFIN and EMPL Commissioners (especially Moscovici). That is why the practice of taking turns answering questions is an effective tool in ECON Committee meetings attended by Dombrovskis and Moscovici. Elsewhere, answers invoking lack of competence imply that the Commission does not have the authority to decide on the matter raised in the question, meaning that responsibility lies either with Member States or with other EU institutions. While only thirty total answers were identified in this category, some are interesting because they allow the Commission to shift attention from the subject of the question to other actors. For example, in response to a question about why the Commission is holding on to its 'austerity approach' vis-à-vis Portugal although this has not improved growth or lowered unemployment, Commissioner Moscovici gave the following reply in an Economic Dialogue in April 2016:

I just wanted to say that [in the Portuguese case] too, the Commission just like in the case of Spain can't get involved in politics. We are here to ensure that certain rules are respected. We have had initial discussions with the Portuguese government which made it possible to avoid the rejection of the budget and necessary to have been taken which we felt made it possible to remain in the right range. And it was done intelligently. It wasn't easy. We had a lot of discussion about it but it was done. (European Parliament 2016c; emphasis added)

The response is equivocated because the Commissioner does not address the effectiveness of austerity measures for the Portuguese economy. 
Moreover, the classic Commission mantra - that it is not allowed to get involved in politics - is hard to believe under the circumstances. Everything that the Commission does with respect to the calculation of budget deficits, macroeconomic imbalances, or compliance with ESM programmes has important political implications (cf. Dawson 2019). Moreover, previous research has shown that the Commission operates in an increasingly politicised environment and often takes into account domestic contestation in different Member States (van der Veer and Haverland 2018).

On the whole, there is a clear hierarchy between the types of answers offered by the Commission in response to parliamentary questions on the European Semester. In most instances, the Commission replies through justification (77 per cent of all answers), followed by equivocation ( 15 per cent of all answers), and finally rectification (8 per cent of all answers). In the realm of justified answers, 61 per cent were full replies - suggesting a general tendency of the Commission to engage with the issues raised by MEPs. At the same time, within the equivocation category, 40 per cent of replies were not clear evasions. Instead, such instances include cases when the format of Economic Dialogues reduced the time available for Commissioners to respond to questions or, alternatively, instances when the Commission was not the relevant authority responsible for the issue at hand. On balance, these statistics portray the Commission as a responsive actor to legislative oversight - focused on explaining and justifying its conduct to MEPs.

\subsection{THE RECORD: HOLDING THE COMMISSION ACCOUNTABLE IN THE EUROPEAN SEMESTER}

To sum up, how accountable is the European Commission to the EP in the framework of the European Semester? Going back to the scenarios of oversight interactions outlined in Chapter 3 (Table 3.1), the analysis above places the Commission mid-way between scenario 2, 'Answerability', and scenario 4, 'Transparency'. Overall, the proportion of stronger oversight questions (34 per cent) is lower than the proportion of weaker oversight questions ( 56 per cent). However, since most questions demand policy changes or the justification of conduct, we can conclude that the type of oversight interactions between the EP and the Commission go beyond the scenario of 'Transparency' applicable to the ECB in banking supervision (Chapter 4).

In fact, the questions addressed by MEPs demonstrate their knowledge of potential problems in the Commission's management of the European Semester. In terms of the variables listed in Figure 3.2, the issue is not the 
asymmetric information between the EP and the Commission but the fact that the European Semester is a multi-level policy framework with several centres of decision-making and implementation dependent on the national level. For example, MEPs ask frequent questions about the general effectiveness of the Semester, which is scarcely implemented in the Member States despite substantial resources invested by the Commission into the process. The complexity of the Semester also has an impact on the types of answers provided by the Commission, which can 'explain away' most problems as located at the national level, depending on the willingness of Member States to carry out reforms.

Furthermore, the aspect of high public pressure (also listed in Figure 3.2) is present in the oversight of the Commission when it comes to the application of sanctions in the EDP and the MIP or the social consequences of austerity measures in the Member States. As shown in the analysis above, MEPs complain about the Commission's discretion to apply different rules (or exceptions) to different countries' budgetary deficits or macroeconomic imbalances. At the same time, MEPs are concerned about the impact of austerity measures in 'programme' countries and consistently demand more social priorities from the Commission. Moreover, in line with the variable on the EP's party system, MEPs raise different questions depending on their political affiliation and country of origin. While there are some signs of a government-opposition dynamic - with stronger oversight questions coming from groups that did not support the current College of Commissioners - the trend is complicated by the nationality of MEPs and whether their Member State was heavily affected by the euro crisis. In any case, the diversity of political and national interests in the EP is undoubtedly a reason for the low number of follow-up questions addressed to the Commission on the European Semester.

As to the Commission's responsiveness to EP oversight, the analysis presented in this chapter revealed a predominantly positive record of the supranational institution in the period under focus. More than half of the questions identified in the data set are answered explicitly and fully. On average, Commission officials who attend Economic Dialogues or answer written questions seem genuinely interested in the concerns of MEPs regarding the management of the European Semester. Attempts at evasion are few, while partial replies are often related to the format of joint Economic Dialogues which allow too many speakers to ask questions simultaneously and thus limit structural opportunities for oversight (see Table 3.2). But although the Commission responds to most questions from MEPs, its answers are generally 
defensive, justifying institutional conduct or explaining decisions in different contexts. As such, the Commission rarely changes its decisions - by promising to rectify previous conduct - in response to demands made by MEPs. For this reason, principal-agent expectations of control by the EP (scenario 1 in Table 3.1) or voluntary accountability by the Commission are clearly not fulfilled in this oversight relationship. To reiterate the assessment above, the Commission is transparent but not fully answerable to the EP in economic governance after the crisis. 


\section{The Economic Dialogues with the ECOFIN Council and the Eurogroup}

The euro crisis re-affirmed the centrality of intergovernmental institutions in EMU decision-making (Csehi and Puetter 2021; Fabbrini 2016; Maricut and Puetter 2018). Next to the European Council - the EU's highest political body - the main actors in the field were the ECOFIN Council and the Eurogroup. Both Council configurations comprise economic and finance ministers, either from all Member States (for ECOFIN) or just from Eurozone countries (for the Eurogroup). Since their portfolio is crucial for a country's economic performance, finance ministers are typically among the highest-ranked members in a cabinet at the national level. In the EU institutional setting, ECOFIN is one of the oldest and most influential Council configurations, with a legal mandate and lead role in EU economic governance since the Maastricht Treaty (Puetter 2014: 155). The Eurogroup functioned outside the Treaty framework from 1998 until 2009, when it was recognised as an informal EU body with a fixed-term president (Protocol 14 TFEU). While both institutions have competences in economic policy coordination, the Eurogroup is the more powerful actor (among others) because it decides on financial assistance programmes that are part of the ESM (ESM Treaty, Article 5). Nowadays, the activities of the two Council configurations are distinct, although ECOFIN has to formally endorse Eurogroup decisions in order to give them legal power (Pisani-Ferry 2006; Puetter 2006).

Owing to their broad mandates and centrality in EMU decision-making during the crisis, the ECOFIN Council and the Eurogroup raise serious accountability concerns (Braun and Hübner 2019; Craig 2017). However, unlike the ECB and the Commission (discussed in the previous chapters), the two intergovernmental bodies have fewer accountability obligations towards the EP. In line with the Treaties, Council bodies are democratically accountable 'to their [own] national parliaments, or to their citizens' (Article $10(2)$ TEU). As a result, the EP does not have legal mechanisms to sanction 
EU intergovernmental institutions for their performance - as opposed to procedures for dismissing the Chair of the Supervisory Board of the ECB (see Chapter 4.2) or passing a motion of censure against the Commission (Chapter 5.2). At the same time, national parliaments and electorates can only hold their own governments accountable, not the ECOFIN Council or the Eurogroup as a whole. There is thus a structural flaw in the EU political system that creates an accountability void for intergovernmental bodies: to put it simply, ministers are individually but not collectively accountable for EU decisions (cf. Brandsma et al. 2016: 624-625). As the only directly elected institution at the EU level, the EP could technically act as the appropriate forum responsible for overseeing collective decision-making by national governments. In fact, the introduction of the Economic Dialogues in the context of the euro crisis acknowledged the need to increase parliamentary scrutiny of EU executive actors, asking the ECOFIN Council and the Eurogroup to appear regularly before the EP's ECON Committee (Chapter 2.2.2).

This chapter examines how MEPs oversee the ECOFIN Council and the Eurogroup in the practice of the Economic Dialogues. Organised since 2012 at the ECON Committee, the Economic Dialogues bring MEPs face to face with the incumbent minister of the ECOFIN Council Presidency on the one hand and the Eurogroup President on the other. While the set-up of Economic Dialogues is similar to meetings with the Commission, the topics discussed and the political dynamic are substantially different. Often, MEPs use Economic Dialogues with ECOFIN to ask about the status of ongoing legislative files, while meetings with the Eurogroup President revolve around financial assistance programmes. Despite the original purpose of Economic Dialogues to ensure EP scrutiny of the European Semester, the emphasis is only partially visible in meetings with the Eurogroup President and almost completely absent from Dialogues with the ECOFIN Council. Moreover, parliamentary questions addressed to the Eurogroup President are both more intense and more relevant to the activity of the Eurogroup as an executive body than the questions posed to the ECOFIN Council Presidency. In fact, in line with the scenarios of legislation oversight outlined in Chapter 3.3.1, the EP's relationship with the Eurogroup qualifies as 'Answerability', whereas the interactions with the ECOFIN Council fall in-between 'Transparency' and 'No control'.

The chapter starts by describing the roles of the ECOFIN Council and the Eurogroup in the EMU governance architecture as well as their centrality during the crisis. The second section problematises the key accountability issues of the two bodies, with an emphasis on their (lack of) accountability towards the EP. Next, the chapter discusses the Economic Dialogues with 
ECOFIN and Eurogroup separately. Since the meetings take place at different times and deal with varying topics, it makes sense to present them independently from each other. In fact, the two types of Economic Dialogues help show the contrast in mandates between ECOFIN and Eurogroup, despite their overlap in composition - as Eurozone finance ministers are part of both institutions. The conclusion reflects on the findings in line with the theoretical expectations set in Chapter 3.3.2.

\subsection{BACKGROUND: ECOFIN, EUROGROUP, AND THE POLITICAL} ACCOUNTABILITY OF INTERGOVERNMENTAL ACTORS IN THE EMU

The ECOFIN Council has had clear responsibilities in EU economic governance since the Maastricht Treaty. Nowadays, Article 121 TFEU specifies the role of ECOFIN in deciding the BEPGs, monitoring economic developments through multi-lateral surveillance, and providing recommendations to Member States depending on their performance and compliance with the BEPGs. In the early zooos, ECOFIN took charge of the Lisbon Agenda and later the Europe 2020 Strategy for growth and jobs (from 2010), becoming the 'dominant political institution' in EU socio-economic policy coordination (Puetter 2014: 161). Starting in 2005, the ECOFIN Council combined the BEPGs with Employment Guidelines into the streamlined 'Integrated Guidelines', which additionally allowed the issuing of CSRs to governments facing specific challenges (Deroose et al. 2008: 836-837). After the crisis, ECOFIN continued to play a key role in economic and social policy coordination in the reformed governance framework of the European Semester (Maricut and Puetter 2018; see below).

Next to economic policy coordination, the ECOFIN Council covers issues related to taxation, financial markets, and capital movements, as well as EU external relations (Council of the European Union 2020a). Similar to other Council configurations, ECOFIN produces legislative acts (regulations, directives, and decisions), often in cooperation with the EP in the ordinary or special legislative procedures, and non-legislative acts such as joint actions and common positions (Lewis 2019: 164). Every six months, the rotating Council Presidency sets ECOFIN priorities - which are especially visible on the legislative front. In terms of external relations, ECOFIN seeks to coordinate the positioning of Member States in international organisations such as the IMF, the World Bank, or the Organisation for Economic Co-operation and Development (Gstöhl 2008).

Furthermore, the ECOFIN Council has competences in the EDP (Article 126 TFEU) as the ultimate decision-maker on whether a government has 
breached EU budget deficit rules and deserves sanctions. As mentioned in Chapter 2.1, sanctions were never applied before the Lisbon Treaty because large Member States such as France and Germany could not be outvoted in ECOFIN (Collignon 2004; Schuknecht et al. 2011: 10). After the crisis, voting rules were modified in order to allow an easier application of sanctions. However, the only instance of penalties ever being imposed on a Member State concerns Spain in 2015; even then, the fine was imposed for failure to provide accurate statistics to the Commission rather than for breaking EDP debt and deficit rules (Savage and Howarth 2018: 213). In 2016, ECOFIN voted that Spain and Portugal had not taken effective measures to correct their excessive deficits, a decision which would normally trigger sanctions under the EDP (Council of the European Union 2016). In the end, however, the Commission chose not to impose a fine given the 'exceptional economic circumstances' in the two countries (Sacher 2019).

While formal votes on the EDP take place in the ECOFIN Council, cases including Eurozone economies are previously agreed in the Eurogroup. With the launch of the Stability and Growth Pact (1997) and the last stage of the EMU (1998), Member States saw an increased need for closer economic and fiscal policy coordination among economies sharing the common currency. In this context, the French demanded a political counterweight to the ECB (a 'gouvernementéconomique'), and the ECOFIN Council was considered insufficient for the task (Howarth 2007). The Eurogroup was the compromise solution: an informal body functioning outside the EU framework, focused on facilitating close interactions between Eurozone finance ministers, while keeping out governments who opted out of the EMU - such as the UK, Denmark, and Sweden (Puetter 2006: 61). Over time, the Eurogroup evolved from 'semi-clandestinity to half-light' as an informal Council caucus in charge of implementing the most significant aspects of the SGP (Pisani-Ferry 2006: 840). After the 2005 reform of the SGP, the Eurogroup was tasked with strengthening the fiscal surveillance of Eurozone Member States by closely assessing their annual national budgets (Hodson 2011: 40-41). With the Lisbon Treaty, the Eurogroup was formally incorporated into the EU institutional framework and assigned the objective to "promote conditions for stronger economic growth' and 'to that end, to develop ever-closer coordination of economic policies within the euro area' (Article 137 and Protocol 14 TFEU).

From the start, the uniqueness of the Eurogroup came from its working methods, which included several features (Puetter 2004: 857-858). The first was informality, which meant that the decisions taken were not official until endorsed by the ECOFIN Council; however, an agreement at the Eurogroup level could not be reversed because it signalled approval by a majority of the 
ECOFIN Council. The second feature referred to its restricted participation; unlike formal Council meetings, where country ambassadors and other officials were present, the Eurogroup deliberately chose to have few people in the room, following a 'minister-plus-one' formula. Third, all Eurogroup debates were strictly confidential, that is, there were no minutes, conclusions, or public votes as in regular Council meetings (cf. Puetter 2006: chapter 3). The latest version of the Eurogroup's working methods dates from 2008, when ministers reiterated their commitment to flexibility/pragmatism and confidentiality as part of the decision-making process (Eurogroup 2008). Overall, informality and secrecy were seen to encourage frank exchanges between ministers and decisions taken by consensus in a form of 'deliberative intergovernmentalism' (Puetter 2012, 2014).

From a legal perspective, the informality of the Eurogroup is a matter of controversy. Despite its significant powers in EU economic governance, the Eurogroup is still not a formal EU institution which can be held liable for its decisions. According to a recent judgment of the CJEU, the Eurogroup 'cannot be equated with a configuration of the Council', 'does not have any competence of its own', and is not 'capable of giving rise to non-contractual liability of the European Union' (Court of Justice of the European Union 2020: 2). The judgment is important because it closes the door for legal accountability through national and EU courts, making the political scrutiny of the Eurogroup all the more relevant.

Between 1998 and 2009, the Eurogroup kept a low profile in the EU governance architecture. This changed with the onset of the euro crisis, which brought the institution to the centre of EMU decision-making while also expanding the scope of the ECOFIN Council portfolio. The following pages describe the main developments involving the two institutions.

\subsubsection{The Euro Crisis and the Domination of Intergovernmental Bodies}

The euro crisis required immediate and decisive executive action at the $\mathrm{EU}$ level, but the institutional framework was not geared towards emergency politics (Kreuder-Sonnen 2019: chapter 5). Although the Eurogroup and the ECOFIN Council were propelled into action, they lacked the political authority to make credible pledges of financial assistance (Puetter 2012: 171). In this context, heads of state and government in the European Council took the lead in crisis management and provided the outlines of the most important reforms (Van Kemseke 2014; Van Rompuy 2014). For Eurozone Member States, a special European Council formation was institutionalised - the 
Euro Summits (Council of the European Union 2019). Yet although the heads of state and government were instrumental in setting the tone for the $\mathrm{EU}$ response to the crisis, finance ministers remained in charge of specialised decisions within the Eurogroup and the ECOFIN Council. Keeping with the rapid pace of the crisis, finance ministers intensified the frequency of their meetings: for example, in the period 2010-2015, the Eurogroup met eightynine times, while ECOFIN held eighty-one meetings (Maricut and Puetter 2018: 201). This means that finance ministers met on average more than once a month.

Both Council configurations saw their activities increase during the crisis. In the early days, ECOFIN ministers extended the practice of 'informal breakfasts' to longer, livelier meetings where they exchanged views on crisis measures (Puetter 2014: 163). In terms of legislative reforms (see Chapter 2.1.1), the ECOFIN Council formalised quick agreements on the Six-Pack (2011), the Two-Pack (2013), and the SSM Regulation (2013). Once the European Semester was established as the new framework for economic policy coordination, ECOFIN engaged in substantive discussions on different instruments such as the AGS or CSRs; however, debates moved over time to preparatory bodies such as the Economic Policy Committee (EPC) or the EFC (Maricut and Puetter 2018: 203). In this context, the ECOFIN Council 'machinery' had to get used to the increased roles of the Commission and the Employment, Social Policy, Health and Consumer Affairs Council (EPSCO Council) in decision-making over the European Semester (Zeitlin and Vanhercke 2018). In parallel, the post-crisis decade (2010-2020) brought more legislative proposals to the ECOFIN Council agenda on issues such as taxation (General Secretariat of the Council 2019a) and financial services (General Secretariat of the Council 2019b). These are complicated files for which ministers needed years to find agreement - if that happened at all.

For its part, the Eurogroup became the centre of decision-making on all aspects related to financial assistance programmes and conditionality negotiations. Members of its main preparatory body - the Eurogroup Working Group (EWG) - sat on the Board of Directors of the temporary European Financial Stability Facility (EFSF) from 2010 to 2012 (European Stability Mechanism 2020a). After the ESM was established as a permanent institution outside the EU framework, Eurozone finance ministers became the Board of Governors of the ESM, while the Eurogroup President served as its Chair (ESM Treaty, Article 5). The practical administration and monitoring of programme countries fell to the 'Troika' - an informal alliance comprising the European Commission, the ECB, and the IMF (European Stability Mechanism 2019: 77). Among the public, the Troika was often considered the face of bailouts and 
austerity measures in the euro crisis; in practice, it was the Eurogroup which brokered agreements and supervised the implementation of aid packages (Craig 2017: 237; Dijsselbloem 2014). This meant that Eurozone finance ministers decided if and how much financial assistance a country received, as well as whether governments fulfilled their obligations for the loans. The interactions between the Eurogroup and the Troika have been compared to a principalagent relationship, where Eurozone finance ministers give a mandate to the Troika to negotiate the conditions of a loan on their behalf and then monitor its implementation (Braun and Hübner 2019: 14). In this respect, the power of the Eurogroup was cemented in the early days of the crisis when the Euro Summit specified that 'any disbursement on the bilateral loans would be decided by the euro area Member States by unanimity' (Euro Summit 2010).

While financial assistance formed the core business of the Eurogroup during the crisis (Hodson and Puetter 2016), there were other activities in the ministers' portfolio. As visible from its biannual work programmes, the Eurogroup has kept a constant interest in the European Semester in respect of assessing DBPs of Eurozone countries, monitoring their Medium-Term Objectives, and evaluating the implementation of the EDP (e.g. Eurogroup 2014, 2018). Eurogroup ministers also focus on the economic situation in the Eurozone as a whole and issue general euro area recommendations (Braun and Hübner 2019: 26). At the level of preparatory bodies, euro area recommendations are the responsibility of the EWG, while economic CSRs are discussed by EFC Alternates and the EPC (Maricut and Puetter 2018: 204). Furthermore, the Eurogroup President was closely involved in designing the post-crisis economic governance framework, having participated in the Four Presidents' Report (Van Rompuy 2012) and the Five Presidents' Report (2015). On the legislative front, the Eurogroup paid special attention to the completion of the banking union and its policy implications for the Eurozone (Eurogroup 2013). Last but not least, with the institutionalisation of Euro Summits, the Eurogroup became responsible for preparing the meetings of Eurozone heads of state and government as well as following up on their conclusions (Council of the European Union 2020b).

Overall, the euro crisis empowered both ECOFIN and the Eurogroup in the economic and financial framework of the EMU. This empowerment came at the cost of political accountability, as discussed below.

\subsection{THE ACCOUNTABILITY OF INTERGOVERNMENTAL BODIES: KEY ISSUES}

The political accountability of intergovernmental bodies is structurally complicated in the EU (see Chapter 2.2.1). In theory, each national government is 
accountable to its own parliament and electorate for decisions taken at the EU level (Article $10 \mathrm{TEU}$ ). Yet intergovernmental agreements are collective, making it difficult for national parliaments or voters to control the outcome of EU decision-making in the absence of unanimity rules (Brandsma et al. 2016: 625; see also Crum and Curtin 2015). The most blatant example is the referendum on a new financial assistance programme for Greece, organised by the Tsipras government in mid-2015. While the referendum had clear populist motivations, asking the Greek people to "say "no" to ultimatums, "no" to blackmail', the vote did not change the outcome of intergovernmental negotiations - as Greek Prime Minister Alexis Tsipras accepted a week later the same if not heavier conditions attached to financial assistance (Lowen 2015). Former Italian Prime Minister Mario Monti described the referendum as a violation of democracy' because it seemingly offered the Greek voters a choice and then 'threw it away' (cited in Vincenti and Michalopoulos 2015). In Monti's view, the culprit was Tsipras, not the EU, yet the problem is systemic: national electorates can vote governments in and out of office, but they have little control over what is decided at the EU level, even when they give cabinets unambiguous mandates in Council negotiations.

The other major issue of intergovernmental bodies concerned how equal Member States were in negotiations. Despite constitutional provisions regarding the 'equality of Member States before the Treaties' (Article $4[2]$ TEU), the dynamics of the euro crisis inevitably created a hierarchical relationship between creditor and debtor countries (Crum and Merlo 2020; Fabbrini 2016). This made accountability difficult because it allowed, de facto, for some national parliaments and electorates to have more control over EU decision-making than others. Germany in particular was an important player in its capacity as the Eurozone's largest and strongest economy as well as the only country whose national parliament had to vote on ESM lending programmes both ex ante and ex post (Moschella 2017: 241). In addition, Germany's influence was ideational, shaping the post-crisis economic governance architecture based on its national model of 'stability through balanced budgets', with clear deficit rules and targets (Schmidt 2020: 127). Wolfgang Schäuble, the German finance minister (2009-2017) in ECOFIN and the Eurogroup, remained a divisive figure throughout the crisis: vilified in Greece as an advocate of austerity who imposed harsh conditions on countries in need of financial assistance while being celebrated at home for protecting taxpayers' money (Kroet and Oliveira 2015).

In the academic literature (and in reality), the idea of German domination is appealing because it makes intuitive sense. Indeed, from a rationalist perspective, we would expect the preferences of the strongest country to shape the 
outcome of EU decision-making (Schimmelfennig 2015). Nevertheless, this view overlooks the role of other 'creditor' countries that shared the philosophy of the German government on balanced budgets. Among others, the Netherlands and Finland were the most fervent supporters of austerity and structural reforms as necessary conditions for countries requesting financial assistance (Schmidt 2020: 134). Given the confidential, collegial, and consensus-seeking mode of decision-making in the Eurogroup, ministers were unlikely to speak out against each other (Puetter 2016: 609). When Greek Finance Minister Yanis Varoufakis broke this taboo in 2015 by publicly questioning the democratic character of secretive deliberations and criticising the treatment of his country, he only attracted hostility from the Eurogroup (Bickerton 2015). No other minister supported his position, although this could have been an opportunity to address the Eurogroup's lack of transparency and accountability to national electorates.

In fact, finance ministers generally see the Eurogroup working methods as an advantage. From their standpoint, the flexibility and confidentiality of Eurogroup meetings are assets because they allow frank discussions among peers without worrying how domestic audiences will react to their positions at the EU level. As (in-)famously explained by former Eurogroup President JeanClaude Juncker:

Monetary policy is a serious issue. We should discuss this in secret, in the Eurogroup. The same applies to economic and monetary policies in the Union. If we indicate possible decisions, we are fuelling speculations on the financial markets and we are throwing in misery mainly the people we are trying to safeguard from this. I'm ready to be insulted as being insufficiently democratic, but I want to be serious. (...) There is insufficient awareness at the European level when it comes to these issues, because each of us wants to show his domestic public that he's the greatest guy under the sky. (Juncker, cited in Pop 2011)

The problem is that the Eurogroup's informal and secret decision-making process is structurally at odds with democratic accountability and transparency (Braun and Hübner 2019; Craig 2017; Mahony 2015). While finance ministers might argue they need the 'space to think' within the EU's intergovernmental institutions, national citizens also have the right to know what positions their respective governments are taking behind closed doors (Hillebrandt and Novak 2016: 528). Unsurprisingly, the Eurogroup believes there is 'an extremely high level of governmental and parliamentary scrutiny' at the national level - even in the controversial cases of financial assistance programmes through the ESM (Dijsselbloem 2014). 
However, if national parliaments cannot hold EMU intergovernmental bodies accountable for collective decisions or are unequal in doing so, the EP is also incapable of compensating for this structural weakness. In the EMU, the EP lacks formal powers to veto or influence executive decisions of the Eurogroup and the ECOFIN Council (Crum and Merlo 2020; Rittberger 2014). From a principal-agent perspective (Chapter 3.2.1), the EP is not the principal of ECOFIN or the Eurogroup, whose ministers have a direct relationship to their domestic electorates. In fact, in relation to EU and national citizens, the EP and EU intergovernmental bodies play the role of 'multiple competing agents' (Strøm 2000: 269), similar to the dynamics found in presidential systems of government (Lupia and McCubbins 1994; McCubbins and Schwartz 1984). Going back to the Treaties, the EP and the Council are envisaged as co-legislators in the ordinary legislative procedure (Articles 289 and 294 TFEU), representing citizens and Member States, respectively, in the EU decision-making process (Article 1o TEU). If anything, the two institutions can frustrate each other's legislative and budgetary agendas and exercise a form of ex ante or pre-emptive accountability. For this reason, the new executive roles of the Eurogroup and the ECOFIN Council in financial assistance or the European Semester sit uncomfortably with the constitutional roles of the institutions prescribed in the Treaties. This is not to say that effective EP scrutiny of the ECOFIN Council and the Eurogroup is impossible, but it is difficult from the onset.

Furthermore, the EP's legislative focus and internal dynamics do not help the effective scrutiny of intergovernmental actors. The profile of the EP as a 'law-making' parliament (Sieberer 2011) with a transnational multi-party system (Russo and Wiberg 2010) is bound to limit the structural opportunities for oversight in the EMU (Ogul 1976; Rockman 1984). In EMU legislative decision-making, the EP may be on equal footing with the Council under the ordinary legislative procedure, but in practice the Council is the stronger actor (Bressanelli and Chelotti 2016, 2018). The ESM is an intergovernmental organisation outside the EU Treaty framework, meaning the EP has no influence whatsoever over financial assistance programmes (Howarth and Quaglia 2014; Rittberger 2014: 117). The only element that gave the EP an advantage over the ECOFIN Council and the Eurogroup since the euro crisis was public attention to EMU governance, especially in respect of bailout decisions. As we know from studies on legislative oversight, public pressure can be an important factor in the parliamentary scrutiny of executive actors (Martin 2011b; McCubbins and Schwartz 1984; Wiberg and Koura 1994).

Against this background, the Economic Dialogues with the ECOFIN Council and the Eurogroup President were established in the hope that they 
will improve political accountability in the EMU (de la Parra 2017; Kluger Dionigi 2020). The legal basis of the Economic Dialogues is the same as that for the Commission, including identical articles on transparency and accountability found in the Two-Pack and the Six-Pack legislation. Accordingly, the EP and the Council could organise Economic Dialogues on the BEPGs, the results of multi-lateral surveillance on budgetary positions (including the EDP) and macroeconomic imbalances, as well as on the content of CSRs - especially if there were deviations from Commission recommendations (the so-called 'comply or explain' principle). ${ }^{23}$ In respect of the Eurozone, the Six-Pack listed as possible topics the sanctions and fines applied in the enforcement of the EDP and the MIP, respectively. ${ }^{24}$ The Two-Pack added two elements to the list of potential subjects of Economic Dialogues: (1) the monitoring and assessing of budgetary plans in the Eurozone ${ }^{25}$ and (2) the special procedures for countries experiencing financial difficulties - namely enhanced surveillance, macroeconomic adjustment programmes, or postprogramme surveillance. ${ }^{26}$ In fact, according to Markakis, the Two-Pack 'lays down the most detailed accountability and transparency requirements to date' (Markakis 2020: 128). While the tasks of the ECOFIN Council and the Eurogroup are difficult to separate in the European Semester (e.g. for the EDP and the MIP), it was clear that the Eurogroup will be the interlocutor for questions on financial assistance programmes - even if the ESM was technically not an EU organisation.

Before moving to the analysis of oversight interactions between the EP and the ECOFIN Council/the Eurogroup, a few words are in order regarding the appropriateness of the type of actor 'giving account' to a parliamentary forum (cf. Bovens 2007). It is well known that finance ministers representing the Presidency of the Council still need to run their own national administrations while knowing the details of legislative and executive decisions taken by ECOFIN at the level of preparatory bodies and ministers' meetings. Under the circumstances, is it reasonable to expect the incumbent of the Presidency to be held accountable for decisions taken by ECOFIN as a whole? The format of the Economic Dialogues would suggest this is the case. The problem is less pronounced for the Eurogroup President, whose position is permanent (for two and a half years) and who chairs an informal and smaller, club-like body. In any case, both Presidents - of ECOFIN and the Eurogroup - are

23 Article zab of Regulation 1466/97, Article 2a of Regulation 1467/97, and Article 14(1) of Regulation 1176/2011.

24 Article 3 of Regulation 1173/2011 and Article 6 of Regulation 1174/2011.

25 Article 15 of Regulation 473/2013.

26 Articles 3, 7, 14, and 18 of Regulation 472/2013. 
perceived to speak on behalf of the Council and articulate the common or consensus position of the Member States in their respective configurations.

The following sections go over the content of the two types of Economic Dialogues in turn, following the analytical framework outlined in Chapter 3.3. Each section starts with an overview of the profile of questioners and respondents identified during Economic Dialogues, which is important in order to grasp political dynamics in the EP as well as differences in responsiveness between Council Presidencies or Eurogroup Presidents. Next, in line with the analytical framework of the book, the emphasis lies on the types of questions asked by MEP - which can request information, justification of conduct, change of decisions, sanctions, or policy views. Finally, the analysis includes the types of answers given in response to parliamentary questions (explicit, intermediate, or non-replies that provide rectification, justification of conduct, or equivocation/evasion of questions). The conclusion reflects on the findings of the analysis in relation to the scenarios of legislative oversight identified in Chapter 3.3.1.

\subsection{THE ECONOMIC DIALOGUES WITH THE ECOFIN COUNCIL PRESIDENCY}

The ECON Committee organises Economic Dialogues with the finance minister of the country holding the ECOFIN Council Presidency between two and four times a year. In the period under focus (January 2012-May 2019), most Presidencies attended ECON meetings at the beginning and at the end of their terms (Denmark, Cyprus, Ireland, Lithuania, Italy, Luxembourg, the Netherlands, Slovakia, Malta, Estonia, and Bulgaria), while others were present only once (Greece, Latvia, Austria, and Romania). If Greece and Romania held the Presidency during EP electoral years (2014 and 2019, respectively), it is not clear why Latvia (2015) and Austria (2018) attended Economic Dialogues only at the beginning of their terms. Keeping in mind that the Six-Pack entered into force in December 2011, the first formal Dialogue with ECOFIN took place on 23 January 2012. At the start of the meeting, the Chair of the ECON Committee described the new procedure as follows:

As you know, it's customary for the incoming president of the ECOFIN Council to come along to the committee and discuss the program and priority of the Presidency and the challenges ahead. And these exchanges of views with the president of the ECOFIN Council are also a good occasion to have an Economic Dialogue as foreseen in the new rules for economic governance 
in the Six-Pack. And in particular, on how the Council will implement the new economic governance framework, both fiscal and macroeconomic imbalances in practice. (Sharon Bowles, cited in European Parliament 2012a)

In other words, the Economic Dialogues were incorporated into an established practice of the ECON Committee to meet the incumbent Presidency of the Council to discuss priorities or achievements for the next/past six months. As the analysis below will demonstrate, this institutional origin of the Economic Dialogues with ECOFIN will prove impervious to change, as the topics covered will continue to revolve around legislative files handled by each Presidency instead of instruments of the European Semester as envisaged in the Six-Pack.

Figure 6.1 shows that the ECOFIN Council Presidency attended 26 Economic Dialogues in the period under investigation: 9 Economic Dialogues took place during the 7 th EP parliamentary term (20092014) and 17 during the 8th parliamentary term (2014-2019). In total, the analysis identified 613 questions raised by MEPs in 26 meetings organised over 7 years. On average, MEPs asked 22 questions per meeting during the 7 th parliamentary term and 25 questions per meeting during the 8 th term.

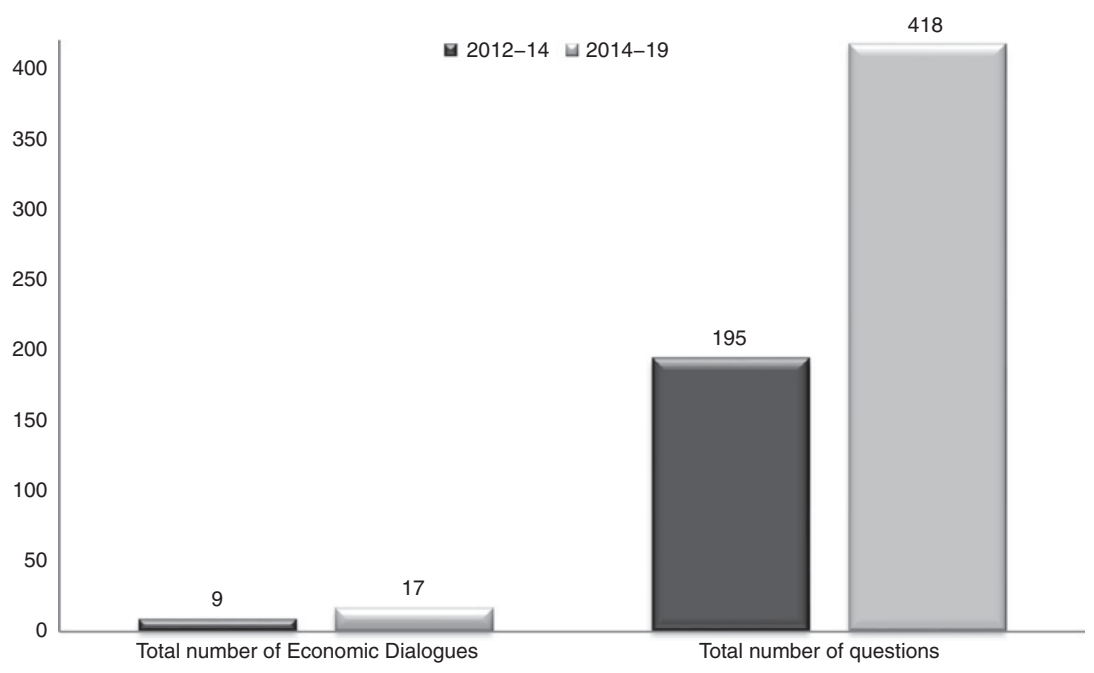

Figure 6.1 Number of Economic Dialogues with the ECOFIN Council Presidency and number of questions identified during each parliamentary term (2012-2014 and 2014-2019, respectively). 
In terms of the format of meetings, the ECON Committee introduced a change in January 2013 by establishing five-minute Q\&A slots for each MEP. This was clearly beneficial for the dynamic of the Economic Dialogues, in contrast to the 2012 meetings when many MEPs made long comments before asking a question (if a question was posed at all). Moreover, the practice of grouping several MEPs in one slot increased the likelihood for incomplete replies, for example, in the first Dialogue with Danish Minister Margrethe Vestager, the time limits did not allow her to address each question in turn; at the same time, when analysing the answers, it was sometimes hard to understand to whom she was replying exactly (a similar problem was found in the early Economic Dialogues with the Commission, see Chapter 5.3.2). The first sub-section discusses the profile of questioners and respondents in detail.

\subsubsection{Profile of Questioners and Respondents}

Who are the MEPs who ask questions during Economic Dialogues with the ECOFIN Council? In respect of nationality, the findings are consistent with the apportionment of EP seats to each Member State. Accordingly, the MEPs who take the floor most often come from the largest Member States: Germany, France, and Italy, and to a lesser extent the UK and Spain (Figure 6.2). There are, however, some discrepancies: most notably, MEPs from Greece and Portugal feature frequently in Economic Dialogues with the ECOFIN Council Presidency, despite having a lower number of MEPs. In contrast, MEPs from Poland and Romania rarely take the floor - although they have a much higher number of MEPs given the population of their countries. This discrepancy reflects the focus on Eurozone countries hit by the euro crisis; indeed, Greece and Portugal were highly affected (as were Ireland and Cyprus, but they have fewer MEPs by default). On a different note, there is no systematic correlation between the nationality of MEPs and the nationality of the minister holding the ECOFIN Council Presidency. The only exception is Italy, when four Italian MEPs asked questions of Minister Pier Carlo Padoan during Economic Dialogues with ECOFIN in 2014-2015.

Furthermore, when it comes to the party affiliation of MEPs asking questions of the ECOFIN Council Presidency, Figure 6.3 shows that the numbers are not entirely consistent with the proportion of seats held by each political group in the EP. For example, while the S\&D ranks second by size in both parliamentary terms (2009-2014 and 2014-2019), it is the leading group asking questions in the Economic Dialogues with ECOFIN. In fact, in the 2009-2014 parliamentary term, the EPP had almost 100 seats more 


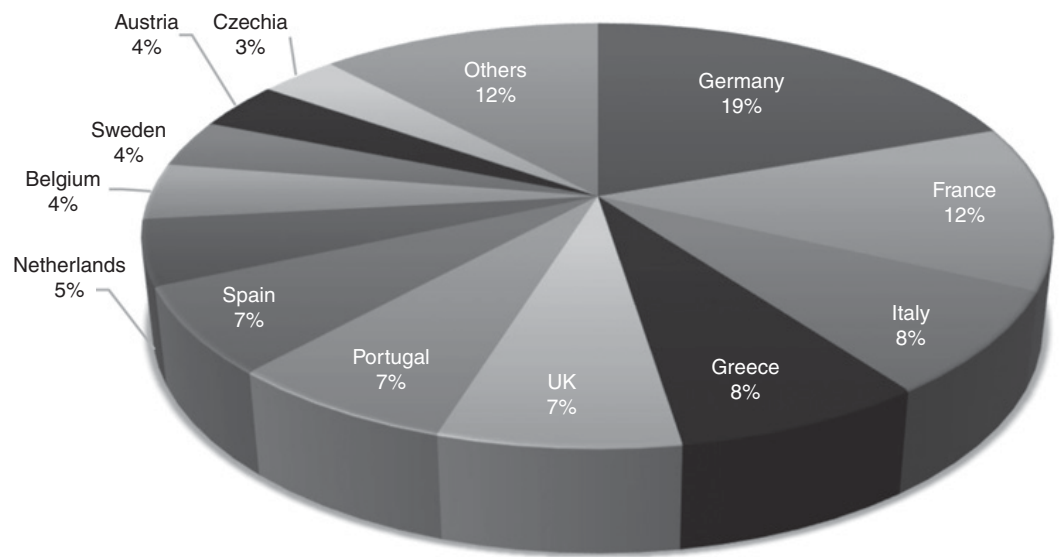

FIGURE 6.2 Nationality of MEPs taking the floor in Economic Dialogues with the ECOFIN Council Presidency (2012-2019). Total MEPs identified: 303

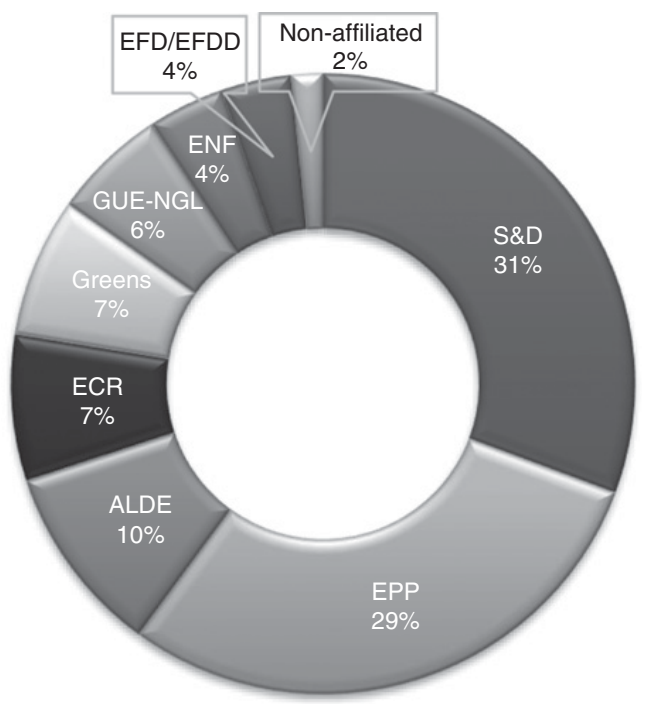

FIGURE 6.3 Political affiliation of MEPs taking the floor in Economic Dialogues with the ECOFIN Council Presidency (2012-2019). Total MEPs identified: 303

than the S\&D. The difference between the S\&D/EPP and other political groups is larger than their proportion of seats in the EP; in fact, in many meetings, after the mandatory round in which all political groups could take 
the floor, only MEPs from EPP and S\&D would continue to ask questions. This is a reflection of the topics covered in the meetings: since numerous questions revolve around legislative files currently under negotiation between the two legislators, there are more MEPs from EPP or S\&D who served as rapporteurs on these files. Otherwise, the order of the smaller political groups varies because their size changed in the two parliamentary terms: that is, ALDE and the Greens had more seats during 2009-2014, while the ECR and GUE-NGL increased their presence in the EP during 2014-2019.

Overall, the political affiliation and nationality of MEPs are important in terms of the variables expected to have a negative effect on legislative oversight: namely the multi-party system of the EP and its profile as a law-making parliament (Chapter 3.3.2). More specifically, the diversity of political and national interests represented in the EP is bound to lead to uncoordinated, diffuse questioning and few follow-ups (see also the dynamic with the Commission, Chapter 5.3). At the same time, the EP's long-term emphasis on law-making is reflected in the interactions with the Council by the relative dominance of MEPs who serve as rapporteurs on legislative files. Given their status as co-legislators with the Council, these MEPs tend to prioritise their legislative activity as opposed to the executive actions of the ECOFIN Council in the EMU.

Furthermore, in respect of the number of questions addressed to the different Council Presidencies, Figure 6.4 provides an overview in absolute numbers. On average, there were two Economic Dialogues per Presidency, organised at the beginning and at the end of the six-month period. The exceptions are Austria, Greece, Latvia, and Romania - which only participated in one Economic Dialogue at the ECON Committee. While the number of questions posed to each Presidency is relatively stable, the outliers are Lithuania, Cyprus, and Romania - which received, for instance, about half of the number of questions addressed to Luxembourg, Denmark, or Malta. There are two reasons why some Presidencies receive more questions: in some cases (such as Luxembourg and Malta), this has to do with domestic developments that attract media attention, for example, "tax haven' allegations connected to LuxLeaks and the Panama Papers. In other instances, Presidencies receive a high number of questions because they advance important legislative dossiers, as was the case of Denmark (2012), Ireland (2013), or Italy (2014).

Overall, the nationality and political affiliation of MEPs asking questions of the ECOFIN Council illustrates the lack of a particular country focus as well as the dominance of MEPs from the two largest political groups. 


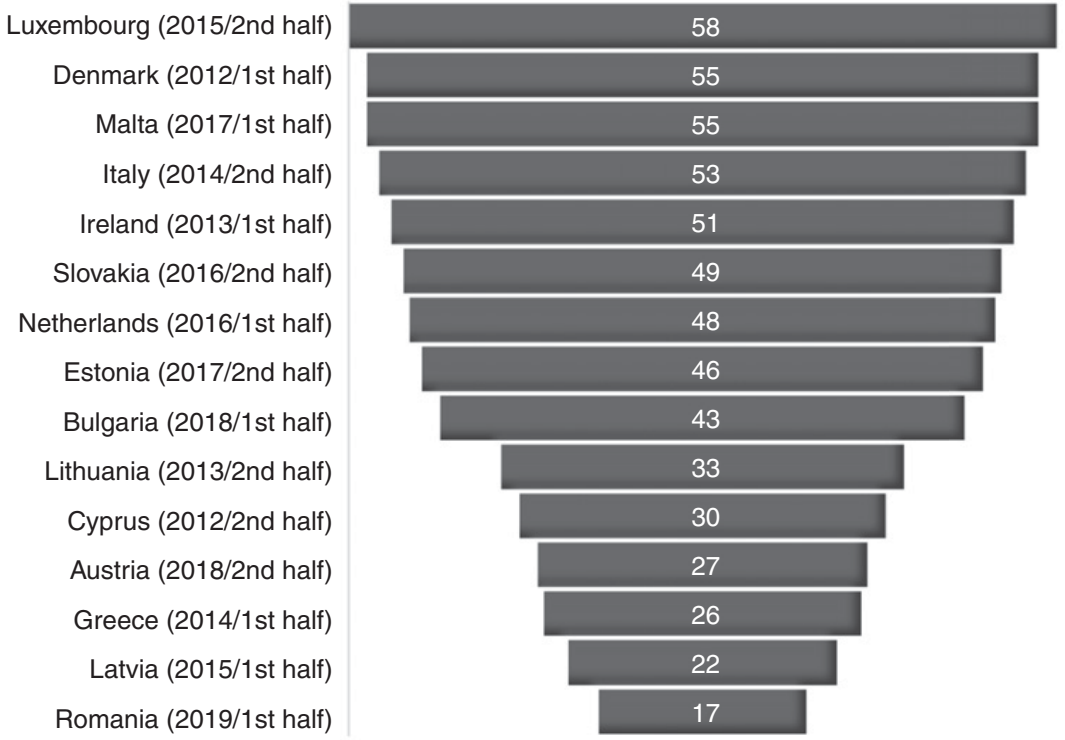

FIGURE 6.4 Number of questions addressed to each country holding the sixmonth ECOFIN Presidency. Total: 613

\subsubsection{Types of Questions Asked}

What kind of questions do MEPs ask in Economic Dialogues with the ECOFIN Council Presidency? Figure 6.5 shows that the majority of questions are requests for policy change (219), followed by requests for information (155). Often, MEPs would pose questions about ongoing legislative dossiers, taking a clear stance on their preferred amendments. Next, there are demands for justification of decisions (128) and questions about policy views (111). Questions requesting policy views encompass specific requests from MEPs on the Presidency's opinion on a variety of issues, such as the likelihood of finding compromises in the Council on given files, the assessment of the Presidency on Commission proposals or actions by the ECB, the Eurozone's prospects for growth, or the potential impact of envisaged reforms. Questions for policy views are open-ended, meaning that MEPs do not voice opinions on necessary reforms, which would imply requests for policy change.

Furthermore, Figure 6.5 reveals that the number of initial questions is higher than follow-up questions for all the five categories identified. This suggests that each MEP asks his/her own questions, with fewer instances of members pushing on a specific topic with multiple rounds of questions. 


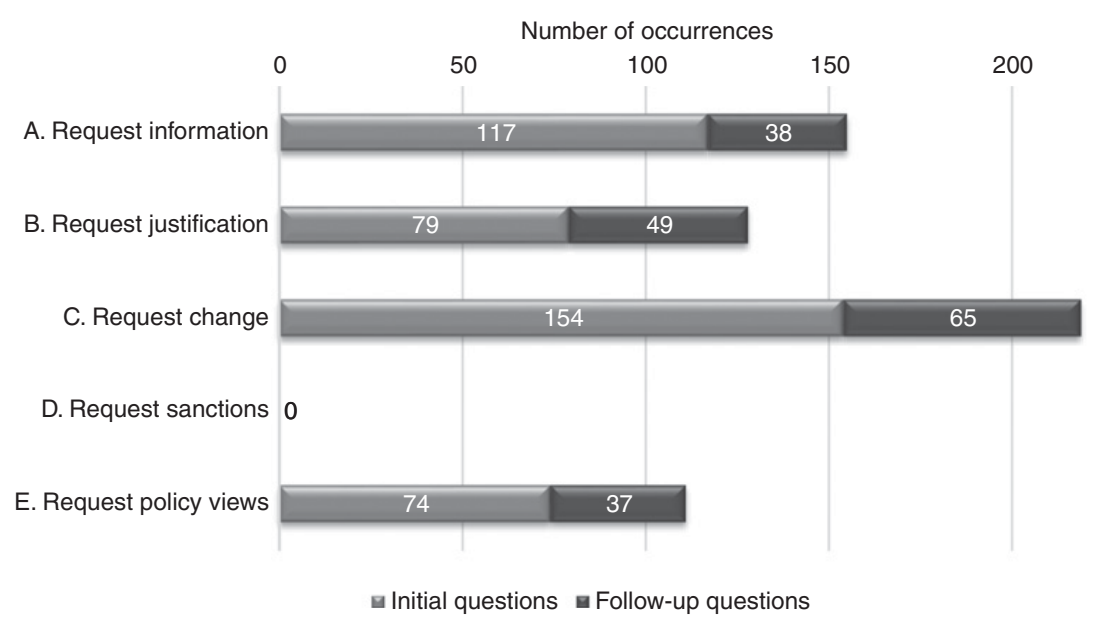

Figure 6.5 Types of questions identified in Economic Dialogues with the ECOFIN Council Presidency (2012-2019). Total questions: 613

Unlike in the Economic Dialogues with the Commission, no irrelevant questions were identified in the analysis (questions type F). The only 'dubious' performance of the ECON Committee was in the first meeting with the Estonian Presidency in July 2017, when several MEPs started their interventions with remarks about what a great country Estonia is, with beautiful landscapes and a successful e-governance infrastructure. Sven Giegold (Greens/EFA, Germany) even referred fondly to a holiday he had in the country in his youth (European Parliament 2017d). However, in the second Dialogue with Estonia, when it becomes clear that the minister has a tendency to evade questions (see below), the same Giegold pushes for replies to his very specific questions. Another instance of questionable conduct by MEPs is the Dialogue with the Bulgarian Finance Minister Vladislav Goranov on 12 July 2018. The meeting is scheduled early in the morning, and at the beginning, only two MEPs are present. Since the room is almost empty, the same two speakers take the floor twice on behalf of their colleagues. This raises questions about parliamentary interest in various ECOFIN Presidencies, based on their Eurozone membership or current controversies captured in the media.

Next, it is important to link the types of questions asked by MEPs with the policy issues raised during Economic Dialogues with the ECOFIN Council Presidency (Figure 6.6). By far, the topic at the forefront of most meetings concerns ongoing legislative files negotiated by the EP and the Council either 


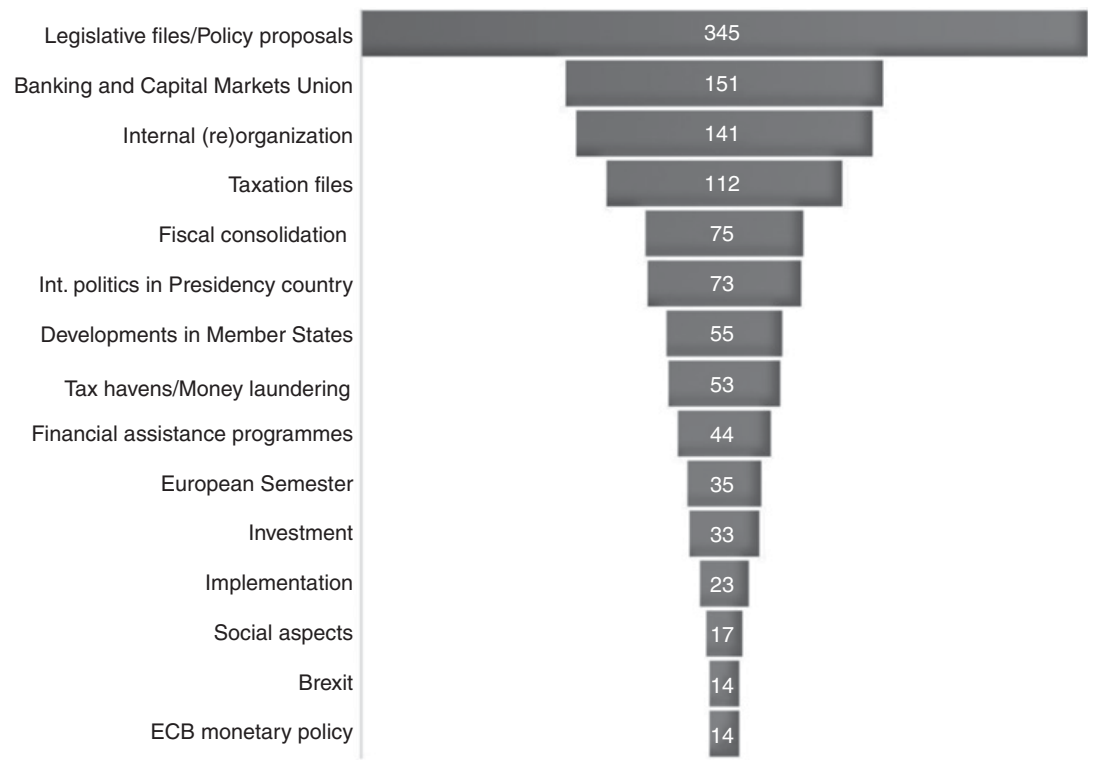

FIGURE 6.6 Range of issues raised by MEPs during Economic Dialogues with the ECOFIN Council Presidency (2012-2019). Most questions are assigned two codes.

Total issues: 1,186

through the ordinary or the special legislative procedure. This clearly reflects the profile of the EP as a law-making parliament (Chapters 1.2 and 3.3). In the data set analysed, questions on legislative dossiers feature in 346 out of the 613 questions identified. Most often, such questions refer to the Banking or the Capital Markets Union (151 times), taxation files (112 times), and less frequently issues concerning planned EMU reforms (46 times) envisaged in documents such as the Five Presidents' Report. In this context, MEPs often inquire about the status of negotiations (requests for information) or they express their own preference for outcomes on given legislative files (requests for policy change). In respect of the latter, the MEPs end the question by asking the ECOFIN Council Presidency what they think about their proposals or whether it is feasible. One Dialogue with more heated exchanges revolved around the negotiations on the SSM Regulation and the CRD IV in January 2013, during the Irish Presidency of the Council. In the meeting, several MEPs accused Minister Michael Noonan of withdrawing support for the compromises reached during the previous Cypriot Presidency. The minister defended his position by saying his team was conducting all the necessary meetings and trialogues, thus showing his country's commitment to solving 
the files. MEP Philippe Lamberts (Greens/EFA, Belgium) pointed out that the problem is not the lack of meetings but the diplomatic language of negotiators who obviously wanted to change things that had already been agreed (European Parliament 2013c). When it comes to questions on legislative dossiers, this meeting was among the few that clearly illustrated attempts by the EP to hold the Council Presidency accountable for its chairing of ECOFIN negotiations on legislative files.

By contrast, questions about the European Semester (including instruments such as the AGS, DBPs, or CSRs) are only present in 35 of the 613 questions identified. Such instruments are sometimes connected to questions about fiscal consolidation (reducing deficits and making structural reforms), identified in 75 questions; however, the discussion on fiscal consolidation can take place independently of the Semester, in connection with the overall EMU architecture and the need for policy reforms (26 times). This is very surprising, given that the main reason for establishing the Economic Dialogues was to discuss fiscal and macroeconomic developments linked to the Semester. In fact, the only meeting that clearly focused on the Semester is the Dialogue on 10 July 2012. In contrast to other meetings, Cypriot Finance Minister Vassos Shiarly did not focus his opening remarks on his country's Presidency priorities on ongoing legislative files. Instead, his speech centred on the recently adopted CSRs for that year, including descriptions of the 'comply -or -explain' principle applied to 10 out of 27 countries. The introduction sets a different tone for the meeting, which ended up debating concrete differences between the Commission proposals and the final version of CSRs adopted in the Council (European Parliament 2012b). Another novelty is that the minister came accompanied by his country's EU ambassador, who answered the more specific questions on the Semester. A nice example of a request for information about the decision-making process behind CSRs can be found below:

Olle Schmidt (ALDE, Sweden): I wonder how the discussion, the debate is going on, because you have a recommendation, and then you do some changing in them and then you do some [more] last-minute changes. How is this actually happening and what is the reasoning behind this? Because that would be interesting to hear. Is it an open debate or is it solved beforehand? (European Parliament 2012b)

From a legal perspective, the Dialogue with Cyprus on 10 July 2012 remained the only meeting where the topics of questions followed the rules set out in the Six-Pack. Otherwise, MEPs continued to use meetings with the ECOFIN Council Presidency in the same way they did before the Six-Pack (and before 
the crisis for that matter), namely to inquire about the status of negotiations on legislative files. From this perspective, it is clear that the Economic Dialogues with the ECOFIN Council Presidency are a missed opportunity for the EP to oversee the activities of the ECOFIN Council as an executive rather than as a legislative body.

Moreover, the interactions between MEPs and the Council Presidency can be described as peaceful if not friendly; it is rare that MEPs confront a finance minister about anything. One example refers to domestic political issues in the Presidency country (present in seventy-three total questions) when MEPs inquire about tax haven allegations made against Luxembourg in 2015, the Netherlands in 2016, and Malta in 2017 (identified fifty-three times). Based on revelations associated with LuxLeaks and the Panama Papers, several MEPs criticised the tax regimes of these countries and demanded justification of conduct and changes in national tax policy. For instance, during both Economic Dialogues with the Maltese Presidency in the first half of 2017 , Finance Minister Edward Scicluna was repeatedly asked about the tax system of his country, so much so that ECON Committee Chair Roberto Gualtieri reminded MEPs that the minister was present in his capacity as ECOFIN President - not as finance minister of Malta - meaning that questions should be raised accordingly (European Parliament 2017b). The intervention of the Chair is problematic, keeping in mind that at the start of the meeting on 25 January 2017 , he mentioned that he was friends with the minister (who was a former MEP).

Overall, the Economic Dialogues with Malta are the most confrontational in the data set, as MEPs also criticise the Council's lack of cooperation with the EP's special investigative committee on the Panama Papers (the PANA Committee). One issue mentioned repeatedly was transparency, especially the PANA Committee's access to tax ruling documents available in the Council. And since the ECOFIN Council Presidency was at the time held by a country accused of being a 'tax haven', several MEPs attacked the minister for keeping important documents secret and thus limiting the EP's inquiry into the topic. Indeed, the meetings with the Maltese minister are one of the few instances of Economic Dialogues with ECOFIN when the EP came across as a strong accountability forum (European Parliament 2017b).

On a different note, MEPs also ask about financial assistance programmes (forty-four times) in different countries and public investment, especially Juncker's Investment Plan for Europe (thirty-three times). Far less discussed are implementation issues (mentioned on twenty-three occasions) and social problems such as unemployment, poverty, and the impact of austerity more generally (identified seventeen times). In contrast to meetings with the 
Commission, MEPs rarely raise social issues with the ECOFIN Council Presidency - although the adoption of CSRs is ultimately done by the Council after the preparatory bodies (the EPC and the EFC) discuss Commission proposals.

Having reviewed the types of questions addressed in the Economic Dialogues with the ECOFIN Council Presidency, the focus now moves to the range of answers received by MEPs in response.

\subsubsection{Types of Answers Provided}

How does the ECOFIN Council Presidency answer questions from MEPs asked during the Economic Dialogues? The data set shows that the majority of questions (313) are answered explicitly, while the rest are answered partially (210) or constitute non-replies (90). Figure 6.7 offers an overview of the types of answers identified, capturing the variation in the willingness of finance ministers to engage with different types of questions. While answers providing information and answers to requests for policy change have similar ratios in the three categories (explicit, intermediate, and non-replies), there is a difference when it comes to requests for justification of conduct and policy views. On average, ministers are more likely to engage with these questions fully, providing an explicit reply.

Intermediate replies also occur frequently for all categories of questions. One example comes from the Dialogue on 21 January 2015 with the Latvian Finance

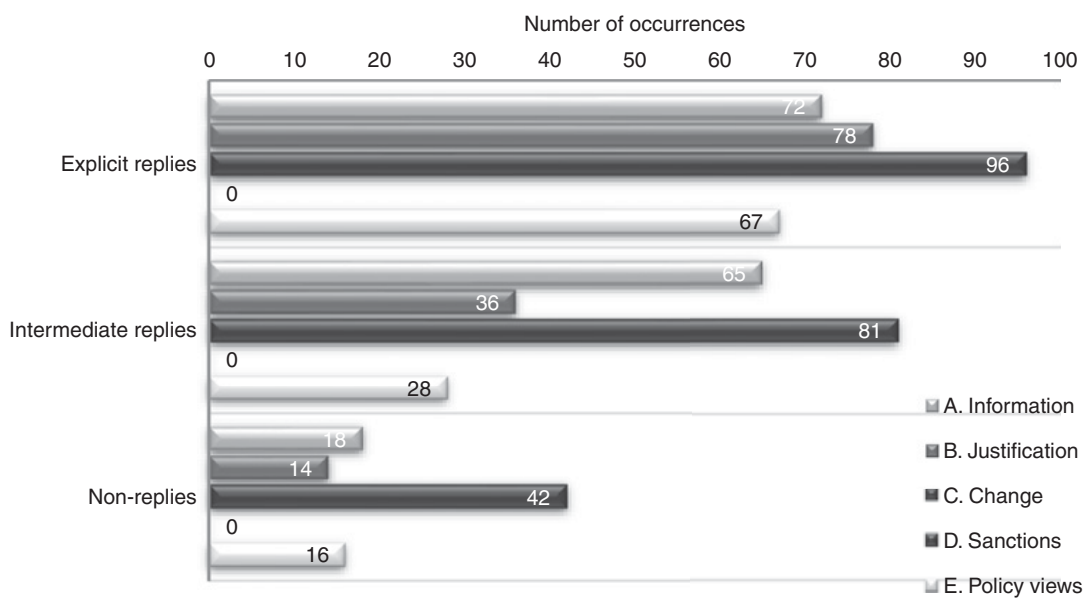

FIGURE 6.7 Types of answers received by MEPs in Economic Dialogues with the ECOFIN Council Presidency (2012-2019). Total replies identified: 613 
Minister Jānis Reirs, who answered most questions by drawing comparisons to domestic developments in his country. In fact, ten out of his total twenty-two replies were intermediate, as the minister did not seem too familiar with several legislative files currently negotiated at the EU level. Although his lack of knowledge could be justified by his recent appointment (less than three months in office at the time of the Dialogue), the minister had a clear tendency to avoid questions rather than engage with them (e.g. he provided six non-replies). A different yet equally unresponsive style can be found in the Dialogue with the Estonian Finance Minister Toomas Tõniste on 11 July 2017. The minister tended to give very brief answers, not going into details for any question. Overall, he provided ten intermediate replies, ten non-replies, and seven explicit replies. However, his short and dry answers seem to be more of a personal feature rather than a lack of interest in engaging with the EP.

On a different note, there were instances when a finance minister avoided or refused to provide policy views on a topic because of the required neutrality of holding the ECOFIN Presidency. In this respect, a relevant exchange occurred during the meeting on 22 January 2014 with the Greek finance minister:

Hans-Peter Martin (Non-affiliated, Austria): What is your position on the forthcoming structural reforms of the banks? On the Liikanen report basis and the perspective of the postponed Commission proposal.

Yiannis Stournaras (ECOFin Presidency, Greece): Actually, we are waiting for this report. If I'm right, ... the Commission will make a proposal towards the end of the month and then we'll take it to ECOFIN. Hans-Peter Martin (Non-affiliated, Austria): Well, actually, my question wasn't about the procedure, but about your position on the substance.

Yiannis Stournaras (ECOFin Presidency, Greece): I haven't seen the report yet, so I'm just waiting for the Commission proposal.

Hans-Peter Martin (Non-affiliated, Austria): But my question is really very specific. What's your position?

Yiannis Stournaras (ECOfin Presidency, Greece): Well, as an economist and an ex-banker, I have many ideas about the problem. But now I am the President of ECOFIN, so I have to be very careful. I have to see the report of the Commission first before I make [an opinion]. ... So be patient. (European Parliament 2014)

Apart from non-replies related to the perceived neutrality of the ECOFIN Presidency, there were cases when ministers simply refused to engage with questions. The most blatant example of this dynamic was found in the 
Dialogue with the Romanian Finance Minister Eugen Teodorovici on 24 January 2019. First, the minister gave the longest introductory remarks to date, where he effectively listed all legislative dossiers currently under negotiations between ECOFIN and the EP. When the first two speakers pushed him to outline three to four concrete priorities of the Presidency where the minister believes progress was possible, he dodged the question twice before finally answering. Several MEPs complained about the lack of preciseness in the minister's answers - most vocally Siegfried Muresan (EPP), a member of an opposition party in Romania. What is surprising in this case is that the nonreplies are in response to easy questions about the government's priorities for the Presidency or the national point of view (as a non-Eurozone country) on the creation of a Eurozone budget. It is hard to understand why the minister avoided giving a clear answer to this type of question. In fact, the minister has the worst record on responsiveness among ECOFIN Presidents, having answered explicitly only five of the seventeen total questions addressed to him.

Next, when examining the range of answers more closely (Figure 6.8), we can observe that finance ministers representing the ECOFIN Council Presidency tend to reply to the majority of questions through justification. In other words,

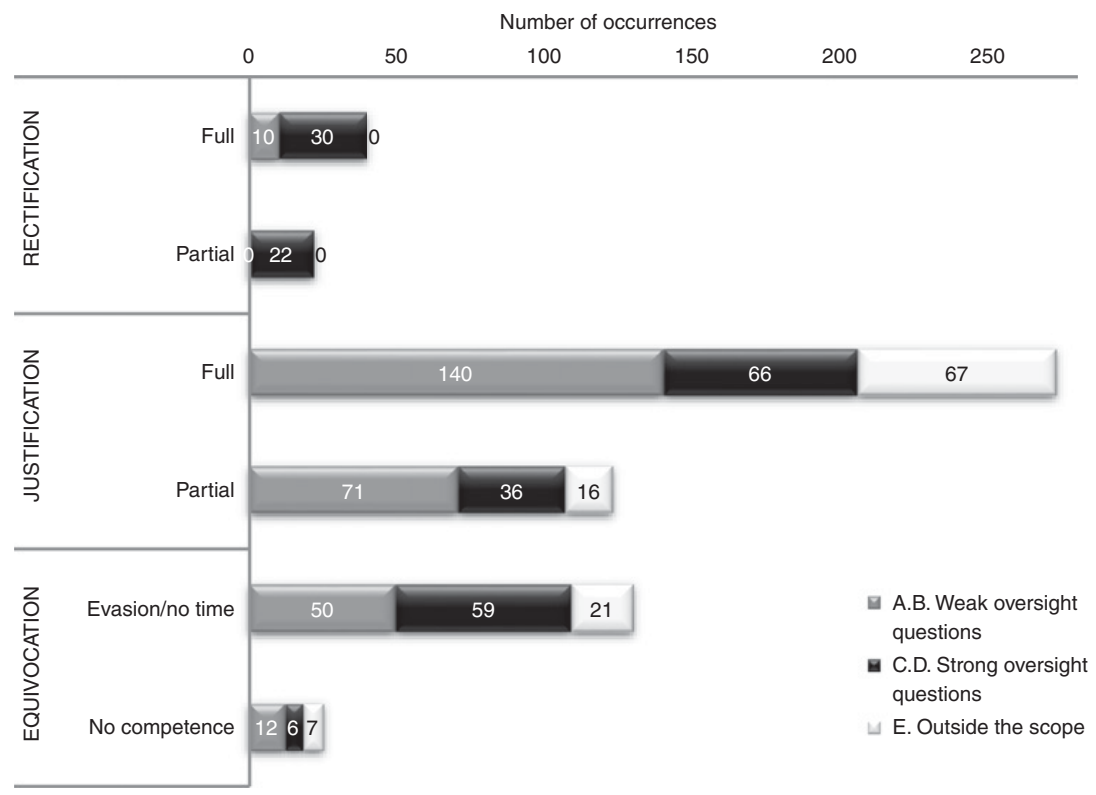

FIGURE 6.8 Degree of responsiveness by ECOFIN ministers holding the Presidency in Economic Dialogues (2012-2019) 
when challenged through parliamentary questions, ECOFIN ministers provide information about their decisions and decision-making processes, rationales for adopting them, or defend their conduct. The high number of policy views is also subsumed under justification, although technically they are outside the scope of legislative oversight (because requesting policy views does not engage with the past activity of an actor, so it is beyond the purpose of accountability).

One illustrative example of justification comes from the Dialogue with Dutch Finance Minister Jeroen Dijsselbloem on 14 June 2016, when Green MEP Philippe Lamberts (Belgium) lamented the lack of progress in the negotiations on EDIS, saying that he had hoped for more from the Dutch Presidency - as opposed to sending the Commission back to the drawing board' and delaying the completion of the banking union until 2024. The minister defended the conduct of the Presidency with an ironic answer, matching the tone of the MEP:

Jeroen Dijsselbloem (ECOFin Presidency, Netherlands): You expected so much more from the Dutch Presidency. We just aim to deliver. You know, this is what we do. We aim to please you. But we still have a couple of days left. Maybe we can improve the final grade that you will give us. So, you say that we're sending the Commission back to the drawing board. I don't think that is true. We are talking about the whole roadmap and how to take the next steps in the coming years. Also, technical work is already being done at Council level on the EDIS proposal itself. So, the Council has taken up on that proposal. Will it be changed in these negotiations? Of course, it always does. But that doesn't mean by sending the Commission back to the drawing board. You're worried about 2024? I'm not. This was already agreed also between us and the Parliament that the resolution fund should be fully completed and set up by 2024. (European Parliament 2016d)

By contrast, Figure 6.8 shows that instances of rectification happen rarely, albeit in response to demands for policy change (on fifty-two occasions). For instance, in the first Dialogue with the Bulgarian finance minister, MEP Paul Tang (S\&D, Netherlands) pushed for the Council to take into account the EP position on the Common Consolidated Corporate Tax Base (CCCTB) file. In fact, a lot of questions since 2016 onwards concern taxation files. The minister replied clearly:

Vladislav Goranov (ECOFin Presidency, Bulgaria): Of course, we will take it into account. We know what the role of the European Parliament here is. I'm a supporter of CCCTB. We are looking forward to your position and we will take it into account. (European Parliament 2018b) 
This means that the ECOFIN Council Presidency is in principle open to listening to the voice of MEPs. The more concerning trend is the relatively high number of equivocations, which occur not only by dodging questions or running out of time for responses but also by providing generic replies that acknowledge the topic of questions but do not respond to the query in any meaningful way (present in forty answers overall). An illustration of the generic replies can be found in this exchange from the Dialogue with the Austrian Presidency:

Othmar Karas (EPP, Austria): And what will you do to make sure that the CSRs of the European Semester are more quickly and completely implemented within Member States?

Hartwig Löger (ECOFin Presidency, Austria): Structural reforms within the Semester? Well, I did say in my introductory remarks that we would be doing everything possible to try and find substantive points which would ensure this is possible. (European Parliament 2018a)

While the minister acknowledges the topic of the question, he does not refer to the implementation of CSRs specifically or give any indication about what the Council will be doing on the topic.

\subsubsection{Summary}

Overall, the Economic Dialogues with the ECOFIN Council show a clear focus on legislative negotiations under the ordinary and special legislative procedures. The ECOFIN Presidency attended ECON Committee meetings prior to the crisis, so in practice little has changed in the interactions between the two institutions since the introduction of the Economic Dialogues in 2012. The emphasis on legislative negotiations corresponds to the classic relationship between the EP and the Council as co-legislators: if anything, MEPs use the Economic Dialogues with ECOFIN in order to exercise influence on future decisions to be made in the EMU. By contrast, there is little ex post oversight of executive actions taken by the ECOFIN Council. Although there were a few instances when MEPs asked about the European Semester in particular, the Economic Dialogues with the ECOFIN Presidency are generally divorced from the legal framework of the Six-Pack on transparency and accountability. When there are controversies in the Member States - for example, the 'tax haven' scandals - MEPs take advantage of the presence of a finance minister in the EP to ask questions about domestic issues. Nevertheless, the practice is rarely related to economic and fiscal policy coordination or the parliamentary scrutiny of the Semester. 
For their part, ECOFIN Presidencies are different, depending on the expertise of the incumbent on EU matters: the more a finance minister knows about the specific EMU issues discussed, the more comprehensive his or her answers. This opens an important question about the appropriateness of holding the current Presidency accountable for the activities of the ECOFIN Council as a whole. Formally, the Council Presidency is supposed to represent the entire institution - not only the reunion of ministers but also the preparatory bodies (senior committees and working parties). The extent to which the incumbent ECOFIN President has knowledge of discussions and negotiations held at various levels depends on the country holding the Presidency and the person involved. In the period under analysis, most finance ministers present in the Economic Dialogues appeared to make an effort to engage with questions from MEPs - with the exception of the Romanian Presidency. At the same time, the number of intermediary and non-replies is not negligible, as finance ministers were sometimes found to dodge questions or provide generic answers on the topic under debate. On average, their performance is worse than that of the Eurogroup President, as shown in the next section.

\subsection{THE ECONOMIC DIALOGUES WITH THE EUROGROUP PRESIDENT}

The first Economic Dialogue with the Eurogroup President took place in March 2013, in connection with the upcoming entry into force of the TwoPack. Since then, there have typically been two Economic Dialogues per year, in March and September, in line with the Eurogroup practice to adopt a work programme every six months. Each programme broadly defines the main areas on which the Eurogroup plans to focus its efforts. An exception to the practice of biannual meetings occurred in 2013, when four Economic Dialogues took place in the context of Juncker's ending mandate as Eurogroup President (in January) and a special meeting on the ESM adjustment programme for Cyprus (in May). Another exception is 2019, when there was no meeting in March due to the upcoming organisation of EP elections. From the four institutions analysed in this book, the Eurogroup clearly has the fewest direct interactions with the EP.

In total, there have been 14 Economic Dialogues in the period under investigation (Figure 6.9), during which 474 questions were identified. Typically, the Economic Dialogues with the Eurogroup President include on average 30 questions per meeting. 


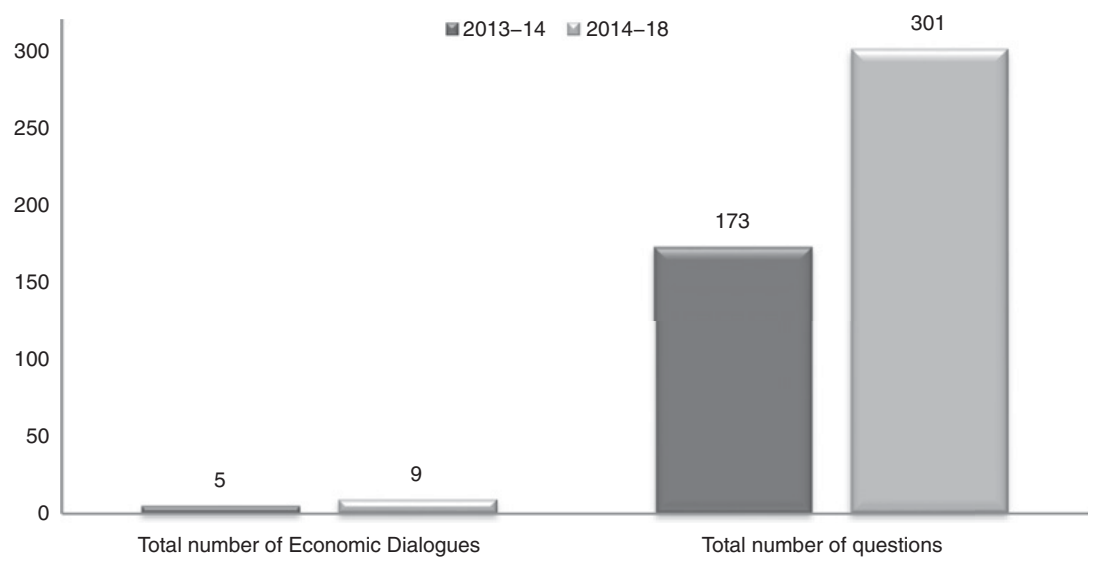

FIGURE 6.9 Number of Economic Dialogues and questions addressed to the Eurogroup President during different parliamentary terms (2013-2014 and 20142018)

As a general observation, the Economic Dialogues with the Eurogroup President tend to last longer than similar meetings with the ECOFIN Council Presidency. Moreover, if smaller political groups sometimes fail to ask questions in the Economic Dialogues with ECOFIN, this rarely happens in meetings with the Eurogroup President. Indeed, the stakes are much higher in Economic Dialogues with the Eurogroup, which also serves as the ESM Board of Governors and thus directly takes decisions on financial assistance programmes. As such, it is not surprising that the ECON Committee room is full whenever the Eurogroup President is attending - in contrast to ECOFIN meetings. The next section discusses the profile of MEPs asking questions and that of the respondents on behalf of the Eurogroup.

\subsubsection{Profile of Questioners and Respondents}

The profile of MEPs asking questions in the Economic Dialogues with the Eurogroup President follows the patterns of interactions with other institutions (Chapters 4 and 5). First, in respect of nationality (Figure 6.10), there is a partial correlation with the national apportionment of seats in the EP and a partial overlap with countries that were subject to financial assistance programmes from the ESM. Consequently, while Germans still take the floor most often (on fortyfive occasions), they are followed by MEPs from Greece (twenty-six times). Portuguese MEPs also rank in the top ten, as do those from the Netherlands and Belgium - a feature likely related to the nationality of the Eurogroup 


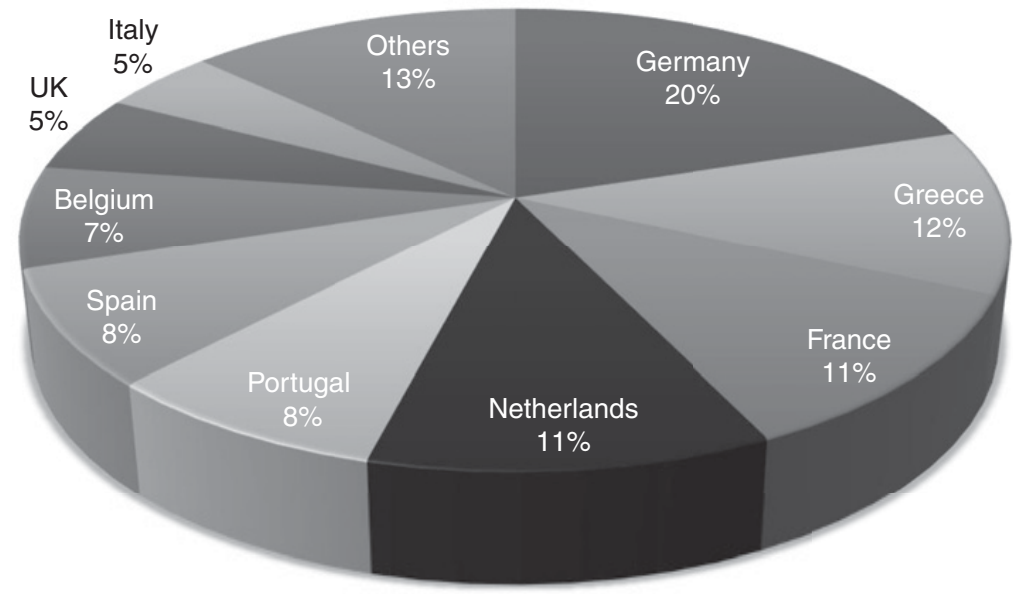

FIGURE 6.10 Nationality of MEPs taking the floor in Economic Dialogues with the Eurogroup President (2013-2018). Total MEPs identified: 224

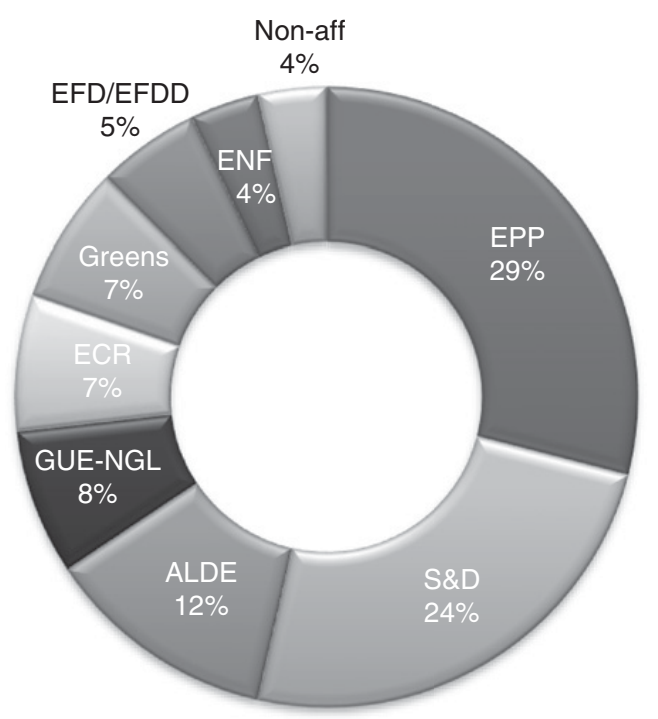

FIGURE 6.11 Party affiliation of MEPs taking the floor in Economic Dialogues with the Eurogroup President (2013-2018). Total MEPs identified: 224

President for most of the period under analysis (Dutch Finance Minister Jeroen Dijsselbloem, 2013-2018). The surprise here comes from the lack of questions from Italian MEPs (only ten during the period under focus), who tend to be more 
active in meetings with the Chair of the Supervisory Board of the ECB (Chapter 4) and the Commission (Chapter 5). By contrast, other absences are to be expected, for example, MEPs coming from large non-euro area countries (the UK, Poland, and Romania) are less likely to ask questions of the Eurogroup President.

Next, when it comes to party affiliation (Figure 6.11), the distribution of MEPs taking the floor in every meeting reflects the political allocation of seats in the EP: during the period under investigation, the EPP is first (identified on sixty-five occasions), followed by the S\&D (with fifty-five interventions). Relative to their representation in the EP, MEPs from ALDE ask questions of the Eurogroup President more frequently (on twenty-seven occasions), while the ECR typically intervenes once per session, as prescribed by EP rules. As with other Economic Dialogues and EP hearings, the coordinators of political groups take the floor in almost every meeting: for example, Jean-Paul Gauzès (EPP, France) and Elisa Ferreira (S\&D, Portugal) for the 2009-2014 parliamentary term and Burkhard Balz (EPP, Germany) and Pervenche Bères (S\&D, France) during 2014-2019.

Furthermore, the Economic Dialogues with the Eurogroup had different interlocutors over time, in line with the changing Presidents of the intergovernmental body (Figure 6.12). Accordingly, MEPs met with Jean-Claude Juncker (in 2013), Jeroen Dijsselbloem (during 2013-2017), and Mário Centeno (in 2018). Figure 6.12 shows that Dijsselbloem answered most questions - which is not surprising since he occupied the office for the longest time during the period under investigation. By contrast, Juncker attended one meeting, while Centeno was present in two. For the Dialogue in November 2015, the ESM Managing Director Klaus Regling accompanied

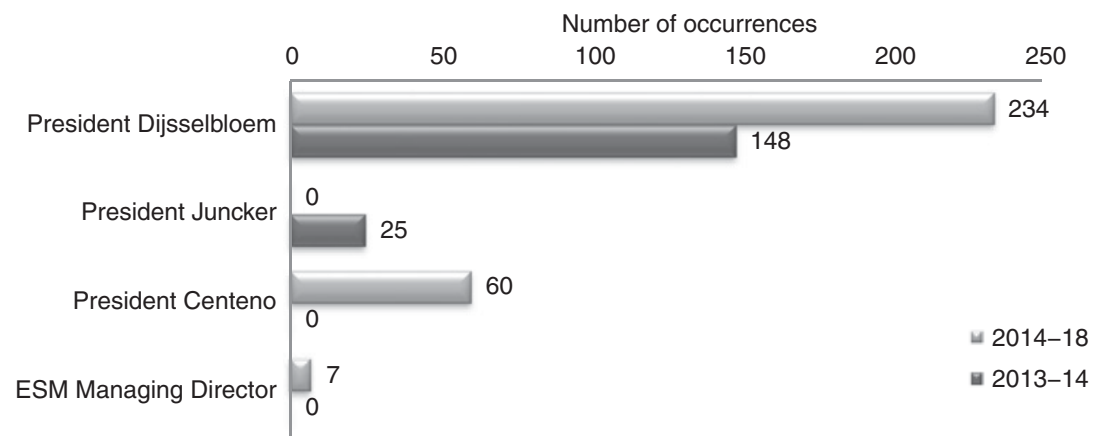

FIGURE 6.12 Number of questions addressed to different interlocutors during Economic Dialogues with the Eurogroup President (2013-2018) 
Dijsselbloem to discuss the latest adjustment programme for Greece. In fact, this meeting is split into two: the first part is considered 'an ad hoc exchange of views on Greece' (following the eventful summer of 2015), while the second half is the 'regular Economic Dialogue' of that autumn.

Having established the profile of questioners and respondents, the following pages provide an overview of the substance of interactions between MEPs and the Eurogroup President in the Economic Dialogues.

\subsubsection{Types of Questions Asked}

What type of questions do MEPs pose to the Eurogroup President? Figure 6.13 shows that the majority of questions are demands for changes of decisions or conduct (166 times), followed by demands for justification (145 times). Requests for information and policy views are almost identical (82 and 81, respectively). While most questions are related to the activity of the Eurogroup as an EU body, there was one instance where the personal conduct of the Eurogroup President was contested due to remarks he made in the media. At the meeting on 21 March 2017, several Spanish MEPs confronted Jeroen Dijsselbloem for claiming in reference to Southern European countries that 'one cannot spend all the money in drinks and women and then ask for help [from] the Eurozone' (European Parliament 2017c). The minister defended

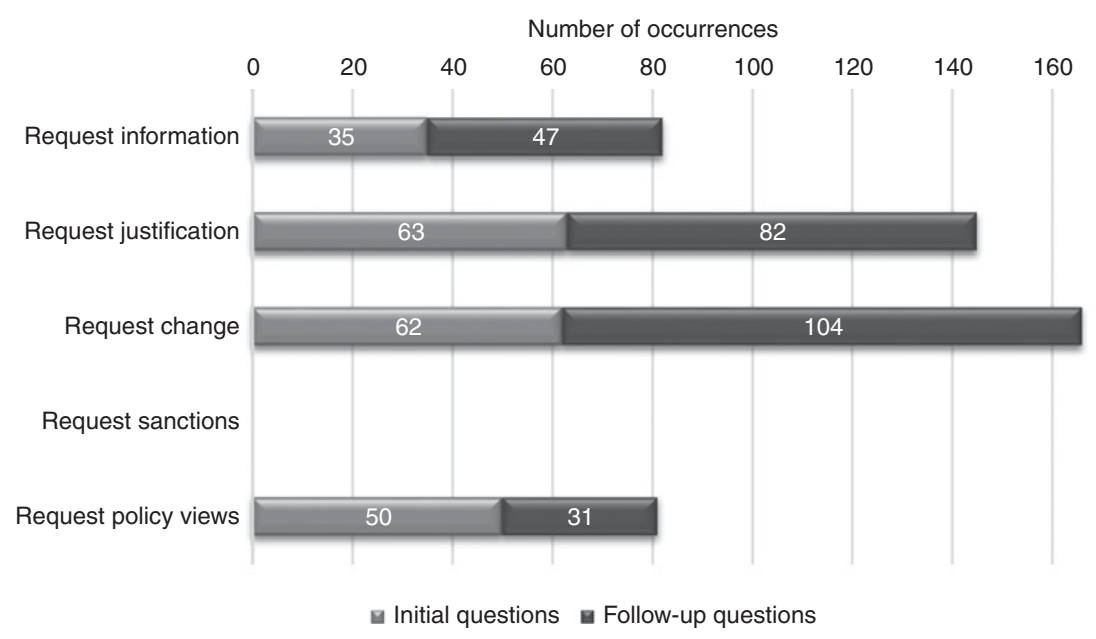

FIgURE 6.13 Types of questions identified in Economic Dialogues with the Eurogroup President (2013-2018). Total questions: 474 
his statements over and over again, saying he was talking about collective efforts to maintain solidarity in the Eurozone - and that his remarks could also apply to the Netherlands. After several back-and-forth exchanges on the topic, MEP Gabriel Mato (EPP, Spain) concluded that the minister missed a third opportunity to apologise' and consequently lost his authority as an impartial Eurogroup President. Unrelated to this controversy, Dijsselbloem was about to lose his mandate as Dutch finance minister following national elections which resulted in his replacement as Eurogroup President by the end of the year.

Furthermore, as a general trend, the Economic Dialogues with the Eurogroup President are characterised by a high number of follow-up questions, with MEPs continuing to push for answers on specific topics. An example is the special Economic Dialogue that took place on 7 May 2013 on the ESM adjustment programme for Cyprus. The meeting started strongly with ECON Committee Chair Sharon Bowles asking twelve questions that requested information about the negotiation process or justification of conduct about the mistakes made. Some iconic questions are extracted below:

Sharon Bowles (Chair, Econ Committee): ... why was the situation allowed to worsen until such time as the two largest Cypriot banks collapsed? What lessons have been learned from the previous experiences with Iceland, Ireland, Spain, and Greece that might have been deployed to good effect in Cyprus? (...) How did the Euro Summit meeting on the night of the 15th and 16th of March reach its conclusions? (...) How was the meeting prepared and by whom? And actually, we're still a little bit curious about who was in the room and how many in particular from the IMF and whether there were any sub rooms. (...) Did the Cyprus authorities provide or withhold all relevant information at all stages of the crisis? (...) And how can we be certain or not that the best value was achieved in the interest of the Cypriot people? (...) but more importantly, we'd quite like to know who opposed the levy on small depositors. And were other wealth tax options investigated or why was a wealth tax targeted just on deposits? (...) How do the capital controls in Cyprus that were applied and some of which still apply conform to EU rules? And can we establish that there has been equality of citizens and Member States in the various bailouts? And is this within both the spirit and the letter of the Treaties and legislation? (European Parliament 2013d)

This is a remarkable example of accountability at work, as we see the EP demanding very concrete information and justification of conduct about the 
decision-making process, the legality of the decisions, and the general fairness of the outcome for Cyprus. In response, Dijsselbloem engages with eleven of these questions in his introductory remarks; the only issue he leaves aside concerns the equality of Cypriot citizens to other EU citizens whose countries were under ESM programmes. The meeting continues with numerous questions on Cyprus, the mistakes of the Eurogroup on the matter, and the need to reform the ESM by bringing it under the democratic control of the EP. Throughout the Dialogue, Dijsselbloem holds his ground and defends the position of the Eurogroup:

Jeroen Dijsselbloem (Eurogroup President, Netherlands): In the Cypriot case, there was a big burden to be carried and there were only a few options. Who is going to carry the burden? We couldn't pass the burden onto the Cypriot government because that would simply not have been sustainable and there would have been no future for Cyprus for a very, very long time. We couldn't pass it on, the whole burden, to the ESM. That would still be a loan to the government and we would have the same problem. We considered [it] because some thought it preferable to put the burden on all the deposits, as you know. That was the first solution within Cyprus. The fallout of that was that people hesitated or were worried about the effects that would have on the deposit guarantee system, which was a completely different thing than the levy. But this was the concern that arose. So finally, the burden was put on those investors and the uninsured depositors of two banks where the main risks were concentrated. Is that a fair way to deal with this crisis in the banks of Cyprus? I think so. And I stand to defend that. (European Parliament 2013d)

Next, which issues do MEPs raise with the Eurogroup President? Figure 6.14 shows that the most discussed topics by far refer to ESM financial assistance programmes ( 187 out of the 474 questions), which often goes hand in hand with developments in Member States other than the country holding the Eurogroup Presidency (167). In fact, out of the 184 questions that address financial assistance programmes, 97 are about Greece (many from 2015) and 58 about Cyprus (the majority from 2013). This finding corresponds to the special Economic Dialogues held on the Cyprus adjustment programme in May 2013 and the ad hoc exchange of views on Greece organised in November 2016. Legislative files also often refer to the Banking and Capital Markets Union ( 75 occurrences), especially the adoption of the SSM, the SRM, and the deadlock of negotiations over EDIS.

Another popular topic refers to planned reforms to the EMU architecture (166 times), especially the Five Presidents' Report and the importance of 


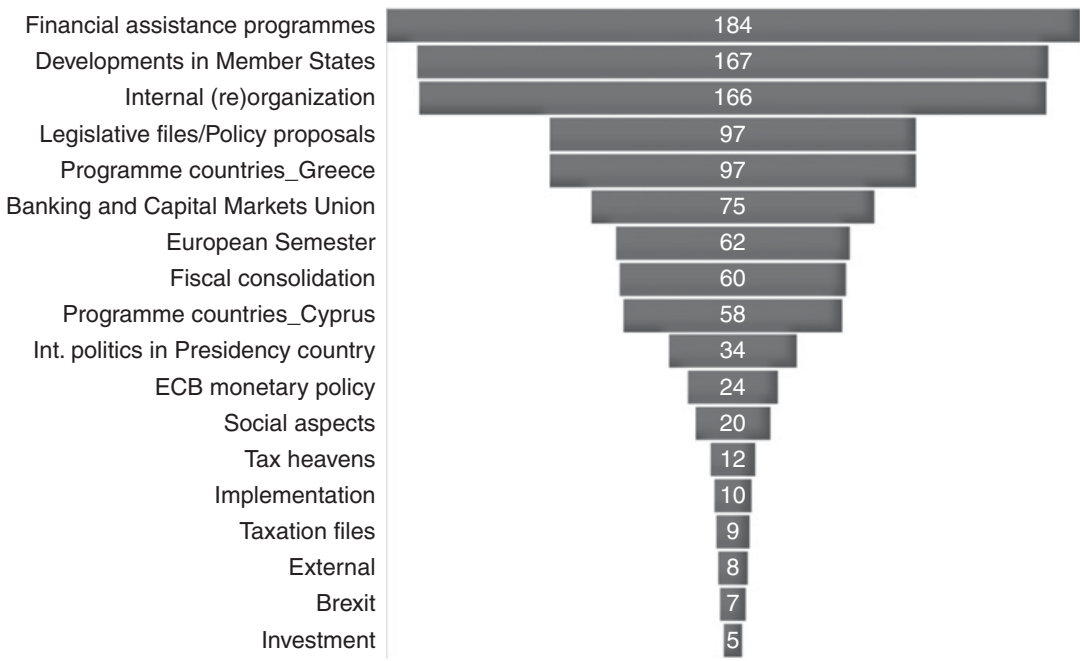

FIgURE 6.14 Types of issues raised by MEPs in Economic Dialogues with the Eurogroup President (2013-2018). Most questions have two codes, except those that address ESM programme countries, Greece and Cyprus (which have three codes).

Total codes assigned: 1,095

integrating the ESM into the Treaties. In fact, MEPs have often voiced their criticism of the intergovernmental nature of the ESM and the need to transform it into a European Monetary Fund accountable to the EP. From this perspective, the code 'internal organisation/EMU architecture' often comes together with 'legislative files/policy proposals' or 'financial assistance programmes'. MEPs have repeatedly demanded increased accountability of the ESM, although the Eurogroup has constantly defended the matter in relation to national parliaments. The dynamic is evident in this exchange from the Dialogue on 20 February 2014:

Jeroen Dijsselbloem (Eurogroup President, Netherlands): The ESM is as you know basically intergovernmental and therefore the ministers ... will go to the national parliaments and be accountable in the national parliaments. There is also if I understand correctly my predecessor Mr Juncker sent a letter to Parliament saying that the EP would be informed on a regular basis on the works of the ESM. And we are always ready and able to do so.... That's why I am here. You see, sometimes you can make things complicated. The easy thing is I am here now. You can ask me anything you want on the ESM. 
Bas Eickhout (Greens/EFA, Netherlands): ... you know very well that for example the Dutch Parliament does not have a veto on any payments and whereas the German Parliament has because of the voting rules. So there is a democratic gap in the ESM and - by promised democratic scrutiny of the Parliaments - that is more than just you that you are here [every] couple of months' time. So how to improve that democratic scrutiny; that's more than just have a nice talk.

Jeroen Dijsselbloem (Eurogroup President, Netherlands): . . . if you think the Dutch Parliament will let for example programs and disbursements from programs to countries from the ESM pass, likely you are mistaken. There is no subject that is debated that much and that often in the Dutch Parliament as the Eurozone agenda including all the programs and all the money that comes from the ESM is heavily debated. And if the Parliament would in majority say 'minister, we do not agree with this disbursement', then I have a major problem. So in fact there is a strong accountability certainly in my Parliament as in the German [one] as is in others. (European Parliament 2014c)

Indeed, the subject of democratic accountability of the Eurogroup and the ESM is a recurrent topic in the Economic Dialogues with Dijsselbloem. He has consistently defended his views that intergovernmental decision-making is completely democratic, while MEPs in turn have repeatedly followed up on their requests to increase the accountability of the Eurogroup to the EP. The gap between the structural weakness of national parliaments in the EU political system and the impossibility for the EP to make up for it - especially in relation to the ESM - is highlighted in the following exchange from 10 November 2015, in relation to a question on the rise of Euroscepticism in Europe:

Jeroen Dijsselbloem (Eurogroup Presidency, Netherlands): My opinion is that the issue of democratic legitimacy is more than a power struggle between institutions. If the European Parliament would have full competences in the field of the ESM and the programmes, I'm not sure that that would reduce the rise of Euroscepticism throughout Europe. I don't think it works that way. I know for a fact that the turnout for national elections in some countries is a lot higher than it is for European elections. I know for a fact that a lot of people in Europe feel more represented maybe by the local Council than they do by the national parliament, and more by the national parliament than they do by European institutions. So it's a bit more complex than that. 
Philippe Lamberts (Greend/EFA, Belgium): I'd like to take one example for that, because here Mr. Dijsselbloem you say that you are open to change the institutional framework that would make you more accountable here. Yet when I read your declaration in the Tweede Kamer [House of Representatives of Netherlands], well known to you, I read a completely different story. Or I see a rather different story where you say "well you know we do not want to go further in the direction of the community method, we are very happy with keeping things intergovernmental.' So the national context in the Netherlands, you sing a Dutch song, you come here you, sing a more European song. This is why, actually, we would like to have a stronger role here, and changing the institutions for that. So which Dijsselbloem do I have to believe?

The 'double hat' of the Eurogroup President - as representative of an EU institution and finance minister of his/her own country - is reflected in the suggestion of duplicity implied by Philippe Lamberts. Indeed, what prevents the Eurogroup President from saying one thing to the EP and another to a national parliament? A solution would be for the Eurogroup President to be a permanent EU official who stops acting as the finance minister of a Member State - in a similar vein to the President of the European Council. This, however, is not an option currently discussed in EMU reform circles.

Furthermore, in comparison to the Economic Dialogues with the ECOFIN Council Presidency, the 'European Semester' and 'fiscal consolidation' feature more frequently in meetings with the Eurogroup - in 112 out of 474 questions - which in relative terms is more than for ECOFIN. This is an interesting finding, keeping in mind that ECOFIN (and not the Eurogroup) is formally responsible for the European Semester - with the exception of the recommendations for the euro area. Another issue worth mentioning is 'domestic politics in the Presidency country', as Jeroen Dijsselbloem was sometimes questioned about the Netherlands (thirty-four times), for example, in relation to allegations that the country serves as a tax haven and should reform its tax laws (on twelve occasions). Otherwise, the Eurogroup President is also asked to comment on ECB monetary policy (twenty-four times), which is always a demand for policy views. Social aspects (twenty times) and investment (five times) are rarer than in Economic Dialogues with ECOFIN, although there are complaints about the ESM treatment of Greece and Cyprus, questioning the soundness of austerity policies or the fairness of 'bailin' measures (seventy times).

Overall, in terms of the relevance and intensity of the questions, the performance of MEPs is very strong - especially when compared to the 
other institutions analysed throughout the book (see Chapter 6.1). The next section turns towards the responsiveness of the Eurogroup President to questions asked during Economic Dialogues.

\subsubsection{Types of Answers Provided}

To what extent is the Eurogroup President open to answering questions from MEPs in the Economic Dialogues? Against common perceptions regarding its democratic accountability flaws, the Eurogroup has the best record of engaging with questions head-on, without trying to change the topic or obfuscate answers (Figure 6.15). Explicit replies rank the highest among all categories of questions identified, showing that on average the Eurogroup leadership does not try to avoid questions from MEPs. However, requests for policy change (type C) are more likely to receive an intermediate or non-reply than other types of questions. In terms of the different Presidents, Dijsselbloem provides explicit replies in response to 66 per cent of all questions, Juncker in response to 60 per cent, and Centeno only in response to 30 per cent of all questions received. The period under investigation includes significantly different observations for the three Presidents because of the duration of their mandates (Juncker was present in one meeting, Centeno in two, and Dijsselbloem in eleven). Overall, Centeno is inclined to acknowledge questions and

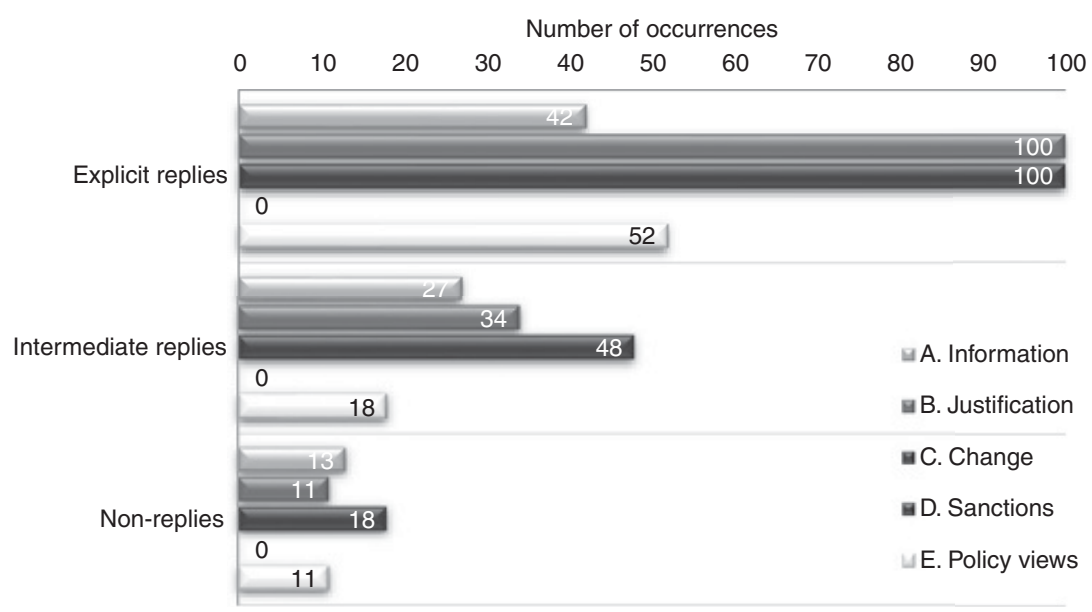

FIGURE 6.15 Types of answers provided by the Eurogroup President in Economic Dialogues at the EP (2013-2018). Total answers identified: 474 
speak about the topics covered in general terms, without giving details as mentioned in the questions of MEPs.

Next, how does the Eurogroup engage with MEPs during Economic Dialogues? Similar to the dynamics with ECOFIN, the majority of answers fall into the 'justification' category - meaning that the Eurogroup President addresses most questions by providing information, explaining the rationale for decisions, or defending the conduct of the institution (Figure 6.16). When taken together with answers giving policy views, the proportion of replies providing justification is 73 per cent of the 474 answers identified in the period under investigation. Such answers typically respond to transparency requests or classic 'why questions', demanding justification of past decisions (173). At the same time, there are numerous answers defending the Eurogroup's conduct and explaining why there can be no changes, for example, in respect of financial assistance programmes. One pertinent example comes from the Dialogue on 24 February 2015 - focused on the situation in Greece and the difficult negotiations with Prime Minister Alexis Tsipras and Finance Minister Yanis Varoufakis as the new interlocutors of the Greek government. At the time of the Dialogue, a 4-month delay had been agreed with the Syriza government on the fifth review of their second adjustment programme (which had been negotiated by the previous cabinet before elections). During the meeting, Dijsselbloem acknowledged the state of uncertainty but re-affirmed

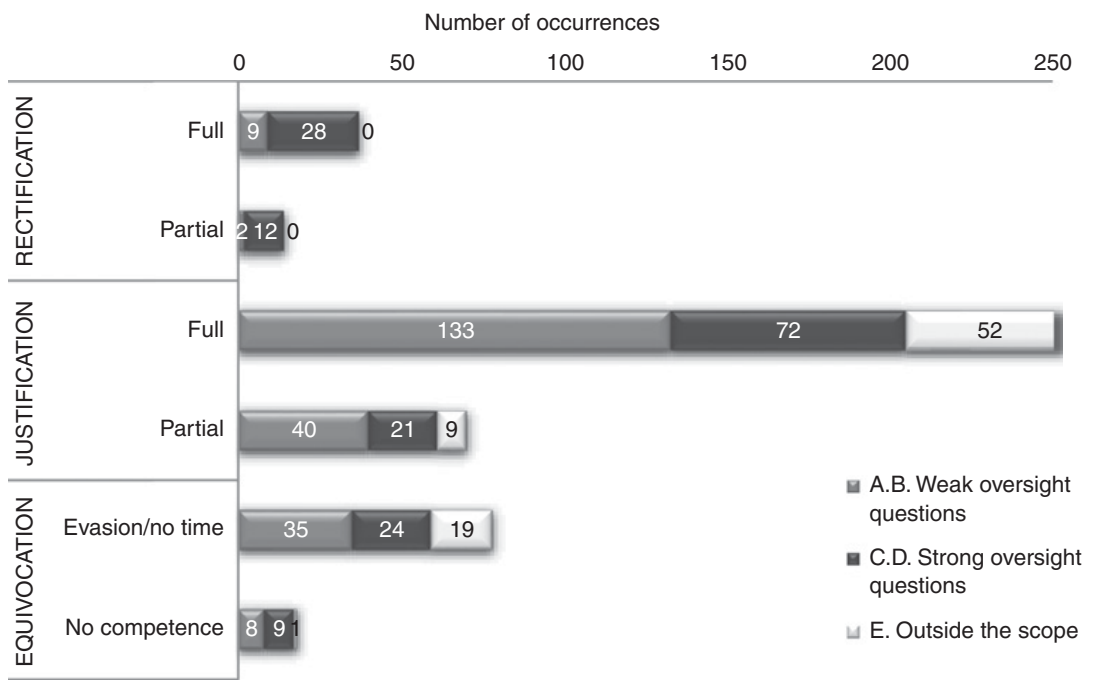

Figure 6.16 Degree of responsiveness by the Eurogroup President in Economic Dialogues (2013-2018) 
the intention to provide further financial assistance as long as Greece stuck to the conditions agreed. Some of exchanges were fierce, as illustrated below:

Marco Valli (EFDD, Italy): First of all, I would like to congratulate the President of the Eurogroup because I think what you have mentioned is incredible. A few weeks ago, we were facing a democratically elected government which had made promises to Greece and obviously that meant a 70 percent haircut to the debt. The end of the program they promised that and reimbursing war debts on the part of Germany. And just a few weeks ago that's what we heard and now we've got this result. So well done then for showing that we are really in a sort of technocratic dictatorship. I'm sure that's going to increase Euroscepticism and the consensus about people who don't believe in this Europe.

Jeroen Dijsselbloem (Eurogroup President, Netherlands): Let me first of all say something about the democratic process and promises made to electorates. I think the outcome of the Greek election was a clear signal from the Greek electorate. But in the Eurogroup we have to deal with 19 ministers who have 19 mandates from 19 electorates. And if there is reason for further support for one specific country it has to be on a joint agreement and therefore 19 mandates are to be taken in consideration. You may not find that democratic but I do. Ministers have to go back to their Parliaments and have to get support in their parliaments for further support, in this case Greece. So it's not just about the choice of the Greek electorate, which we have to respect and I'm sure that the new Greek government will put their stamp on the programme as we know it given the flexibility that we have. But you are mistaken if you think democracy is that one election results can change the way we work in the Eurozone or in the European Union. That will be a very strange interpretation of democracy. (European Parliament 2015b)

Answers to demands for policy views are also included under justification (61 times), although they are not a traditional accountability instrument. As part of the interinstitutional relationship between the Eurogroup and the EP, questions for policy views are most of the time 'easy' to answer - although they can occasionally touch upon controversial policy issues.

In Figure 6.16, the next category is made of equivocated answers ( 16 per cent overall) - including 5 per cent generic replies, that is, answers that acknowledge the topic of a question but discuss the subject in broad terms, without referring to the specific issues raised by MEPs. One interesting example comes from the regular Dialogue on 10 November 2015, when Dijsselbloem is asked by Jonás Fernández (S\&D, Spain) whether he is ready to sign an 
interinstitutional agreement in which he 'agrees to answer written questions from MEPs' in order to show 'the democratic legitimacy of the European Union'. The answer is evaded, as the minister does not mention the prospect of answering written questions at all:

Jeroen Dijsselbloem (Eurogroup President, Netherlands): The inter-institutional agreement, as mentioned in the Five Presidents' Report, had a different function. It was about involving the Parliament at the beginning of the Semester and at the end of the Semester and having a debate also on the euro area recommendations - the euro area stance before the CSRs etc. are designed. That's how I understand what we had outlined in the Five Presidents' Report and I hope that the Commission will pick that idea up. (European Parliament 2015c)

Finally, there are answers in which the Eurogroup President recognises that mistakes were made in the past or, alternatively, that there is a need for a change of approach on a given issue (11 per cent of the total, Figure 6.16). It is worth noting that Eurogroup Presidents acknowledge errors at times: for example, Dijsselbloem has repeatedly taken responsibility for the decisions regarding Cyprus in March-April 2013 - especially when it came to the controversial decision of 'bailing in' all depositors (including those with less than 100,000 euros) in order to 'bail out' the banking system. In this particular instance, MEPs insisted to know which governments supported the move, but Dijsselbloem refused to reveal internal Eurogroup dynamics, arguing that the Council takes decisions as a whole and it does not matter who supported what during the negotiations. This is consistent wih Puetter's accounts of informal working methods in the Eurogroup, focused on secret deliberations and consensus decision-making (Puetter 2004, 2006, 2016). It also suggests that the Eurogroup President is an appropriate interlocutor for the EP in accountability exchanges; so far, the person holding the office of Eurogroup President has consistently been able to speak on behalf of the nineteen Eurozone Member States.

\subsubsection{Summary}

On the whole, the Economic Dialogues with the Eurogroup President are probably the most targeted and straightforward oversight interactions in the ECON Committee. Given the high profile of the Eurogroup in the EMU, MEPs were interested in asking questions about financial assistance, upcoming Eurozone reforms, or sensitive issues in the European Semester such as the EDP. The period under focus has also covered some of the most 
controversial episodes in the euro crisis - including the ESM programmes for Cyprus in 2013 and Greece in 2015. The media paid attention to such Economic Dialogues and MEPs asked a lot of questions about ongoing negotiations and decisions taken. In 2018, as the Eurozone was back to economic growth and Mario Centeno took over the Eurogroup Presidency, MEPs seemed less antagonistic towards the intergovernmental body. But given the lack of formal control the EP has over the Eurogroup and the ESM, it is not surprising that MEPs have consistently complained about the democratic accountability credentials of the institution. What is surprising is the answerability of the Eurogroup President in response to oral questions by MEPs. Given the notorious secrecy of the institution, we would have expected less engagement with parliamentary questions. While this responsiveness might be related to the personal style of Jeroen Dijsselbloem - who served as Eurogroup President for five years - it is a positive finding that the majority of questions identified were explicit replies. Judging by the answers, it is clear that the Eurogroup has a specific understanding of its accountability obligations to the EP, namely it stands ready to describe and explain its decisions (justification) but not change them (rectification). The dynamic also reveals the ultimate accountability flaw of EMU intergovernmental bodies, whose collective decisions can be scrutinised but not controlled in the EU political system.

\subsection{THE RECORD: HOLDING FINANCE MINISTERS ACCOUNTABLE IN THE EMU}

Drawing on the analysis above, it is possible to make an assessment of the type of legislative oversight scenario that fits the Economic Dialogues with the ECOFIN Council and the Eurogroup. In line with Chapter 3.3.1, the choices are based on a continuum from 'High control' by the EP (oversight scenario 1) to 'No control' (scenario 6). Depending on the strength of questions asked and the corresponding responsiveness of executive actors, the continuum further includes the possibility for 'Answerability' (scenario 2), 'Voluntary accountability' (scenario 3), 'Transparency' (scenario 4), and 'Drift' (scenario 5). Bearing in mind the EU Treaty framework and the representative roles of the EP and the Council thereof, the relationship between the two institutions can be compared to legislative-executive interactions in a presidential system - where the legislature is not the principal of the executive and both actors have a direct mandate from citizens. In this respect, the best-case scenario of oversight interactions expected between the EP and ECOFIN/the Eurogroup was 'Answerability' (see Chapter 3.3.2). 
Furthermore, as illustrated in the analytical framework (Figure 3.2), there were additional variables considered such as the extent of public pressure on key oversight topics and structural opportunities for parliamentary scrutiny, which were expected to have positive effects on accountability interactions. By contrast, other variables were seen to have negative effects on oversight, namely the profile of the EP as a law-making parliament and its multi-party system, the asymmetry of information between the EP and executive bodies, and the difficulty to disentangle collective decision-making in intergovernmental bodies. In the analysis presented in this chapter, some variables turned out to be similar in the EP's relationship with ECOFIN and the Eurogroup: for instance, structural opportunities for oversight are limited to oral questions in committee meetings for both executive bodies, albeit the ECOFIN Council Presidency comes to the ECON Committee more often than the Eurogroup President. At the same time, it is equally difficult to disentangle collective decision-making in the ECOFIN Council and the Eurogroup, as ministers do not disclose the positions of individual Member States in intergovernmental negotiations.

However, there are also important differences between the variables of the analytical framework reflected in the EP's oversight interactions with ECOFIN and the Eurogroup. Most crucially, public attention to Economic Dialogues varies significantly, as the media covers meetings with the Eurogroup President much closer than encounters with the ECOFIN Council Presidency. In terms of parliamentary questions, this is visible in the types of questions asked to the Eurogroup (which focus on financial assistance programmes, future Eurozone reforms, or European Semester decisions) and the high number of follow-up questions identified across political groups and nationalities of MEPs. In other words, high public pressure on specific EMU issues outweighs other variables such as the profile of the EP as a law-making parliament and its multi-party system. Conversely, in the relationship with the ECOFIN Council, where media attention and public pressure are generally low, parliamentary questions reflect much closer the emphasis of the EP on law-making and its multi-party, multi-national system. This is illustrated by the high number of questions regarding legislative dossiers and the low number of follow-up questions addressed to ECOFIN ministers (as opposed to the Eurogroup President). Last but not least, when it comes to the asymmetry of information between the EP and the ECOFIN Council/the Eurogroup, it was expected that the Eurogroup would perform worse than ECOFIN due to its informal and secretive proceedings (Craig 2017; Puetter 2006). In practice, however, the Eurogroup provided more explicit replies and less equivocations than ECOFIN in the period under focus, showing a higher readiness to engage with substantive 
oversight questions from MEPs. Nevertheless, this record could just be owed to the personal style of Jeroen Dijsselbloem, who tended to give direct and frank answers in response to parliamentary questions.

Taking all this into consideration and in line with the expectations of different oversight scenarios (Chapter 3.3.1), the Economic Dialogues with the ECOFIN Council are considered an example of 'Transparency' (scenario 4), with some elements of 'No control' (scenario 6) - given the focus on legislative negotiations (ex ante policy-making as opposed to ex post accountability). The assessment takes into account the proportion of weaker oversight questions (283 in total), which is slightly higher than stronger oversight questions (219 in total) but with more requests for information than justification of conduct. In turn, the ECOFIN Council answers the majority of questions through justification: either in full (273 times) or partially (123 times). In addition, a relatively high number of replies are equivocations based on generic answers or dodged questions (130 in total). Given this record, both MEPs and the ECOFIN Council Presidency could do more to improve their accountability interactions, as discussed in the next chapter.

For its part, the Eurogroup President also receives weaker oversight questions (227 times) more frequently than stronger oversight questions (166 times). Nonetheless, the topic of questions is much more relevant for the parliamentary scrutiny of an executive actor than the questions addressed to ECOFIN. In the Economic Dialogues with the Eurogroup, MEPs actually inquire about the past activities and specific decisions of the institution in the ESM or the European Semester. By contrast, the Economic Dialogues with ECOFIN revolve around legislative negotiations and are thus less a case of parliamentary scrutiny of the executive as they are an example of interactions between co-legislators in a bicameral political system. Moreover, the general responsiveness of the Eurogroup President - answering more than half of the questions through full justification - puts this type of Economic Dialogue in the 'Answerability' scenario of legislative oversight (see Chapter 3.3.1, scenario 2). In other words, the EP has no control over Eurogroup decisions, but it can successfully scrutinise its actions ex post by demanding transparency and justification of conduct. The next chapter situates this record in relation to the oversight interactions examined in the book. 


\section{7}

\section{Conclusions}

\section{Comparative Evaluation and Necessary Reforms}

This book examined the effectiveness of the EP as an accountability forum that oversees EU executive actors on a day-to-day basis. The policy area under focus was the EMU - a politically sensitive field whose salience at the EU level increased significantly as a result of the euro crisis. Debates about the accountability of EMU executive actors included controversial issues such as the fairness of austerity measures, the need for solidarity between countries, divisions between North and South, the stability of the Eurozone banking system, the importance of equal treatment of the Member States, the dominance of national executives in EU decision-making, and so forth. Owing to its transnational composition and European profile - as the only directly elected institution at the EU level - the EP showed great promise to hold executive actors accountable for collective decisions that affect the EU as a whole. Against this background, the book explored four case studies of EP oversight of EMU executive actors, namely the ECB, the Commission, the ECOFIN Council, and the Eurogroup, respectively. Notwithstanding small variations dependent on the date when EP oversight was established, all cases covered the period during and/or after the euro crisis (2010-2019).

The conclusion consists of three parts. The first section compares the oversight interactions between the EP and the four institutions discussed throughout the book. Based on the analytical framework described in Chapter 3.3, the findings show that the EP has the strongest accountability record in the EMU vis-à-vis the Eurogroup, followed by the Commission, the ECB in banking supervision, and finally the ECOFIN Council. But there are important limitations even in the case of the Eurogroup, which is answerable but not responsive to EP oversight. In other words, the EP can make the Eurogroup justify its conduct but cannot control its decisions or change the direction of existing policies. Moreover, the EP's oversight interactions with the other institutions display different problems. In the accountability 
relationship with the Commission, MEPs ask few follow-up questions and generally put less pressure than on the Eurogroup. When overseeing the ECB, MEPs are willing to be confrontational on multiple topics but face structural obstacles such as the secrecy regime in banking supervision and the ECB's institutional independence. Finally, in interactions with ECOFIN, the EP focuses on influencing legislative decision-making rather than overseeing executive measures adopted by the Council. Based on the scenarios of legislative oversight specified in the analytical framework (Chapter 3.3.1), the four case studies are correspondingly positioned on the continuum from 'High control' to 'No control' by the EP.

The second section is forward-looking, outlining ways to improve the performance of the EP as an accountability forum and increase the responsiveness of executive actors in the EMU. The idea is to provide concrete policy recommendations for both the EP and EMU executive actors, in line with the accountability purposes emphasised in the analytical framework. The final section situates EP oversight in the broader context of EU accountability and democratic legitimacy. Despite the fact that the EP is only one piece of the puzzle of EU accountability, its scrutiny powers can undoubtedly contribute to bridging the gap between citizens and executive actors in the EU political system.

\subsection{CASE COMPARISON}

The findings of previous chapters reveal a nuanced picture of oversight interactions in the EMU. In order to facilitate the analysis, the comparison below focuses on the percentages ${ }^{27}$ of questions and answers identified across the four cases. The discussion starts with the types of questions asked by the EP as an accountability forum, followed by a description of the answers provided by executive actors, and finally an assessment of the cases in relation to the six scenarios of oversight interactions outlined in the analytical framework.

\subsubsection{The Performance of the EP as an Accountability Forum}

Figure 7.1 provides an overview of the share of initial and follow-up questions posed by MEPs to the ECB, the Commission, the ECOFIN Council, and the

27 A comparison of absolute numbers of Q\&A would not make sense given the different time periods under investigation, varying from five years (in the case of the ECB) to nine years (in the case of the Council and the Eurogroup). Moreover, the chapters on the ECB and the Commission include written questions, which are not available when analysing the relationship with ECOFIN and the Eurogroup. 


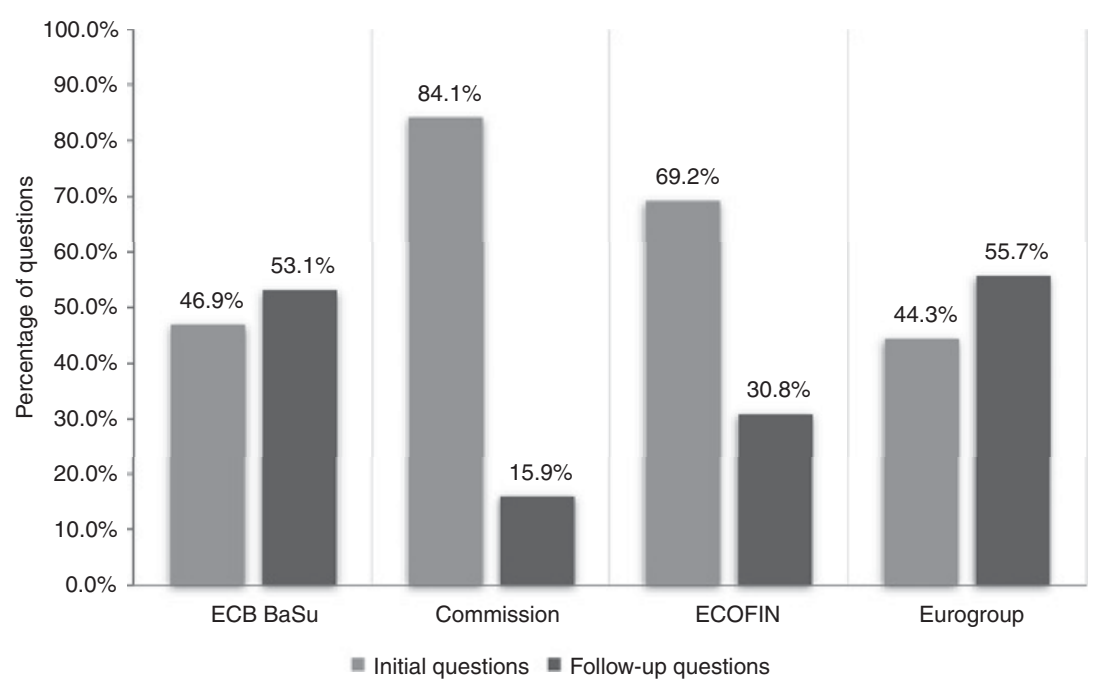

FIGURE 7.1 Percentage of initial and follow-up questions posed by MEPs to each institution, based on Chapters 4-6

Eurogroup in the case studies analysed in the book. As a reminder, follow-up questions can be asked by MEPs from different political groups, keeping in mind that EP Rules of Procedure have strict time limitations for oral questions posed by the same member. Examining the four data sets side by side, we can see clearly that there are more follow-up questions addressed to the Eurogroup and the ECB on banking supervision than to the ECOFIN Council or to the Commission. In fact, only $15.9 \%$ of the questions posed to the Commission are follow-ups, which suggests a lower intensity of oversight. MEPs ask the Commission numerous questions, but these are unrelated - illustrating the diverse interests of Member States and political groups represented in the EP. A similar dynamic can be found vis-à-vis the ECOFIN Council, albeit with a higher number of follow-up questions (30.8\% of all questions identified). By contrast, MEPs ask more follow-up questions of the ECB on banking supervision $(53.1 \%)$ and the Eurogroup ( $55.7 \%)$, revealing an overlap of interests from MEPs regardless of national or political affiliation. To put it differently, the EP is more likely to push the ECB on its supervisory decisions or the Eurogroup on financial assistance than it is to press the Commission on the European Semester or the ECOFIN Council on ongoing legislative files.

Next, there is also variation in relation to the types of questions asked by MEPs of the four institutions. In line with the analytical framework (Chapter 3.3), a distinction is made between weaker oversight questions 


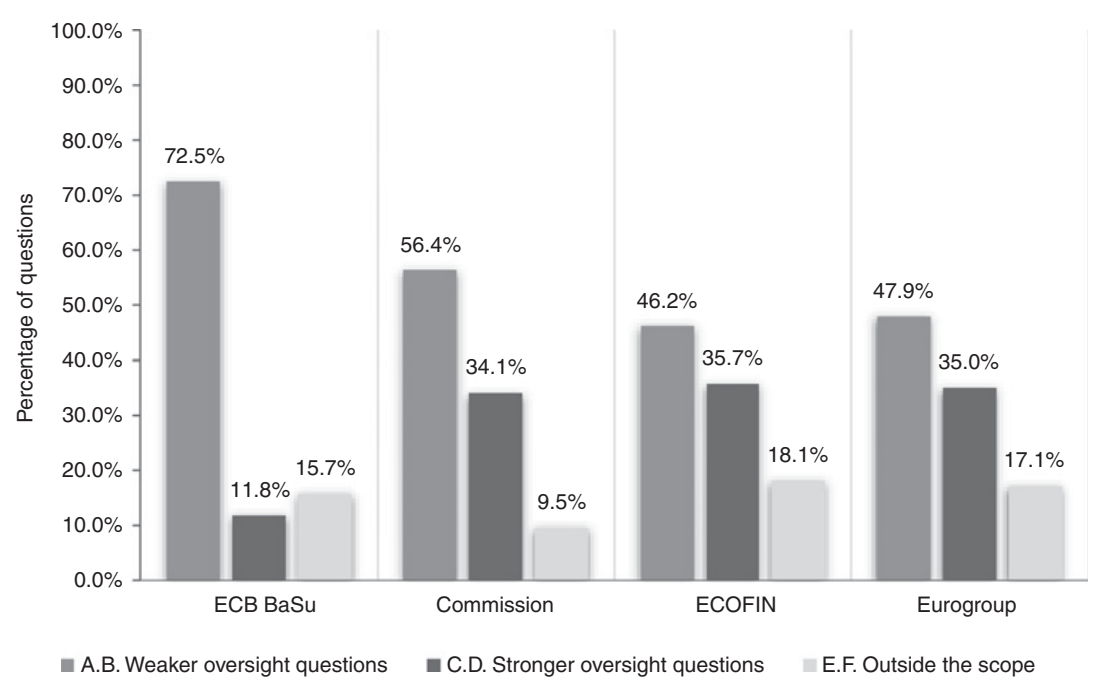

FIGURE 7.2 Types of questions posed by MEPs to each institution, based on Chapters 4-6

(types A and B), stronger oversight questions (types C and D), and questions outside the scope of oversight (types $\mathrm{E}$ and $\mathrm{F}$, where applicable). As stated at the outset, weaker oversight questions request information and justification of decisions by executive actors. Stronger oversight questions demand changes of decisions or conduct, and in more extreme cases, the imposition of sanctions on actors considered responsible for past errors. Stronger oversight questions are relevant for the responsiveness of executive actors to accountability forums and overlap with notions of control in principal-agent theory (Fearon 1999; Strøm 2000). Finally, questions outside the scope of oversight simply ask for policy views from executive actors or mention irrelevant issues that have nothing to do with oversight or the policy area under discussion.

Figure 7.2 offers a snapshot of the typology of questions identified in the four cases covered in the book. While weaker oversight questions are the most frequent category employed by MEPs for all institutions, there is significant variation between the ECB in banking supervision (which received weaker oversight questions over 70 per cent of the time) and the ECOFIN Council or the Eurogroup (which received weaker oversight questions less than 50 per cent of the time). This finding is related to the institutional independence of the ECB in the EU political system and, subsequently, the sensitive nature of asking the ECB to change supervisory policy or conduct (see Chapter 4.1). The Commission is not far behind intergovernmental bodies, 
receiving weaker oversight questions 56 per cent of the time. Keeping in mind that the Eurogroup, ECOFIN, and the Commission are political bodies with key responsibilities in setting or implementing the policy agenda in economic governance, it would have been expected to find more examples of 'stronger oversight questions'. Yet it is worth noting that within the category of 'weaker oversight questions', the number of requests for justification of conduct is higher than the number of requests for information (at least for the Commission and the Eurogroup, see Chapters 5 and 6). The only exception is the ECOFIN Council, which receives numerous demands for information as well as many questions for policy views (type E, outside the scope).

When it comes to ECOFIN and the Eurogroup, Figure 7.2 illustrates a similar division between types of questions; however, the topics discussed vary significantly. According to the book's analytical framework (Chapter 3.3), accountability has an important ex post dimension of executive decisions. Yet in the Economic Dialogues with ECOFIN, MEPs focus on legislative dossiers in the ordinary or special legislative procedure and thus examine the activity of the Council as a legislative rather than as an executive body. In this respect, Dialogues with ECOFIN are better described as a form of ex ante policymaking by the EP as opposed to ex post oversight of executive decisions and conduct (Bovens 2007a: 453). By comparison, the Economic Dialogues with the Eurogroup focus on financial assistance programmes and the role of Eurozone finance ministers on the ESM's Board of Governors. It means that MEPs emphasise ex post oversight of executive decisions in the field. This is not to say that MEPs do not address questions for policy views to the Eurogroup, as these are present in 17.1 per cent of the identified instances. The difference is that such questions inquire about prospective Eurozone reforms, whose contours are typically set by the Eurogroup (and the European Council) before moving to the Commission and the Council in the formal decision-making process. While the questions still illustrate a form of ex ante policy-making, they are related to the role of the Eurogroup as the key executive actor in the EMU.

Overall, the performance of the EP as an accountability forum depends more on the activity than on the type of executive actor under scrutiny. Somewhat surprisingly, there is no significant difference between EP oversight of supranational institutions (the ECB and the Commission) and oversight of intergovernmental bodies (ECOFIN and the Eurogroup). The Eurogroup and the ECB are subject to more intense oversight by MEPs (as shown by the number of follow-up questions), but the direction of the scrutiny differs: MEPs often request the Eurogroup to change policies but do not (and cannot) ask the same of the independent ECB. Conversely, EP oversight of the Commission 
lacks focus, potentially because the Commission's competences in the European Semester cover a variety of socio-economic issues that attract different attention in the Member States. Finally, the ECOFIN Council seems reduced to a legislative body from the perspective of EP oversight, which is unexpected because the Council machinery is still responsible for many executive decisions on the European Semester.

Keeping this in mind, the next section moves to comparing the types of answers provided by executive actors in response to EP oversight in the EMU.

\subsubsection{The Responsiveness of EMU Executive Actors to EP Oversight}

Figure 7.3 captures the classification between explicit, intermediate, and nonreplies identified for the four institutions under consideration. A first observation stemming from the figure is that all institutions tend to provide more explicit replies than intermediate and non-replies combined. This is an important finding, confirming that EMU executive actors do not systematically seek to evade questions or give partial answers in response to the questions raised by MEPs. On the contrary, there is a tendency to engage with parliamentary questions head-on, especially on the part of Eurogroup President Jeroen Dijsselbloem and the Chair of the ECB Supervisory Board, Danièle Nouy. In respect of the Commission, there are some differences between

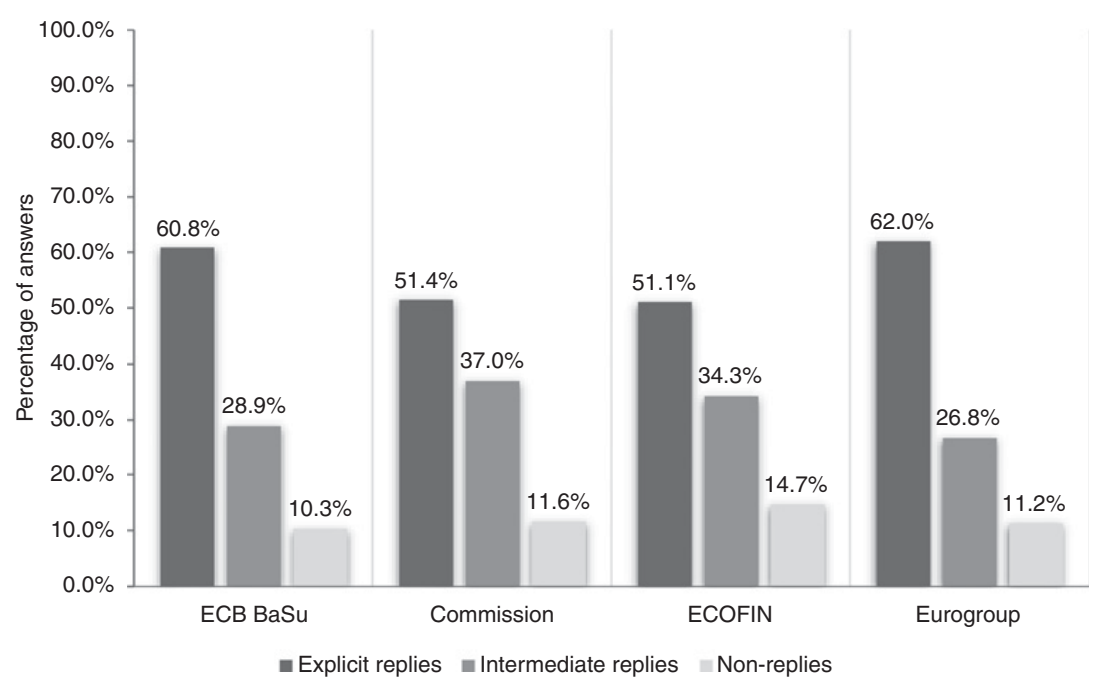

FIGURE 7.3 Percentage of explicit, intermediate, and non-replies provided by each institution, based on Chapters 4-6 
ECOFIN Commissioners and the Vice-President for the Euro (who have similar levels of responsiveness) and EMPL Commissioners (with Marianne Thyssen having a better record than László Andor).

Moving to the categories of intermediate replies, Figure 7.3 shows that the Commission and the ECOFIN Council have a higher tendency to give partial answers than the Eurogroup and the ECB on banking supervision. On the one hand, this might be due to the composite nature of questions put to the Commission and ECOFIN, as MEPs inquire about multiple dimensions regarding social or economic issues in the European Semester (for the Commission) or different points of ongoing legislative files (for the ECOFIN Council). On the other hand, some respondents simply do not engage with the substance of questions asked. In the case of the Commission, László Andor had the tendency to make generic statements that did not clearly address any of the questions raised, while in respect of ECOFIN, there were some Presidencies with a higher percentage of evasions or partial answers (e.g. finance ministers from Romania, Latvia, or Estonia). In fact, ECOFIN Presidencies also scored the highest number of non-replies $(14.7 \%)$, although the difference is not as large when compared to the Commission (11.6\%) and the Eurogroup (11.2\%). In respect of non-replies, the ECB is a special case because its answers are often not about attempts at evasion but references to the secrecy regime in banking supervision and the institution's lack of competence on the issues discussed by MEPs. In fact, out of the four institutions, the ECB has the most reasonable and legally defensible justification as to why it sometimes provides non-replies to parliamentary questions (10.3\% of all instances).

Furthermore, the analytical framework (Chapter 3.3) additionally made the distinction between answers that provide rectification (a promise to change conduct or correct past errors), answers that provide justification (defending conduct or explaining the rationale/content of a decision), and answers that try to equivocate ('dodging a question' or rejecting to comment because of confidentiality requirements or lack of competence on the matter). As shown in Figure 7.4, there is a general trend across the four institutions to answer questions through justification: this applies to over $70 \%$ of all replies from the Commission and the ECB on banking supervision, followed by the Eurogroup (69.0\%), and the ECOFIN Council (64.6\%). In other words, most parliamentary questions get answers providing information about existing/ past/future policies, the rationale for past conduct, or explanations why a decision taken was the correct one. The last category is especially prevalent in answers given by the Eurogroup, the Commission, and ECOFIN in response to requests for policy change. This is a notable distinction because 


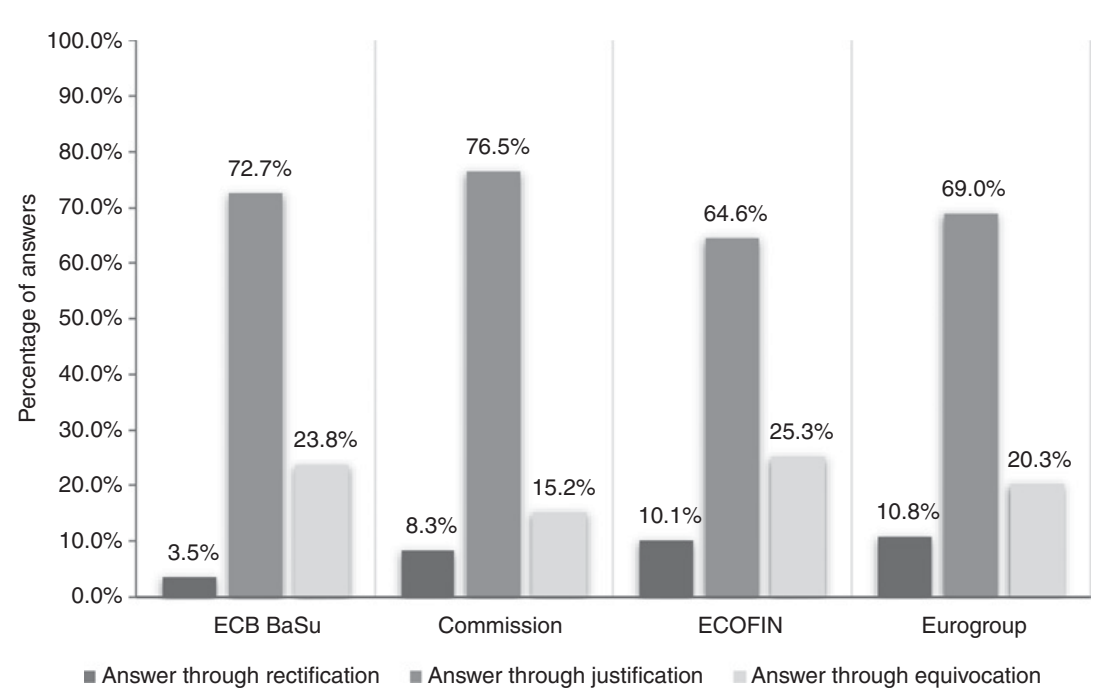

FIGURE 7.4 Types of answers provided by each institution, based on Chapters 4-6

it suggests that EMU executive actors rarely commit to changing their decisions or conduct as a result of EP oversight. The ECB case is different because the majority of questions identified are 'weak' (types A and B), so the institution can only answer through the provision of information and justification of conduct.

The low number of questions answered through 'rectification' reveals the limited responsiveness of the four institutions to the EP. In principal-agent terms, this means that parliamentary questions ensure little to no control of executive actors in the EMU. Due to its political independence, the ECB's record is the poorest: MEPs cannot just ask the ECB to change supervisory policy in the SSM. In the few instances when rectification occurs, it is related to potential abuses of power by the ECB (a legal matter) as opposed to the direction of policy (a political matter). This logic does not apply to the other three institutions, which have political leadership and should in theory be responsive to the EP as a democratic accountability forum. Nevertheless, the analysis discovered a very low number of instances categorised as rectification, ranging from $8.3 \%$ to $10.8 \%$ of the replies identified for the three institutions.

In respect of equivocated replies, the Commission is doing better than the Eurogroup, the ECB, and the ECOFIN Council - which provide evasions or non-replies in more than 20 per cent of all instances. Again, the ECB is a special case because of the secrecy requirements in banking supervision, allowing the institution not to answer questions by invoking confidentiality 
rules. The Eurogroup and the ECOFIN Council do not have the same legal defence regarding the secrecy of their decisions. In fact, most of their equivocated answers are either examples of 'dodging questions' in Economic Dialogues or openly refusing to make public the positions of specific Member States in intergovernmental negotiations. For instance, in 2013, after the tumultuous negotiations of the financial assistance programme for Cyprus, Eurogroup President Jeroen Dijsselbloem repeatedly rejected questions on the internal dynamics of Eurogroup negotiations, arguing that the Council takes decisions as a whole and there is no reason to make country positions public (see Chapter 6.4.3). In the literature on Council and Eurogroup decision-making, consensus is a strong institutional norm protected by Council Presidencies and the Eurogroup President (Puetter 2006, 2014). From this perspective, it is essential for the Council to present a unified front to the 'outside' world - including vis-à-vis the EP.

To sum up, there are many similarities regarding the responsiveness of executive actors to EP oversight in the EMU. All actors tend to provide explicit replies and answers justifying their conduct - offering information about past decisions, decision-making processes, or the rationale behind executive action. However, there are also clear differences between oversight interactions: the ECB and the Eurogroup provide fewer intermediate replies than the Commission and the ECOFIN Council, yet the Commission has the lowest number of equivocated answers. Moreover, there were only a handful of instances when executive bodies promised to rectify past policies or change decisions in response to demands made by MEPs. Yet although the percentage of answers through rectification remains low across the four institutions, the Eurogroup is outperforming the others - a surprising finding given its reputation for lacking accountability in the EMU (Braun and Hübner 2019; Craig 2017). The next section discusses the comparative findings in light of the theoretical expectations of the book.

\subsubsection{Assessing Oversight Interactions: A Comparison}

In respect of the six scenarios of oversight interactions outlined in Chapter 3.3.1, it is possible to plot the four cases studies in the book on a continuum from 'High control' to 'No control' by the EP. When deciding the hierarchy among cases, the relative effect of the variables listed in Table 3.2 was considered in a qualitative fashion. ${ }^{28}$ Most significantly, the analysis

28 Further quantitative analyses on the independent variables listed in Table 3.2 would have to be conducted in order to discern their individual effect on Q\&A in legislative oversight. 
showed that MEPs asked stronger oversight questions when there was public pressure on an issue, as was the case of financial assistance programmes agreed by the Eurogroup or FOLTF decisions taken by the ECB in banking supervision. The more the media reported on an issue, the higher the likelihood for follow-up questions and stronger oversight requests by MEPs. Moreover, the influence of high public pressure was often related to 'scandals' reported by the media rather than the persistent discontent of citizens on sensitive topics such as the impact of austerity in countries affected by the euro crisis. Moreover, public attention to an EMU issue can offset the effect of other variables that would otherwise impact the performance of the EP as an accountability forum, such as its profile as a law-making parliament and its multi-party, multinational composition. The interest of the EP in legislative dossiers was most significant in oversight interactions with the ECOFIN Council (given the relationship between the two institutions as co-legislators) and in the accountability hearings with the ECB on banking supervision (when MEPs would take advantage of the presence of the Chair of the Supervisory Board in the ECON Committee to ask for the ECB's expert opinion on upcoming files). Conversely, the EP poses fewer questions to the Commission on legislative dossiers, although technically the Commission has exclusive right of initiative in the EU law-making process. Furthermore, under conditions of low public pressure - for example, in many Economic Dialogues with the Commission and the ECOFIN Council - parliamentary questions are diverse and diffuse, with few follow-ups, illustrating the diversity of political and national interests in the EP.

Next to public pressure, structural opportunities for oversight also had an important positive effect on the EP's accountability relationships with executive actors in the EMU. The effect was evident in the format of committee meetings: whenever committee meetings were combined and more speakers were allowed in one round of Q\&A, the number of intermediate replies and non-replies increased proportionately. For instance, joint Economic Dialogues with the Commission had so many speakers that it was difficult, if not impossible, for Commissioners to answer all the questions posed within the allocated time. Conversely, committee meetings with only one executive actor present allowed MEPs to get answers to their questions right away, for example, hearings with the Chair of the Supervisory Board or Dialogues with the Eurogroup President. The other issue related to structural opportunities for oversight concerns the adequacy of staff supporting MEPs to ask relevant questions of executive actors, which would could theoretically close the gap of asymmetric information usually found in executive-legislative relations (see Chapter 3.3.1). In this respect, most questions 'outside the scope' or 'irrelevant' 
requests were identified in accountability interactions with the ECB and the Commission, which carry out complex tasks in the EMU and benefit from a high level of expertise in comparison to MEPs (and their assistants). Under the circumstances, structural opportunities for oversight are limited because at times the EP lacks an understanding of the division of competences and the responsibilities of different institutions in the EMU.

In fact, the variable of asymmetric information between the EP and executive actors is most clearly present in the oversight interactions with the ECB in banking supervision. This confirms the expectation regarding the relationship between legislatures and bureaucracies/independent agencies (Table 3.2): indeed, the ECB is the least political of the four institutions covered in the book. As an expert body delegated to perform specific functions (banking supervision in the Eurozone), the ECB has much more information than MEPs regarding the operation of the SSM. Moreover, the ECB benefits from the professional secrecy requirements in banking supervision, which permit the Chair of the Supervisory Board not to disclose details about the individual banks supervised by the ECB. For this reason, the majority of questions addressed to the ECB are weaker, requesting information or justification of conduct. The dynamic of asymmetric information is less pronounced vis-à-vis the Commission, which is simultaneously an expert institution and a political body whose leadership was elected by the EP, according to Articles 14(1) and ${ }_{17}(7)$ TEU. In respect of ECOFIN and the Eurogroup, the aspect of asymmetric information goes hand in hand with the difficulties of disentangling collective decision-making in intergovernmental negotiations, as finance ministers are unlikely to share with the EP the details of country positions and compromises reached inside the Council.

At the same time, given the ex post definition of oversight used throughout the book, it was crucial to consider the focus of parliamentary questions, namely whether MEPs were interested in the ex post scrutiny of executive actors or if they were attempting to influence future decisions (ex ante policymaking). Regular definitions of accountability emphasise the ex post dimension, that is, accountability for past decisions and conduct (Bovens 2007a: 453). Figure 7.5 shows the variation between the Eurogroup (placed in scenario 2, 'Answerability') and the ECOFIN Council (placed mid-way between scenario 4, 'Transparency', and scenario 6, 'No control'). Not only does the ECOFIN Council have the highest number of non-reply, but also the issues covered in Economic Dialogues with ECOFIN revolve around the legislative process instead of the activities of the Council as an executive body. The ECON Committee used to meet with Council Presidencies before the introduction of the European Semester in 2010, so the euro crisis failed to change the dynamic 


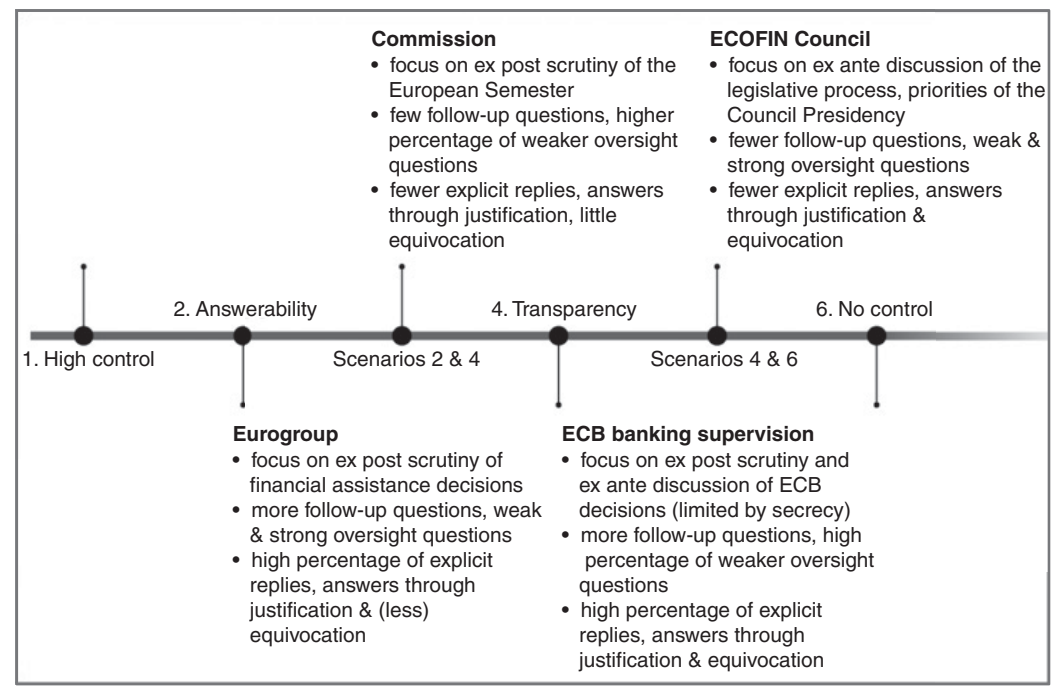

FIGURE 7.5 Overview of case studies in the book on the continuum from 'high control' to 'no control' by the EP in the EMU

between the two institutions - which interact as co-legislators rather than as parliaments and executives in legislative oversight. For this reason, the ECOFIN Council is placed on the lower end of the continuum from 'High control' to 'No control' by the EP in the EMU.

The ex ante emphasis of EP scrutiny of the ECOFIN Council is also the reason why the case is classified below that of the Commission. Although the Commission gives a similar number of intermediate and non-replies as the ECOFIN Council (Figure 7.3), the supranational institution receives questions that are much more relevant for accountability than ECOFIN. Considering the topic of parliamentary questions, it is evident that MEPs use this type of oversight to scrutinise, ex post facto, decisions taken by the Commission on various instruments of the European Semester - their arbitrariness, effectiveness, or benefit for Member States in economic and social terms. By contrast, MEPs use the Economic Dialogues with ECOFIN to get their points across on legislative dossiers, demand information about the status of legislative negotiations in the Council, or ask the opinion of different Presidencies on the (desirable) outcome of a decision-making process. When MEPs press the ECOFIN Council on given issues, these are related to domestic developments in the country holding the Presidency (e.g. tax haven allegations against Cyprus, the Netherlands, or Luxembourg, see Chapter 6.2.2). Last but not least, the Commission has a better record than 
ECOFIN on equivocated answers $-15.2 \%$ as opposed to $25.3 \%$ of all replies in the data set - which shows that one in four replies provided by Council Presidencies do not engage with the issues at stake.

Next, if we compare the Commission to the Eurogroup, there are three reasons why the latter is ranked higher than the former on the continuum from 'High control' to 'No control' by the EP. First, MEPs pose far more follow-up questions to the Eurogroup President than they do to the Commission (55.7\% vs $15.9 \%$ of all questions ${ }^{29}$ ). This clearly shows a keen interest from the EP to press the Eurogroup on specific issues - in particular financial assistance programmes or Eurozone-specific decisions in the European Semester. Although the preponderance of weak and strong oversight questions is similar for the two executive actors, it does matter whether MEPs push to get answers on the same topic or if they move on with other subjects in line with their diverse national or political interests. Furthermore, even though most questions focus on past activities of the two institutions (ex post scrutiny), it is easier for the Commission to get away with partial or equivocated replies than it is for the Eurogroup President. One explanation for this is the format of joint Economic Dialogues with the Commission, where time constraints do not allow MEPs to follow up on issues of interest to their committee or political group. Yet differences in answerability between two institutions cannot be ignored, as the Eurogroup provides on average more explicit replies than the Commission (62.0\% as opposed to $51.4 \%$ of all replies). In fact, this is the second reason why the intergovernmental body was placed higher than the Commission in scenario 2 of oversight interactions - namely 'Answerability'. The finding, however, might be related to the personal style of Jeroen Dijsselbloem, who was Eurogroup President for most of the period under investigation. By contrast, Mário Centeno displayed a lower responsiveness to parliamentary questions. ${ }^{3 \circ}$

The third reason why the Commission is considered to have a worse record than the Eurogroup is related to democratic expectations in the EU political system. Legally speaking, the Commission is accountable to the EP (Article $234 \mathrm{TFEU}$ ), while finance ministers in the Eurogroup remain accountable to their respective national parliaments and citizens (Article 10 TEU). Accordingly, we would have expected the EP to exercise the strongest control over the Commission and, in turn, the Commission to be the most responsive

29 Even when we discard written questions to the Commission and only consider those addressed in the Economic Dialogues, the percentage of follow-up questions is still low - at $19.5 \%$.

30 It is difficult to provide an evaluation for Jean-Claude Juncker because he was present in only one meeting included in the data set. 
executive actor in the EMU. Overall, the Commission is less prone to equivocation than the Eurogroup (15.2\% vs $20.3 \%$ of all replies), but the Eurogroup acknowledges errors and promises rectification more often than the Commission ( $10.8 \%$ as opposed to $8.3 \%$ of all replies). For example, the Commission tends to justify its decisions on EDP sanctions or the MIP by claiming to apply the existing framework of rules in EU economic governance. But as demonstrated by the lax approach to sanctions or the arbitrary definitions of macroeconomic imbalances (Dawson 2019), the framework of rules in the EMU is more open to political interpretation than the Commission is ready to acknowledge. Conversely, the Eurogroup President repeatedly took responsibility for collective decisions taken by finance ministers, for instance, regarding the controversial financial assistance programmes for Cyprus in 2013 and Greece in 2015 (see Chapter 6.4). The problem is that the Eurogroup explains its decisions and defends them before MEPs, but there is nothing the EP can actually do to change the policies or course set by Eurozone finance ministers. For this reason, we can talk about 'Answerability' when it comes to EP oversight of the Eurogroup but certainly not about EP 'control' over the institution.

Finally, EP scrutiny of the ECB in banking supervision is a clear-cut case of scenario 4, 'Transparency'. Given the low number of strong oversight questions addressed to the Chair of the Supervisory Board, the case could not compete with the Eurogroup and the Commission - which receive numerous requests for policy change. However, the ECB does better than the ECOFIN Council on two dimensions. First, MEPs pose more follow-up questions to the ECB than to ECOFIN ( $53.1 \%$ vs $30.8 \%$ of all questions). As discussed earlier in the case of the Eurogroup, follow-up questions reveal cross-national and crosspolitical interests of MEPs in holding an institution accountable on specific issues. Second, the Chair of the Supervisory Board is more open to answering questions than finance ministers representing Council Presidencies (bearing in mind that $60.8 \%$ as opposed to $51.1 \%$ of all replies given by the ECB are explicit). Moreover, if the ECB provides non-replies, this typically happens because of confidentiality requirements or lack of competence rather than due to evasion - which is the case with ECOFIN Presidencies. The secrecy regime in banking supervision remains a caveat for the oversight interactions between the EP and the ECB, blemishing an otherwise 'clean record' of the supranational expert institution.

On the whole, the analysis of EP oversight of executive actors in the EMU yields both expected and surprising results. The expected findings concern the focus on transparency in the scrutiny of the ECB in banking supervision, taking into account the institution's independence and the confidentiality 
requirements of the field. In addition, we could have also anticipated the poor oversight of the ECOFIN Council by the EP - given that the two institutions used to meet in the ECON Committee prior to the accountability reforms introduced during the euro crisis. Conversely, results are surprising when it comes to the Commission and the Eurogroup: on the one hand, EP oversight of the Eurogroup was much more intense and better targeted than that of the Commission; on the other hand, the Eurogroup was more open than the Commission to accepting political responsibility for EMU decisions (through defence of conduct and sometimes rectification). But even in the case of the Eurogroup, EP oversight stopped short of 'control' in principal-agent terms: in other words, MEPs could make the Eurogroup answerable but not responsive (meaning amenable) to the EP as an accountability forum.

Having established the main features of oversight interactions between the EP and executive actors in the EMU, the following pages turn towards avenues for reform - in line with the deficiencies identified.

\subsection{LOOKING FORWARD: POLICY RECOMMENDATIONS}

What implications does the analysis above have for the future of the EP as an accountability forum in the EMU? This section outlines concrete policy recommendations applicable to MEPs and the executive actors covered in the book. Based on the theoretical framework introduced in Chapter 3.3, policy recommendations are connected to broader 'accountability purposes' applied to the empirical evaluation of oversight interactions. Starting with the EP, the focus should be on increasing opportunities for follow-up questions (through the format of meetings), improving the relevance and strength of questions, and encouraging higher responsiveness from actors. In order to act as an effective accountability forum, the EP needs to examine, ex post facto, decisions by executive actors - demanding justification of conduct, changes of policy, and sanctions when deemed appropriate. Table 7.1 captures the key policy recommendations coming out of the empirical analysis. All items are applicable to oral questions, whereas recommendations \#3-5 are also valid for written questions.

The first accountability purpose, namely 'improving opportunities for follow-up questions' by MEPs, is well known in the specialised literature. With some variation, recommendation $\#_{1}$ has been made in previous research on the EP's performance as an accountability forum, especially in respect of the Monetary Dialogues (see recently Claeys and Domínguez-Jiménez 2020; Lastra 2020; Whelan 2020). In terms of the format of meetings, many critics agree that the EP needs to lower the number of speakers per session to allow 
TABLE 7.1 Policy recommendations addressed to the EP in order to improve its performance as an accountability forum

\begin{tabular}{|c|c|}
\hline Accountability purpose & Concrete recommendations \\
\hline $\begin{array}{l}\text { Increase opportunities for follow-up } \\
\text { questions }\end{array}$ & $\begin{array}{l}\text { (1) Change the format of committee meetings } \\
\text { to address specific topics in order, one } \\
\text { question at a time (streamline Q\&A session) } \\
\text { (2) Centralise questions at the committee level, } \\
\text { ensure that there is coordination between } \\
\text { political groups (deliberate choice to press } \\
\text { on similar/different issues) }\end{array}$ \\
\hline Improve the relevance of questions & $\begin{array}{l}\text { (3) Expand in-house expertise by tasking } \\
\text { research units to provide a monthly round- } \\
\text { up of possible questions to various executive } \\
\text { actors in the EMU (offer MEPs a selection } \\
\text { of appropriate questions) }\end{array}$ \\
\hline Improve the strength of questions & $\begin{array}{l}\text { (4) Coordinate a division of labour within pol- } \\
\text { itical groups, with different MEPs taking } \\
\text { the lead in overseeing specific executive } \\
\text { actors (specialisation of oversight) } \\
\text { (5) Focus questions on the mandate of the insti- } \\
\text { tution and its performance of tasks (ex post } \\
\text { oversight) }\end{array}$ \\
\hline $\begin{array}{l}\text { Encourage higher responsiveness } \\
\quad \text { from executive actors }\end{array}$ & $\begin{array}{l}\text { (6) Use the existing voting system to allow } \\
\text { MEPs to give instant feedback on the } \\
\text { answers of executive actors to parliamentary } \\
\text { questions. Voting 'yes' would indicate } \\
\text { approval, and 'no' would suggest dissatis- } \\
\text { faction, while 'abstain' would show indif- } \\
\text { ference to the topic. } \text {. }^{31}\end{array}$ \\
\hline
\end{tabular}

more time for each question and ensure a back-and-forth between MEPs and executive actors. In Table 7.1, the novelty concerns the coordination between political groups (recommendation \#2) in advance of accountability hearings or dialogues with executive actors. Keeping in mind that all political groups appoint coordinators for each committee (Rule 214 of the EP's current Rules of Procedure), the idea is to use coordinators' meetings to organise the questioning of executive actors along specific lines of inquiry. This would give more

${ }^{31}$ I am grateful to Marcel Magnus from the EP's EGOV unit for this suggestion (email correspondence, 11 May 2020). 
coherence to the meetings and allow MEPs to put pressure on single issues, depending on their interests at a given moment in time.

The next accountability goal in Table 7.1 refers to the need to "improve the relevance of questions' addressed by MEPs in accountability interactions. In any parliament, it is not realistic to expect members to have expertise on all the issues pertinent to the activity of executive actors. The EMU is more complicated than a national system because of overlapping competences between different EU institutions and national authorities (as shown in Chapter 4.3 in relation to banking regulation, supervision, and resolution). For their part, parliamentary assistants may be overwhelmed by the amount of information available on the implementation of different EMU policies. As a result, it would be beneficial for MEPs to receive expert guidance on policy issues relevant for legislative oversight (recommendation $\#_{3}$ ). For example, research departments in the EP's administration could provide MEPs with a list of potential questions relevant for each executive actor in a given month/quarter. In EMU sub-fields, questions can be compiled by research-oriented departments such as the EGOV or the economic branch of the DG for Internal Policies of the Union. While this might increase the workload of the departments, the solution would take advantage of existing in-house knowledge regarding institutional competences and policy problems in the EMU.

Next, there is the goal to 'improve the strength of parliamentary questions' by going beyond requests for information to demands for justification of conduct, changes of policy, or sanctions of actors. While such an increase would not apply equally to all institutions (e.g. the ECB), the point is to shift the focus from what EMU executive actors are doing to assessing the appropriateness - however defined - of a course of action. Such an evaluation would require MEPs to specialise in the activities of all executive actors, which is not feasible given the high number of executive institutions in the EMU (the Commission, the ECB, the Council, Eurogroup, SRB, etc.). For this reason, recommendation $\#_{4}$ proposes a division of labour within political groups, allowing different MEPs to take the lead in different oversight interactions. For example, permanent members of the ECON Committee could choose to focus on the ECB, the Commission, or the Eurogroup - facilitating a gradual specialisation in the mandate and instruments adopted by one institution. This was illustrated in the past in the accountability relationship between the EP and the ECB in banking supervision, when members like Pervenche Berès (France, S\&D) or Sven Giegold (Germany, the Greens/EFA) clearly had the expertise to question supervisory decisions in a systematic manner (see Chapter 4.3) - which improved the quality and intensity of Q\&A sessions. 
Politically speaking, MEPs might reject such specialisation as undesirable because they would like to keep a 'generalist profile' in case they change committees or careers after their term comes to an end. Nevertheless, the move would make a lot of sense in the EP - given both the size of the assembly and the diversity of national interests (as well as the EU interest) it seeks to represent. The point is to facilitate a parliamentary focus on the ex post decisions taken by specific institutions and examine their appropriateness (recommendation \#5). A similar notion is advocated in policy research by those who argue that MEPs need to ask more 'technical' questions, in line with the mandate of each executive actor (e.g. Claeys and Domínguez-Jiménez 2020; Lastra 2020; Whelan 2020). The 'appropriateness' of executive action can be judged in multiple ways - assessing for instance whether decisions have been transparent, non-arbitrary, effective, or advancing the public interest (Dawson and Maricut-Akbik 2020). In other words, the current allocation of MEPs into committees is not sufficient to achieve the goal of specialised oversight.

Finally, the EP could 'encourage higher responsiveness from executive actors' using the existing voting system to evaluate instantly answers to parliamentary questions (recommendation \#6). This would offer MEPs the chance to signal on the spot whether they accept, reject, or are indifferent to replies given by executive actors in a committee meeting. The system would be imperfect because political groups on the fringes will always be inclined to evaluate the responsiveness of executive actors in a negative manner. Yet the more interesting finding will refer to the voting behaviour of MEPs from the main political groups, who also supported the Commission President and the College. For their part, executive actors will be more likely to answer questions explicitly, avoid generic answers, or refrain from dodging questions if they know their performance is evaluated immediately by MEPs present in committee meetings.

Moving to the responsiveness of executive actors, Table 7.2 provides both general and institution-specific recommendations. The first accountability goal mentioned refers to the imperative to reduce the number of non-replies or equivocated answers. These occur for different reasons, so two of the recommendations are general and two are tailored to the ECB and the Commission, respectively. In respect of oral questions, it is essential for all executive actors to stop making generic statements in order to pass the time allocated to an answer in committee meetings (recommendation \#1). When MEPs ask questions that are outside the competence of an executive body, the responding actor should explain the division of competence and why their institution is not the appropriate addressee for that specific issue 
TABLE 7.2 Policy recommendations addressed to EMU executive actors in order to improve their responsiveness to the EP

\begin{tabular}{|c|c|}
\hline Accountability purpose & Concrete recommendations \\
\hline \multirow{6}{*}{$\begin{array}{l}\text { Reduce number of non- } \\
\text { replies or equivocated } \\
\text { answers }\end{array}$} & Applicable to all: \\
\hline & $\begin{array}{l}\text { (1) For oral questions: stop making generic state } \\
\text { ments to pass the time allocated to an answer } \\
\text { (2) For oral and written questions: when you are } \\
\text { not the competent institution for an issue } \\
\text { raised by an MEP, explain which other body is } \\
\text { responsible and why. }\end{array}$ \\
\hline & $\underline{\text { Specific to the ECB: }}$ \\
\hline & $\begin{array}{l}\text { (3) Reform the confidentiality regime in banking } \\
\text { supervision to allow supervisory decisions to be } \\
\text { disclosed under certain conditions, for } \\
\text { example, after a sufficient period of time has } \\
\text { passed. }\end{array}$ \\
\hline & Specific to the Commission: \\
\hline & $\begin{array}{l}\text { (4) For oral questions: cooperate with the EP to } \\
\text { change the format of Economic Dialogues in } \\
\text { order to ensure that each MEP asks one ques- } \\
\text { tion at a time of one respondent (streamline } \\
\text { Q\&A session). }\end{array}$ \\
\hline $\begin{array}{l}\text { Reduce number of } \\
\text { intermediate replies }\end{array}$ & $\begin{array}{l}\text { (5) In response to multi-pronged questions, make } \\
\text { sure to address all the parts mentioned by an } \\
\text { MEP. When a full answer is not possible due } \\
\text { to time constraints, promise to deliver a written } \\
\text { response (and do so after the meeting). }\end{array}$ \\
\hline $\begin{array}{l}\text { Increase number of answers } \\
\text { through rectification }\end{array}$ & $\begin{array}{l}\text { (6) When several political groups demand } \\
\text { a change of policy or decisions, show consid- } \\
\text { eration and reflection }{ }^{*} \text { : how complicated } \\
\text { would it be to meet the demand? } \\
\text { * Legal exception: the ECB in respect of sub- } \\
\text { stantive policy issues }\end{array}$ \\
\hline
\end{tabular}

(recommendation $\#_{2}$ ). In banking supervision, the problem is the strict secrecy regime that does not allow the ECB to answer many questions on supervisory decisions on individual banks (see Chapter 4). A possible solution is to reform the system in a way that takes into account the concerns of supervised banks and responds to the public interest in knowing what the ECB actually does in the field. The idea proposed here is to establish a specific time period after which supervisory decisions can become public 
(recommendation $\#_{3}$ ). The waiting period will ensure that the positions of financial institutions are not jeopardised in the eyes of depositors or competitors - thus alleviating key concerns regarding transparency in banking supervision (Angeloni 2015). For the Commission, one problem identified in Chapter 5 was the format of joint committee meetings, which allowed several speakers to pose multiple questions to two to three Commissioners in one sitting. Accordingly, the proposed solution invites the Commission to collaborate with the EP in order to streamline the Q\&A process in Economic Dialogues, ensuring that one question is put to one respondent at a time (recommendation $\#_{4}$ ).

The second accountability goal listed in Table 7.2 emphasises the need to 'reduce the number of intermediate replies'. As found in Chapters 3-6, intermediate replies are often the result of multi-pronged questions, when MEPs inquire about several issues using one or two interrogative sentences. In response, executive actors tend to answer such questions only in part, making it difficult to assess whether the reason is obfuscation or lack of time to engage with all the aspects raised by an MEP. If the reason is obfuscation, it is essential for executive actors to engage with different parts of a question by providing clear and concise responses. When time does not allow for comprehensive replies, actors could promise MEPs to provide written answers after the meeting - and then task their administrative staff to do so (recommendation \#5).

Last but not least, there is the sensitive issue of 'answering more questions through rectification' - by promising to change policies or conduct in the future (recommendation \#6). This is particularly applicable to executive bodies with political leadership: the Eurogroup, the ECOFIN Council, and the Commission. Being responsive to EP oversight would mean that systematic demands for policy change by MEPs are taken into account by executive actors. This is not to say that executive bodies should make endless promises to implement changes in response to every request made by an MEP. Nevertheless, when several political groups draw attention to specific decisions or conduct, executive actors should show openness and consideration of the merits of the claims.

Overall, the feasibility of the recommendations above depends on the political will of MEPs and the leadership of executive actors in the future. The following years will be crucial to establish a functional oversight relationship between the EP and EMU executive actors. The EU response to the COVID-19 crisis will have long-term implications on the economic governance framework given the adoption of the Recovery and Resilience Facility (RRF) - expected to last until 2027. The RRF is a financial support 
instrument of up to $€ 672.5$ billion that will be allocated to Member States in the form of grants and loans designed to help alleviate some of the negative economic effects of the pandemic (European Commission 2021). The RRF is revolutionary in many ways, allowing the accumulation of $\mathrm{EU}$ debt for the purposes of common expenditure and creating EU fiscal capacity for the first time, albeit as a temporary measure (Guttenberg et al. 2021).

In terms of institutional changes, the RRF will be merged with the European Semester for the 2021 cycle, with governments being asked to replace the submission of annual reform programmes with national recovery and resilience plans, listing the investments for which they require EU funding (European Commission 2020a). The Commission will be in charge of evaluating the plans (similar to the Semester process), while the Council will give final approval on a case-by-case basis (European Commission 2021). This means that both the Commission and the ECOFIN Council (rather than the Eurogroup) will have a prominent role in the RRF and be subject to public scrutiny. In this context, MEPs have a chance to affirm their role as an accountability forum by keeping a close eye on decision-making and ensuring that executive actors stick to the promises made in order to obtain EP support, for example, the focus on green transition, digital transformation, or respect for the rule of law (European Parliament Press Release 2021). From the perspective of democratic accountability, the EP should seize the opportunity to oversee this new yet significant increase of executive power in EU economic and fiscal policies.

Beyond the EMU, the analysis in the book raises important questions about the role of the EP in improving the EU's democratic accountability credentials. The final section problematises the discussion.

\subsection{THE BIG PICTURE: EP OVERSIGHT AND EU ACCOUNTABILITY}

To put the analysis of the book into perspective, the final question addressed is whether effective oversight by the EP will solve the EU's long-standing accountability deficit - in the EMU and beyond. As described in Chapter 3.1, accountability is a multi-faceted concept that carries political, legal, and administrative connotations (Bovens 2007a; Dubnick 2014). EP oversight of executive actors is a form of political accountability that cannot replace judicial review of $\mathrm{EU}$ decisions by national and $\mathrm{EU}$ courts, auditing by the ECA, or administrative review by the European Ombudsman. These mechanisms need to function simultaneously: a strong process of judicial 
review will not make up for weak political accountability mechanisms - or the other way around (Dawson et al. 2019). Even in the realm of political accountability, improving the EP's performance in legislative oversight will not fix, on its own, the EU's long-standing democratic accountability problems. The issues are systemic, rooted in the complexity of a multi-level, multi-national polity (Brandsma et al. 2016: 624-625) in which democratic elections take place regularly but where political competition does not translate into control of the policy agenda (Føllesdal and Hix 2006). Improving the effectiveness of EP oversight of executive actors is therefore a necessary but insufficient condition to overcome the EU's systemic accountability problems. However, such reforms can help expand political accountability at the supranational level and improve perceptions of democratic legitimacy among citizens. The argument is developed below.

The starting point is the complexity of the EU political system, which makes it difficult to identify the 'right actors' accountable for past decisions (Brandsma 2013: 50-51). First, EU decisions are taken collectively, so it is impossible to disentangle individual responsibility at the national level which means that citizens cannot easily assign blame via the ballot box (Hobolt und Tilley 2014). Second, EU decision-making involves numerous networks of national and sub-national authorities that lead to a dilution of responsibility and a higher likelihood of blame-shifting from one level of governance to the other (Bovens 2007b; Harlow and Rawlings 2007; Papadopoulos 2010). Third, from a principal-agent perspective, EU executive actors can have multiple principals with conflicting objectives, for example, national electorates, EU citizens, national governments, the EP, and so on, which inflate and confuse the object of accountability (Busuioc 2013; Dehousse 2008). To put it bluntly, the EU political system makes it difficult to know who is responsible for what or why that is the case.

Furthermore, democratic elections take place on a regular basis but offer citizens few opportunities to hold EU actors accountable in practice (Gustavsson et al. 2009). As mentioned above, national elections are undermined by collective decision-making at the EU level, whereas EP elections remain disconnected from EU politics or considerations of control over the policy agenda. In respect of the EP, the lack of an 'electoral connection' between MEPs and their voters is notorious (Hix and Høyland 2013: 184). EU citizens do not vote in EP elections in response to the performance of individual MEPs or their political groups; instead, voters often cast ballots in order to 'punish' national governments for domestic issues (Hix and Marsh 2007). Moreover, even if citizens had clear preferences about the direction of EU policies, EP political groups would not be able to translate them into 
policy outputs in the same way as national parties (Lindberg et al. 2008; Mühlböck 2012). Given the complexity of the EU decision-making process, the EP has to negotiate constantly and reach compromises with the other institutions (Hix and Høyland 2011: 131-133). The dynamic illustrates the problem described above, namely the difficulties of identifying the 'right actors' responsible for EU decisions and subsequently holding them accountable.

Taking all this into consideration, it becomes clear that EP oversight of executive actors is only one element of political accountability in the EU. Improving its effectiveness will not magically solve the EU's infamous democratic deficit (Føllesdal and Hix 2006). Yet there is significant added value in enhancing EP scrutiny of EU executive actors in the EMU and beyond. To begin with, parliamentary oversight offers a way to bridge the gap between those who hold authority in the EU political system (the citizens) and those who exercise it on their behalf (EU executive institutions) (cf. Føllesdal and Hix 2006). Indeed, MEPs can ask questions of EU executive actors drawing on items of concern in their own constituency which is one of the basic purposes of parliamentary questions (Martin 2on1a; Wiberg and Koura 1994). Next, effective oversight can improve citizen perceptions of democratic legitimacy in the EU and increase their attentiveness to the EP as a representative assembly. For instance, if citizens see footage of confrontations between MEPs and EU executive actors in committee meetings or if they read media reports of effective parliamentary questioning, they are likely to appreciate the activity of their representatives in holding executive actors accountable.

At the same time, effective oversight can increase the informal influence of the EP in the EU political system. Heated committee hearings or pointed written questions are likely to attract media attention and put public pressure on EU executive actors to change conduct or adjust policy decisions. The EP has thus a lot to gain from expanding its profile as an accountability forum, keeping in mind that ex post scrutiny has pre-emptive effects on the behaviour of actors - who know they will be constantly observed and questioned about their decisions (Schillemans 2016: 1408). To put it differently, after fighting for decades to expand its budgetary and legislative competences, the time has come for the EP to assert its scrutiny powers - which it already possesses in many policy fields. In this respect, the EMU provides an excellent setting for the EP to exercise its oversight powers and hold EU executive actors accountable in an area at the heart of citizens' concerns. 


\section{References}

Aberbach, J. D. (1990) Keeping a Watchful Eye: The Politics of Congressional Oversight, Washington, DC: Brookings Institution Press.

Adamski, D. (2015) 'Economic Constitution of the Euro Area after the Gauweiler Preliminary Ruling', Common Market Law Review 52(6): 1451-1490.

Alcidi, C. and Gros, D. (2017) 'How to Strengthen the European Semester', Brussels: Center for European Policy Studies, available at https://pdfs.semanticscholar.org/ao 68/fdeef4e84b8o6d4b7f3fifindo7ofgfeofao.pdf.

Alesina, A. and Summers, L. H. (1993) 'Central Bank Independence and Macroeconomic Performance: Some Comparative Evidence', Journal of Money, Credit and Banking 25(2): 151-162.

Alexander, K. (2015) 'European Banking Union: A Legal and Institutional Analysis of the Single Supervisory Mechanism and the Single Resolution Mechanism', European Law Review 40(2): 154-187.

Alexander, K. (2016) 'The European Central Bank and Banking Supervision: The Regulatory Limits of the Single Supervisory Mechanism', European Company \& Financial Law Review 13(3): 467-494.

Amtenbrink, F. and Markakis, M. (2019) 'Towards a Meaningful Prudential Supervision Dialogue in the Euro Area? A Study of the Interaction between the European Parliament and the European Central Bank in the Single Supervisory Mechanism', European Law Review 44(1): 3-23.

Amtenbrink, F. and van Duin, K. (2009) 'The European Central Bank before the European Parliament: Theory and Practice after Ten Years of Monetary Dialogue', European Law Review 34(4): 561-583.

Angeloni, I. (2015) Transparency and Banking Supervision, Remarks by Ignazio Angeloni, Member of the Supervisory Board of the European Central Bank at the ICMA Capital Market Lecture Series, Frankfurt am Main, 27 January 2015, available at www.bankingsupervision.europa.eu/press/speeches/date/2015/html/se150127 .en.html (accessed October 2018).

Angerer, J., Dias Costa Esteves, P. N., Hagelstam, K. and Zoppe, A. (2019) 'The European Semester for Economic Policy Coordination: A Reflection Paper', European Parliament Think Tank, available at www.europarl.europa.eu/RegData/ etudes/STUD/2019/624440/IPOL_STU(2019)624440_EN.pdf (accessed April 2020). 
Auel, K. (2007) 'Democratic Accountability and National Parliaments: Redefining the Impact of Parliamentary Scrutiny in EU Affairs', European Law Journal 13(4): $487-504$.

Auel, K. and Höing, O. (2014) 'Parliaments in the Euro Crisis: Can the Losers of Integration Still Fight Back?', Journal of Common Market Studies 52(6): $1184-1193$.

Auel, K. and Höing, O. (2015) 'National Parliaments and the Eurozone Crisis: Taking Ownership in Difficult Times?', West European Politics 38(2): 375-395.

Bache, I., Bulmer, S., George, S. and Parker, O. (2015) Politics in the European Union, $4^{\text {th }}$ ed., New York: Oxford University Press.

Bagehot, W. (1873) The English Constitution, 2nd ed., London: H. S. King.

Bailer, S. (2014) 'Interviews and Surveys in Legislative Research', in S. Martin, T. Saalfeld, and K. Strøm (eds). The Oxford Handbook of Legislative Studies. Oxford and New York: Oxford University Press, pp. 167-193.

Baldwin, R. et al. (2015) 'Rebooting the Eurozone: Step 1 - Agreeing a Crisis Narrative', CEPR Policy Insight No. 85, available at https://cepr.org/sites/default/files/policy_in sights/PolicyInsight85.pdf (accessed November 2020).

Barrett, G. (2018) 'European Economic Governance: Deficient in Democratic Legitimacy?', Journal of European Integration 4O(3): 249-264.

Bauer, M. W. and Becker, S. (2014) 'The Unexpected Winner of the Crisis: The European Commission's Strengthened Role in Economic Governance', Journal of European Integration 36(3): 213-229.

Beetham, D. (1991) The Legitimation of Power, Houndmills: Palgrave Macmillan.

Behn, R. D. (2001) Rethinking Democratic Accountability, Washington, DC: Brookings Institution Press.

Belke, A. (2017) 'Central Bank Communication: Managing Expectations through the Monetary Dialogue', ROME Working Papers 04/2017, available at https://ideas .repec.org/p/rmn/wpaper/201704.html (accessed January 2019).

Bergman, T. (1997) 'National Parliaments and EU Affairs Committees: Notes on Empirical Variation and Competing Explanations', Journal of European Public Policy 4(3): $373-3^{8} 7$.

Bickerton, C. (2015) 'The Real Sins of Varoufakis: Why Greece is Being Punished for Refusing to Play by the Eurogroup's Rules', Euro Crisis in the Press, available at https:// blogs.lse.ac.uk/eurocrisispress/2015/07/13/the-real-sins-of-varoufakis-why-greece-is-beingpunished-for-refusing-to-play-by-the-eurogroups-rules/ (accessed December 2020).

Bickerton, C., Hodson, D. and Puetter, U. (2015) 'The New Intergovernmentalism: European Integration in the Post-Maastricht Era', Journal of Common Market Studies 53(4): 703-722.

Blondel, J., Sinnott, R. and Svensson, P. (1998) People and Parliament in the European Union: Participation, Democracy, and Legitimacy, Oxford: Oxford University Press.

Bokhorst, D. J. (2019) Governing Imbalances in the Economic and Monetary Union: A Political Economy Analysis of the Macroeconomic Imbalance Procedure, Amsterdam: University of Amsterdam, available at https://dare.uva.nl/search?identi fier $=85$ d 7 b956-ood 5-47ac-95d2-284115cagbbf (accessed December 2020).

Borger, V. (2013) 'How the Debt Crisis Exposes the Development of Solidarity in the Euro Area', European Constitutional Law Review 9(1): 7-36. 
Boswell, C. (2008) 'The Political Functions of Expert Knowledge: Knowledge and Legitimation in European Union Immigration Policy', Journal of European Public Policy 15(4): 471-488.

Bovens, M. (2007a) 'Analysing and Assessing Accountability: A Conceptual Framework', European Law Journal 13(4): 447-468.

Bovens, M. (2007b) 'New Forms of Accountability and EU-Governance', Comparative European Politics 5(1): 104-120.

Bovens, M. (2010) 'Two Concepts of Accountability: Accountability as a Virtue and as a Mechanism', West European Politics 33(5): 946-967.

Bovens, M., Curtin, D. and 't Hart, P. (2010a) 'Studying the Real World of EU Accountability: Framework and Design', in M. Bovens, D. Curtin and P. 't Hart (eds). The Real World of EU Accountability: What Deficit?. Oxford and New York: Oxford University Press, pp. 31-62.

Bovens, M., Curtin, D. and 't Hart, P. (eds) (2010b) The Real World of EU Accountability: What Deficit?, Oxford and New York: Oxford University Press.

Bovens, M. and Schillemans, T. (2014) 'Meaningful Accountability', in M. Bovens, R. E. Goodin and T. Schillemans (eds). The Oxford Handbook of Public Accountability. Oxford: Oxford University Press, pp. 673-682.

Bovens, M., Schillemans, T. and Goodin, R. E. (2014) 'Public Accountability', in M. Bovens, R. E. Goodin and T. Schillemans (eds). The Oxford Handbook Public Accountability. Oxford: Oxford University Press, pp. 1-22.

Brack, N. (2017) Opposing Europe in the European Parliament: Rebels and Radicals in the Chamber, London: Palgrave Macmillan.

Brack, N. and Costa, O. (2018) 'Introduction: The European Parliament at a Crossroads', The Journal of Legislative Studies 24(1): 1-10.

Brandsma, G. J. (2013) Controlling Comitology: Accountability in a Multi-Level System, Houndsmills, Basingstoke: Palgrave Macmillan.

Brandsma, G. J. (2014) 'Quantitative Analysis', in M. Bovens, R. E. Goodin, and T. Schillemans (eds). The Oxford Handbook Public Accountability. Oxford: Oxford University Press, pp. $143^{-15} 8$.

Brandsma, G. J. (2016) 'Holding the European Commission to Account: The Promise of Delegated Acts', International Review of Administrative Sciences 82 (4): 656-673.

Brandsma, G. J., Heidbreder, E. and Mastenbroek, E. (2016) 'Accountability in the Post-Lisbon European Union', International Review of Administrative Sciences 82(4): 621-637.

Brandsma, G. J. and Schillemans, T. (2013) 'The Accountability Cube: Measuring Accountability', Journal of Public Administration Research and Theory 23(4): 953-975.

Braun, B. (2017) Two Sides of the Same Coin? Independence and Accountability at the ECB, Berlin: Transparency International EU, available at https://transparency.eu/wpcontent/uploads/2017/03/TI-EU_ECB_Report_DIGITAL.pdf (accessed January 2018).

Braun, B. and Hübner, M. (2019) Vanishing Act: The Eurogroup's Accountability, Brussels: Transparency International EU, available at http://transparency.eu/wpcontent/uploads/2019/o2/TI-EU-Eurogroup-report.pdf (accessed February 2019).

Braun, D. and Guston, D. H. (2003) 'Principal-Agent Theory and Research Policy: An Introduction', Science and Public Policy 30(5): 302-308. 
Bressanelli, E. and Chelotti, N. (2016) 'The Shadow of the European Council. Understanding Legislation on Economic Governance', Journal of European Integration 38(5): 511-525.

Bressanelli, E. and Chelotti, N. (2018) 'The European Parliament and Economic Governance: Explaining a Case of Limited Influence', The Journal of Legislative Studies 24(1): 72-89.

Buiter, W. H. (2014) 'Central Banks: Powerful, Political and Unaccountable?', Journal of the British Academy 2: 269-303.

Buiter, W. and Rahbari, E. (2012) 'The European Central Bank as Lender of Last Resort for Sovereigns in the Eurozone', Journal of Common Market Studies 5o(s2): 6-35.

Bull, P. (1994) 'On Identifying Questions, Replies, and Non-Replies in Political Interviews', Journal of Language and Social Psychology 13(2): 115-131.

Bull, P. and Mayer, K. (1993) 'How Not to Answer Questions in Political Interviews', Political Psychology 14(4): 651-666.

Bull, P. and Strawson, W. (2020) 'Can't Answer? Won't Answer? An Analysis of Equivocal Responses by Theresa May in Prime Minister's Questions', Parliamentary Affairs 73(2): 429-449.

Bürgin, A. (2018) 'Intra- and Inter-Institutional Leadership of the European Commission President: An Assessment of Juncker's Organizational Reforms', Journal of Common Market Studies 56(4): 837-853.

Burns, C. (2019) 'The European Parliament', in M. Cini and N. P.-S. Borragán (eds). European Union Politics. Oxford and New York, NY: Oxford University Press, pp. $176-188$.

Busuioc, M. (2009) 'Accountability, Control and Independence: The Case of European Agencies', European Law Journal 15(5): 599-615.

Busuioc, M. (2013) European Agencies: Law and Practices of Accountability, Oxford: Oxford University Press.

Busuioc, M. and Lodge, M. (2016) 'The Reputational Basis of Public Accountability', Governance 29(2): 247-263.

Buti, M., Eijffinger, S. C. and Franco, D. (2003) 'Revisiting the Stability and Growth Pact: grand design or internal adjustment?', CEPR Discussion Paper (No. 3692).

Carman, J. G. (2009) 'Nonprofits, Funders, and Evaluation: Accountability in Action', The American Review of Public Administration 39(4): 374-390.

Chalmers, D. (2012) 'The European Redistributive State and a European Law of Struggle', European Law Journal 18(5): 667-693.

Cheibub, J. A., Elkins, Z. and Ginsburg, T. (2014) 'Beyond Presidentialism and Parliamentarism’, British Journal of Political Science 44(3): 515-544.

Chester, D. N. and Bowring, N. (1962) Questions in Parliament, Oxford: Clarendon Press.

Christiansen, T. (2016) 'After the Spitzenkandidaten: Fundamental Change in the EU's Political System?', West European Politics 39(5): 992-1010.

Claeys, G. and Domínguez-Jiménez, M. (2020) How Can the European Parliament Better Oversee the European Central Bank?, Luxembourg: European Parliament, Policy Department for Economic, Scientific and Quality of Life Policies, In-depth analysis PE 652.747 .

Claeys, G., Hallerberg, M. and Tschekassin, O. (2014) 'European Central Bank Accountability: How the Monetary Dialogue could be Improved', Bruegel Policy 
Contribution 2014/04, available at http://bruegel.org/2014/o3/european-central-bankaccountability-how-the-monetary-dialogue-could-be-improved/ (accessed October 2017).

Cœuré, B. (2017) Independence and Accountability in a Changing World, 8 March 2017, Introductory remarks by Benoit Cœuré, Member of the Executive Board of the ECB, at the Transparency International EU Event 'Two sides of the same coin? Independence and accountability of the European Central Bank', available at www.ecb.europa.eu/press/key/date/2017/html/sp170328_1.en.html (accessed June 2018).

Cole, M. (1999) 'Accountability and Quasi-Government: The Role of Parliamentary Questions', The Journal of Legislative Studies 5(1): 77-101.

Collignon, S. (2004) 'The End of the Stability and Growth Pact?', International Economics and Economic Policy 1(1): 15-19.

Collignon, S. and Diessner, S. (2016) 'The ECB's Monetary Dialogue with the European Parliament: Efficiency and Accountability during the Euro Crisis?', Journal of Common Market Studies 54(6): 1296-1312.

Committee for the Study of Economic and Monetary Union (1989) Report on Economic and Monetary Union in the European Community, 12 April 1989, available at www.ecb.europa.eu/ecb/access_to_documents/archives/delors/docu ments/shared/data/ecb.dr.delors890412_DraftFullReport.en.pdf?oc860717agfob foe $_{42}$ e6 $_{7} \mathrm{cf}_{7}$ efa $7 \mathrm{fe}_{4}$ (accessed November 2020).

Committee on Budgetary Control (2020) Practical Information | Discharge procedure, 202O, available at www.europarl.europa.eu/committees/en/cont/discharge-procedure/ practical-information (accessed January 2021).

Cooper, I. (2016) 'The Politicization of Interparliamentary Relations in the EU: Constructing and Contesting the "Article 13 Conference" on Economic Governance', Comparative European Politics 14(2): 196-214.

Copeland, P. and Daly, M. (2018) 'The European Semester and EU Social Policy', Journal of Common Market Studies 56(5): 1001-1018.

Copelovitch, M., Frieden, J. and Walter, S. (2016) 'The Political Economy of the Euro Crisis', Comparative Political Studies 49(7): 811-840.

Corbett, R. (1998) The European Parliament's Role in Closer EU Integration, Houndmills, Basingstoke: Palgrave Macmillan.

Corbett, R., Jacobs, F. and Shackleton, M. (2003) 'The European Parliament at Fifty: A View from the Inside', Journal of Common Market Studies 41(2): 353-373.

Cornelissen, M. (2012) Written Question - Civil Society and Social Partner Participation in the European Semester - E-002121/2012, 22 February 2012, European Parliament, available at https://www.europarl.europa.eu/doceo/ document/E-7-2012-002121_EN.pdf (accessed April 2020).

Costamagna, F. (2013) 'The European Semester in Action: Strengthening Economic Policy Coordination While Weakening the Social Dimension?', LPF Working Paper No. 5, 1-25, available at https://ssrn.com/abstract $=2367768$ (accessed September 2021).

Costello, D. (2001) 'The SGP: How Did We Get There?', in A. Brunila, M. Buti, and D. Franco (eds). The Stability and Growth Pact: The Architecture of Fiscal Policy in EMU. London: Palgrave Macmillan, pp. 106-136. 
Council of the European Union (2003) ECOFIN Council Conclusions of 25 November 2003, 2003, available at https://ec.europa.eu/commission/presscorner/ detail/en/PRES_03_320 (accessed December 2020).

Council of the European Union (2016) Excessive Deficit Procedure: Council finds that Portugal and Spain have not taken Effective Action, 12 July 2016, available at www .consilium.europa.eu/en/press/press-releases/2016/o7/12/portugal-spain-excessive-deficit/ (accessed December 2020).

Council of the European Union (2018a) Amendments to the Banking Union Rules Consilium, May 2018, available at www.consilium.europa.eu/en/policies/bankingunion/2016-amendments/ (accessed October 2018).

Council of the European Union (2018b) Banking Union - Consilium, 24 September 2018, available at www.consilium.europa.eu/en/policies/bankingunion/ (accessed October 2018).

Council of the European Union (2019) Euro Summit, 2019, available at www .consilium.europa.eu/en/european-council/euro-summit/ (accessed December 2020).

Council of the European Union (2020a) Economic and Financial Affairs Council Configuration (Ecofin), 3 September 2020, available at www.consilium.europa.eu/ en/council-eu/configurations/ecofin/ (accessed November 2020).

Council of the European Union (2020b) Eurogroup, 2020, available at www .consilium.europa.eu/en/council-eu/eurogroup/ (accessed December 2020).

Council of the European Union (2020c) Eurogroup Meeting, 11 September 2020, 2020, available at www.consilium.europa.eu/en/meetings/eurogroup/2020/og/11/ (accessed November 2020).

Council of the European Union (n.d.) Eurogroup - Consilium, available at www .consilium.europa.eu/en/council-eu/eurogroup/ (accessed October 2018).

Court of Justice of the European Union (2020) The Court of Justice upholds the judgments of the General Court in so far as it dismissed the actions for damages brought by a number of individuals and companies on account of acts and conduct adopted by the EU institutions in connection with financial assistance granted to Cyprus that was conditional upon the restructuring of its banking sector, 16 December 2020, Press Release No 160/2, available at https://curia.europa.eu/jcms/ upload/docs/application/pdf/2020-12/cp20016oen.pdf (accessed March 2021).

Craig, P. (2017) 'The Eurogroup, Power and Accountability', European Law Journal 23 $(3-4): 234-249$.

Crum, B. (2018) 'Parliamentary Accountability in Multilevel Governance: What Role for Parliaments in Post-crisis EU Economic Governance?', Journal of European Public Policy 25(2): 268-286.

Crum, B. and Curtin, D. (2015) 'The Challenge of Making European Union Executive Power Accountable', in S. Piattoni (ed.). The European Union: Democratic Principles and Institutional Architectures in Times of Crisis. Oxford: Oxford University Press, pp. 63-87.

Crum, B. and Merlo, S. (2020) 'Democratic Legitimacy in the Post-crisis EMU', Journal of European Integration 42(3): 399-413.

Csehi, R. and Puetter, U. (2021) 'Who Determined What Governments Really Wanted? Preference Formation and the Euro Crisis', West European Politics 44(3): 463-484.

Cukierman, A., Webb, S. B. and Neyapti, B. (1992) 'Measuring the Independence of Central Banks and Its Effect on Policy Outcomes', The World Bank Economic Review 6(3): 353-398. 
Curtin, D. (2009) Executive Power of the European Union: Law, Practices, and the Living Constitution, Oxford: Oxford University Press.

Curtin, D. (2014) 'Overseeing Secrets in the EU: A Democratic Perspective', Journal of Common Market Studies 52(3): 684-700.

Curtin, D. (2017) “'Accountable Independence” of the European Central Bank: Seeing the Logics of Transparency', European Law Journal 23(1-2): 28-44.

Curtin, D. and Egeberg, M. (2008) 'Tradition and Innovation: Europe's Accumulated Executive Order', West European Politics 31(4): 639-661.

Cygan, A. (2017) 'Legal Implications of Economic Governance for National Parliaments', Parliamentary Affairs 70(4): 710-727.

Darvas, Z. and Leandro, Á. (2015) 'The Limitations of Policy Coordination in the Euro Area under the European Semester', Bruegel Policy Contribution 2015/19, available at http://bruegel.org/2015/11/the-limitations-of-policy-coordination-in-the-euro-area-underthe-european-semester/ (accessed November 2016).

Dawson, M. (2015) "The Legal and Political Accountability Structure of "Post-Crisis" EU Economic Governance', Journal of Common Market Studies 53 (5): 976-993.

Dawson, M. (2016) 'Better Regulation and the Future of EU Regulatory Law and Politics', Common Market Law Review 53(5): 1209-1235.

Dawson, M. (2018) 'New Governance and the Displacement of Social Europe: The Case of the European Semester', European Constitutional Law Review 14(1): 191-209.

Dawson, M. (2019) 'How Can EU Law Contain Economic Discretion?', in J. Mendes (ed.). EU Executive Discretion and the Limits of Law. Oxford: Oxford University Press, pp. 64-84.

Dawson, M. and Bobić, A. (2019) 'Quantitative Easing at the Court of Justice - Doing Whatever it Takes to Save the Euro: Weiss and Others', Common Market Law Review 56(4): 1005-1040.

Dawson, M. and Maricut-Akbik, A. (2020) 'Procedural vs Substantive Accountability in EMU Governance: Between Payoffs and Trade-offs', Journal of European Public Policy, DOI: 10.1080/13501763.2020.1797145.

Dawson, M., Maricut-Akbik, A. and Bobić, A. (2019) 'Reconciling Independence and Accountability at the European Central Bank: The False Promise of Proceduralism', European Law Journal 25(1): 75-93.

Day, P. and Klein, R. (1987) Accountabilities: Five Public Services, London: Tavistock. de Grauwe, P. (2011) 'The Governance of a Fragile Eurozone', CEPS Working Document No. 364, available at www.ceps.eu/wp-content/uploads/2011/05/WD\%20346\%20De\% zoGrauwe\% zoon\%zoEurozone\% zoGovernance.pdf (accessed November 2020).

De Haan, J. (1997) 'The European Central Bank: Independence, Accountability and Strategy: A Review', Public Choice 93(3/4): 395-426.

De Haan, J., Amtenbrink, F. and Eijffinger, S. C. W. (1999) 'Accountability of Central Banks: Aspects and Quantifications', Banca Nazionale del Lavoro Quarterly Review 52(209): 169-193.

de la Parra, S. (2017) 'The Economic Dialogue: An Effective Accountability Mechanism?', in L. Daniele, P. Simone, and R. Cisotta (eds). Democracy in the EMU in the Aftermath of the Crisis. Cham: Springer International Publishing, pp. $101-120$.

De Vries, C. E. (2018) Euroscepticism and the Future of European Integration, Oxford: Oxford University Press. 
De Wilde, P., Koopmans, R. and Zürn, M. (2014) 'The Political Sociology of Cosmopolitanism and Communitarianism: Representative Claims Analysis', WZB Discussion Paper (SP IV 2014-102).

Dehousse, R. (2008) 'Delegation of Powers in the European Union: The Need for a Multi-principals Model', West European Politics 31(4): 789-805.

Dehousse, R. (2016) 'Why Has EU Macroeconomic Governance Become More Supranational?', Journal of European Integration 38(5): 617-631.

D’Erman, V., Haas, J., Schulz, D. F. and Verdun, A. (2019) 'Measuring Economic Reform Recommendations under the European Semester: "One Size Fits All" or Tailoring to Member States?', Journal of Contemporary European Research 15(2): $194-211$.

Deroose, S., Hodson, D. and Kuhlmann, J. (2008) 'The Broad Economic Policy Guidelines: Before and After the Re-launch of the Lisbon Strategy', Journal of Common Market Studies 46(4): 827-848.

Dijsselbloem, J. (2014) Letter to Ms Bowles, Chairwoman of the Committee of Economic and Monetary Affairs, January 2014, available at www.europarl.europa.eu/cmsdata/ 59958/att_20140114ATT77339-6443094514033203696.pdf (accessed December 2020).

Dombrovskis, V. (2015) Answer to Question No E-013654/15, 7 December 2015, European Parliament, available at www.europarl.europa.eu/doceo/document/E-8-2 015-013654-ASW_EN.html (accessed December 2020).

Dombrovskis, V. (2018) Answer to Question No E-o02159/18, 16 July 2018, European Parliament, available at www.europarl.europa.eu/doceo/document/E-8-2018-oo2159ASW_EN.html (accessed December 2020).

Dowdle, M. W. (ed.) (2006) Public Accountability: Designs, Dilemmas and Experiences, Cambridge: Cambridge University Press.

Dubnick, M. J. (2002) 'Seeking Salvation for Accountability', Paper prepared for the Annual Meeting of the American Political Science Association, August 29September 1, 2002, Boston, available at http://mjdubnick.dubnick.net/papersrw/200 2/salv2002.pdf (accessed September 2021).

Dubnick, M. J. (2011) 'Move Over Daniel: We Heed Some “Accountability Space”, Administration \& Society 43(6): 704-716.

Dubnick, M. J. (2014) 'Accountability as a Cultural Keyword', in M. Bovens, R. E. Goodin, and T. Schillemans (eds). The Oxford Handbook Public Accountability. Oxford: Oxford University Press, pp. 23-38.

Dubnick, M. J. and Frederickson, H. G. (2011) Public Accountability: Performance Measurement, the Extended State, and the Search for Trust, Washington, DC: National Academy of Public Administration and The Kettering Foundation.

Dyson, K. and Featherstone, K. (1999) The Road to Maastricht: Negotiating Economic and Monetary Union, Oxford: Oxford University Press.

Dyson, K., Featherstone, K. and Michalopoulos, G. (1995) 'Strapped to the Mast: EC Central Bankers between Global Financial Markets and Regional Integrationı', Journal of European Public Policy 2(3): 465-487.

Dyson, K. H. F. (2000) The Politics of the Euro-zone: Stability Or Breakdown?, Oxford: Oxford University Press.

Efstathiou, K. and Wolff, G. B. (2018) 'Is the European Semester Effective and Useful?', Bruegel Policy Contribution 2018/o9, available at www.bruegel.org/2018/06/is-theeuropean-semester-effective-and-useful/ (accessed March 2021). 
Egeberg, M. (2006) 'Europe’s Executive Branch of Government in the Melting Pot: an Overview', in M. Egeberg (ed.). Multilevel Union Administration: The Transformation of Executive Politics in Europe. Basingstoke and New York, NY: Palgrave Macmillan, pp. 1-16.

Egeberg, M. (2009) 'The European Commission’, in M. Cini and N. Perez-Solorzano Borragan (eds). European Union Politics. Oxford: Oxford University Press, pp. $125-140$.

Eijffinger, S. C. W. and Mujagic, E. (2004) 'An Assessment of the Effectiveness of the Monetary Dialogue on the ECB's Accountability and Transparency: A Qualitative Approach', Intereconomics 39(4): 190-203.

Elgie, R. (1998) 'Democratic Accountability and Central Bank Independence: Historical and Contemporary, National and European Perspectives', West European Politics 21(3): 53-76.

Elgie, R. (2002) 'The Politics of the European Central Bank: Principal-Agent Theory and the Democratic Deficit', Journal of European Public Policy 9(2): 186-200.

Enderlein, H. and Verdun, A. (2009) 'EMU's Teenage Challenge: What Have We Learned and Can We Predict from Political Science?', Journal of European Public Policy 16(4): 490-507.

Estella, A. (2018) Legal Foundations of EU Economic Governance, Cambridge: Cambridge University Press.

EurActiv (2016) 'Dijsselbloem Berates Juncker for Failing to Apply EU Pacts', www .euractiv.com, available at https:/www.euractiv.com/section/eurofinance/news/ dijsselbloem-raps-juncker-for-failing-to-apply-eu-pacts/ (accessed December 2020).

Euro Area Summit (2012) Euro Area Summit Statement 29 June 2012, available at www .consilium.europa.eu/media/21400/20120629-euro-area-summit-statement-en.pdf (accessed July 2018).

Euro Summit (2010) Statement by the Heads of State and Government of the Euro Area, 25 March 2010, available at www.consilium.europa.eu/media/21429/20100325-statementof-the-heads-of-state-or-government-of-the-euro-area-en.pdf (accessed December 2020).

Eurogroup (2008) Working Methods of the Eurogroup, 3 October 2008, available at www.consilium.europa.eu/media/21457/08-10-03-eurogroup-working-methods.pdf (accessed November 2020).

Eurogroup (2013) Work Programme for the Eurogroup for the First Half of 2014, 9 December 2013, available at www.consilium.europa.eu/media/21473/eurogroupwp-i-2014.pdf (accessed December 2020).

Eurogroup (2014) Work Programme for the Eurogroup for the First Half of 2015, 8 December 2014, available at www.consilium.europa.eu/media/21471/eurogroupwp-i-2015.pdf (accessed December 2020).

Eurogroup (2018) Work Programme for the Eurogroup for the Second Half of 2018, 22 June 2018, available at www.consilium.europa.eu/media/35748/20180622-eg-workprogramme.pdf (accessed December 2020).

European Central Bank (2002) The Accountability of the ECB, ECB Monthly Bulletin, available at www.ecb.europa.eu/pub/pdf/other/pp45-57_mb200211en.pdf?26663b co462f8fi71df $27 a 3 f_{3} 3 a 78$ ez2 (accessed January 2018).

European Central Bank (2013) Interinstitutional Agreement between the European Parliament and the European Central Bank on the Practical Modalities of the Exercise of Democratic Accountability and Oversight over the Exercise of the Tasks 
Conferred on the ECB within the Framework of the Single Supervisory Mechanism (2013/694/EU), available at www.ecb.europa.eu/ecb/legal/pdf/celex_32013 q113001_en_txt.pdf (accessed October 2018).

European Central Bank (2017) Press Release: ECB reinforces its NPL Guidance for Banks, 4 October 2017, European Central Bank - Banking Supervision, available at www.bankingsupervision.europa.eu/press/pr/date/2017/html/ssm.pr171004.en.html (accessed August 2018).

European Central Bank (2018) Comparison of Pre-and Post-consultation versions of the Addendum, March 2018, ECB Banking Supervision, available at www .bankingsupervision.europa.eu/legalframework/publiccons/pdf/npl_/ssm.npl_adde ndum_compare.en.pdf (accessed August 2018).

European Central Bank (2019) Single Supervisory Mechanism, 2019, European Central Bank - Banking Supervision, available at www.bankingsupervision.europa.eu/abou t/thessm/html/index.en.html (accessed June 2018).

European Central Bank (2020a) Single Supervisory Mechanism, 28 December 2020, available at www.bankingsupervision.europa.eu/about/thessm/html/index.en.html (accessed February 2021).

European Central Bank (2020b) Stages of Economic and Monetary Union, 2020, available at www.ecb.europa.eu/ecb/history/emu/html/index.en.html (accessed November 2020).

European Central Bank (2021a) Accountability of ECB Banking Supervision, 2021, European Central Bank - Banking Supervision, available at www.bankingsupervi sion.europa.eu/organisation/accountability/html/index.en.html (accessed April 2021).

European Central Bank (2021b) All ECB Opinions, 2021, available at https://eurlex.europa.eu/browse/institutions/bank.html (accessed April 2021).

European Commission (2004) Communication from the Commission to the Council and the European Parliament - Strengthening Economic Governance and Clarifying the Implementation of the Stability and Growth Pact, 2004, COM(2004) 581, available at ht tps:/eur-lex.europa.eu/LexUriServ/LexUriServ.do?uri=COM:2004:0581:FIN:EN:PDF (accessed December 2020).

European Commission (2015a) Communication 'Towards the Completion of the Banking Union', 2015, COM(2015) 587 final, available at https://eur-lex.europa.eu/ legal-content/EN/TXT/HTML/?uri=CELEX:52015DC0587\&from=en (accessed November 2020).

European Commission (2015b) Recommendation for a COUNCIL Recommendation with a View to Bringing an End to the Excessive Government Deficit in France /* $\mathrm{COM} / 2015 / 0115$ final, 2015, available at https://eur-lex.europa.eu/legal-content/EN/ TXT/?uri=CELEX\% $3 \mathrm{~A}_{52015} \mathrm{PCo115}$ (accessed December 2020).

European Commission (2017) Commission Staff Working Document accompanying the document Report from the Commission to the European Parliament and the Council on the Single Supervisory Mechanism established pursuant to Regulation (EU) No 1024/2013 $\{\mathrm{COM}(2017) 591$ final $\}$, available at https://ec.europa.eu/info/sites/default/ files/171011-ssm-review-report-staff-working-document_en.pdf (accessed September 2021).

European Commission (2019) Social Priorities under the Juncker Commission, November 2019, available at https://ec.europa.eu/info/sites/default/files/social_ priorities_juncker_commission_en.pdf (accessed May 2020). 
European Commission (2020a) European Semester 2021 - An Exceptional Cycle, 2020, available at https:/ec.europa.eu/info/business-economy-euro/economic-and-fiscal-pol icy-coordination/eu-economic-governance-monitoring-prevention-correction/euro pean-semester/european-semester-timeline/european-semester-2021-exceptional-cyc le_en (accessed March 2021).

European Commission (2020b) The EU's Economic Governance Explained, 2020, available at https://ec.europa.eu/info/business-economy-euro/economic-and-fiscal-policy-coordin ation/eu-economic-governance-monitoring-prevention-correction/european-semester/fr amework/eus-economic-governance-explained_en (accessed April 2020).

European Commission (2021) Recovery and Resilience Facility, 2021, available at https:// ec.europa.eu/info/business-economy-euro/recovery-coronavirus/recovery-and-resili ence-facility_en (accessed March 2021).

European Council (1988) Conclusions of the Hanover European Council: Excerpt on Monetary Union (27 and 28 June 1988), 1988, available at www.cvce.eu/en/obj/con clusions_of_the_hanover_european_council_excerpt_on_monetary_unio n_27_and_28_june_1988-en-7066oe36-5c11-424e-a6f8-9ege4dofgfa7.html (accessed November 2020).

European Council (2010) Strengthening Economic Governance in the EU. Report of the Task Force of the European Council, available at www.consilium.europa.eu/en/pre ss/press-releases/2010/10/pdf/strengthening-economic-governance-in-the-eu-report-o f-the-task-force-to-the-european-council/ (accessed February 2016).

European Court of Auditors (2018) Audit of the Macroeconomic Imbalance Procedure (MIP), 2018, Special Report 03/2018, available at www.eca.europa.eu/Lists/ECADo cuments/SR18_03/SR_MIP_EN.pdf (accessed December 2020).

European Parliament (2010a) Debates - Conclusions of the European Council Meeting (17 June), 23 June 2010, available at www.europarl.europa.eu/doceo/document/CRE7-2010-06-23-ITM-009_EN.html (accessed November 2020).

European Parliament (2010b) Rules of Procedure of the European Parliament, 7 th Parliamentary Term, available at www.europarl.europa.eu/sides/getDoc.do?pubRe $\mathrm{f}=-/ / \mathrm{EP} / / \mathrm{NONSGML}+\mathrm{RULES}-\mathrm{EP}+20100705+\mathrm{O}+\mathrm{DOC}+\mathrm{PDF}+\mathrm{Vo} / / \mathrm{EN}$ (accessed November 2020).

European Parliament (2012a) Economic Dialogue with Margrethe Vestager, Danish Minister for Economic Affairs and the Interior and President of the ECOFIN Council, 23 January 2012, Multimedia Centre, available at https://multimedia.europarl.europa.e u/en/committee-on-economic-and-monetary-affairs_20120123-1500-COMMITTEE-EC ON_vd (accessed August 2020).

European Parliament (2012b) Economic Dialogue with Vassos Shiarly, Cypriot Minister of Finance and President of the ECOFIN Council, 10 July 2012, Multimedia Centre, available at https://multimedia.europarl.europa.eu/en/committee-on-economic-andmonetary-affairs_20120710-1500-COMMITTEE-ECON_vd (accessed August 2020).

European Parliament (2012c) Economic Dialogue with Vice-President Olli Rehn and Commissioner Laszlo Andor, 28 November 2012, Multimedia Centre, available at https://multimedia.europarl.europa.eu/en/committee-on-economic-and-monetaryaffairs_20121128-1500-COMMITTEE-ECON_vd (accessed December 2020).

European Parliament (2013a) ECON Committee Meeting Economic Dialogue and Exchange of Views with Members of the Troika on Financial Assistance to Cyprus, 8 May 2013, Multimedia Centre, available at https://multimedia.europarl.europa.eu/ 
fr/econ-committee-meeting-economic-dialogue-and-exchange-of-views-with-mem bers-of-troika-on-financial-a_6345a_c (accessed December 2020).

European Parliament (2013b) Economic Dialogue and Exchange of Views with the Commission on the Draft Country-Specific Recommendations. Vice-President Rehn and Commissioner Andor, 17 June 2013, Multimedia Centre, available at https://mu ltimedia.europarl.europa.eu/en/committee-on-economic-and-monetary-affair s_20130617-1500-COMMITTEE-ECON_vd (accessed December 2020).

European Parliament (2013c) Economic Dialogue with Michael Noonan, Irish Minister of Finance and President of the ECOFIN Council, 22 January 2013, Multimedia Centre, available at https://multimedia.europarl.europa.eu/en/committee-oneconomic-and-monetary-affairs_20130122-1500-COMMITTEE-ECON_vd (accessed August 2020).

European Parliament (2013d) Economic Dialogue with the Eurogroup President, Jeroen Dijsselbloem, 7 May 2013, Multimedia Centre, available at https://multimedia .europarl.europa.eu/en/committee-on-economic-and-monetary-affairs_20130507-14 30-COMMITTEE-ECON_vd (accessed August 2020).

European Parliament (2014a) Debates - Conclusions of the European Council Meeting (26-27 June), 2 July 2014, available at www.europarl.europa.eu/doceo/document/C RE-8-2014-07-02-ITM-005_EN.html (accessed November 2020).

European Parliament (2014b) Debates - Role and Operations of the Troika with Regard to the Euro Area Programme Countries - Employment and Social aspects of the Role and Operations of the Troika, 12 March 2014, available at www.europarl.europa.eu/ doceo/document/CRE-7-2014-03-12-ITM-012_EN.html (accessed December 2020).

European Parliament (2014c) Economic Dialogue with the Eurogroup President, Jeroen Dijsselbloem, 20 February 2014, Multimedia Centre, available at https://multimedia .europarl.europa.eu/en/committee-on-economic-and-monetary-affairs_20140220-o9 oo-COMMITTEE-ECON_vd (accessed August 2020).

European Parliament (2014d) Economic Dialogue with Yiannis Stournaras, Greek Minister of Finance and Presdient of the ECOFIN Council, 22 January 2014, Multimedia Centre, available at https://multimedia.europarl.europa.eu/en/commit tee-on-economic-and-monetary-affairs_20140122-1500-COMMITTEE-ECON_vd (accessed August 2020).

European Parliament (2014e) Parliamentary Questions, 2014, EP - At a Glance, available at www.europarl.europa.eu/EPRS/Parliamentary-questions-EN.pdf (accessed November 2020).

European Parliament (2014f) Resolution on the Role and Operations of the Troika with Regard to the Euro Area Programme Countries (2013/2277(INI)), 13 March 2014, available at www.europarl.europa.eu/doceo/document/TA-7-2014-0239_EN.html (accessed December 2020).

European Parliament (2015a) Economic Dialogue and Exchange of Views with VicePresident Valdis Dombrovskis and Commissioner Pierre Moscovici, 14 April 2015, Multimedia Centre, available at https://multimedia.europarl.europa.eu/en/commit tee-on-economic-and-monetary-affairs_20150414-0900-COMMITTEE-ECON_vd (accessed December 2020).

European Parliament (2015b) Economic Dialogue with the Eurogroup President, Jeroen Dijsselbloem, 24 February 2015, Multimedia Centre, available at https://multimedia 
.europarl.europa.eu/en/committee-on-economic-and-monetary-affairs_20150224-o9 oo-COMMITTEE-ECON_vd (accessed August 2020).

European Parliament (2015c) Economic Dialogue with the Eurogroup President, Jeroen

Dijsselbloem, 10 November 2015, Multimedia Centre, available at https://multimedia .europarl.europa.eu/en/committee-on-economic-and-monetary-affairs_20151110-1720COMMITTEE-ECON22_vd?EPV_REPLAY=true\&EPV_PHOTO=true\&EPV_A UDIO=true\&EPV_EDITED_VIDEOS=false (accessed August 2020).

European Parliament (2015d) Meeting of the Committee on Economic and Monetary Affairs, 14 April 2015, Multimedia Centre, available at https://multimedia.europarl.eur opa.eu/en/committee-on-economic-and-monetary-affairs_20150414-ogoo-COMMITTE E-ECON_vd (accessed April 2020).

European Parliament (2016a) Economic Dialogue and Exchange of Views with VicePresident Valdis Dombrovskis and Commissioner Marianne Thyssen, 14 June 2016, Multimedia Centre, available at https://multimedia.europarl.europa.eu/en/jointmeeting_20160614-163o-COMMITTEE-ECON-EMPL_vd (accessed December 2020).

European Parliament (2016b) Economic Dialogue and Exchange of Views with VicePresident Valdis Dombrovskis and Commissioner Pierre Moscovici, 12 December 2016, Multimedia Centre, available at https://multimedia.europarl.europa.eu/en/commit tee-on-economic-and-monetary-affairs_20161212-2115-COMMITTEE-ECON_vd (accessed December 2020).

European Parliament (2016c) Economic Dialogue and Exchange of Views with VicePresident Valdis Dombrovskis and Commissioner Pierre Moscovici, 11 April 2016, Multimedia Centre, available at https://multimedia.europarl.europa.eu/en/commit tee-on-economic-and-monetary-affairs_20160411-1900-COMMITTEE-ECON_vd (accessed December 2020).

European Parliament (2016d) Economic Dialogue with Jeroen Dijsselbloem, Dutch Minister of Finance and President of the ECOFIN Council, 14 June 2016, Multimedia Centre, available at https://multimedia.europarl.europa.eu/en/commit tee-on-economic-and-monetary-affairs_20160614-ogoo-COMMITTEE-ECON_vd (accessed August 2020).

European Parliament (2016e) Joint Meeting ECON and REGI Committees, 3 October 2016, Multimedia Centre, available at https:/multimedia.europarl.eur opa.eu/en/joint-meeting_20161003-180o-COMMITTEE-REGI-ECON_vd (accessed April 2020).

European Parliament (2016f) Nuno Melo Parliamentary Activities - Questions to the ECB, 2016, European Parliament - Public Register of Documents, available at https:/www.europarl.europa.eu/meps/en/96978/NUNO_MELO/other-activities/ written-questions-other (accessed October 2018).

European Parliament (2016g) Resolution of 6 July 2016 on Tax Rulings and Other Measures Similar in Nature or Effect (2016/2038(INI)), 2016, available at www.europarl.europa.eu/ doceo/document/TA-8-2016-0310_EN.html (accessed January 2021).

European Parliament (2017a) Economic Dialogue and Exchange of Views with VicePresident Valdis Dombrovskis and Commissioner Pierre Moscovici, 27 November 2017, Multimedia Centre, available at https://multimedia.europarl.e uropa.eu/en/committee-on-economic-and-monetary-affairs_20171127-1645-COMMI TTEE-ECON_vd (accessed December 2020). 
European Parliament (2017b) Economic Dialogue with Edward Scicluna, Maltese Minister of Finance and President of the ECOFIN Council, 19 June 2017, Multimedia Centre, available at https:/multimedia.europarl.europa.eu/en/commit tee-on-economic-and-monetary-affairs_20170619-1500-COMMITTEE-ECON_vd (accessed August 2020).

European Parliament (2017c) Economic Dialogue with the Eurogroup President, Jeroen Dijsselbloem, 21 March 2017, Multimedia Centre, available at https:/multimedia .europarl.europa.eu/en/committee-on-economic-and-monetary-affairs_20170321-150 o-COMMITTEE-ECON_vd (accessed August 2020).

European Parliament (2017d) Economic Dialogue with Toomas Toniste, Estonian Minister of Finance and President of the ECOFIN Council, 11 July 2017, Multimedia Centre, available at https:/multimedia.europarl.europa.eu/en/commit tee-on-economic-and-monetary-affairs_20170711-160o-COMMITTEE-ECON_vd (accessed August 2020).

European Parliament (2017e) Rules of Procedure 8th Parliamentary Term January 2017, available at www.europarl.europa.eu/sides/getDoc.do?pubRef=-//E $\mathrm{P} / / \mathrm{NONSGML}+\mathrm{RULES}-\mathrm{EP}+20170116+\mathrm{o}+\mathrm{DOC}+\mathrm{PDF}+\mathrm{Vo} / / \mathrm{EN} \&$ language $=\mathrm{EN}$ (accessed April 2018).

European Parliament (2018a) Economic Dialogue with Hartwig Löger, Austrian Minister of Finance and President of the ECOFIN Council, 11 July 2018, Multimedia Centre, available at https://multimedia.europarl.europa.eu/en/commit tee-on-economic-and-monetary-affairs-ordinary-meeting_20180711-1430-COMMIT TEE-ECON_vd (accessed August 2020).

European Parliament (2018b) Economic Dialogue with Vladislav Goranov, Bulgarian Minister of Finance and President of the ECOFIN Council, 24 January 2018, Multimedia Centre, available at https:/multimedia.europarl.europa.eu/en/commit tee-on-economic-and-monetary-affairs_20180124-0900-COMMITTEE-ECON_vd (accessed August 2020).

European Parliament (2019a) Briefing: Economic Dialogue with the Other EU Institutions under the European Semester Cycles (2014-2019), available at www .europarl.europa.eu/RegData/etudes/BRIE/2015/528782/IPOL_BRI(2015)528782_E N.pdf (accessed April 2020).

European Parliament (2019b) The European Parliament: Powers | Fact Sheets on the European Union, November 2019, available at www.europarl.europa.eu/factsheets/ en/sheet/19/the-european-parliament-powers (accessed January 2020).

European Parliament (2020a) Rules of Procedure of the European Parliament - $9^{\text {th }}$ Parliamentary Term, February 2020, available at www.europarl.europa.eu/doceo/do cument/RULES-9-2020-02-03_EN.pdf (accessed April 2020).

European Parliament (2020b) Shades of Green on the European Parliamentary Week 2020,2020 , available at www.epgenpro.europarl.europa.eu/static/relnatparl/en/hi gh-level-conferences/european-parliamentary-week.html (accessed November 2020).

European Parliament Plenary (n.d.) All the Questions | Parliamentary Questions | Questions and Declarations, n.d., available at www.europarl.europa.eu/plenary/en/ parliamentary-questions.html (accessed January 2021).

European Parliament Press Release (2021) Parliament Gives Go-ahead to €672.5 Billion Recovery and Resilience Facility, 10 February 2021, available at www.europarl.europa 
.eu/news/en/press-room/20210204IPR97105/parliament-gives-go-ahead-to-EU672-5-b illion-recovery-and-resilience-facility (accessed March 2021).

European Stability Mechanism (2019) Safeguarding the Euro in Times of Crisis: The Inside Story of the ESM, Luxembourg: Publications Office of the European Union. European Stability Mechanism (2020a) EFSF Governance, 2020, available at www .esm.europa.eu/efsf-governance (accessed December 2020).

European Stability Mechanism (2020b) Lending Toolkit, 2020, available at www .esm.europa.eu/assistance/lending-toolkit\#lending_toolkit (accessed November 2020).

European Union (2016) European Commission, 16 June 2016, Europa.eu, available at https://europa.eu/european-union/about-eu/institutions-bodies/european-commissio n_en (accessed December 2020).

European Union (2018) Which Countries Use the Euro, 10 August 2018, available at https://europa.eu/european-union/about-eu/euro/which-countries-use-euro_en (accessed March 2021).

Fabbrini, S. (2013) 'Intergovernmentalism and Its Limits Assessing the European Union's Answer to the Euro Crisis', Comparative Political Studies 46(9): 1003-1029.

Fabbrini, S. (2016) 'From Consensus to Domination: The Intergovernmental Union in a Crisis Situation', Journal of European Integration 38(5): 587-599.

Fasone, C. (2014a) 'European Economic Governance and Parliamentary Representation. What Place for the European Parliament?', European Law Journal 20(2): 164-185.

Fasone, C. (2014b) 'Eurozone, Non-Eurozone and "Troubled Asymmetries" among National Parliaments in the EU. Why and To What Extent This Is of Concern', Perspectives on Federalism 6(3): 1-41.

Fearon, J. D. (1999) 'Electoral Accountability and the Control of Politicians: Selecting Good Types versus Sanctioning Poor Performance’, in A. Przeworski, S. C. Stokes, and B. Manin (eds). Democracy, Accountability, and Representation. Cambridge: Cambridge University Press, pp. 55-97.

Fish, M. S. and Kroenig, M. (2009) The Handbook of National Legislatures: A Global Survey, Cambridge: Cambridge University Press.

Five Presidents' Report (2015) Completing Europe's Economic and Monetary Union, 2015, available at https://wayback.archive-it.org/1209o/20191231140925/https://ec .europa.eu/commission/sites/beta-political/files/5-presidents-report_en.pdf (accessed December 2020).

Flinders, M. (2011) 'Daring to be a Daniel: The Pathology of Politicized Accountability in a Monitory Democracy', Administration E Society 43(5): 595-619.

Føllesdal, A. and Hix, S. (2006) 'Why There Is a Democratic Deficit in the EU: A Response to Majone and Moravcsik', Journal of Common Market Studies 44(3): $533-562$.

Fraccaroli, N., Giovannini, A. and Jamet, J.-F. (2018) 'The Evolution of the ECB's Accountability Practices during the Crisis', ECB Economic Bulletin (Issue 5/2018): 47-71.

Franklin, M. N. and Norton, P. (eds) (1993) Parliamentary Questions, Oxford: Clarendon Press.

Frears, J. (1990) 'The French Parliament: Loyal Workhorse, Poor Watchdog', West European Politics 13(3): 32-51.

Fromage, D. (2017) 'Executive Accountability to National Parliaments in Post-crisis EU Affairs: The Persistent Shortcomings in the Council and European Council 
Oversight', in D. Jancic (ed.). National Parliaments after the Lisbon Treaty and the Euro Crisis: Resilience or Resignation?. Oxford: Oxford University Press, pp. 159-176.

Fromage, D. (2018) 'The European Parliament in the Post-Crisis Era: An Institution Empowered on Paper Only?', Journal of European Integration 40(3): 281-294.

Fromage, D. and Ibrido, R. (2018) 'The "Banking Dialogue" as a Model to Improve Parliamentary Involvement in the Monetary Dialogue?', Journal of European Integration 40(3): 295-308.

Gailmard, S. (2014) 'Accountability and Principal-Agent Theory', in M. Bovens, R. E. Goodin, and T. Schillemans (eds). The Oxford Handbook of Public Accountability. Oxford: Oxford University Press.

Gandrud, C. and Hallerberg, M. (2018) 'Explaining Variation and Change in Supervisory Confidentiality in the European Union', West European Politics 41(4): $1025-1048$.

General Secretariat of the Council (2019a) ECOFIN Report to the European Council on Tax Issues, 9 December 2019, available at https://data.consilium.europa.eu/doc/ document/ST-14863-2019-INIT/en/pdf (accessed December 2020).

General Secretariat of the Council (2019b) Progress on Financial Services Legislative Files, 13 May 2019, available at https://data.consilium.europa.eu/doc/document/ST9045-2019-INIT/en/pdf (accessed December 2020).

Genschel, P. and Jachtenfuchs, M. (2014) Beyond the Regulatory Polity?: The European Integration of Core State Powers, Oxford: Oxford University Press.

Genschel, P. and Jachtenfuchs, M. (2016) 'More Integration, Less Federation: The European Integration of Core State Powers', Journal of European Public Policy 23(1): $42-59$.

Genschel, P. and Jachtenfuchs, M. (2018) 'From Market Integration to Core State Powers: The Eurozone Crisis, the Refugee Crisis and Integration Theory', Journal of Common Market Studies 56(1): 178-196.

Giegold, S. (2013) Question for Written Answer E-005066-13 to the Commission Rule 117, 7 May 2013, European Parliament, available at www.europarl.europa.eu/doceo/ document/E-7-2013-005066_EN.html (accessed December 2020).

Gilbert, M. (2011) European Integration: A Concise History, updated 2nd ed., Lanham, MD: Rowman \& Littlefield Publishers.

Gnath, K., McKeon, M. and Petersen, T. (2018) Germany's Current Account and Trade Surpluses, 2018, Bertelsmann Foundation, available at www.bertelsmann-stiftung.de/fil eadmin/files/BSt/Publikationen/GrauePublikationen/EZ_BFNA_Germanys_Curren t_Account_2018_ENG.pdf (accessed December 2020).

Goldoni, M. (2017) 'The Limits of Legal Accountability of the European Central Bank', George Mason Law Review 24(2): 595-616.

Gregory, R. (1990) 'Parliamentary Control and the Use of English', Parliamentary Affairs 43(1): 59-76.

Gros, D. (2004) 5 Years of Monetary Dialogue, Brussels: European Parliament.

Gros, D. and Alcidi, C. (2015) 'Economic Policy Coordination in the Euro Area under the European Semester.' CEPS Special Report No. 123, December 2015, available at https://www.ceps.eu/download/publication/?id=9197\&pdf=SR\%20No\%20123\%20Eco nomic\%zoPolicy\%zoCoordination\%zounder\%zoEuropean\%zoSemester_o.pdf (accessed September 2021). 
Gros, D. and Busse, M. (2013) 'The Macroeconomic Imbalance Procedure and Germany: When Is a Current Account Surplus an "Imbalance"?', CEPS Policy Brief No. 301, available at www.ceps.eu/download/publication/?id=8220\&pdf=PB\% 20No\%20301\%20DG\%20and\%20MB\%200n\%20EIP.pdf (accessed December 2020).

Gstöhl, S. (2008) “Patchwork Power” Europe?’, Bruges Regional Integration ङ Global Governance Papers No. 2/2008, available at https://www.coleurope.eu/research/publica tions/bruges-regional-integration-global-governance-papers (accessed September 2021).

Guarascio, F. (2016) 'EU Gives Budget Leeway to France "Because It Is France" Juncker', Reuters 31 May, available at https://uk.reuters.com/article/uk-eu-deficitfrance-idUKKCNoYMiNo (accessed December 2020).

Gustavsson, S., Karlsson, C. and Persson, T. (2009) 'Examining the Illusion of Accountability', in S. Gustavsson, C. Karlsson, and T. Persson (eds). The Illusion of Accountability in the European Union. Abingdon and New York, NY: Routledge, pp. $1-10$.

Guttenberg, L., Hemker, J. and Tordoir, S. (2021) Everything Will be Different: How the Pandemic Is Changing EU Economic Governance, Berlin: Jacques Delors Centre, available at www.delorscentre.eu/en/publications/detail/publication/everything-will-be -different-how-the-pandemic-is-changing-eu-economic-governance (accessed March 2021).

Hallerberg, M., Marzinotto, B. and Wolff, G. B. (2018) 'Explaining the Evolving Role of National Parliaments under the European Semester', Journal of European Public Policy 25(2): 250-267.

Harlow, C. and Rawlings, R. (2007) 'Promoting Accountability in Multilevel Governance: A Network Approach', European Law Journal 13(4): 542-562.

Harris, J. P. (1964) Congressional Control of Administration, Washington, DC: Brookings Institution Press.

Hefftler, C. and Wessels, W. (2013) 'The Democratic Legitimacy of the EU's Economic Governance and National Parliaments', IAI Working Papers (13).

Heipertz, M. and Verdun, A. (2010) Ruling Europe: The Politics of the Stability and Growth Pact, Cambridge: Cambridge University Press.

Henning, C. R. (2017) Tangled Governance: International Regime Complexity, the Troika, and the Euro Crisis, Oxford: Oxford University Press.

Hermann, C. (2017) 'Crisis, Structural Reform and the Dismantling of the European Social Model(s)’, Economic and Industrial Democracy 38(1):51-68.

Hillebrandt, M. and Novak, S. (2016) "Integration without Transparency"? Reliance on the Space To Think in the European Council and Council', Journal of European Integration 38(5): 527-540.

Hix, S. and Høyland, B. (2011) The Political System of the European Union, 3rd ed., New York, NY: Palgrave Macmillan.

Hix, S. and Høyland, B. (2013) 'Empowerment of the European Parliament', Annual Review of Political Science 16(1): 171-189.

Hix, S. and Marsh, M. (2007) 'Punishment or Protest? Understanding European Parliament Elections', The Journal of Politics 69(2): 495-510.

Hix, S. and Marsh, M. (2011) 'Second-order Effects Plus Pan-European Political Swings: An Analysis of European Parliament Elections across Time', Electoral Studies 30(1): 4-15. 
Hix, S., Noury, A. G. and Roland, G. (2007) Democratic Politics in the European Parliament, Cambridge and New York, NY: Cambridge University Press.

Hobolt, S. B. (2014) 'A Vote for the President? The Role of Spitzenkandidaten in the 2014 European Parliament Elections', Journal of European Public Policy 21(10): 1528-1540.

Hobolt, S. B. (2019) 'European Elections 2019: A More Fragmented Parliament', Political Insight 10(3): 16-19.

Hobolt, S. B. and de Vries, C. (2016) 'Turning against the Union? The Impact of the Crisis on the Eurosceptic Vote in the 2014 European Parliament Elections', Electoral Studies 44: 504-514.

Hobolt, S. B. and Tilley, J. (2014) Blaming Europe?: Responsibility Without Accountability in the European Union, Oxford: Oxford University Press.

Hobolt, S. B. and Wratil, C. (2015) 'Public Opinion and the Crisis: The Dynamics of Support for the Euro', Journal of European Public Policy 22(2): $238-256$.

Hodson, D. (2011) Governing the Euro Area in Good Times and Bad, Oxford: Oxford University Press.

Hodson, D. and Maher, I. (2001) 'The Open Method as a New Mode of Governance: The Case of Soft Economic Policy Co-ordination', Journal of Common Market Studies 39(4): 719-746.

Hodson, D. and Maher, I. (2004) 'Soft Law and Sanctions: Economic Policy Co-ordination and Reform of the Stability and Growth Pact', Journal of European Public Policy 11(5): 798-813.

Hodson, D. and Puetter, U. (2016) 'The Euro Crisis and European Integration', in M. Cini and N. Pérez-Solórzano Borragán (eds). European Union Politics. Oxford: Oxford University Press, pp. 365-379.

Hood, C. (2010) The Blame Game: Spin, Bureaucracy, and Self-Preservation in Government, Princeton, NJ: Princeton University Press.

Hooghe, L. and Marks, G. (2009) 'A Postfunctionalist Theory of European Integration: From Permissive Consensus to Constraining Dissensus', British Journal of Political Science 39(01): 1-23.

House of Commons Treasury Committee (2011) Accountability of the Bank of England. Twenty-first Report of Session 2010-12, available at https://publications.parliament.uk /pa/cm201012/cmselect/cmtreasy/874/874.pdf (accessed April 2018).

House of Lords (2011) Report of the Leader's Group on Working Practices - Leader's Group on Working Practices, 2011, UK Parliament, available at https://publications .parliament.uk/pa/ld201012/ldselect/ldspeak/136/13605.htm (accessed March 2019).

Howarth, D. J. (2007) 'Making and Breaking the Rules: French Policy on EU "Gouvernement économique", Journal of European Public Policy 14(7): $1061-1078$.

Howarth, D. and Quaglia, L. (2013) 'Banking Union as Holy Grail: Rebuilding the Single Market in Financial Services, Stabilizing Europe's Banks and "Completing" Economic and Monetary Union', Journal of Common Market Studies 51(Annual Review): 103-123.

Howarth, D. and Quaglia, L. (2014) 'The Steep Road to European Banking Union: Constructing the Single Resolution Mechanism', Journal of Common Market Studies 52(S1): 125-140. 
Howarth, D. and Quaglia, L. (2018) 'The Difficult Construction of a European Deposit Insurance Scheme: A Step Too Far in Banking Union?', Journal of Economic Policy Reform 21(3): 190-209.

Hutter, S. and Kriesi, H. (2019) 'Politicizing Europe in Times of Crisis', Journal of European Public Policy 26(7): 996-1017.

Jabko, N. (2003) 'Democracy in the Age of the Euro', Journal of European Public Policy $10(5): 710-739$.

Jacobs, F. and Corbett, R. (1990) The European Parliament, New York, NY and Abington: Routledge.

Jančić, D. (2016) 'National Parliaments and EU Fiscal Integration', European Law Journal 22(2): 225-249.

Jančić, D. (2017) 'Accountability of the European Central Bank in a Deepening Economic and Monetary Union', in D. Jančić (ed.). National Parliaments after the Lisbon Treaty and the Euro Crisis: Resilience or Resignation?. Oxford: Oxford University Press, pp. 141-158.

Jancic, D. (ed.) (2017) National Parliaments after the Lisbon Treaty and the Euro Crisis: Resilience or Resignation?, Oxford: Oxford University Press.

Jensen, C. B., Proksch, S.-O. and Slapin, J. B. (2013) 'Parliamentary Questions, Oversight, and National Opposition Status in the European Parliament', Legislative Studies Quarterly 38(2): 259.

Jones, E. (2002) 'Macroeconomic Preferences and Europe's Democratic Deficit', in A. Verdun (ed.). The Euro: European Integration Theory and Economic and Monetary Union. Lanham, MD: Rowman \& Littlefield, pp. 145-164.

Jones, E., Kelemen, R. D. and Meunier, S. (2016) 'Failing Forward? The Euro Crisis and the Incomplete Nature of European Integration', Comparative Political Studies 49(7): 1010-1034.

Judge, D. and Earnshaw, D. (2002) 'The European Parliament and the Commission Crisis: A New Assertiveness?', Governance 15(3): 345-374.

Judge, D. and Earnshaw, D. (2003) The European Parliament, Basingstoke: Palgrave Macmillan.

Karagianni, A. and Scholten, M. (2018) 'Accountability Gaps in the Single Supervisory Mechanism SSM Framework', Utrecht Journal of International and European Law 34: 185 .

Katz, R. S. and Wessels, B. (eds) (1999) The European Parliament, the National Parliaments, and European Integration, Oxford and New York, NY: Oxford University Press.

Kiewiet, D. R. and McCubbins, M. D. (1991) The Logic of Delegation: Congressional Parties and the Appropriations Process, Chicago, IL: University of Chicago Press.

King, T. (2014) 'In What Way Are Commission Vice-Presidents Special?', Politico Europe 4 December, available at www.politico.eu/article/in-what-way-arecommission-vice-presidents-special/ (accessed December 2020).

Kluger Dionigi, M. (2020) 'The European Parliament's Oversight Powers in Economic Governance: Proper Scrutiny or a Play to the Gallery?', The Journal of Legislative Studies 26(1): 74-96.

Koenig-Archibugi, M. (2004) 'Transnational Corporations and Public Accountability', Government and Opposition 39(2): 234-259. 
Koop, C. (2014) 'Theorizing and Explaining Voluntary Accountability', Public Administration 92(3): 565-581.

Koopmans, R. and Statham, P. (1999) 'Political Claims Analysis: Integrating Protest Event and Political Discourse Approaches', Mobilization: An International Joumal 4(2): 203-221.

Koppell, J. G. (2005) 'Pathologies of Accountability: ICANN and the Challenge of "Multiple Accountabilities Disorder", Public Administration Review 65(1): 94-108.

Kreilinger, V. (2016) 'National Parliaments, Surveillance Mechanisms and Ownership in the Euro Area', Jacques Delors Institut Studies E Reports No. 110, available at https://institutdelors.eu/wp-content/uploads/2020/o8/nat.parl_ .surveillanceownership-kreilinger-jdib-mar16-4.pdf (accessed November 2020).

Kreilinger, V. (2018a) 'From Procedural Disagreement to Joint Scrutiny? The Interparliamentary Conference on Stability, Economic Coordination and Governance', Perspectives on Federalism 10(3): 155-184.

Kreilinger, V. (2018b) 'Scrutinising the European Semester in National Parliaments: What Are the Drivers of Parliamentary Involvement?', Journal of European Integration $40(3)$ : 325-340.

Kreppel, A. (2002) The European Parliament and Supranational Party System: A Study in Institutional Development, Cambridge: Cambridge University Press.

Kreppel, A. and Tsebelis, G. (1999) 'Coalition Formation in the European Parliament', Comparative Political Studies 32(8): 933-966.

Kreuder-Sonnen, C. (2019) Emergency Powers of International Organizations, Oxford: Oxford University Press.

Kriesi, H. and Grande, E. (2016) 'The Euro Crisis: A Boost to Politcization of European Integration?', in S. Hutter, E. Grande, and H. Kriesi (eds). Politicising Europe: Integration and Mass Politics. Cambridge: Cambridge University Press, pp. 240-276.

Kroet, C. and Oliveira, I. (2015) 'Hungry Like the Wolfgang', Politico Europe 5 August, available at www.politico.eu/article/schauble-germany-economy-ministerchancellor-career-powerful-cdu/ (accessed December 2020).

Laffan, B. (2003) 'Auditing and Accountability in the European Union', Journal of European Public Policy 10(5): 762-777.

Laffan, B. (2016) 'Core-Periphery Dynamics in the Euro Area: From Conflict to Cleavage?', in J. M. Magone, B. Laffan, and C. Schweiger (eds). Core-Periphery Relations in the European Union: Power and Conflict in a Dualist Political Economy. Abingdon and New York, NY: Routledge, pp. 19-34.

Lane, P. R. (2012) 'The European Sovereign Debt Crisis', Journal of Economic Perspectives 26(3): 49-68.

Lastra, R. M. (2020) Accountability Mechanisms of the Bank of England and of the European Central Bank, Luxembourg: European Parliament, Policy Department for Economic, Scientific and Quality of Life Policies.

Leifeld, P. and Haunss, S. (2010) 'A Comparison between Political Claims Analysis and Discourse Network Analysis: The Case of Software Patents in the European Union', Preprints of the Max Planck Institute for Research on Collective Goods Bonn 2010/21, available at https:/homepage.coll.mpg.de/pdf_dat/2010_210nline.pdf (accessed September 2021). 
Leruth, B., Startin, N. and Usherwood, S. (eds) (2017) The Routledge Handbook of Euroscepticism, Abingdon and New York, NY: Routledge.

Levy, D. A. (1995) 'Does an Independent Central Bank Violate Democracy?', Journal of Post Keynesian Economics 18(2): 189-210.

Lewis, J. (2019) 'The European Council and the Council of the European Union', in M. Cini and N. P.-S. Borragán (eds). European Union Politics. Oxford and New York, NY: Oxford University Press, pp. 157-175.

Liedorp, F., Mosch, R., van der Cruijsen, C. and de Haan, J. (2013) 'Transparency of Banking Supervisors', IMF Economic Review 61(2): 310-335.

Lindberg, B., Rasmussen, A. and Warntien, A. (2008) 'Party Politics as Usual? The Role of Political Parties in EU Legislative Decision-making', Journal of European Public Policy 15(8): 1107-1126.

Lindberg, S. I. (2013) 'Mapping Accountability: Core Concept and Subtypes', International Review of Administrative Sciences 79(2): 202-226.

Linz, J. J. (1990) 'The Perils of Presidentialism', Journal of Democracy 1(1): 51-69.

Lord, C. (2013) 'No Representation without Justification? Appraising Standards of Justification in European Parliament Debates', Journal of European Public Policy 20(2): $243-259$.

Lowen, M. (2015) 'Greek Debt Crisis: What Was the Point of the Referendum?', BBC News 11 July, available at www.bbc.com/news/world-europe-33492387 (accessed December 2020).

Lupia, A. (2006) 'Delegation and its Perils', in K. Strøm, W. C. Müller, and T. Bergman (eds). Parliamentary Democracy: Promise and Problems. Oxford: Oxford University Press, pp. 33-54.

Lupia, A. and McCubbins, M. D. (1994) 'Learning from Oversight: Fire Alarms and Police Patrols Reconstructed', Journal of Law, Economics, \& Organization 10(1): 96-125.

Lupo, N. and Griglio, E. (2018) 'The Conference on Stability, Economic Coordination and Governance: Filling the Gaps of Parliamentary Oversight in the EU', Journal of European Integration 40(3): 358-373.

Maatsch, A. (2017) 'Effectiveness of the European Semester: Explaining Domestic Consent and Contestation', Parliamentary Affairs 70(4): 691-709.

MacMahon, A. W. (1943) 'Congressional Oversight of Administration: The Power of the Purse. I', Political Science Quarterly 58(2): 161-190.

Maes, I. (2004) 'On the Origins of the Franco-German EMU Controversies', European Joumal of Law and Economics 17(1): 21-39.

Magnette, P. (2000) "Towards "Accountable Independence”? Parliamentary Controls of the European Central Bank and the Rise of a New Democratic Model', European Law Journal 6(4): 326-340.

Magnette, P. (2001) 'Appointing and Censuring the European Commission: The Adaptation of Parliamentary Institutions to the Community Context', European Law Journal 7(3): 292-310.

Mahony, H. (2015) The Rise of the Untransparent 'Eurogroup', 6 May 2015, EUobserver, available at https://euobserver.com/economic/128582 (accessed December 2020).

Majone, G. (1994) 'The Rise of the Regulatory State in Europe', West European Politics $17(3): 77-101$. 
Majone, G. (1998) 'Europe's “Democratic Deficit”: The Question of Standards', European Law Journal 4(1): 5-28.

Majone, G. (1999) 'The Regulatory State and its Legitimacy Problems', West European Politics 22(1): 1-24.

Majone, G. (2001) 'Two Logics of Delegation: Agency and Fiduciary Relations in EU Governance', European Union Politics 2(1): 103-122.

Mansbridge, J. (2014) 'A Contingency Theory of Accountability', in M. Bovens, R. E. Goodin, and T. Schillemans (eds). The Oxford Handbook of Public Accountability. Oxford: Oxford University Press, pp. 56-70.

Maricut, A. and Puetter, U. (2018) 'Deciding on the European Semester: the European Council, the Council and the Enduring Asymmetry between Economic and Social Policy Issues', Journal of European Public Policy 25(2): 193-211.

Maricut-Akbik, A. (2020) 'Contesting the European Central Bank in Banking Supervision: Accountability in Practice at the European Parliament', Journal of Common Market Studies 58(5): 1199-1214.

Maricut-Akbik, A. (2021) 'Q\&A in Legislative Oversight: A Framework for Analysis', European Journal of Political Research 60(3): 539-559.

Markakis, M. (2020) Accountability in the Economic and Monetary Union: Foundations, Policy, and Governance, Oxford: Oxford University Press.

Martin, D. and Mélin, J. (2015) Question for Written Answer E-013654-15 to the Commission Rule 130 Dominique Martin (ENF), Joëlle Mélin (ENF), 8 October 2015, available at www.europarl.europa.eu/doceo/document/E-8-2015-01 3654_EN.html (accessed December 2020).

Martin, S. (2011a) 'Parliamentary Questions, the Behaviour of Legislators, and the Function of Legislatures: An Introduction', The Journal of Legislative Studies 17(3): 259-270.

Martin, S. (2011b) 'Using Parliamentary Questions to Measure Constituency Focus: An Application to the Irish Case', Political Studies 59(2): 472-488.

McCubbins, M. D. and Schwartz, T. (1984) 'Congressional Oversight Overlooked: Police Patrols versus Fire Alarms', American Journal of Political Science 28(1): 165.

McNamara, K. R. (1999) The Currency of Ideas: Monetary Politics in European Union, Ithaca, NY: Cornell University Press.

Mill, J. S. (1861) Considerations on Representative Government, Web Edition., South Australia: The University of Adelaide Library, available at https://ebooks .adelaide.edu.au/m/mill/john_stuart/m645r/ (accessed February 2019).

Moe, T. M. (1984) 'The New Economics of Organization', American Journal of Political Science 28(4): 739-777.

Moore, M. H. (2014) 'Accountability, Legitimacy, and the Court of Public Opinion', in M. Bovens, R. E. Goodin, and T. Schillemans (eds). The Oxford Handbook Public Accountability. Oxford: Oxford University Press, pp. 632-646.

Moravcsik, A. (2002) 'In Defence of the "Democratic Deficit": Reassessing Legitimacy in the European Union', Journal of Common Market Studies 40(4): 603-624.

Morris, R., Ongena, H. and Schuknecht, L. (2006) 'The Reform and Implementation of the Stability and Growth Pact', ECB Occasional Paper Series (No. 47), available at www.ecb.europa.eu/pub/pdf/scpops/ecbocp47.pdf (accessed March 2021). 
Moschella, M. (2017) 'When Some Are More Equal than Others: National Parliaments and Intergovernmental Bailout Negotiations in the Eurozone', Government and Opposition 52(2): 239-265.

Mühlböck, M. (2012) 'National versus European: Party Control over Members of the European Parliament', West European Politics 35(3): 607-631.

Mulgan, R. (2000a) “Accountability”: An Ever-Expanding Concept?', Public Administration 78(3): 555-573.

Mulgan, R. (2000b) 'Comparing Accountability in the Public and Private Sectors', Australian Journal of Public Administration 59(1): 87-97.

Mulgan, R. (2003) Holding Power to Account: Accountability in Modern Democracies, Houndmills, Basingstoke: Palgrave Macmillan.

Müller, W. C. (2000) 'Political Parties in Parliamentary Democracies: Making Delegation and Accountability Work', European Journal of Political Research 37 (3): 309-333.

Müller, W. C., Bergman, T. and Strøm, K. (2006) 'Parliamentary Democracy: Promise and Problems', in K. Strøm, W. C. Müller, and T. Bergman (eds). Parliamentary Democracy: Promise and Problems. Oxford: Oxford University Press, pp. 3-32.

Mundell, R. A. (1961) 'A Theory of Optimum Currency Areas', The American Economic Review 51(4): 657-665.

Mzes, H. S. (2005) 'The European Parliament Elections of June 2004: Still Second-Order?', West European Politics 28(3): 650-679.

Naert, F. (2016) 'The New European Union Economic Governance: What about Accountability?', International Review of Administrative Sciences 82(4): 638-655.

National Democratic Institute (2000) Strengthening Legislative Capacity in LegislativeExecutive Relations, Washington, DC: National Democratic Institute for International Affairs.

Naurin, D. (2009) 'The European Central Bank - Independent and Accountable?', in S. Gustavsson, C. Karlsson, and T. Persson (eds). The Illusion of Accountability in the European Union. London: Routledge, pp. 126-140.

Nielsen, J. H. and Franklin, M. N. (eds) (2017) The Eurosceptic 2014 European Parliament Elections: Second Order or Second Rate?, London: Palgrave Macmillan UK, DOI: $10.1057 / 978-1-137-58696-4$.

Niskanen, W. A. (1973) Bureaucracy-servant or Master?: Lessons from America, London: Institute of Economic Affairs.

Noonan, L., Binham, C. and Shotter, J. (2016) 'Deutsche Bank Received Special Treatment in EU Stress Tests', Financial Times 10 October, available at www .ft.com/content/44768ea8-8c71-11e6-8aa5-f79f5696c731 (accessed June 2018).

Nouy, D. (2014) Introductory Remarks by Danièle Nouy, Chair of the Supervisory Board of the ECB, Regular Hearing at the European Parliament's Economic and Monetary Affairs Committee, Brussels, 3 November 2014, 2014, ECB Banking Supervision, available at www.bankingsupervision.europa.eu/press/speeches/date/2014/html/s e141103.en.html (accessed June 2018).

Nouy, D. (2015) The Banking Union, One Year On, 21 October 2015, Speech at the Center for European Reform, London, available at www.bankingsupervision.europa.eu/press/ speeches/date/2015/html/se151021.en.html (accessed June 2018). 
Nouy, D. (2016a) Letter from Danièle Nouy, Chair of the Supervisory Board, to Mr José Manuel Fernandes, MEP, With Respect to a Credit Institution under ECB Supervision, 22 November 2016, ECB Banking Supervision, available at www .bankingsupervision.europa.eu/ecb/pub/pdf/161122letter_fernandes.en.pdf (accessed August 2018).

Nouy, D. (2016b) Letter from Danièle Nouy, Chair of the Supervisory Board, to $\mathrm{Mr}$ Melo, MEP, Regarding a Less Significant Credit Institution, 3 March 2016, ECB Banking Supervision, available at www.bankingsupervision.europa.eu/ecb/pub/pdf/ 160303letter_melo.en.pdf (accessed October 2018).

Nouy, D. (2017) Letter from Danièle Nouy, Chair of the Supervisory Board, to Mr Hayes, MEP, regarding Professional Secrecy Requirements, 14 June 2017, ECB Banking Supervision, available at www.bankingsupervision.europa.eu/ecb/pub/pdf/ssm.meplet ter170614_hayes.en.pdf?d4fe5a6f7bb3e 77 e8697352785d4cced (accessed October 2017).

Nugent, N. and Rhinard, M. (2015) The European Commission, London and New York, NY: Palgrave Macmillan.

Ogul, M. S. (1976) Congress Oversees the Bureaucracy, 1st ed., Pittsburgh, PA: University of Pittsburgh Press.

Ogul, M. S. and Rockman, B. A. (1990) 'Overseeing Oversight: New Departures and Old Problems', Legislative Studies Quarterly 15(1): 5-24.

Oliver, D. (1991) Government in the United Kingdom: The Search for Accountability, Effectiveness, and Citizenship, Milton Keynes: Open University Press.

Panke, D. (2019) 'Greek-EU Debt Dueling in the Endgame', in I. W. Zartman (ed.). How Negotiations End: Negotiating Behavior in the Endgame. Cambridge: Cambridge University Press, pp. 46-61.

Papadopoulos, Y. (2007) 'Problems of Democratic Accountability in Network and Multilevel Governance', European Law Journal 13(4): 469-486.

Papadopoulos, Y. (2010) 'Accountability and Multi-level Governance: More Accountability, Less Democracy?', West European Politics 33(5): 1030-1049.

Parker, O. and Pye, R. (2018) 'Mobilising Social Rights in EU Economic Governance: A Pragmatic Challenge to Neoliberal Europe', Comparative European Politics 16(5): $805-824$.

Pavy, E. (2020) The European Parliament: Powers $\mid$ Fact Sheets on the European Union, January 2020 , available at www.europarl.europa.eu/factsheets/en/sheet/19/theeuropean-parliament-powers (accessed January 2021).

Pelizzo, R. and Stapenhurst, F. (2012) Parliamentary Oversight Tools: A Comparative Analysis, London and New York, NY: Routledge.

Philp, M. (2009) 'Delimiting Democratic Accountability', Political Studies 57(1): 28-53.

Pisani-Ferry, J. (2006) 'Only One Bed for Two Dreams: A Critical Retrospective on the Debate over the Economic Governance of the Euro Area', Journal of Common Market Studies 44(4): 823-844.

Pisani-Ferry, J. (2012) 'The Euro Crisis and the New Impossible Trinity', Bruegel Policy Contribution 2012/1, available at www.bruegel.org/2012/01/the-euro-crisis-and-thenew-impossible-trinity-2/ (accessed November 2020).

Pollack, M. A. (1997) 'Delegation, Agency, and Agenda Setting in the European Community', International Organization 51(1): 99-134. 
Pollack, M. A. (1998) 'The Engines of Integration? Supranational Autonomy and Influence in the European Union', in W. Sandholtz and A. Stone Sweet (eds). European Integration and Supranational Governance. Oxford and New York: Oxford University Press, pp. 217-249.

Pollitt, C. (2003) The Essential Public Manager, Maidenhead and Philadelphia, PA: Open University Press/McGraw-Hill.

Pop, V. (2011) 'Eurogroup Chief: “I'm for Secret, Dark Debates", EUobserver 21 April, available at https://euobserver.com/economic/32222 (accessed November 2020).

Proksch, S.-O. and Slapin, J. B. (2011) 'Parliamentary Questions and Oversight in the European Union', European Journal of Political Research 50(1): 53-79.

Przeworski, A., Stokes, S. C. and Manin, B. (1999) Democracy, Accountability, and Representation, Cambridge: Cambridge University Press.

Puetter, U. (2004) 'Governing Informally: The Role of the Eurogroup in EMU and the Stability and Growth Pact', Journal of European Public Policy 11(5): 854-870.

Puetter, U. (2006) The Eurogroup: How a Secretive Circle of Finance Ministers Shape European Economic Governance, Manchester: Manchester University Press.

Puetter, U. (2012) 'Europe's Deliberative Intergovernmentalism: The Role of the Council and European Council in EU Economic Governance', Journal of European Public Policy 19(2): 161-178.

Puetter, U. (2013) 'The European Council - The New Centre of EU Politics', SIEPS European Policy Analysis 16: 1-16.

Puetter, U. (2014) The European Council and the Council: New Intergovernmentalism and Institutional Change, Oxford: Oxford University Press.

Puetter, U. (2016) 'The Centrality of Consensus and Deliberation in Contemporary EU Politics and the New Intergovernmentalism', Journal of European Integration 38(5): 601-615.

Radaelli, C. M. (1999) Technocracy in the European Union, London: Longman.

Rasmussen, M. B. (2018) 'Accountability Challenges in EU Economic Governance? Parliamentary Scrutiny of the European Semester', Journal of European Integration 40(3): 341-357.

Raunio, T. (1996) 'Parliamentary Questions in the European Parliament: Representation, Information and Control', The Journal of Legislative Studies 2(4): $35^{6}-382$.

Raunio, T. (2005) 'Holding Governments Accountable in European Affairs: Explaining Cross-national Variation', The Journal of Legislative Studies 11(3-4): 319-342.

Regan, A. (2017) 'The Imbalance of Capitalisms in the Eurozone: Can the North and South of Europe Converge?', Comparative European Politics 15(6): 969-990.

Rehn, O. (2012) Answer to Question No E-002121/12, 12 April 2012, European Parliament, available at www.europarl.europa.eu/doceo/document/E-7-2012-002121ASW_EN.html (accessed December 2020).

Reif, K. and Schmitt, H. (1980) 'Nine Second-Order National Elections a Conceptual Framework for the Analysis of European Election Results', European Journal of Political Research 8(1): 3-44.

Remáč, M. (2019) 'Parliamentary Scrutiny of the European Commission: Implementation of Treaty Provisions', EPRS_STU(2019)631748_EN, European 
Parliamentary Research Service, available at www.europarl.europa.eu/thinktank/en/ document.html?reference=EPRS_STU(2019)631748 (accessed January 2020).

Ringe, N. (2005) 'Government-opposition Dynamics in the European Union: The Santer Commission Resignation Crisis', European Journal of Political Research 44 (5): 671-696.

Rittberger, B. (2003) 'The Creation and Empowerment of the European Parliament', Journal of Common Market Studies 41(2): 203-225.

Rittberger, B. (2005) Building Europe's Parliament: Democratic Representation Beyond the Nation State, Oxford and New York, NY: Oxford University Press.

Rittberger, B. (2014) 'Integration without Representation? The European Parliament and the Reform of Economic Governance in the EU', Journal of Common Market Studies 52(6): 1174-1183.

Rockman, B. A. (1984) 'Legislative-Executive Relations and Legislative Oversight', Legislative Studies Quarterly 9(3): 387-440.

Romzek, B. S. and Dubnick, M. J. (1987) 'Accountability in the Public Sector: Lessons from the Challenger Tragedy', Public Administration Review 47(3): 227-238.

Romzek, B. S. and Dubnick, M. J. (1998) 'Accountability', in J. M. Shafritz (ed.). International Encyclopedia of Public Policy and Administration. Boulder, CO: Westview Press, pp. 6-11.

Rozenberg, O. (2017) The Role of National Parliaments in the EU after Lisbon: Potentialities and Challenges, Luxembourg: European Parliament Policy Department for Citizen's Rights and Constitutional Affairs.

Rozenberg, O. and Martin, S. (2011) 'Questioning Parliamentary Questions', The Journal of Legislative Studies 17(3): 394-404.

Russack, S. (2017) 'How Is Juncker's “Last-chance Commission” Faring at Mid-Term?', SIEPS European Policy Analysis 2017(4): 1-12.

Russo, F. and Wiberg, M. (2010) 'Parliamentary Questioning in 17 European Parliaments: Some Steps towards Comparison', The Journal of Legislative Studies 16(2): 215-232.

Saalfeld, T. (2000) 'Members of Parliament and Governments in Western Europe: Agency Relations and Problems of Oversight', European Journal of Political Research 37(3): $353-376$.

Sabel, C. F. and Zeitlin, J. (2008) 'Learning from Difference: The New Architecture of Experimentalist Governance in the EU', European Law Journal 14(3): 271-327.

Sacher, M. (2019) 'Macroeconomic Conditionalities: Using the Controversial Link Between EU Cohesion Policy and Economic Governance', Journal of Contemporary European Research 15(2): 179-193.

Sánchez de Dios, M. and Wiberg, M. (2011) 'Questioning in European Parliaments', The Journal of Legislative Studies 17(3): 354-367.

Sauer, H. (2015) 'Doubtful It Stood: Competence and Power in European Monetary and Constitutional Law in the Aftermath of the CJEU's OMT Judgment', German Law Journal 16(4): 971-1002.

Savage, J. D. and Howarth, D. (2018) 'Enforcing the European Semester: The Politics of Asymmetric Information in the Excessive Deficit and Macroeconomic Imbalance Procedures', Journal of European Public Policy 25(2): 212-230.

Savage, J. D. and Verdun, A. (2016) 'Strengthening the European Commission's Budgetary and Economic Surveillance Capacity since Greece and the Euro Area 
Crisis: A Study of Five Directorates-General', Journal of European Public Policy 23 (1): 101-118.

Schedler, A. (1999) 'Conceptualizing Accountability', in A. Schedler, L. J. Diamond, and M. F. Plattner (eds). The Self-restraining State: Power and Accountability in New Democracies. London and Boulder, CO: Lynne Rienner Publishers, pp. 13-28.

Schelkle, W. (2017) The Political Economy of Monetary Solidarity: Understanding the Euro Experiment, Oxford: Oxford University Press.

Scheller, H. K. (2004) The European Central Bank: History, Role and Functions, Frankfurt am Main: European Central Bank.

Schillemans, T. (2008) 'Accountability in the Shadow of Hierarchy: The Horizontal Accountability of Agencies', Public Organization Review 8(2): 175.

Schillemans, T. (2013) 'The Public Accountability Review. A Meta-Analysis of Public Accountability Research in Six Academic Disciplines', Utrecht University Repository Working Paper, available at http://dspace.library.uu.nl/handle/1874/275784 (accessed January 2019).

Schillemans, T. (2016) 'Calibrating Public Sector Accountability: Translating Experimental Findings to Public Sector Accountability', Public Management Review 18(9): 1400-1420.

Schillemans, T. and Bovens, M. (2011) 'The Challenge of Multiple Accountability: Does Redundancy Lead to Overload?', in M. J. Dubnick and H. G. Frederickson (eds). Accountable Governance: Problems and Promises. Armonk, NY and London: M.E. Sharpe, pp. $3^{-21 .}$

Schillemans, T. and Busuioc, M. (2015) 'Predicting Public Sector Accountability: From Agency Drift to Forum Drift', Journal of Public Administration Research and Theory 25(1): 191-215.

Schimmelfennig, F. (2015) 'Liberal Intergovernmentalism and the Euro Area Crisis', Journal of European Public Policy 22(2): 177-195.

Schmidt, V. A. (2020) Europe's Crisis of Legitimacy: Governing by Rules and Ruling by Numbers in the Eurozone, Oxford: Oxford University Press.

Schmitter, P. C. (2004) 'The Ambiguous Virtues of Accountability', Journal of Democracy 15(4): 47-60.

Schmitter, P. C. and Karl, T. L. (1991) 'What Democracy Is ... and Is Not', Journal of Democracy 2(3): 75-88.

Schoeller, M. G. and Héritier, A. (2019) 'Driving Informal Institutional Change: The European Parliament and the Reform of the Economic and Monetary Union', Journal of European Integration 41(3): 277-292.

Schoenmaker, D. (2018) 'Building a Stable European Deposit Insurance Scheme', Journal of Financial Regulation 4(2): 314-320.

Schoenmaker, D. and Véron, N. (2016) 'European Banking Supervision: The First Eighteen Months', Bruegel Blueprint Series 2, available at www.bruegel.org/2016/o6/ blueprint-european-banking-supervision-the-first-eighteen-months/ (accessed March 2021).

Schuknecht, L., Moutot, P., Rother, P. and Stark, J. (2011) 'The Stability and Growth Pact: Crisis and Reform', ECB Occasional Paper No. 129, available at www .ecb.europa.eu/pub/pdf/scpops/ecbocp129.pdf (accessed November 2020).

Scott, C. (2000) 'Accountability in the Regulatory State', Journal of Law and Society 27 $(1): 38-60$. 
Scully, R. and Farrell, D. M. (2003) 'MEPs as Representatives: Individual and Institutional Roles', Journal of Common Market Studies 41(2): 269-288.

Scully, R., Hix, S. and Farrell, D. M. (2012) 'National or European Parliamentarians? Evidence from a New Survey of the Members of the European Parliament", Journal of Common Market Studies 50(4): 670-683.

Seikel, D. (2016) 'Flexible Austerity and Supranational Autonomy. The Reformed Excessive Deficit Procedure and the Asymmetry between Liberalization and Social Regulation in the EU', Journal of Common Market Studies 54(6): $1398-1416$.

Sieberer, U. (2011) 'The Institutional Power of Western European Parliaments: A Multidimensional Analysis', West European Politics 34(4): 731-754.

Single Resolution Board (2017) Single Resolution Mechanism (SRM), 11 September 2017, available at https://srb.europa.eu/en/content/single-resolutionmechanism-srm (accessed November 2020).

Slapin, J. B. and Proksch, S.-O. (2014) 'Words as Data: Content Analysis in Legislative Studies', in S. Martin and T. Saalfeld (eds). The Oxford Handbook of Legislative Studies. Oxford: Oxford University Press, pp. 126-144.

Smith-Meyer, B. (2016) 'Brussels Decides against Fining Portugal, Spain', Politico Europe 27 July, available at www.politico.eu/article/no-fines-for-portugal-spain-overbudget-failures-european-commission-deficit/ (accessed December 2020).

Sozzi, F. (2016) 'Electoral Foundations of Parliamentary Questions: Evidence from the European Parliament', Journal of Legislative Studies 22(3): 349-367.

Statham, P. and Trenz, H.-J. (2015) 'Understanding the Mechanisms of EU Politicization: Lessons from the Eurozone Crisis', Comparative European Politics 13(3): 287-306.

Stiglitz, J. (1998) 'Central Banking in a Democratic Society', De Economist 146(2): 199-226.

Strøm, K. (1995) 'Parliamentary Government and Legislative Organisation', in H. Döring (ed.). Parliaments and Majority Rule in Western Europe. University of Mannheim: Mannheim Centre for European Social Research (MZES), pp. 51-82.

Strøm, K. (2000) 'Delegation and Accountability in Parliamentary Democracies', European Journal of Political Research 37(3): 261-289.

Strøm, K. (2006) 'Parliamentary Democracy and Delegation', in K. Strøm, W. C. Müller, and T. Bergman (eds). Parliamentary Democracy: Promise and Problems. Oxford: Oxford University Press, pp. 55-106.

Sweet, A. S. and Sandholtz, W. (1997) 'European Integration and Supranational Governance', Journal of European Public Policy 4(3): 297-317.

Tarabella, M. and Cottigny, J. L. (2013) Question for Written Answer E-012086-13 to the Commission Rule 117, 23 October 2013, European Parliament, available at www.europarl .europa.eu/doceo/document/E-7-2013-012086_EN.html (accessed December 2020).

Ter Kuile, G. , Wissink, L. and Bovenschen, W. (2015) 'Tailor-made Accountability within the Single Supervisory Mechanism', Common Market Law Review 52(1): $155^{-189}$.

Thatcher, M. (2005) 'The Third Force? Independent Regulatory Agencies and Elected Politicians in Europe', Governance 18(3): 347-373.

Thatcher, M. and Sweet, A. S. (2002) 'Theory and Practice of Delegation to Non-Majoritarian Institutions', West European Politics 25(1): 1-22. 
Topan, A. (2002) "The Resignation of the Santer-Commission: The Impact of "Trust" and "Reputation", European Integration online Papers (EIoP) 6(14), http://eiop.or.at /eiop/texte/2002-014a.htm.

Trondal, J. (2010) An Emergent European Executive Order, Oxford: Oxford University Press.

Tsebelis, G. (1994) 'The Power of the European Parliament as a Conditional Agenda Setter', American Political Science Review 88(o1): 128-142.

Tuori, Kaarlo and Tuori, Klaus (2014) The Eurozone Crisis: A Constitutional Analysis, Cambridge and New York: Cambridge University Press.

Urtasun, E. (2015) Question for Written Answer E-004058/2015 to the Commission, 12 March 2015, European Parliament, available at www.europarl.europa.eu/doceo/ document/E-8-2015-004058_EN.pdf (accessed April 2020).

van de Steeg, M. (2009) 'Public Accountability in the European Union: Is the European Parliament Able to Hold the European Council Accountable?', European Integration online Papers (EIoP) 13, available at https://papers.ssrn.com/a bstract $=1476905$ (accessed September 2017).

van der Veer, R. A. and Haverland, M. (2018) 'Bread and Butter or Bread and Circuses? Politicisation and the European Commission in the European Semester', European Union Politics 19(3): 524-545.

Van Kemseke, P. (2014) 'The European Council: Crisis Manager or Engine of European Integration?', in Lecture delivered at the Central European University, Budapest. 26 March 2014, Budapest, available at https://pp.ceu.edu/events/2014-03-26/europeancouncil-crisis-manager-or-engine-european-integration (accessed September 2021).

Van Rompuy, H. (2012) Towards a Genuine Economic and Monetary Union, 26 June 2012, Report by the President of the European Council, Herman van Rompuy, EUCO 120/12, Brussels, available at http://data.consilium.europa.eu/doc/ document/ST-120-2012-INIT/en/pdf (accessed June 2018).

Van Rompuy, H. (2014) Europe in the Storm: Promise and Prejudice, Leuven: Davidsfonds.

Verdun, A. (1998) ‘The Institutional Design of EMU: A Democratic Deficit?', Journal of Public Policy 18(2): 107-132.

Verdun, A. (1999) 'The Role of the Delors Committee in the Creation of EMU: An Epistemic Community?', Journal of European Public Policy 6(2): 308-328.

Verdun, A. and Zeitlin, J. (2018) 'Introduction: The European Semester as a New Architecture of EU Socioeconomic Governance in Theory and Practice', Journal of European Public Policy 25(2): 137-148.

Véron, N. (2015) 'Europe's Radical Banking Union', Bruegel Essay and Lecture Series No. 5, available at www.bruegel.org/wp-content/uploads/imported/publications/ess ay_NV_CMU.pdf (accessed November 2020).

Vincenti, D. and Michalopoulos, S. (2015) 'Monti: Ignoring the Greek Referendum Was a Violation of Democracy', Euractiv.com, available at www.euractiv.com/section/eurofinance/news/monti-ignoring-the-greek-referendum-was-a-violation-of-democracy/ (accessed December 2020).

Vliegenthart, R., Walgrave, S. and Zicha, B. (2013) 'How Preferences, Information and Institutions Interactively Drive Agenda-Setting: Questions in the Belgian Parliament, 1993-2000', European Journal of Political Research 52(3): 390-418. von Beyme, K. (2000) Parliamentary Democracy, London: Palgrave Macmillan. 
VoteWatch Europe (2014) End of Term Scorecard: The Activity Records of MEPs Analysed by Member State, available at www.votewatch.eu/blog/wp-content/upload s/2014/o5/votewatch-europe-special-policy-brief-meps-activities-final-6-may.pdf (accessed April 2020).

Wallace, H. (2005) 'An Institutional Anatomy and Five Policy Modes', in H. Wallace, W. Wallace, and M. A. Pollack (eds). Policy-making in the European Union. Oxford and New York: Oxford University Press, pp. 49-92.

Warren, T. (2018) 'The European Parliament and the Eurozone Crisis: An Exceptional Actor?', The British Journal of Politics and International Relations https://doi.org/10 $.1177 / 1369148118768141$.

Weingast, B. R. (1984) 'The Congressional-Bureaucratic System: A Principal Agent Perspective (with applications to the SEC)', Public Choice 44(1): 147-191.

Werner Report (1970) Report to the Council and the Commission on the realization by stages of economic and monetary union in the Community, Supplement to Bulletin $11-1970$ of the European Communities, available at https://ec.europa.eu/economy_ finance/publications/pages/publication6142_en.pdf (accessed September 2021).

Wessels, W. et al. (2013) Democratic Control in the Member States of the European Council and the Euro Zone Summits, Brussels: European Parliament, Policy Department C: Citizens' Rights and Constitutional Affairs.

Whelan, K. (2020) Accountability at the Fed and the ECB, Luxembourg: European Parliament, Policy Department for Economic, Scientific and Quality of Life Policies.

Wiberg, M. and Koura, A. (1994) 'The Logic of Parliamentary Questioning', in M. Wiberg (ed.). Parliamentary Control in the Nordic Countries: Forms of Questioning and Behavioural Trends. Helsinki: The Finnish Political Science Association, pp. 19-43.

Wille, A. (2010) 'Political-Bureaucratic Accountability in the EU Commission: Modernising the Executive', West European Politics 33(5): 1093-1116.

Wille, A. (2013) The Normalization of the European Commission: Politics and Bureaucracy in the EU Executive, Oxford: Oxford University Press.

Wishart, I. (2012) 'ECB “Will Do Whatever It Takes" to Save the Euro', Politico Europe 26 July, available at www.politico.eu/article/ecb-will-do-whatever-it-takes-to-save-the -euro/ (accessed November 2020).

Woods, M., Paulus, T., Atkins, D. P. and Macklin, R. (2016) 'Advancing Qualitative Research Using Qualitative Data Analysis Software (QDAS)? Reviewing Potential Versus Practice in Published Studies Using ATLAS.ti and NVivo, 1994-2013', Social Science Computer Review 34(5): 597-617.

Yamamoto, H. (2007) Tools for Parliamentary Oversight: A Comparative Study of 88 National Parliaments, Geneva: Inter-Parliamentary Union.

Yang, K. (2014) 'Qualitative Analysis', in M. Bovens, R. E. Goodin, and T. Schillemans (eds). The Oxford Handbook Public Accountability. Oxford: Oxford University Press, pp. 159-176.

Yordanova, N. and Zhelyazkova, A. (2020) 'Legislative Control over Executive Law-making: Delegation of Quasi-legislative Powers to the European Commission', Journal of Common Market Studies 58(2): 345-364.

Zeitlin, J. and Vanhercke, B. (2018) 'Socializing the European Semester: EU Social and Economic Policy Co-ordination in Crisis and Beyond', Journal of European Public Policy 25(2): 149-174. 
Zilioli, C. (2016) 'The ECB's Powers and Institutional Role in the Financial Crisis: A Confirmation from the Court of Justice of the European Union', Maastricht Journal of European and Comparative Law 23(1): 171-184.

Zoppè, A. (2020) Implementation of the Macroeconomic Imbalance Procedure: State of Play (August 2020), 2020, European Parliament In-depth Analysis, Economic Governance Support Unit (EGOV), PE 497.739, available at www.europarl.eur opa.eu/RegData/etudes/IDAN/2016/497739/IPOL_IDA(2016)497739_EN.pdf (accessed April 2021). 


\section{Index}

accountability

comparative evaluation, $177-190$

conceptualisation, 36-41

political accountability in the EMU, 27-34

vis-à-vis finance ministers in the Economic and Monetary Union, 133-175

vis-à-vis the Commission in the European

Semester, $130-132$

vis-à-vis the European Central Bank in banking supervision, 95-96

ALDE. See Group of the Alliance of Liberals and Democrats for Europe

Alert Mechanism Report, 102, 122, 123

Andor, László, 109, 124, 129, 182

Annual Growth Survey, 102, 104, 122, 123, 138, 152

austerity, 4, 5, 108, 123, 129, 131, 139, 140, 153, $168,176,185$

Austria, 20, 57, 144, 148, 155, 158

Balz, Burkhard, 83, 162

Banco Populare de Vicenza, 87

Banif, 87, 93

banking supervision. See Single Supervisory Mechanism

Belgium, 20, 114, 121, 152, 157, 160, 168

Berès, Pervenche, 83,192

Bovens, Mark, 37-40

Bowles, Sharon, 145, 164

Broad Economic Policy Guidelines, 21, 27, 101-102, 104, 135, 143

Bulgaria, 24, 144, 150, 157

Caixa Geral de Depósitos, 87

Capital Markets Union, 151, 165

Capital Requirements Directive, 76, 87, 151

Capital Requirements Regulation, 76
Centeno, Mário, 162, 169, 173, 188

claims analysis, 11, 16, 63

Committee on Economic and Monetary

Affairs, 16, 31, 71-73, 74-75, 77-83, 88-91, 98, 109-110, 116, 121, 124, 129, 134, 144, 150, $153,158,160,164,172,174,185,186,190,192$

Committee on Employment and Social

Affairs, 109, 115-116, 129, 182

Committee on Regional Development, 110, 117

Confederal Group of the European United

Left-Nordic Green Left, 81-85, 112-115, 148

Cornelissen, Marije, 118, 125

Cottigny, Jean Louis, 121

Country-Specific Recommendations, 30, 103, 106, 109-111, 117, 126-129, 135, 138, 143, 152, 154,172

Court of Justice of the European Union, 27, 100-101, 137

Crețu, Corina, 109, 117

Cyprus, 20, 23, 30, 144, 146, 148, 151, 152, 159, $164-166,168,184,187,189$

Delors, Jacques, 19, 99

Denmark, 24, 57, 136, 144, 146, 148

Deutsche Bank, 87-88

Dijsselbloem, Jeroen, 1, 106, 157, 160-175, 181, 184,188

Directorate-General for Economic and Financial Affairs, 100, 103, 105, 116

Directorate-General for Employment, Social Affairs and Inclusion, 12, 103, 115, 116

Directorates-General, 97, 103, 116

Dombrovskis, Valdis, 109, 116, 126, 127, 129

Draft Budgetary Plans, 102-104, 109, 123, 139,152

Draghi, Mario, 80 
ECOFIN Council

Council Presidency/Presidencies, 16, 31, 67,144

key accountability issues, 139-144

ECON Committee. See Committee on Economic and Monetary Affairs

Economic and Financial Committee, 100, 138, 139,154

Economic and Monetary Union accountability framework, 27-34 case comparison, $176-177,180-182$, 185-190 euro crisis overview, 28-34

history, 19-27

Economic Dialogues

with the Commission, 108-112, 116-119, $123-125,128-130$

with the ECOFIN Council, 144-155

with the Eurogroup, 159-167, 168-170

Economic Governance Support Unit, 96, 191,192

Economic Policy Committee, 138-139, 154

ECR. See European Conservatives and Reformists Group

EFDD. See Europe of Freedom and Direct Democracy Group

Eickhout, Bas, 167

EMPL Committee. See Committee on Employment and Social Affairs

ENF. See Europe of Nations and Freedom

EPP. See Group of the European People's Party

Estonia, 20, 144, 150, 155, 182

Eurogroup

background, $135^{-139}$

Eurogroup President, 159-173

key accountability issues, 139-144

Eurogroup Working Group, 100, 138-139

Europe 2020 Strategy, 135

Europe of Freedom and Direct Democracy Group, 81-83, 115, 120, 171

Europe of Nations and Freedom, 115, 120, 126

European Banking Authority, 92, 93

European Central Bank

Interinstitutional Agreement, 32, 70, 74-76, $77,87,172$

Monetary Dialogues, 13, 31-32, 35, 72, 74, 114,190

Monetary policy, 4, 12, 18, 19, 21, 26, 28, 31, $70-71,72,74,76,83,141,168$

Quantitative easing, 26

secrecy, 17, 52, 62, 68, 77, 87, 93-95, 96, 98, $119,137,173,177,182,183,186,189$
SSM. See Single Supervisory Mechanism

Supervisory Board, 70, 74-80, 86, 88, 91, 134, $162,181,185,189$

European Commission

background, 99-104

Commission President, 6, 8, 19, 33, 61, 99, 193

key accountability issues after the crisis, 104-108

European Conservatives and Reformists Group, 84, 148, 162

European Council, 4, 7, 8-10, 12, 19, 24, 26, 28-30, 33-34, 61, 73, 97, 100, 104, 133, 137, 168,180

European Court of Auditors, 27, 106, 196

European Deposit Insurance Scheme, 24, 157,165

European Financial Stability Facility, 23, 138

European Parliament

accountability forum, 34, 35-36, 41, 62, 69, $73,77,89,94,105,108,153,176-181,183$, $185,190-192,196,198$

background, 5-7

national affiliation / nationality, 67, 81-84, 112-114, 120, 131, 146, 148, 160

oversight mechanism, 8-11

political groups, 10, 26, 33, 62, 77, 80-85, 95, $105,112-115,146-148,160,174,178$, 190-196, 197

role in the EMU, 32-34

Rules of Procedure, 10, 31, 33, 46, 53, 80, 84, 109, 112, 178, 191

European Stability Mechanism, 1-2, 23, 26, 32, $67,98,108,130,133,138,140-143,159-168$, 173,180

bailout, 1, 4, 22, 26, 30, 108, 138, 142, 164

financial assistance, 1, 16, 23, 26, 62, 67, 98, $108,118,123,133,137-143,153,160,165,170$, $172,180,184$

Troika, 26, 98, 108, 123, 124, 127, 138

Eurostat, 100, 103, 105

Excessive Deficit Procedure, 21, 25, 101-104, 106, 109, 116, 119, 122, 123, 131, 135-136, 139, $143,172,189$

Excessive Imbalances Procedure, 107

failing or likely to fail, $88,93,95,185$

Feio, Diogo, 111, 114, 117

Fernández, Jonás, 171

Ferreira, Elisa, 1, 162

Finland, 20, 141 
Fiscal Compact, $23-24$

France, 20-22, 83, 95, 101, 106, 112, 116, 120, 121, $128,135-137,146,162,192$

Gauzès, Jean-Paul, 162

Germany, 20-22, 81, 101, 112, 120, 128-129, 136, $146,150,160,162,167,171,192$

German dominance, $140-141$

Giegold, Sven, 83, 120, 150, 192

Goranov, Vladislav, 150, 157

Goulard, Sylvie, 83

Greece, 1, 20-23, 30, 81, 84, 101, 114, 115, 119, $123-124,139-140,144,146,148,155,160$, $163,164-165,168,170-171,173,189$

Group of the Alliance of Liberals and Democrats for Europe, 81-83, 112-114, 118, $148,152,162$

Group of the European People's Party, 81-83, $112-115,146,162$

Group of the Progressive Alliance of Socialists and Democrats in the European

Parliament, 6, 81-85, 112-115, 121, 123, 127, $146,157,162,171,192$

Gualtieri, Roberto, 77, 121, 153

GUE-NGL. See Confederal Group of the European United Left-Nordic Green Left

In-Depth Review, 102, 106

International Monetary Fund, 23, 26, 98, 108, $135,138,164$

Ireland, 20, 23, 30, 81, 101-102, 144, 146, 148, 164 Italian, 140, 146, 161

Italy, 20, 21, 30, 81, 83, 87, 95, 101, 114, 120, 121, $144,146,148,171$

Joint Supervisory Teams, 74

Juncker, Jean-Claude, 106, 107, 116, 121, 141, 153, 159, 162, 166, 169, 188

Karas, Othmar, 158

Katainen, Jyrki, 109, 117

Kratsa-Tsagaropoulou, Rodi, 119

Lamberts, Philippe, 152, 157, 168

Latvia, 20, 144, 148, 154, 182

legislative oversight. See oversight

legitimacy, 2, 5, 29, 37, 39, 57, 72, 77, 94, 121, $127,167,172,177,197,198$

Lisbon Agenda, 135

Lisbon Treaty, 6, 25, 33, 136

Lithuania, 20, 144, 148
Löger, Hartwig, 158

Luxembourg, 19, 20, 144, 148, 153, 187

LuxLeaks, 148, 153

Maastricht Treaty, 6, 9, 18, 20, 21, 22, 33, 97, 99 , $102,133,135$

Macroeconomic Imbalances Procedure, 24, 103-104, 106-107, 109, 119, 122, 129, 131, $142-143,189$

Malta, 20, 144, 148, 153

Martin, Dominique, 126

Martin, Hans-Peter, 155

Mato, Gabriel, 164

Mélin, Joëlle, 126

Monte dei Paschi di Siena, 87

Monti, Mario, 140

Moscovici, Pierre, 109, 116, 126, 129

Muresan, Siegfried, 156

National Competent Authorities, 22, 26, 74, 78,92

National parliaments, 4, 6-8, 13-15, 18, 27, 29-31, 34, 61, 74, 121, 127, 133, 140, 165-168, 188

Netherlands, 1, 20, 21, 101, 117, 118, 125, 141, 144, $153,157,160,161,164,165,166,167,168,171$, 172,187

Non-performing loans, $87-89$

Noonan, Michael, 151

Nouy, Danièle, 70, 79, 89, 181

oversight

conceptualisation, 41-47

evaluation, 95-96, 130-132, 133-175, 184-190 scenarios of oversight, $54-63$

Padoan, Piercarlo, 146

Panama Papers, 148, 153

parliamentary questions

background, 41-45

conceptualisation, $48-63$

profile of questioners, 10, 78, 81, 99, 111, 144, $146,160,163$

types of answers, 15, 78, 89, 124-126, 130-131, $144,154,169,181$

types of questions, $15,49,68,72,78,85-86$, 99, 116-118, 144, 149-152, 154, 163, 169, 174, $177,178,180$

Podimata, Anni, 123, 127

Poland, 146, 162

policy recommendations, 190-196 
Portugal, 20, 23, 30, 81, 84, 93, 95, 101, 106, 109, $111,112-114,115,117,119,126,129,136$, 146,160

principal-agent, 11, 14, 15, 36, 38, 41-45, 48, 51, $54,56-61,62,71,75,76,95,104,132,139$, $142,179,183,190,197$

Recovery and Resilience Facility, 195-196

Regling, Klaus, 1, 162

Rehn, Olli, 109, 124, 127

Reirs, Jānis, 155

Romania, 24, 144, 146, 148, 155-156, 159, 162,182

S\&D. See Progressive Alliance of Socialists and Democrats in the European Parliament

Schäuble, Wolfgang, 140

Schmidt, Olle, 152

scrutiny. See oversight

Shiarly, Vassos, 152

Single Resolution Board, 12, 24, 32-33, 93, 192

Single Resolution Mechanism, 24

Single Supervisory Mechanism

background, 72-75

key accountability issues, $75-78$

SSM Regulation, 16, 26, 70-76, 138, 151

Six-Pack, 17, 23, 26, 32, 98, 104, 108, 110, 121, 123, $138,143,144,145,152,158$

Slovakia, 20, 144

Slovenia, 20, 120, 121, 126

Spain, 20, 21, 22-23, 30, 57, 81, 83, 87, 95, 106, $109,112,114,117,120,129,136,146$, $163-164,171$

Stability and Growth Pact, 22, 23, 27-28, 100-102, 106, 122-123, 136

Stournaras, Yiannis, 155 structural reforms, 5, 23, 98, 101, 105, 107, 141, $152,155,15^{8}$

Sweden, 136,152

Tang, Paul, 157

Tarabella, Marc, 121

Teodorovici, Eugen, 156

The European Semester

key issues, 104-108

overview, 102-104

The Greens/European Free Alliance, 112-115, $120,125,150-152,167,192$

Thyssen, Marianne, 109, 182

Tomc, Romana, 120, 126

Tõniste, Toomas, 155

Treaty on European Union, 6-8, 29, 33, 61-62

Treaty on the Functioning of the European Union, 6-9, 22, 26, 31, 33, 61, 72-74, 76, $101,133-136,142,188$

Tsipras, Alexis, 140, 170

Tusk, Donald, 33

Two-Pack, 17, 23, 26, 104, 108, 123, 138, 143, 159

United Kingdom, 46, 57, 136, 146, 162

United States, 22, 40, 42

Valli, Marco, 83, 120, 171

van Nieuwenhuizen, Cora, 118

Van Rompuy, Herman, 25, 33, 73

Varoufakis, Yanis, 141, 170

Veneto Banca, 87

Vestager, Margrethe, 146

Viegas, Miguel, 119, 126

Waigel, Theo, 100

Werner, Pierre, 19

Zanni, Marco, 83 
